\title{
Independent Review of Mitigating System Performance Indicator Reporting in the EPIX Database
}

Thomas E. Wierman

May 2009

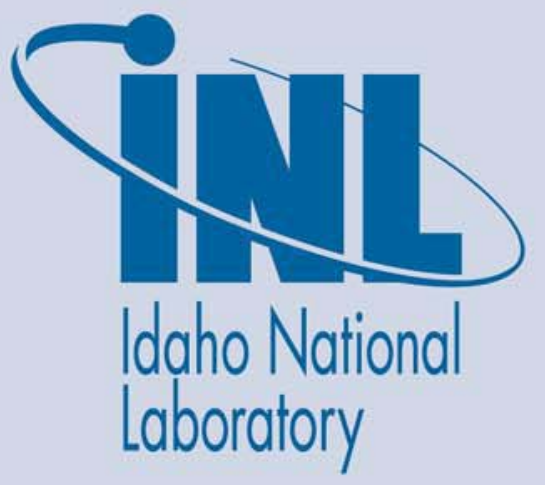

The INL is a U.S. Department of Energy National Laboratory operated by Battelle Energy Alliance 
INL/EXT-09-16120

\title{
Independent Review of Mitigating System Performance Indicator Reporting in the EPIX Database
}

\author{
Thomas E. Wierman
}

May 2009

\author{
Idaho National Laboratory \\ Idaho Falls, Idaho 83415 \\ http://www.inl.gov
}

Prepared for the

Washington, DC 20555 


\section{Independent Review of Mitigating System Performance Indicator Reporting in the EPIX Database}

May 28, 2009

Thomas E. Wierman (INL) 


\section{Table of Contents}

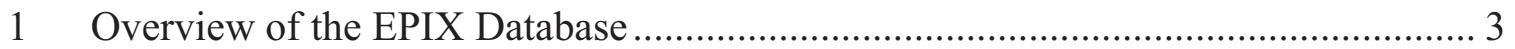

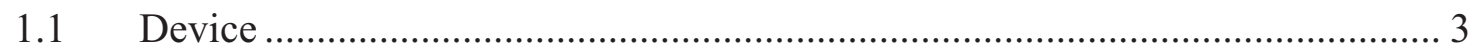

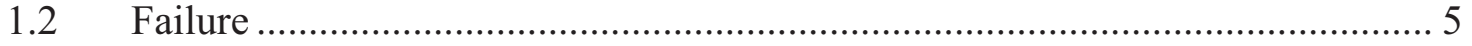

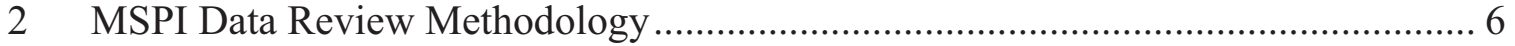

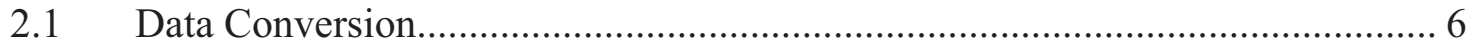

2.2 Device Failure Mode and MSPI Failure Mode Correlation............................... 8

3 MSPI Data Review Results.............................................................................. 10

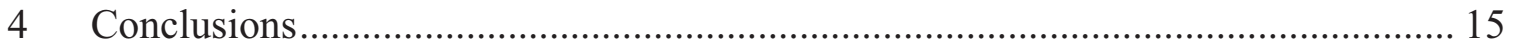

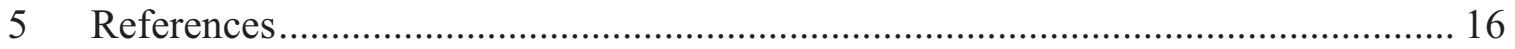

Appendix A $\quad$ MSPI Failure Comparison No Match List ....................................... A-1 


\section{Independent Review of Mitigating System Performance Indicator Reporting in the EPIX Database}

The staff at the Idaho National Laboratory (INL) has been reading and classifying mitigating system performance index (MSPI) equipment performance information exchange (EPIX) data to support the industry trends program and to support the independent review of MSPI failure data as requested by the NRC. The purpose of the review is to verify the component, failure mode, and method of detection.

This task is to select reports from EPIX and determine if their categorization as MSPI or non-MSPI failures is consistent with the development of unreliability baseline failure rates, and whether this significantly affects estimates of plant risk.

This review is of all MSPI devices in EPIX that were reported as failures. The components include emergency generators; motor-driven, turbine-driven, and enginedriven pumps; and air and motor-operated valves. The date range for this report includes all MSPI device reported failures from 2003 to the most current EPIX data at the INL (up to the $3^{\text {rd }}$ quarter 2008).

\section{Overview of the EPIX Database}

The EPIX database was developed as an improvement over the retired nuclear plant reliability database system (NPRDS) database and implemented in 1997 by the Institute of Nuclear Power Operations (INPO). The mission of EPIX is to promote excellence in nuclear power plant equipment performance through the exchange of component-level operating experience. Of primary interest to this discussion are the tables in EPIX that report failures of devices. The documents that describe and implement the EPIX data reporting requirements are: "Equipment Performance and Information Exchange System (EPIX): Reporting Requirements" (Reference 1) and "Regulatory Assessment Performance Indicator Guideline" (Reference 2).

The EPIX database is provided to the INL through the NRC sponsor to enable the analysis and reporting of U.S. Commercial Nuclear Power Plant (NPP) equipment operating performance. The EPIX database that is current at the INL is the $3^{\text {rd }}$ quarter 2008 set of data.

This discussion will require the reader to have an understanding of some of the facets of the EPIX database. The following sections provide this background information.

\subsection{Device}

The device table (EPIX table "tblAlternateDevice") is essentially a list of all components at the plants that are tracked. Devices can be Key, Sub-component, or Supporting. For example: a motor-operated valve is the key component; the valve body, actuator, and circuit breaker are sub-components; and the instrumentation to actuate the valve is a supporting component. The most important function of the device table is to identify the plant, component, and system, which is accomplished with the key device. EPIX is not built to be PRA-data-friendly in that it does not use simplified component IDs like a MOV in the RHR system. For use at the INL (RADS and SPAR), a complete translation table is built to identify each key device in PRA terminology. 
The device table contains almost a million devices, of which approximately 140,000 are key devices. Figure 1 shows raw counts of the key devices in the device table in three categories.

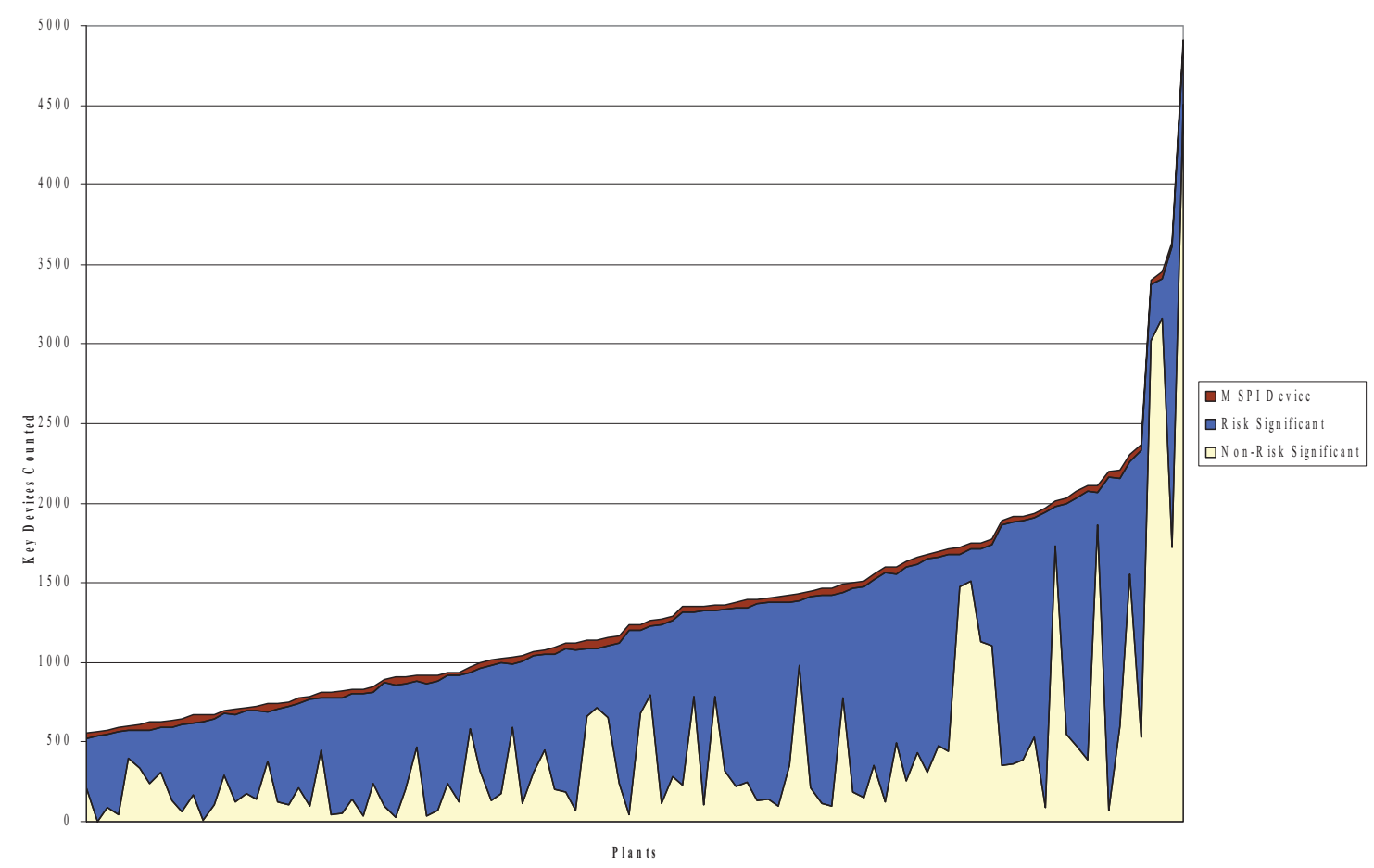

Figure 1. Distribution of MSPI and non-MSPI key devices by plant in EPIX.

The total key device count per plant ranges from 556 to 4,910 (the total area in Figure 1). The MSPI key device count per plant ranges from 17 to 59 (the red area in Figure 1, which is shown in detail in Figure 2). Risk-significant device counts per plant are shown in blue and the combined maintenance rule (MR) and generation loss devices are shown in yellow in Figure 1.

Each plant has determined the specific devices that are to be designated as MSPI in accordance with the controlling documents (References 1 and 2). The high Birnbaum devices (e.g., EDG, MDP, and TDP) appear to be representative of the installed device count in the MSPI systems. The plants at each end of the MSPI device count spectrum have large differences in the reports of valves. The plants at the low end report two or seven motor-operated valves (MOVs), while the plant at the high end reports 18 airoperated valves (AOVs) and 20 motor-operated valves (MOVs) per plant (total 38). 


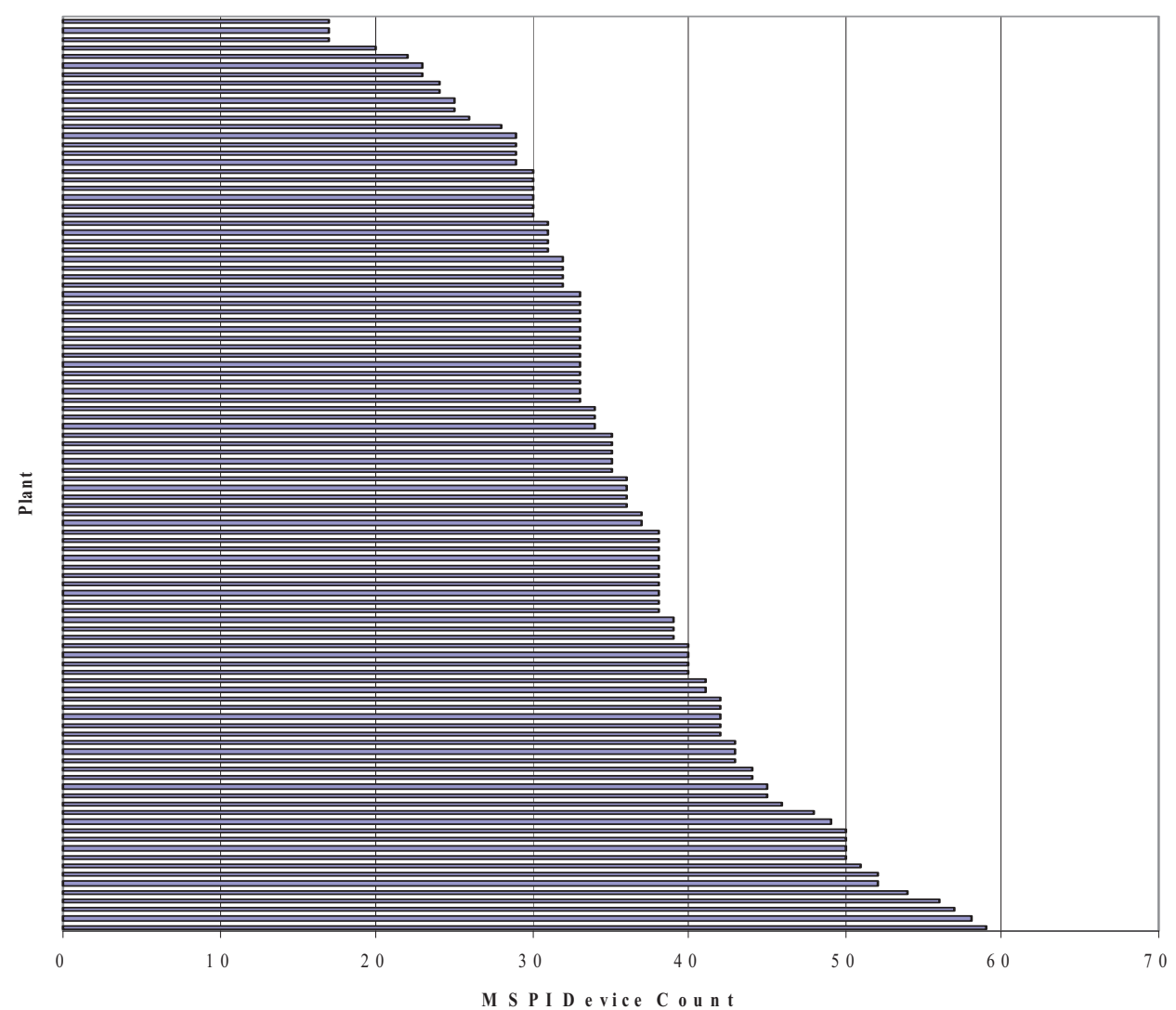

Figure 2. MPSI device count per plant in EPIX.

\subsection{Failure}

Component (key device) failures are reported in EPIX using two tables. The first is the table "dboFailure" and the second is "dboDeviceFailure." These two tables are joined (a database term) using the "FailureID." There can be more than one record in "dboDeviceFailure" joined to a single record in "dboFailure."

The table "dboFailure" contains information common to all individual component failures (failure discovery and end dates, plant status, discovery method, etc). The table "dboDeviceFailure" contains specific information about each device affected by the failure. For example: the MOV circuit breaker fails to shut causing the MOV key device to fail to operate. This event would contain two device failure records. The circuit breaker (supporting component) would have a device failure mode of fail-to-close. The MOV (key device) would have a device failure mode of fail-to-operate. In addition, the failure cause, preventive action, and corrective action would be listed for each device. The database also contains a table with the failure narrative(s).

A specialized sub-table to "dboFailure" contains MSPI failure information. It essentially answers the questions: "Is this an MSPI failure; and if not, why is it not?" This table has only 1,890 records (1,060 are MSPI failures) compared to 44,772 failure records in EPIX. Presumably, any failure not in the MSPI failure table is not an MSPI failure. The discovery date goes back to 1996. 
Figure 3 shows the counts of MSPI failures reported at each plant by year. The colored bars show the mean (top of the bar) and the median (bottom of the bar) of MSPI failure counts per plant and the whiskers show the $95^{\text {th }}$ and $5^{\text {th }}$ percentiles of MSPI failure counts at a plant. The trend line shows that the mean number of reported MSPI failures per plant has remained relatively constant since 2003. However, the number of MSPI failures reported varies considerably from plant-to-plant. Several plants have reported zero MSPI failures per year from 2003 - 2007 (the range for the whole period is $0-20$ per plant with a single plant reporting zero MSPI failures for the 5-year period). Only the current 104 operating plants were considered.

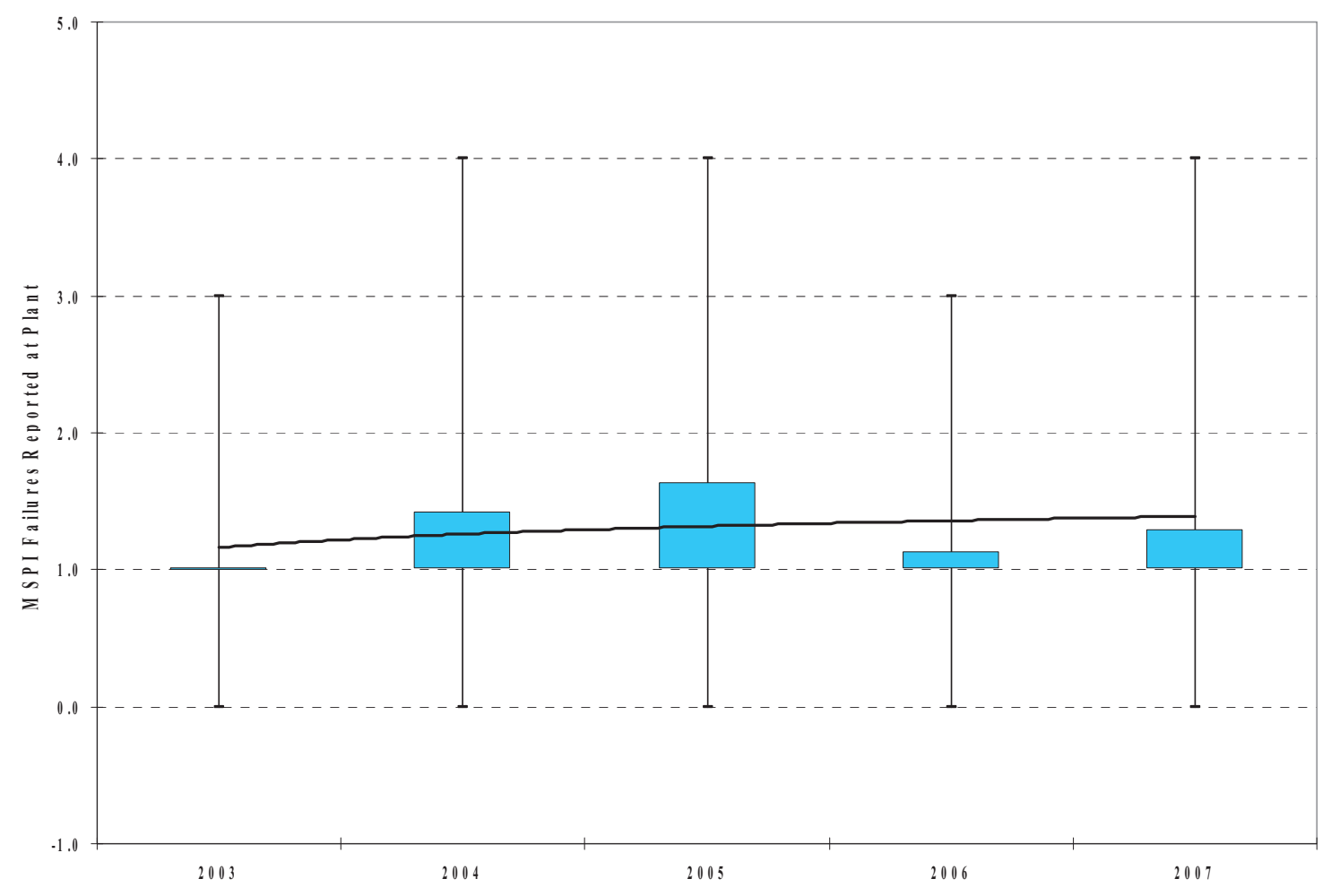

Figure 3. Distribution of MSPI failures at plants by year.

\section{MSPI Data Review Methodology}

The MSPI data review was implemented in the INL data collection database, which also collects information to support the common-cause failure (CCF) database and the component performance trending calculations. The MSPI data review data collection was set up so that INL staff had access to the original EPIX failure data and the guidance available in References 1 and 2. The staff reviewed the EPIX failure record and made a determination of what the appropriate failure mode should be based on how the failure would be applied in a probabilistic risk assessment (PRA).

\subsection{Data Conversion}

The failure mode selected for each failure record comes from Table 1. Since this effort also supports the standardized plant assessment risk (SPAR) models, the collection of 
failure modes is broader than the MSPI collection. Table 1 shows the mapping of the collected failure modes to the MSPI failure modes. Note that the MSPI failure mode scheme does not have a failure mode to describe the failure to run $<1$ hour (for pumps). The INL failure collection effort is now collecting that piece of information. It is uncertain whether to consistently convert these to fail-to-start or fail-to-run, so the failure to run $<1$ hour is retained. This causes some of the differences noted in Section 3.

Table 1. Lookup table to convert INL failure mode to MSPI failure mode.

\begin{tabular}{ll}
\hline \multicolumn{1}{c}{ INL Collection Failure Modes } & \multicolumn{1}{c}{ MSPI Failure Modes } \\
\hline Fail to Close & Fail on Demand \\
Fail to Control & Fail on Demand \\
Fail to Load/Run & Fail to Load/Run \\
Fail to Open & Fail on Demand \\
Fail to Operate & Fail on Demand \\
Fail to Run & Fail to Run \\
Fail to Run $<1 \mathrm{H}$ & Fail to Run $<1 \mathrm{H}$ \\
Fail to Start & Fail to Start \\
Fail to Stop & Unavailable (T\&M) \\
Leak (External) & Unavailable (T\&M) \\
Leak (Internal) & Unavailable (T\&M) \\
Spurious Closing & Unavailable (T\&M) \\
Spurious Opening & Unavailable (T\&M) \\
Spurious Operation & Unavailable (T\&M) \\
Unavailable (T\&M) & Unavailable (T\&M) \\
\hline
\end{tabular}

The MSPI failure modes reported in EPIX are inconsistent (MSPI-S, MSPI-D, and MSPI$\mathrm{SD}$ are used interchangeably). Table 2 shows the lookup table developed at the INL to create enough consistency to perform this evaluation. The lookup table is based on component types and failure modes since demand failures have different meanings between pumps and generators and valves and circuit breakers. Whether or not the failure is a MPSI failure determines whether the MSPI failure mode is "Unavailable T\&M" or the listed MSPI failure mode.

Table 2. Lookup table to convert MSPI failure mode to a consistent failure mode.

\begin{tabular}{|c|c|c|c|c|}
\hline Component Type & MSPI FM & MSPI Failure? & $\begin{array}{c}\text { MSPI Failure Mode } \\
\text { Corrected }\end{array}$ & $\begin{array}{l}\text { MSPI Failure } \\
\text { Modes }\end{array}$ \\
\hline $\mathrm{AOV}$ & (MSPI-D) & $\mathrm{N}$ & (MSPI-D) & Unavailable (T\&M) \\
\hline $\mathrm{AOV}$ & (MSPI-SD) & $\mathrm{N}$ & (MSPI-D) & Unavailable (T\&M) \\
\hline $\mathrm{CRB}$ & (MSPI-SD) & $\mathrm{Y}$ & (MSPI-D) & Fail on Demand \\
\hline CRB & (MSPI-SD) & $\mathrm{N}$ & (MSPI-D) & Unavailable (T\&M) \\
\hline EDP & (MSPI-D) & $\mathrm{N}$ & (MSPI-S) & Unavailable (T\&M) \\
\hline EDP & (MSPI-R) & $\mathrm{Y}$ & (MSPI-R) & Fail to Run \\
\hline EDP & (MSPI-R) & $\mathrm{N}$ & (MSPI-R) & Unavailable (T\&M) \\
\hline EDP & (MSPI-SD) & $\mathrm{Y}$ & (MSPI-S) & Fail to Start \\
\hline EDP & (MSPI-SD) & $\mathrm{N}$ & (MSPI-S) & Unavailable (T\&M) \\
\hline GEN & (MSPI-L) & $\mathrm{Y}$ & (MSPI-L) & Fail to Load/Run \\
\hline GEN & (MSPI-S) & $\mathrm{Y}$ & (MSPI-S) & Fail to Start \\
\hline GEN & (MSPI-S) & $\mathrm{N}$ & (MSPI-S) & Unavailable (T\&M) \\
\hline GEN & (MSPI-SD) & $\mathrm{Y}$ & (MSPI-S) & Fail to Start \\
\hline GEN & (MSPI-SD) & $\mathrm{N}$ & (MSPI-S) & Unavailable (T\&M) \\
\hline $\mathrm{HOV}$ & (MSPI-D) & $\mathrm{Y}$ & (MSPI-D) & Fail on Demand \\
\hline $\mathrm{HOV}$ & (MSPI-D) & $\mathrm{N}$ & (MSPI-D) & Unavailable (T\&M) \\
\hline MDP & (MSPI-D) & $\mathrm{Y}$ & (MSPI-S) & Fail to Start \\
\hline MDP & (MSPI-D) & $\mathrm{N}$ & (MSPI-S) & Unavailable (T\&M) \\
\hline MDP & (MSPI-R) & $\mathrm{Y}$ & (MSPI-R) & Fail to Run \\
\hline MDP & (MSPI-R) & $\mathrm{N}$ & (MSPI-R) & Unavailable (T\&M) \\
\hline MDP & (MSPI-SD) & $\mathrm{Y}$ & (MSPI-S) & Fail to Start \\
\hline
\end{tabular}




\begin{tabular}{ccccc}
\hline Component Type & MSPI FM & MSPI Failure? & $\begin{array}{c}\text { MSPI Failure Mode } \\
\text { Corrected }\end{array}$ & $\begin{array}{c}\text { MSPI Failure } \\
\text { Modes }\end{array}$ \\
\hline MDP & (MSPI-SD) & $\mathrm{N}$ & (MSPI-S) & Unavailable (T\&M) \\
Fail on Demand \\
MOV & (MSPI-D) & $\mathrm{Y}$ & (MSPI-D) & Unavailable (T\&M) \\
MOV & (MSPI-D) & $\mathrm{N}$ & (MSPI-D) & Fail on Demand \\
MOV & (MSPI-SD) & $\mathrm{Y}$ & (MSPI-D) & Unavailable (T\&M) \\
TDP & (MSPI-SD) & $\mathrm{N}$ & (MSPI-S) & Fail to Start \\
TDP & (MSPI-D) & $\mathrm{Y}$ & (MSPI-S) & Unavailable (T\&M) \\
TDP & (MSPI-D) & $\mathrm{N}$ & (MSPI-R) & Fail to Run \\
TDP & (MSPI-R) & $\mathrm{Y}$ & (MSPI-R) & Unavailable (T\&M) \\
TDP & (MSPI-R) & $\mathrm{N}$ & (MSPI-S) & Fail to Start \\
TDP & (MSPI-SD) & $\mathrm{Y}$ & (MSPI-S) & Unavailable (T\&M) \\
\hline
\end{tabular}

\subsection{Device Failure Mode and MSPI Failure Mode Correlation}

Table 3 shows the unique pairs of device failure modes in EPIX with the MSPI failure mode suffix removed and shown separately as column headings. For example, the "operated, but not within specified parameters" device failure mode always has the MSPI failure mode string "MSPI-SD" added as a suffix. The entry of a number at the intersection shows the number of times that device failure/MSPI failure mode was used in the data for that component.

In addition, the data collected in EPIX does not screen these failure modes as appropriate to the component type the failure is describing, which leads to MSPI failure modes of fail to start for valves as shown in Table 2 and Table 3. Also note that MSPI-S (start), MSPID (demand), and MSPI-SD (start demand except diesels) are used interchangeably

Table 3. Matrix of EPIX device failure modes and MSPI failure modes.

\begin{tabular}{|c|c|c|c|c|c|c|}
\hline $\begin{array}{l}\text { Comp } \\
\text { Type }\end{array}$ & Device Failure Mode & (MSPI-D) & (MSPI-L) & (MSPI-R) & (MSPI-S) & (MSPI-SD) \\
\hline AOV & discovered to be unable to close (MSPI-D) & 2 & & & & \\
\hline $\mathrm{AOV}$ & discovered to be unable to open (MSPI-D) & 3 & & & & \\
\hline $\mathrm{AOV}$ & external leakage (MSPI-D) & 2 & & & & \\
\hline $\mathrm{AOV}$ & failed to close on demand (stuck open) (MSPI-D) & 1 & & & & \\
\hline $\mathrm{AOV}$ & failed to close within setpoint tolerance (MSPI-D) & 1 & & & & \\
\hline $\mathrm{AOV}$ & failed to control (MSPI-D) & 11 & & & & \\
\hline $\mathrm{AOV}$ & failed to open on demand (stuck closed) (MSPI-D) & 4 & & & & \\
\hline $\mathrm{AOV}$ & failed to open within setpoint tolerance (MSPI-D) & 1 & & & & \\
\hline $\mathrm{AOV}$ & $\begin{array}{l}\text { failed to remain closed (drifted off closed seat) } \\
\text { (MSPI-D) }\end{array}$ & 2 & & & & \\
\hline $\mathrm{AOV}$ & $\begin{array}{l}\text { found unavailable during nondemand observation } \\
\text { (MSPI-SD) }\end{array}$ & & & & & 1 \\
\hline $\mathrm{AOV}$ & internal leakage when fully seated (MSPI-D) & 3 & & & & \\
\hline $\mathrm{AOV}$ & misalignment-human error (MSPI-SD) & & & & & 1 \\
\hline $\mathrm{AOV}$ & $\begin{array}{l}\text { operated, but not within specified parameters } \\
\text { (MSPI-SD) }\end{array}$ & & & & & 7 \\
\hline $\mathrm{AOV}$ & $\begin{array}{l}\text { partially opened on demand (not stuck closed) } \\
\text { (MSPI-D) }\end{array}$ & 1 & & & & \\
\hline $\mathrm{AOV}$ & premature opening (MSPI-D) & 1 & & & & \\
\hline $\mathrm{AOV}$ & unaffected by failure (MSPI-SD) & & & & & 2 \\
\hline CRB & $\begin{array}{l}\text { operated, but not within specified parameters } \\
\text { (MSPI-SD) }\end{array}$ & & & & & 2 \\
\hline EDP & $\begin{array}{l}\text { discovered to be unable to run for mission time } \\
\text { (MSPI-R) }\end{array}$ & & & 3 & & \\
\hline EDP & discovered to be unable to start (MSPI-SD) & & & & & 2 \\
\hline EDP & external leakage (MSPI-D) & 2 & & & & \\
\hline EDP & failed to start on demand (MSPI-D) & 1 & & & & \\
\hline EDP & $\begin{array}{l}\text { found unavailable during nondemand observation } \\
\text { (MSPI-SD) }\end{array}$ & & & & & 1 \\
\hline EDP & spuriously started (MSPI-D) & 1 & & & & \\
\hline EDP & tripped/stopped during warmup ( & 4 & & & & \\
\hline GEN & corrective maintenance prior to failure (MSPI-SD) & & & & & 3 \\
\hline GEN & discovered to be unable to load (MSPI-L) & & 42 & & & \\
\hline
\end{tabular}




\begin{tabular}{|c|c|c|c|c|c|c|}
\hline $\begin{array}{l}\text { Comp } \\
\text { Type }\end{array}$ & Device Failure Mode & (MSPI-D) & (MSPI-L) & (MSPI-R) & (MSPI-S) & (MSPI-SD) \\
\hline GEN & $\begin{array}{l}\text { discovered to be unable to run for mission time } \\
\text { (MSPI-R) }\end{array}$ & & & 37 & & \\
\hline GEN & discovered to be unable to start (MSPI-SD) & & & & & 16 \\
\hline GEN & $\begin{array}{l}\text { edg did not reach rated rpm \& v on auto start } \\
\text { (MSPI-S) }\end{array}$ & & & & 11 & \\
\hline GEN & $\begin{array}{l}\text { edg did not reach rated rpm \& } \mathrm{v} \text { on manual start } \\
\text { (MSPI-S) }\end{array}$ & & & & 24 & \\
\hline GEN & edg tripped after warmup (>1hr.) (MSPI-R) & & & 35 & & \\
\hline GEN & edg tripped during auto loading \& warmup ( & & 13 & & & \\
\hline GEN & edg tripped during manual loading \& warmup ( & & 36 & & & \\
\hline GEN & erratic output (MSPI-S) & & & & 15 & \\
\hline GEN & failed to start on demand (not edg) (MSPI-S) & & & & 1 & \\
\hline GEN & failed to stop (not edg) (MSPI-S) & & & & 1 & \\
\hline GEN & found during observation (MSPI-S) & & & & 3 & \\
\hline GEN & $\begin{array}{l}\text { found unavailable during nondemand observation } \\
\text { (MSPI-SD) }\end{array}$ & & & & & 20 \\
\hline GEN & high output (MSPI-S) & & & & 3 & \\
\hline GEN & misalignment-human error (MSPI-SD) & & & & & 7 \\
\hline GEN & not yet specified (MSPI-SD) & & & & & 5 \\
\hline GEN & $\begin{array}{l}\text { operated, but not within specified parameters } \\
\text { (MSPI-SD) }\end{array}$ & & & & & 34 \\
\hline GEN & preventive maintenance (MSPI-SD) & & & & & 4 \\
\hline GEN & unaffected by failure (MSPI-SD) & & & & & 81 \\
\hline GEN & unavailable, not failed (MSPI-SD) & & & & & 45 \\
\hline GEN & unstable v/a/frequency control (not edg) (MSPI-S) & & & & 3 & \\
\hline $\mathrm{HOV}$ & failed to close on demand (stuck open) (MSPI-D) & 1 & & & & \\
\hline HOV & failed to open on demand (stuck closed) (MSPI-D) & 2 & & & & \\
\hline MDP & corrective maintenance prior to failure (MSPI-SD) & & & & & 10 \\
\hline MDP & $\begin{array}{l}\text { design change to improve reliability/efficiency } \\
\text { (MSPI-SD) }\end{array}$ & & & & & 2 \\
\hline MDP & $\begin{array}{l}\text { discovered to be unable to run for mission time } \\
\text { (MSPI-R) }\end{array}$ & & & 30 & & \\
\hline MDP & discovered to be unable to start (MSPI-SD) & & & & & 21 \\
\hline MDP & external leakage (MSPI-D) & 22 & & & & \\
\hline MDP & failed to start on demand (MSPI-D) & 112 & & & & \\
\hline MDP & failed to stop on demand (MSPI-D) & 3 & & & & \\
\hline MDP & $\begin{array}{l}\text { found unavailable during nondemand observation } \\
\text { (MSPI-SD) }\end{array}$ & & & & & 34 \\
\hline MDP & misalignment-human error (MSPI-SD) & & & & & 16 \\
\hline MDP & not yet specified (MSPI-SD) & & & & & 11 \\
\hline MDP & $\begin{array}{l}\text { operated, but not within specified parameters } \\
\text { (MSPI-SD) }\end{array}$ & & & & & 37 \\
\hline MDP & $\begin{array}{l}\text { ran, but failed to develop adequate flow/pressure } \\
\text { (MSPI-D) }\end{array}$ & 17 & & & & \\
\hline MDP & spuriously started (MSPI-D) & 4 & & & & \\
\hline MDP & tripped/stopped after warmup (>1 hr.) (MSPI-R) & & & 37 & & \\
\hline MDP & tripped/stopped during warmup ( & 17 & & & & \\
\hline MDP & unaffected by failure (MSPI-SD) & & & & & 60 \\
\hline MDP & unavailable, not failed (MSPI-SD) & & & & & 36 \\
\hline MOV & corrective maintenance prior to failure (MSPI-SD) & & & & & 4 \\
\hline MOV & discovered to be unable to close (MSPI-D) & 3 & & & & \\
\hline MOV & discovered to be unable to open (MSPI-D) & 5 & & & & \\
\hline MOV & external leakage (MSPI-D) & 4 & & & & \\
\hline MOV & failed to close on demand (stuck open) (MSPI-D) & 24 & & & & \\
\hline MOV & failed to close within setpoint tolerance (MSPI-D) & 1 & & & & \\
\hline MOV & failed to control (MSPI-D) & 12 & & & & \\
\hline MOV & failed to open on demand (stuck closed) (MSPI-D) & 13 & & & & \\
\hline MOV & failed to open within setpoint tolerance (MSPI-D) & 3 & & & & \\
\hline MOV & $\begin{array}{l}\text { found unavailable during nondemand observation } \\
\text { (MSPI-SD) }\end{array}$ & & & & & 10 \\
\hline MOV & $\begin{array}{l}\text { internal leakage due to being improperly seated } \\
\text { (MSPI-D) }\end{array}$ & 1 & & & & \\
\hline MOV & internal leakage when fully seated (MSPI-D) & 10 & & & & \\
\hline MOV & operated on required demand (MSPI-D) & 2 & & & & \\
\hline MOV & $\begin{array}{l}\text { operated, but not within specified parameters } \\
\text { (MSPI-SD) }\end{array}$ & & & & & 8 \\
\hline MOV & $\begin{array}{l}\text { partially closed on demand (not stuck open) } \\
\text { (MSPI-D) }\end{array}$ & 3 & & & & \\
\hline
\end{tabular}




\begin{tabular}{|c|c|c|c|c|c|c|}
\hline $\begin{array}{l}\text { Comp } \\
\text { Type }\end{array}$ & Device Failure Mode & (MSPI-D) & (MSPI-L) & (MSPI-R) & (MSPI-S) & (MSPI-SD) \\
\hline MOV & $\begin{array}{l}\text { partially opened on demand (not stuck closed) } \\
\text { (MSPI-D) }\end{array}$ & 3 & & & & \\
\hline MOV & unaffected by failure (MSPI-SD) & & & & & 4 \\
\hline MOV & unavailable, not failed (MSPI-SD) & & & & & 9 \\
\hline TDP & corrective maintenance prior to failure (MSPI-SD) & & & & & 1 \\
\hline TDP & $\begin{array}{l}\text { discovered to be unable to run for mission time } \\
\text { (MSPI-R) }\end{array}$ & & & 13 & & \\
\hline TDP & discovered to be unable to start (MSPI-SD) & & & & & 7 \\
\hline TDP & external leakage (MSPI-D) & 4 & & & & \\
\hline TDP & failed to start on demand (MSPI-D) & 18 & & & & \\
\hline TDP & failed to stop on demand (MSPI-D) & 1 & & & & \\
\hline TDP & $\begin{array}{l}\text { found unavailable during nondemand observation } \\
\text { (MSPI-SD) }\end{array}$ & & & & & 12 \\
\hline TDP & misalignment-human error (MSPI-SD) & & & & & 1 \\
\hline TDP & not yet specified (MSPI-SD) & & & & & 2 \\
\hline TDP & $\begin{array}{l}\text { operated, but not within specified parameters } \\
\text { (MSPI-SD) }\end{array}$ & & & & & 22 \\
\hline TDP & $\begin{array}{l}\text { ran, but failed to develop adequate flow/pressure } \\
\text { (MSPI-D) }\end{array}$ & 5 & & & & \\
\hline TDP & spuriously started (MSPI-D) & 2 & & & & \\
\hline TDP & tripped/stopped after warmup ( $>1 \mathrm{hr}$.) (MSPI-R) & & & 8 & & \\
\hline TDP & tripped/stopped during warmup ( & 13 & & & & \\
\hline TDP & unaffected by failure (MSPI-SD) & & & & & 15 \\
\hline TDP & unavailable, not failed (MSPI-SD) & & & & & 21 \\
\hline
\end{tabular}

\section{MSPI Data Review Results}

The review of the EPIX MSPI component failure data either verified the EPIX MSPI supplied failure mode or identified a more appropriate failure mode.

The comparison of the failure modes is accomplished through the translations shown in Table 1 and Table 2. Tables 4 through 10 show these results at a high level. In Tables 4 through 10, the columns labeled "EPIX MSPI Failure Mode" are the MSPI failure modes entered into EPIX by the industry, the subsequent column headings are the failure modes determined by INL staff. Appendix A gives a detailed presentation of the individual failures that do not fall in the green highlighted table entries (those where there is no match between the failure modes).

The column, EPIX MSPI Failure Mode, is a translation of the EPIX supplied MSPI failure mode which is appended to the device failure mode in the device failure table. The failure mode "Unavailable T\&M" was created to show that the event was not a countable MSPI failure; rather the event was an unavailability of the piece of equipment. "Unavailable T\&M" is equivalent to "Not an MSPI failure."

The green highlighted cells indicate the number of failure records observed for each failure mode where the INL review agreed with the original EPIX determination. All other cells indicate the degree of disagreement between the two. It is not unusual for the INL EPIX check to reclassify a MSPI failure as a non-MSPI failure. A listing of some of the reasons why there are differences is shown after these tables.

Table 4 shows the results for the comparison of emergency generator failure modes. The failure mode with the highest rate of error is the MSPI fail-to-start failure mode. Of the 104 reported EDG fail-to-start events, the INL review agreed with that failure mode assignment for only 64 events. The INL review determined that 17 events should have 
been fail-to-Load/Run, four should have been fail-to-run and 19 should have been Unavailable T\&M. Most of the misclassification is due to a systemic (not random) problem with the EPIX data collection software. The proliferation of device failure modes mapped to the MSPI-S and -SD MSPI failure mode leads to the large variation shown for the fail-to-start failure mode.

Table 4. Emergency generator failure mode comparison matrix.

\begin{tabular}{lccccc}
\hline \multicolumn{1}{c}{$\begin{array}{c}\text { EPIX MSPI } \\
\text { Failure Mode }\end{array}$} & $\begin{array}{c}\text { Fail to } \\
\text { Start }\end{array}$ & $\begin{array}{c}\text { Fail to } \\
\text { Load/Run }\end{array}$ & $\begin{array}{c}\text { Fail to } \\
\text { Run }\end{array}$ & $\begin{array}{c}\text { Unavailable } \\
\text { (T\&M) }\end{array}$ & Total \\
\hline Fail to Start & 64 & 17 & 4 & 19 & 104 \\
Fail to Load/Run & & 75 & & 5 & 80 \\
Fail to Run & 2 & 53 & 2 & 57 \\
$\begin{array}{l}\text { Unavailable } \\
\text { (T\&M) }\end{array}$ & 5 & 9 & 6 & 178 & 198 \\
\hline Total & 69 & 103 & 63 & 204 & 439 \\
\hline
\end{tabular}

Table 5 and Table 6 show the results of failure mode comparisons for motor-operated valves (MOVs) and air-operated valves (AOVs). For valves (and circuit breakers), the EPIX assignment of whether the failure is an MSPI failure is dependent on the direction of the observed failure (fail-to-open or fail-to-close) and the PRA required direction of the failure for that specific device. If the PRA failure is fail-to-open, and the observed failure is fail-to-close, the event is designated as a non-MSPI failure (which typically maps to Unavailable T\&M).

To meet the wide range of data applications, the INL data collection allows for collecting the specific failure direction, or fail-to-operate when the failure direction could not be determined, regardless of the PRA failure direction. This item alone accounts for most of the reclassifying of "Unavailable T\&M" to fail-on-demand.

Table 5. Motor operated valve failure mode comparison matrix.

\begin{tabular}{lccc}
\hline $\begin{array}{c}\text { EPIX MSPI Failure } \\
\text { Mode }\end{array}$ & $\begin{array}{c}\text { Fail on } \\
\text { Demand }\end{array}$ & $\begin{array}{c}\text { Unavailable } \\
(\mathrm{T} \& \mathrm{M})\end{array}$ & Total \\
\hline Fail on Demand & 52 & 10 & 62 \\
Unavailable (T\&M) & 24 & 33 & 57 \\
\hline Total & 76 & 43 & 119 \\
\hline
\end{tabular}

Table 6. Air operated valve failure mode comparison matrix.

\begin{tabular}{lccc}
\hline $\begin{array}{c}\text { EPIX MSPI Failure } \\
\text { Mode }\end{array}$ & $\begin{array}{c}\text { Fail on } \\
\text { Demand }\end{array}$ & $\begin{array}{c}\text { Unavailable } \\
\text { (T\&M) }\end{array}$ & Total \\
\hline Fail on Demand & 22 & 5 & 27 \\
Unavailable (T\&M) & 4 & 12 & 16 \\
\hline Total & 26 & 17 & 43 \\
\hline
\end{tabular}

Table 7, Table 8 and Table 9 show the results for the comparison of motor, turbine, and engine-driven pump failure modes. The failure mode with the highest rate of error is the MSPI fail-to-start failure mode. Most of the misclassification is due to a systemic (not random) problem with the EPIX data collection software as noted in Section 2. The proliferation of device failure modes mapped to the MSPI-S and -SD MSPI failure mode leads to the large variation shown in the fail-to-start row in Table 7, Table 8 and Table 9. 
Table 7. Motor driven pump failure mode comparison matrix.

\begin{tabular}{lccccc}
\hline $\begin{array}{c}\text { EPIX MSPI } \\
\text { Failure Mode }\end{array}$ & $\begin{array}{c}\text { Fail to } \\
\text { Start }\end{array}$ & $\begin{array}{c}\text { Fail to } \\
\text { Run }<1 \mathrm{H}\end{array}$ & $\begin{array}{c}\text { Fail to } \\
\text { Run }\end{array}$ & $\begin{array}{c}\text { Unavailable } \\
\text { (T\&M) }\end{array}$ & Total \\
\hline Fail to Start & 138 & 14 & 24 & 31 & 207 \\
Fail to Run $<1 \mathrm{H}$ & & & & & 0 \\
Fail to Run & 1 & 5 & 46 & 5 & 57 \\
$\begin{array}{l}\text { Unavailable } \\
\text { (T\&M) }\end{array}$ & 15 & 2 & 19 & 169 & 205 \\
\hline Total & 154 & 21 & 89 & 205 & 469 \\
\hline
\end{tabular}

Table 8. Turbine driven pump failure mode comparison matrix.

\begin{tabular}{lccccc}
\hline $\begin{array}{l}\text { EPIX MSPI Failure } \\
\text { Mode }\end{array}$ & $\begin{array}{c}\text { Fail to } \\
\text { Start }\end{array}$ & $\begin{array}{c}\text { Fail to } \\
\text { Run }<1 \mathrm{H}\end{array}$ & $\begin{array}{c}\text { Fail to } \\
\text { Run }\end{array}$ & $\begin{array}{c}\text { Unavailable } \\
\text { (T\&M) }\end{array}$ & Total \\
\hline Fail to Start & 38 & 11 & 8 & 3 & 60 \\
Fail to Run $<1 \mathrm{H}$ & & & & & 0 \\
Fail to Run & 1 & 4 & 10 & & 15 \\
$\begin{array}{l}\text { Unavailable } \\
\text { (T\&M) }\end{array}$ & 10 & 2 & 2 & 56 & 70 \\
\hline Total & 49 & 17 & 20 & 59 & 145 \\
\hline
\end{tabular}

Table 9. Engine driven pump failure mode comparison matrix.

\begin{tabular}{lccccc}
\hline \multicolumn{1}{c}{$\begin{array}{c}\text { EPIX MSPI } \\
\text { Failure Mode }\end{array}$} & $\begin{array}{c}\text { Fail to } \\
\text { Start }\end{array}$ & $\begin{array}{c}\text { Fail to } \\
\text { Run }<1 \mathrm{H}\end{array}$ & $\begin{array}{c}\text { Fail to } \\
\text { Run }\end{array}$ & $\begin{array}{c}\text { Unavailable } \\
(\mathrm{T \& M})\end{array}$ & Total \\
\hline Fail to Start & & & & & 0 \\
Fail to Run $<1 \mathrm{H}$ & & & & & 0 \\
Fail to Run & & & 3 & & 3 \\
Unavailable (T\&M) & & & & 3 & 3 \\
\hline Total & 0 & 0 & 3 & 3 & 6 \\
\hline
\end{tabular}

Table 10 shows the results of failure mode comparisons for hydraulic-operated valves (HOVs) and circuit breakers.

Table 10. Hydraulic operated valve and circuit breaker failure mode comparison matrix.

\begin{tabular}{llccc}
\hline $\begin{array}{c}\text { Component } \\
\text { Type }\end{array}$ & $\begin{array}{c}\text { EPIX MSPI Failure } \\
\text { Mode }\end{array}$ & $\begin{array}{c}\text { Fail on } \\
\text { Demand }\end{array}$ & $\begin{array}{c}\text { Unavailable } \\
(\mathrm{T} \& \mathrm{M})\end{array}$ & Total \\
\hline HOV & Fail on Demand & 2 & & 2 \\
HOV & Unavailable (T\&M) & 1 & & 1 \\
\hline CRB & Fail on Demand & & & 0 \\
CRB & Unavailable (T\&M) & 1 & 1 & 2 \\
\hline & Total & 4 & 1 & 5 \\
\hline
\end{tabular}

Comments on a sampling of failure events reviewed during this effort on why MSPI failure modes are different than the INL coded failure modes. A detailed listing of the EPIX failure events where there is disagreement between industry and the INL can be found in Appendix A.

1. According to the EPIX guidelines, failure of a component outside the key component boundary should be coded as the failure of that component and the key component should be Unavailable, unless the key component subsequently fails. There are several instances in EPIX where this guidance is not followed. 
2. Incorrect application of the Load/Run or 1-hour failure criterion for running devices.

3. Reporting of only the EDG output breaker (a supporting component) and not the full EDG key component. To correct this error, the INL manually adds the EDG key component and assigns the applicable failure mode to it. Most of these changes result in adding a fail-to-load/run MSPI failure.

4. Cases have been observed where EPIX has called an event an MSPI failure when a component failure would only occur given another event, but the conditioning event never happened. For example, a component might not be able to function during a seismic event. Unless there was a seismic event, the INL deems these events as Unavailable, not a failure.

5. The pump circuit breaker trips open while the pump is running; the pump is designated as "Unaffected by Failure (MSPI-SD)". Reference 2 shows that EPIX considers the breaker to be inside the pump boundary, therefore this event should have been counted as an MSPI failure.

6. The RCIC pump flow controller failed and the RCIC pump was not considered failed. The INL review felt that this should have been an MSPI failure.

7. A post-maintenance test (PMT) revealed a failure due to the maintenance and the event was designated as an MSPI failure. Reference 2 guidance indicates that PMT should not be classified as a failure, rather as Unavailable.

8. The EDG established load but experienced erratic output. The failure mode was designated as "Erratic Output (MSPI-S)", which maps to fail-to-start instead of fail-to-load/run. This is an example of the problems with the MSPI failure mode string being automatically appended to the device failure mode string. For those device failure modes that are not descriptive of the PRA failure mode, the appended MSPI failure mode is always MSPI-S,-D, or -SD. This biases these entries towards the fail-to-start failure mode and away from the fail-to-run and fail-to-load/run failure modes.

9. The TDP governor did not regulate speed and the pump was manually tripped before automatically tripping. The event was designated as a non-MSPI failure. The INL review felt that this should be an MSPI failure.

10. Pump seal water flow problems. There seems to be inconsistency in the interpretation of pump operability when seal water flow is lost or degraded.

11. A leaking water jacket was called an MSPI failure, but there was no indication that the amount of water leaking would have harmed the component. The INL review felt that this should not be an MSPI failure.

12. A tagged-out pump was called an MSPI failure. The INL review felt that this should not be an MSPI failure.

13. A non-functioning delta-pressure gauge was called a pump MSPI failure. With no indication that this would lead to failure of the pump, the INL review felt that this should not be an MSPI failure. 
14. Valves are designated as MSPI failures or not, based on the direction of the failure and whether or not that failure direction is safety-significant. This is a source of many observed differences between the INL determined failure mode and the EPIX listed failure mode. The INL coding identified these events as a failure to reposition in the intended direction: fail-to-open or fail-to-close (when that can be discerned).

15. There have been a number of instances where the key component was called Unavailable Not Failed when a sub-component (e.g., pump motor) failed. The INL contends that it is a pump failure when the pump motor fails. In addition, due to the idiosyncrasies of EPIX, Unavailable Not Failed is always mapped to fail-to-start, which is not necessarily correct.

16. Hydrogen voiding in the suction of the spare HPI Charging Pump was listed as not an MSPI failure. INL felt otherwise.

17. Circuit breaker charging motor/spring failures are designated as Unavailable if detected right away. Failure of the breaker charging motor/spring results in a possible failure on the next demand to start. The INL feels that these failures should be an MSPI failure if the breaker is left in that condition for any length of time. The only ones to qualify for Unavailable are those where the operator is there at the breaker and detects the condition (noise, indicating lights).

18. A service water pump experienced high vibration and failed bearings but was not called an MSPI failure. The INL review felt that this should be an MSPI failure.

19. The loss of control power to an AFW pump governor was not listed as an MSPI failure. The INL review felt that this should be an MSPI failure.

20. A 6 drop per minute leak on the EDG radiator was called an MSPI failure, but there was no indication that this amount of water leaking would have harmed the component. The INL review felt that this should not be an MSPI failure.

21. Significant (17 of 20 tubes) fouling of the HPI pump lube oil coolers was not labeled as an MSPI failure. The INL review felt that this should be an MSPI failure-to-run.

22. An EDG was leaking water into the oil while shutdown. Discovered while preparing for a test run. The test run was not conducted. The EDG had been inoperable for 5-days. The leakage would have been greater when running. EPIX listed this as not an MPSI failure. The INL review felt that this should be an MSPI failure.

23. Sand filling the service water pump motor coolers resulted in a complete loss of service water flow but was not called an MSPI failure in EPIX. INL lists this as an MSPI failure.

24. An EDG experienced an elevated crankcase pressure over two times normal, with oil spraying from shaft seals, and high exhaust temperature. This event was coded as not an MSPI failure. The INL review felt that this should be an MSPI failure. 
25. EDGs operating in droop-mode experience load swings. Some EPIX records say this is not an MSPI failure, others say it is. The INL position is that these are not MSPI failures.

The following is reproduced from the EPIX guidance and shows how to classify failures where the failed device is outside the MSPI devices boundary:

Failures and Discovered Conditions of Non-Monitored Structures, Systems, and Components (SSC)

Failures of SSC's that are not included in the performance index will not be counted as a failure or a demand. Failures of SSC's that would have caused an SSC within the scope of the performance index to fail will not be counted as a failure or demand. An example could be a manual suction isolation valve left closed which would have caused a pump to fail. This would not be counted as a failure of the pump. Any mis-positioning of the valve that caused the train to be unavailable would be counted as unavailability from the time of discovery. The significance of the mis-positioned valve prior to discovery would be addressed through the inspection process. (Note, however, in the above example, if the shut manual suction isolation valve resulted in an actual pump failure, the pump failure would be counted as a demand and failure of the pump.)

\section{Conclusions}

A full review of MSPI device failures from 2003 to current was performed by INL staff for the purposes of collecting data for the NRC industry trends program and to support the MSPI Technical Analysis and Support program.

The review shows that there were 275 device failure records for when the INL review did not agree with the EPIX coding for the failure mode, out of a total of 1,234 MSPI device failure records in the current dataset available at the INL. The INL staff believes that the MSPI failure mode is correct approximately 78 percent of the time.

The review also shows that there remain some significant problems in the collection of data for the MSPI.

- Misunderstanding by coding personnel of component boundaries.

- Post maintenance testing failures are misclassified as MSPI failures.

- There exists a systemic bias to the fail-to-start failure mode due to an inadequate data collection scheme that does not allow the data input to reflect independent assessment of the device failure mode and the MSPI failure mode.

- There exists a systemic confusion resulting from not screening the failure mode pick list to only those failure modes applicable to the component the failure is being applied to.

Inaccurate reporting contributes significantly to undercounting failures. Examples of this include assigning the observed failure to the wrong component, and not tying the failure to a key component; but the major quality shortcoming of the EPIX data is the prevalence of incorrect assignment of the component failure mode. 


\section{References}

1. Equipment Performance and Information Exchange System (EPIX): Reporting Requirements, INPO 98-001, Revision 5, January 2007.

2. Regulatory Assessment Performance Indicator Guideline, NEI 99-02, Revision 5, July 2007. 


\section{MSPI Failure Compare NoMatch}


Component Type $\quad A O V$ 


\section{Component Type $\quad A O V$}

EPIX MSPI Failure Mode Fail on Demand

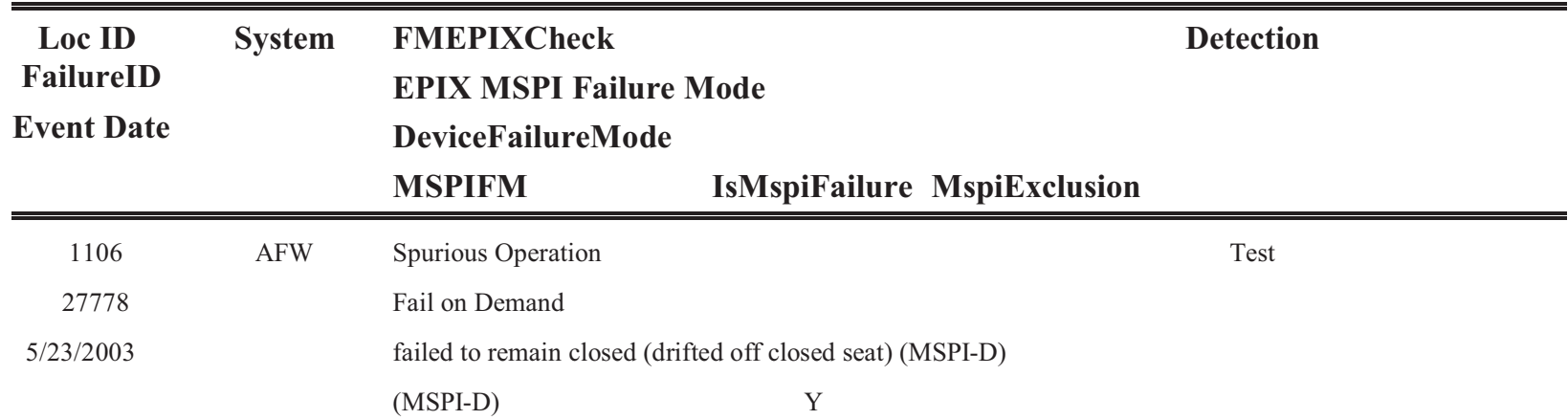

Inadvertent unlatching of the (1MS52) trip valve when the (1MS132) steam admission valve popped open, caused the AFW pump trip.

The MS132 valve popped off its closed seat as the plug and cage were binding during initial opening of the valve. As a result, an initial in-rush of steam caused mechanical agitation (shaking and vibration) of the steam line and the latching mechanism on the trip valve (1MS52) during the ST, causing it to unlatch.

The popping of the 1MS132 appears to have been caused by the valve plug and cage binding during initial opening of the piloted, cage guided, globe valve. This binding only occurred when steam was applied to the valve. A steam vortex and pressure wave formed as the inrush of steam through the cage impacted the valve plug immediately after the pilot lifted. As a result, the valve plug and stem assembly could shift slightly to the side and be rotated (much like a corkscrew) if the valve stem is not properly restrained at the coupling block.

\begin{tabular}{|c|c|c|c|}
\hline 1100 & RHR & Leak (External) & Test \\
\hline 29200 & & Fail on Demand & \\
\hline \multirow[t]{3}{*}{$9 / 19 / 2003$} & & external leakage (MSPI-D) & \\
\hline & & (MSPI-D) & $\mathrm{Y}$ \\
\hline & \multicolumn{3}{|c|}{$\begin{array}{l}\text { On } 09 / 19 / 03 \text { at } 22: 40 \text {, during performance of IC-ST-IA-3004, HCV-386, SIRW tank SI- } 5 \text { recirculation valve, failed } \\
\text { acceptance criteria of pressure drop less than or equal to } 3 \text { PSIG in an hour. The actuator was leaking around the hand wheel } \\
\text { stem and bonnet diaphragm. }\end{array}$} \\
\hline 1100 & RHR & Leak (External) & Test \\
\hline 29200 & & Fail on Demand & \\
\hline \multirow[t]{3}{*}{$9 / 19 / 2003$} & & external leakage (MSPI-D) & \\
\hline & & (MSPI-D) & $\mathrm{Y}$ \\
\hline & \multicolumn{3}{|c|}{$\begin{array}{l}\text { On 09/19/03 at 22:40, during performance of IC-ST-IA- } 3004, \mathrm{HCV}-386 \text {, SIRW tank SI- } 5 \text { recirculation valve, failed } \\
\text { acceptance criteria of pressure drop less than or equal to } 3 \text { PSIG in an hour. The actuator was leaking around the hand wheel } \\
\text { stem and bonnet diaphragm. }\end{array}$} \\
\hline
\end{tabular}




\section{Component Type $\quad A O V$}

EPIX MSPI Failure Mode Fail on Demand

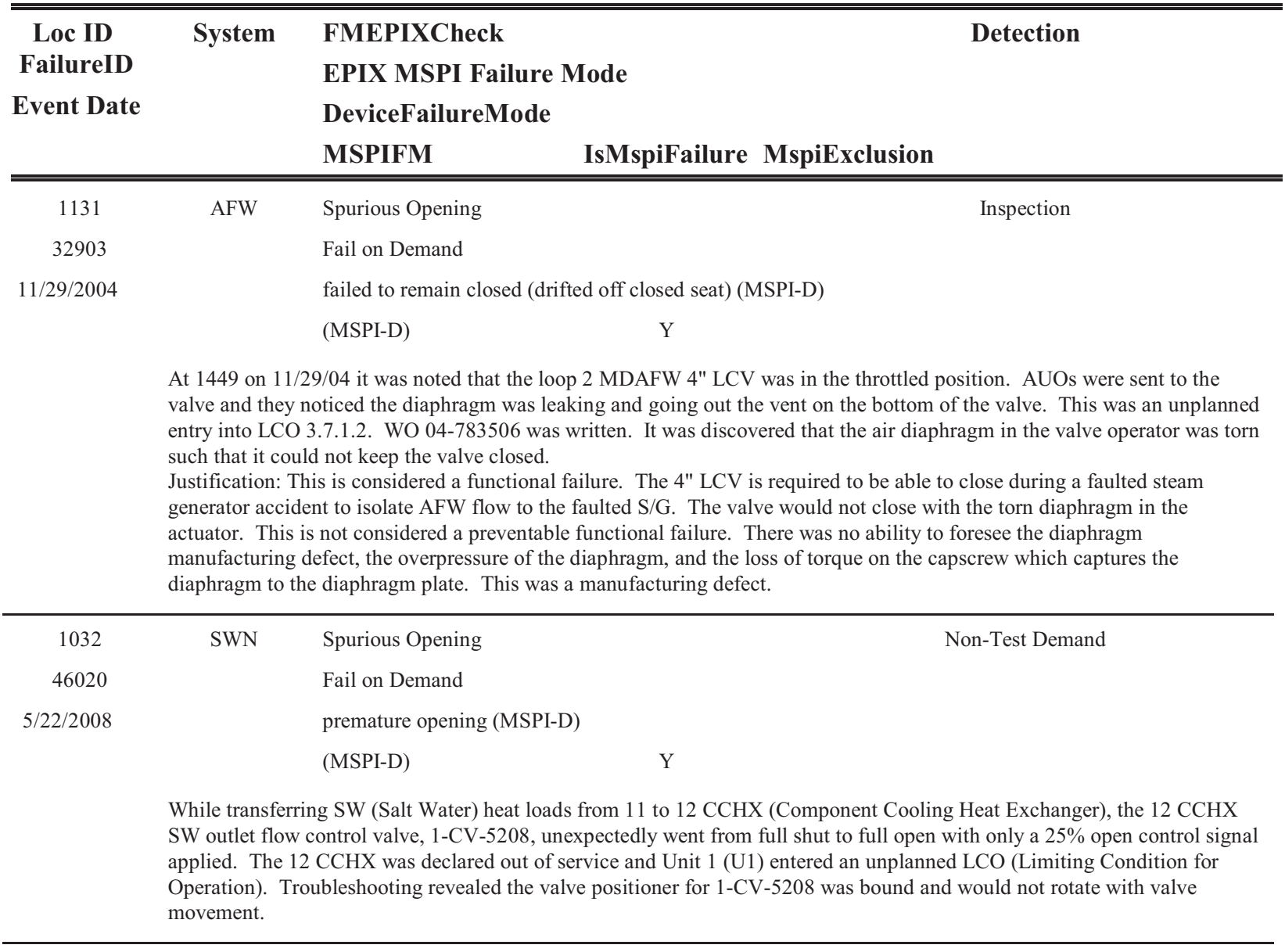




\section{Component Type $\quad A O V$}

EPIX MSPI Failure Mode Unavailable (T\&M)

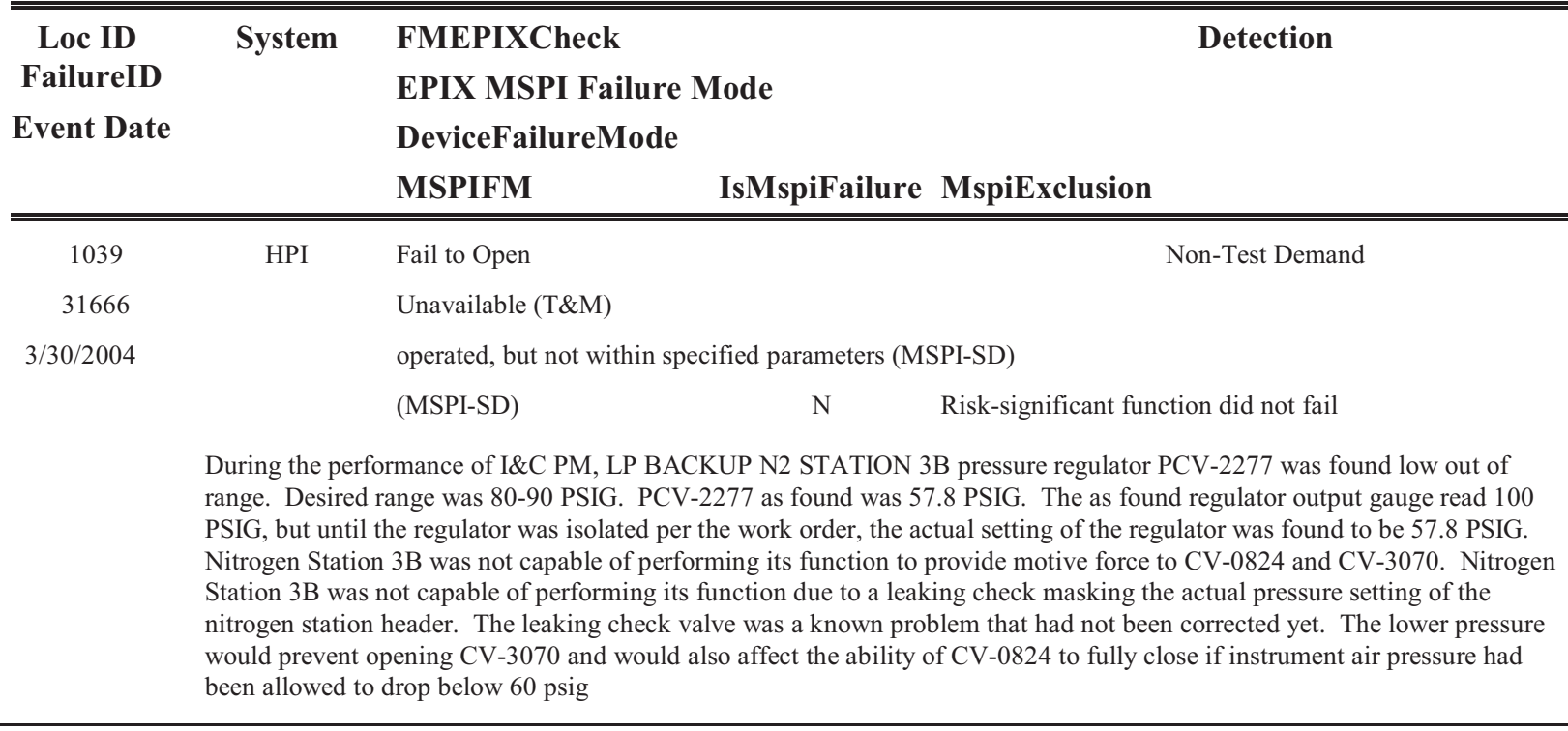

\begin{tabular}{|c|c|c|c|}
\hline 1039 & SWN & Fail to Close & Non-Test Demand \\
\hline 31666 & & \multicolumn{2}{|l|}{ Unavailable (T\&M) } \\
\hline \multirow[t]{3}{*}{$3 / 30 / 2004$} & & \multicolumn{2}{|c|}{ operated, but not within specified parameters (MSPI-SD) } \\
\hline & & (MSPI-SD) & Risk-significant function did not fail \\
\hline & \multicolumn{3}{|c|}{$\begin{array}{l}\text { During the performance of I\&C PM, LP BACKUP N2 STATION 3B pressure regulator PCV- } 2277 \text { was found low out of } \\
\text { range. Desired range was } 80-90 \text { PSIG. PCV-2277 as found was } 57.8 \text { PSIG. The as found regulator output gauge read } 100 \\
\text { PSIG, but until the regulator was isolated per the work order, the actual setting of the regulator was found to be } 57.8 \text { PSIG. } \\
\text { Nitrogen Station 3B was not capable of performing its function to provide motive force to CV- } 0824 \text { and CV-3070. Nitrogen } \\
\text { Station 3B was not capable of performing its function due to a leaking check masking the actual pressure setting of the } \\
\text { nitrogen station header. The leaking check valve was a known problem that had not been corrected yet. The lower pressure } \\
\text { would prevent opening CV-3070 and would also affect the ability of CV-0824 to fully close if instrument air pressure had } \\
\text { been allowed to drop below } 60 \text { psig }\end{array}$} \\
\hline 1106 & SWN & Fail to Control & Non-Test Demand \\
\hline 32598 & & Unavailable (T\&M) & \\
\hline \multirow[t]{3}{*}{$10 / 2 / 2004$} & & failed to control (MSPI-D) & \\
\hline & & (MSPI-D) & Risk-significant function did not fail \\
\hline & \multicolumn{3}{|c|}{$\begin{array}{l}\text { The SW flow for } 11 \mathrm{CC} \text { heat exchanger failed high due to the flow device indicating low, causing } 11 \mathrm{CC} \text { heat exchanger to } \\
\text { be inoperable. }\end{array}$} \\
\hline
\end{tabular}




\section{Component Type $\quad A O V$}

EPIX MSPI Failure Mode Unavailable (T\&M)

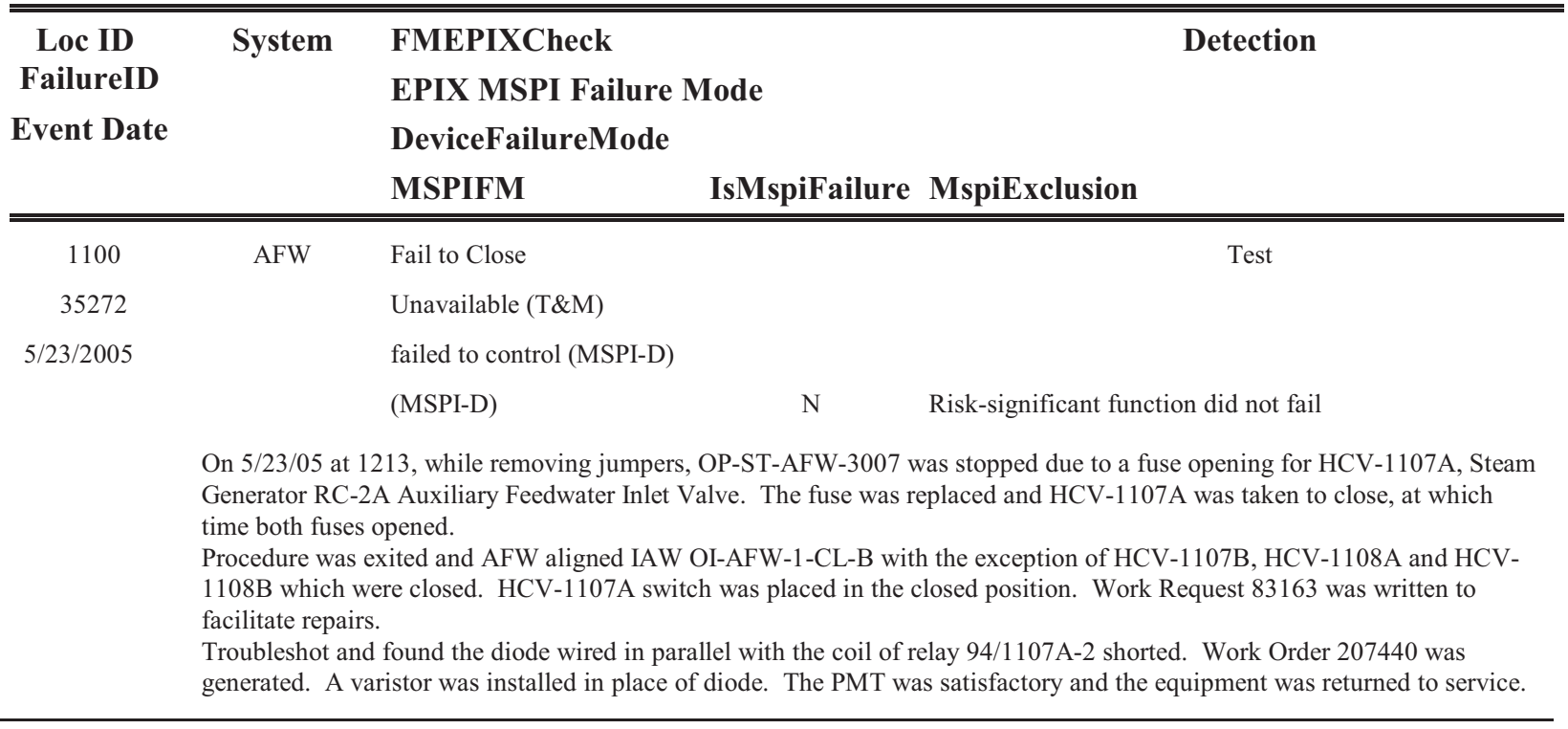




\section{Component Type $\quad C R B$}

EPIX MSPI Failure Mode Unavailable (T\&M)

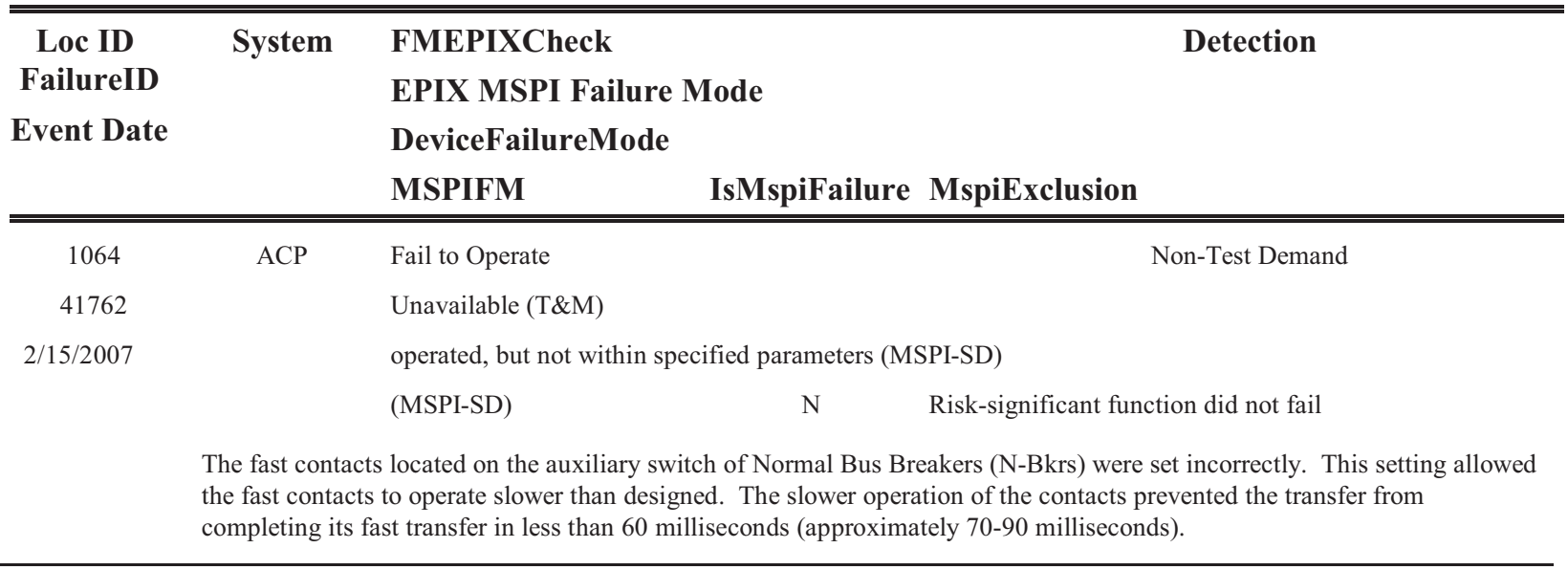


Component Type EDP 


\section{Component Type EDP}

EPIX MSPI Failure Mode Fail to Start

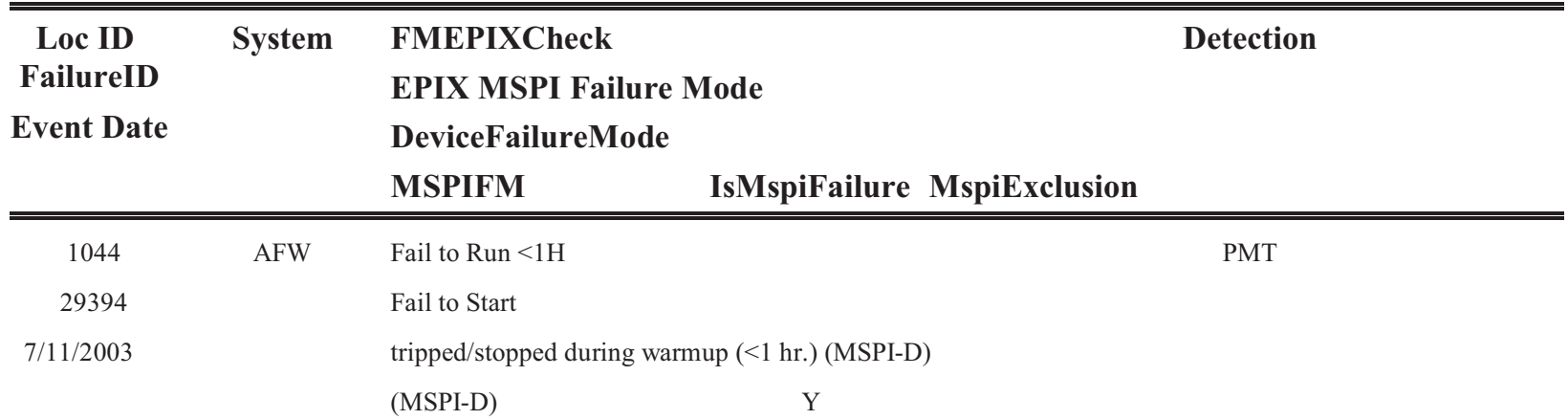

On 7/11/03 at 13:00 the $1 \mathrm{~B}$ AF pump was started per a routine run per BwOP AF-7. It was noted $\sim 2$ minutes after engine start that gray smoke/mist was coming from the valve cover breathers. The engine was manually tripped at 13:04 by Operations and a troubleshooting team was formed to investigate the failure.

During the inspection, aluminum material was found in the airbox, this discovery lead to a detailed inspection of the combustion air blowers. This inspection revealed a failed combustion air blower and what appear to be failed bearings and indication of lubrication/cooling starvation. Definitive confirmation of bearing failure cannot be made without performing disassembly of the failed blower.

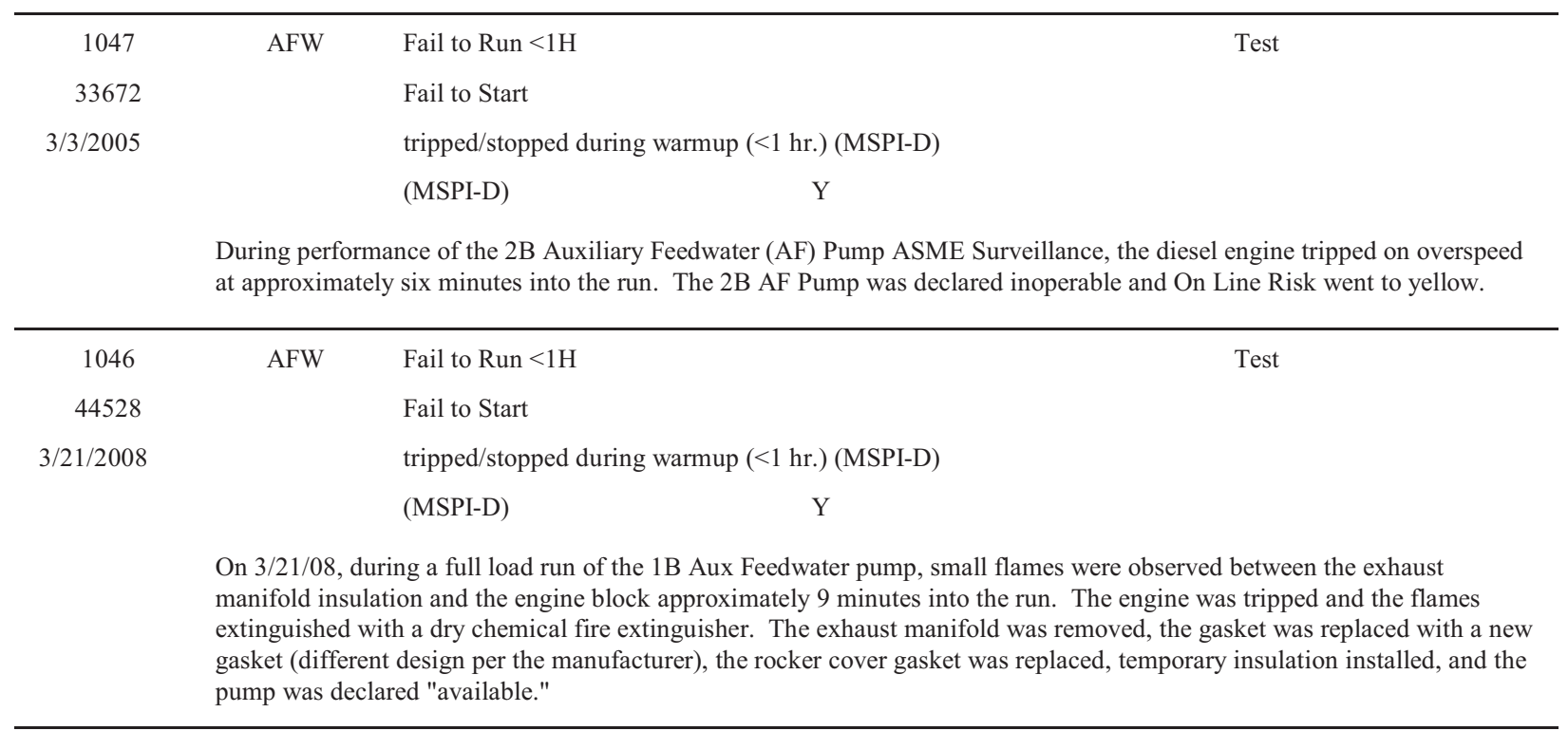




\section{Component Type EDP}

EPIX MSPI Failure Mode Fail to Start

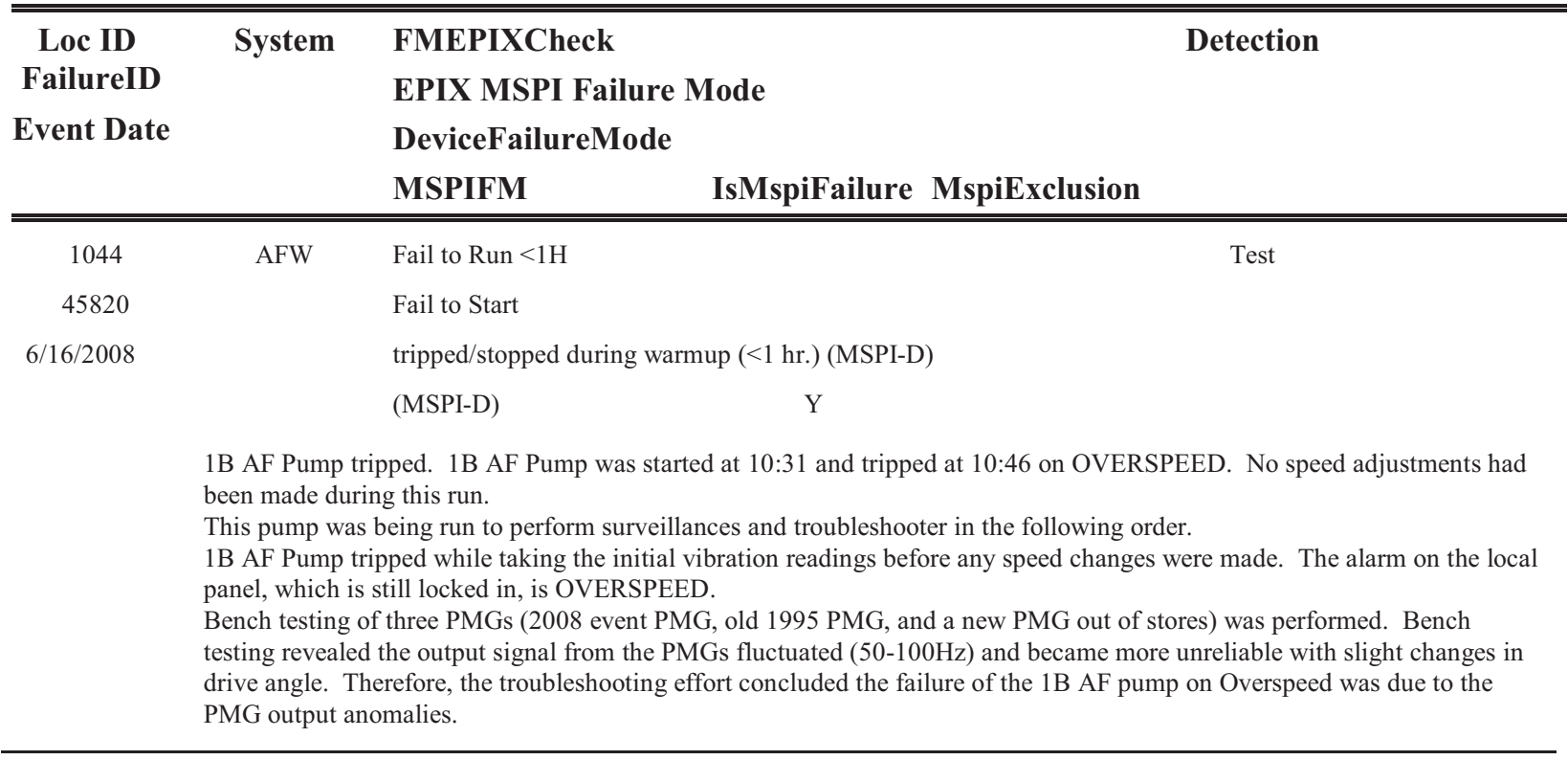


Component Type GEN 


\section{Component Type GEN}

EPIX MSPI Failure Mode Fail to Load/Run

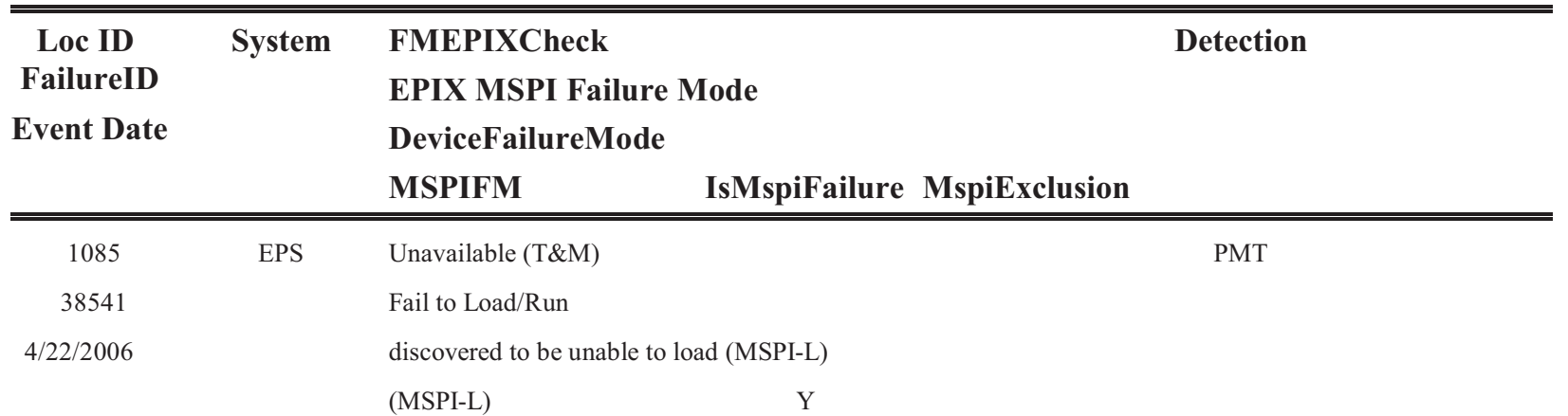

While performing post maintenance testing on the Unit 2, 2CD EDG (2-OME-150-CD) between April 18th and April 24th, 2006, seven fuel injection pumps (2-PP-163-*-CD) seized. All failures were limited to the 2CD EDG only.

Summary of Root Cause and Corrective Actions to Prelude Recurrence

These events stem from two (2) Root Causes. The first was an inadequate barrier that permitted new fuel injection pumps to contain foreign material of sufficient size and hardness to damage the pumps. The second was due to an inefficient duplex filter design that ultimately allowed foreign material to enter the supply of fuel oil to the fuel injection pumps that was of sufficient size to damage the pumps.

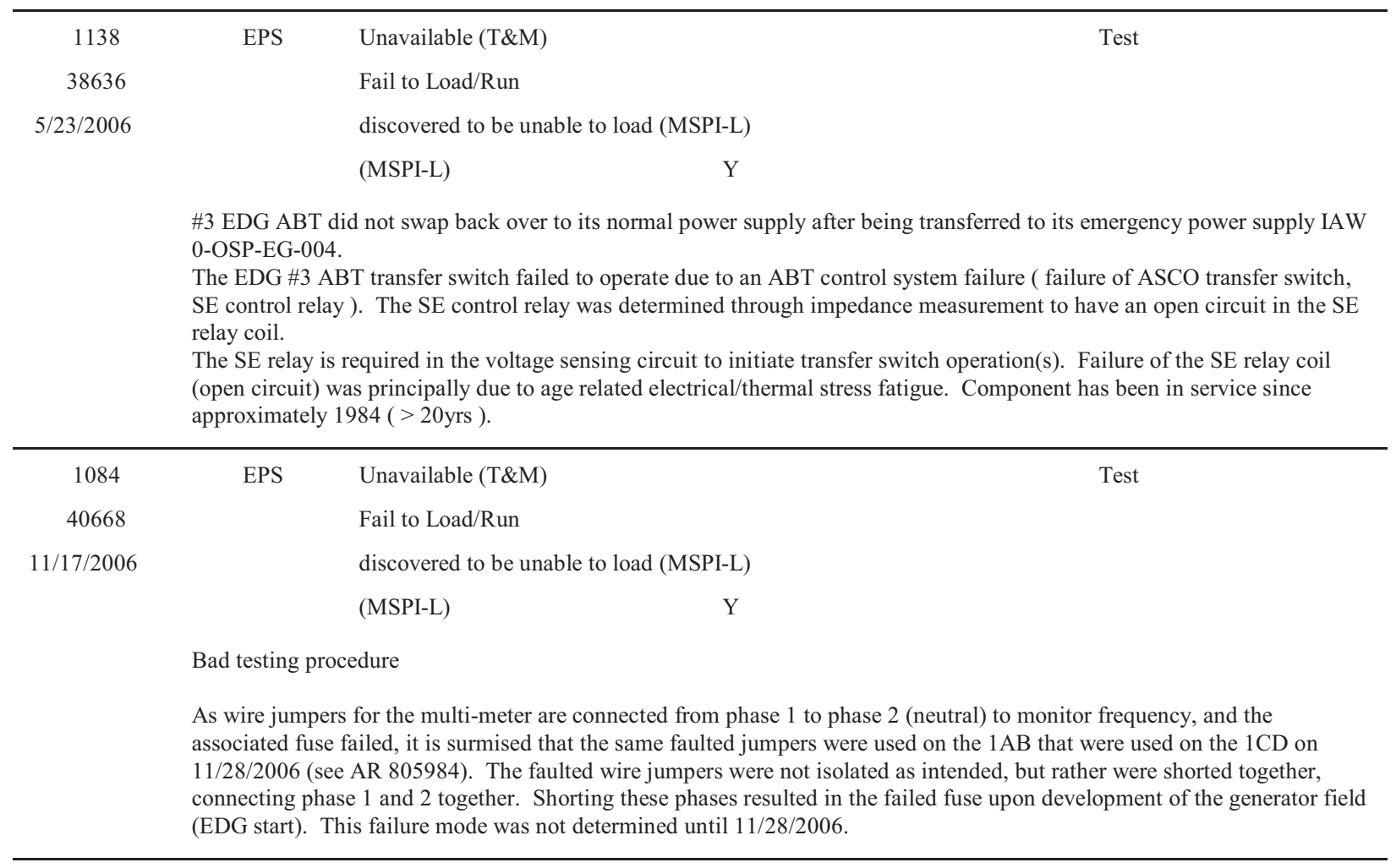




\section{Component Type GEN}

EPIX MSPI Failure Mode Fail to Load/Run

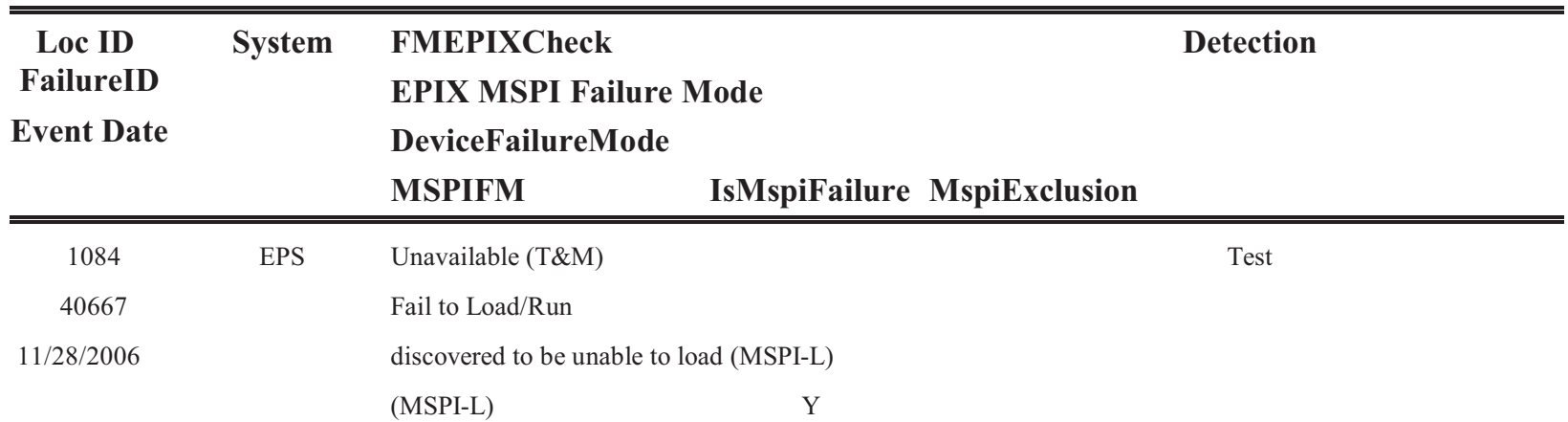

Bad testing procedure

On 11/28/06 Maintenance I\&C technicians were assisting with the testing of the slow speed start on 1-OME-150-CD (Unit 1 CD Emergency Diesel Generator) per 1-OHP-4030-132-027CD (CD DIESEL GENERATOR OPERABILITY TEST TRAIN A). The technician hooked up a set of test leads to the diesel watt meter. The leads the technician was using had both wires hooked up to one lead. This lead shorted phases $1 \& 2$ of the 1-CD diesel metering circuits resulting in an open fuse and loss of indication (i.e., phase, voltage, etc.) in the control room and locally at the 1-CD diesel.

The special test leads had been made up for other uses in the past and were accidentally used in this instance.

The inappropriate act was the failure of the technician to ensure the leads were hooked up correctly to prevent shorting the phases. The organization involved in the inappropriate act was Maintenance (MNT). The Work Process in use during the event was maintenance (MN). The Key Activity involved was Fieldwork (FW). The Human Error Type was Skill based.

\begin{tabular}{|c|c|c|c|}
\hline 1130 & EPS & Unavailab & Test \\
\hline 44658 & & \multicolumn{2}{|c|}{ Fail to Load/Run } \\
\hline \multirow[t]{9}{*}{$3 / 13 / 2008$} & & \multicolumn{2}{|c|}{ discovered to be unable to load (MSPI-L) } \\
\hline & & (MSPI-L) & Y \\
\hline & \multicolumn{3}{|c|}{ Looks like a sequencer issue. } \\
\hline & \multicolumn{3}{|c|}{ Not sure why there are two records associated with this event. Looks like it should be a maintenance unavailability. } \\
\hline & \multirow{4}{*}{\multicolumn{3}{|c|}{$\begin{array}{l}\text { During the performance of 3-SR-3.8.1.9(3D OL) Diesel Generator breaker } 1836 \text { failed to trip when given a simulated } \\
\text { Common Accident logic signal during step 7.8.26.1 of the SR. } \\
\text { Maintenance Troubleshooting Work Order } 04-712707-000 \text { was initiated to identify and correct the problem. Subsequent } \\
\text { troubleshooting revealed that the 52STA switch contact } 4-4 \text { C was not Closed when the diesel generator breaker } 1836 \text { was in } \\
\text { the Closed position. Also, found Damaged Breaker Grounding Clamp Device, see attached supporting documentation. }\end{array}$}} \\
\hline & & & \\
\hline & & & \\
\hline & & & \\
\hline & \multicolumn{3}{|c|}{$\begin{array}{l}\text { Subsequent troubleshooting on WO } 04-712707-000 \text { revealed that the } 52 \text { STA switch contact } 4-4 \mathrm{C} \text { was not Closed when the } \\
\text { diesel generator breaker } 1836 \text { was in the Closed position. Replaced Breaker Ground Contact on the breaker which was } \\
\text { damaged during racking in. The 52STA switch was also found to be defective and is being replaced under the } \\
\text { Troubleshooting WO. OP's acquired the breaker contact for briefings on proper racking of this type of breaker. }\end{array}$} \\
\hline
\end{tabular}




\section{Component Type GEN}

EPIX MSPI Failure Mode Fail to Run

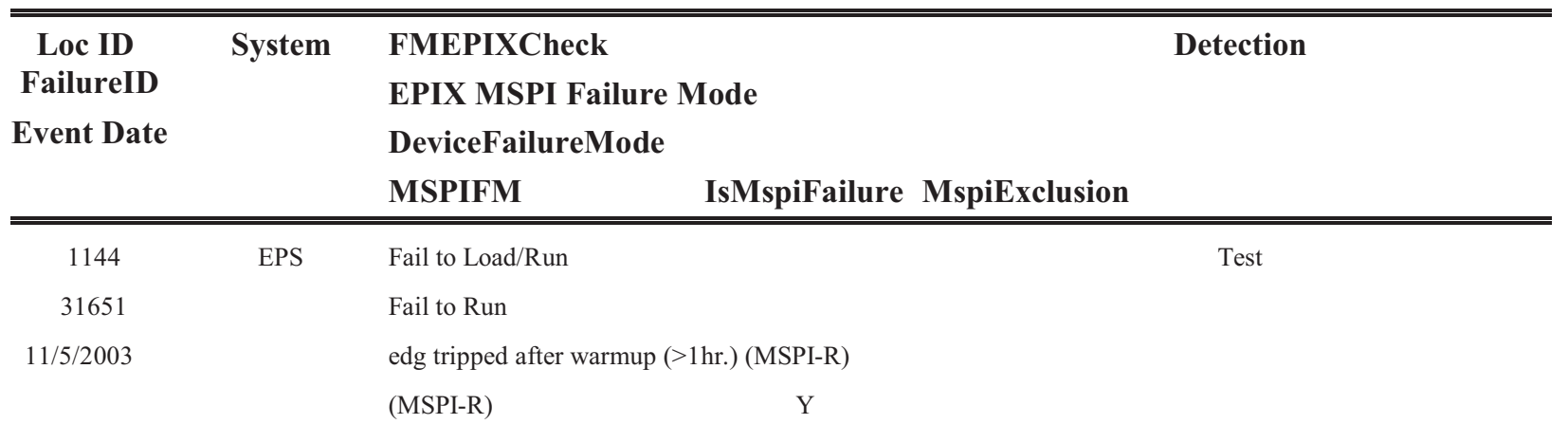

During performance of OSP-ELEC-S701 (Diesel Generator 1 semi-annual Operability Test), E-CB-DG1/7 tripped immediately upon parallel and DG-GEN-DG1 locked out.

During the Semi-Annual Operability test, the Division One EDG tripped and locked out (86 Lockout Relay actuated) when the DG1 output breaker was being closed to parallel the unit to offsite power. The unit was verified to be shut down and in a stable condition, and the local panels were inspected to attempt to determine the cause of the trip. An inspection of the Protective relays showed that the LOSS OF FIELD Relay DG-RLY-40/DG1 had a target dropped. DG-RLY-30/2/DG1 also had a target dropped indicating the 40 relay had tripped.

Maintenance and engineering personnel evaluated the population of relays affected by maintenance activities prior to the DG1 surveillance. Sixteen relays were replaced with calibrated spares. One of the calibrated spare relays failed causing this event. Five of the calibrated spare relays were tested by the initial start of DG1 and worked satisfactorily. Ten relays required further inspection. Maintenance personnel performed this inspection. No problems were identified.

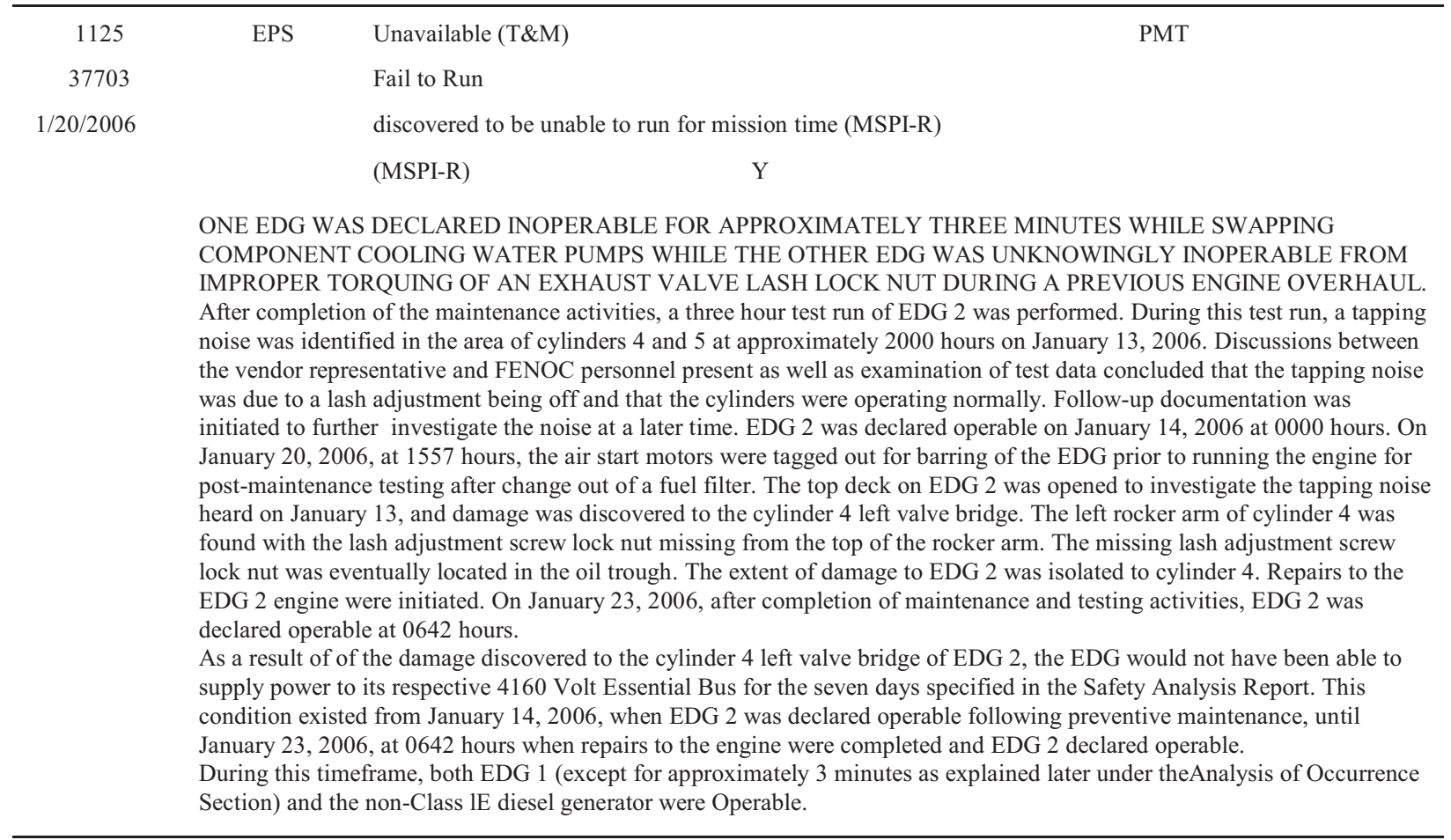




\section{Component Type GEN}

EPIX MSPI Failure Mode Fail to Run

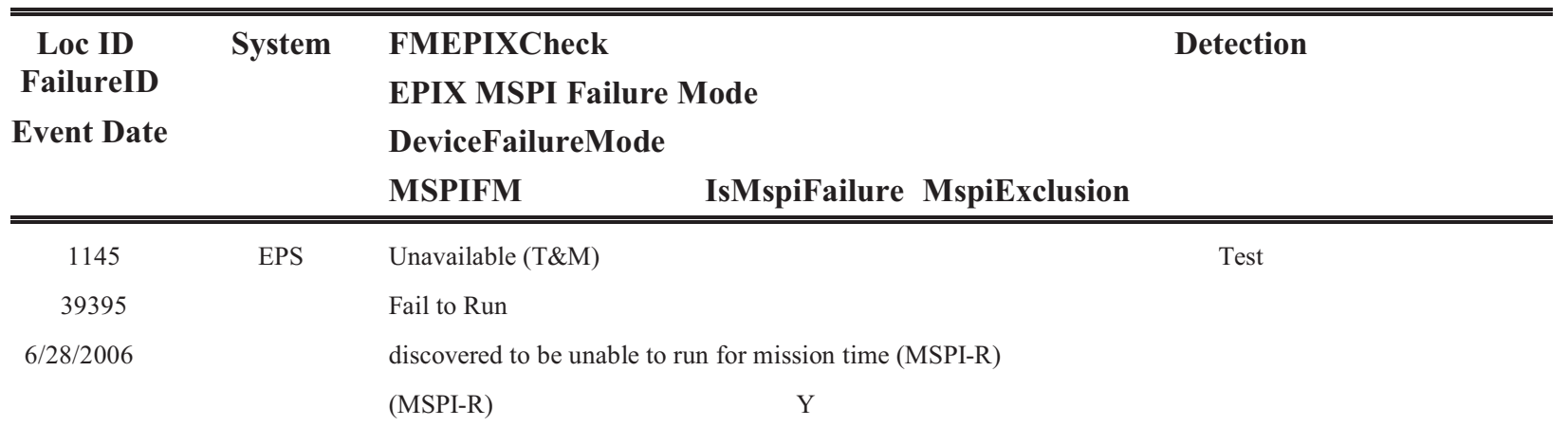

The Keep Warm system appears to be malfunctioning.

At 17:35 on 8/17/06, after approximately 10 minutes of operation during a planned surveillance test on Emergency Diesel Generator (EDG) A, a previously identified minor fuel oil leak (approximately 1 drop/minute) increased and required an unplanned engine shutdown.

The EDG had been declared inoperable at the start of the surveillance test and remained so following the leak. At its maximum, the Ieakrate was estimated at between 0.12 and $0.25 \mathrm{gpm}$. By 05:53 on 8/18, the leak had been repaired, the surveillance test completed, and the EDG restored to OPERABLE status. The fuel oil leak was initially identified on 6/28/06 at 16:48. Between 6/28 and 8/17, the EDG had been operated four times with a cumulative run time of approximately 3.1 hours. Note: Numerous Train B components were inoperable at varoius times during the EDG's period of inoperability.

On 10/26/06, the leak was determined to be from an approximately 350 degree circumferential crack in the copper tubing of the fuel supply line inside a 3/8" fitting to a pressure gauge. On 12/15/06, the cracked tubing was tested on a similar diesel generator. The tubing fully severed after approximately one hour of diesel generator operation at rated load. Thus it is concluded that the EDG was not capable of meeting its design basis between the originally identified leak on 6/28/06 and its return to operability on $8 / 18 / 06$.

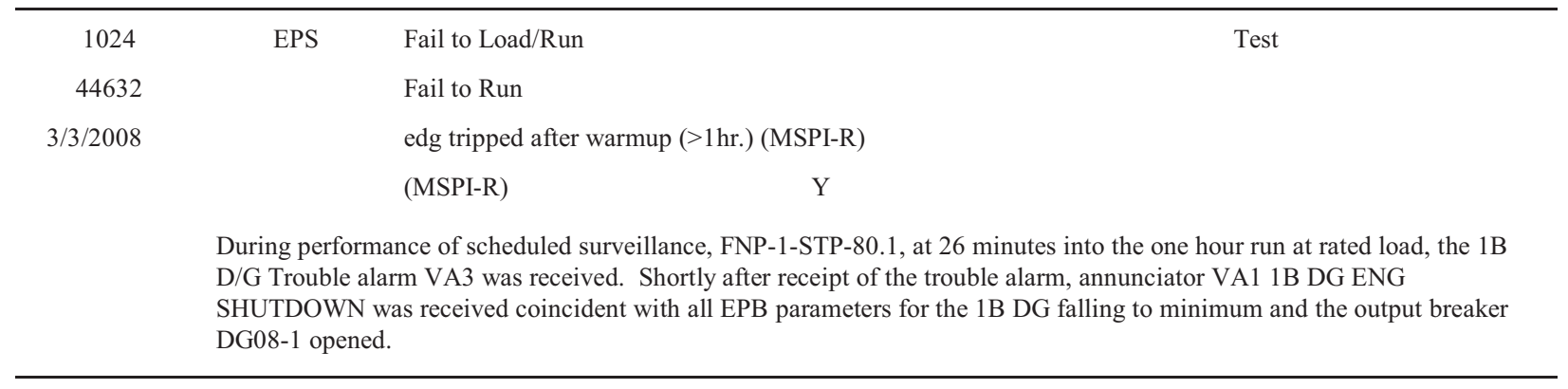




\section{Component Type GEN}

EPIX MSPI Failure Mode Fail to Start

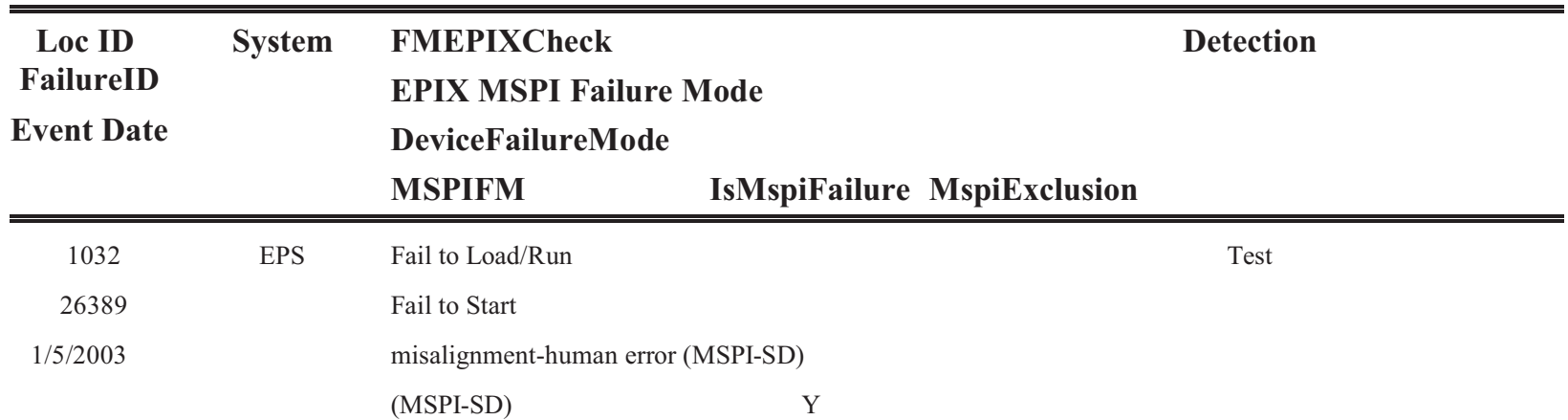

EPIX coded this event as an MSPI Start Demand failure. The INL review believes that this event is not an MSPI Start Demand failure.

Unit 1 was at $100 \%$ and the $4 \mathrm{Kv}$ and 480 Volt Electrical Systems and Emergency Diesel Generator (EDG) System were in service. While performing STP O-008B-1 on 1B EDG, operators discovered that 1BKR152-1403, DG 1B TO 4KV BUS 14 Feeder Breaker, failed to close on demand. The breaker's Maintenance Rule function to provide power to vital loads was lost. The failure caused a delay in restoration of the 1B EDG. There were no other effects on plant operation Troubleshooting identified the problem to be with the 152B contact which failed. This prevented the close coil from being energized dues to a broken Lexan Cam follower. Lab results indicated the failure was due to low cycle fatigue. 1BKR152-1403 was replaced with a spare breaker. The replacement breaker was tested satisfactorily and returned to service. The broken cam follower was replaced with a different material cam follower.

\begin{tabular}{|c|c|c|c|}
\hline 1136 & \multirow[t]{4}{*}{ EPS } & Unavailable (T\&M) & \multirow{4}{*}{ d observation (MSPI-SD) } \\
\hline 25824 & & Fail to Start & \\
\hline \multirow[t]{3}{*}{$1 / 6 / 2003$} & & \multirow[t]{2}{*}{ found unavailable during nondemand observation (MSPI-SD) } & \\
\hline & & & \\
\hline & \multicolumn{3}{|c|}{ Changed the FM } \\
\hline 1133 & EPS & Unavailable (T\&M) & PMT \\
\hline 27326 & & Fail to Start & \\
\hline \multirow[t]{3}{*}{$2 / 28 / 2003$} & & \multicolumn{2}{|c|}{ operated, but not within specified parameters (MSPI-SD) } \\
\hline & & (MSPI-SD) & $\mathrm{Y}$ \\
\hline & \multicolumn{3}{|c|}{$\begin{array}{l}\text { The cause of this failure was determined to be a loose wire on contact } 3-6 \text { of relay ES2AY. Fault exposure hours are being } \\
\text { calculated due to the loose contact wire discovered on relay ES2AY which prevented the 86LOR relay from toggling after an } \\
\text { emergency start of Diesel Generator 2A-A. The last time that the contact function was verified to operate correctly was on } \\
\text { September 27, } 2002 \text { at which time the diesel generator emergency started following a loss of off site power from the Watts } \\
\text { Bar Hydroelectric Plant. An evaluation of the 86LOR functions determined that as long as the diesel was aligned for "unit" } \\
\text { operation, which is the normal alignment, the diesel would have functioned as designed. The } 86 \mathrm{LOR} \text { normally removes } \\
\text { voltage droop from the system in the event of an emergency start. With the diesel aligned for "parallel" operation, it is } \\
\text { inconclusive as to whether the presence of voltage droop would have maintained the bus above the voltage load shedding } \\
\text { trip setpoint. }\end{array}$} \\
\hline
\end{tabular}




\section{Component Type GEN}

EPIX MSPI Failure Mode Fail to Start

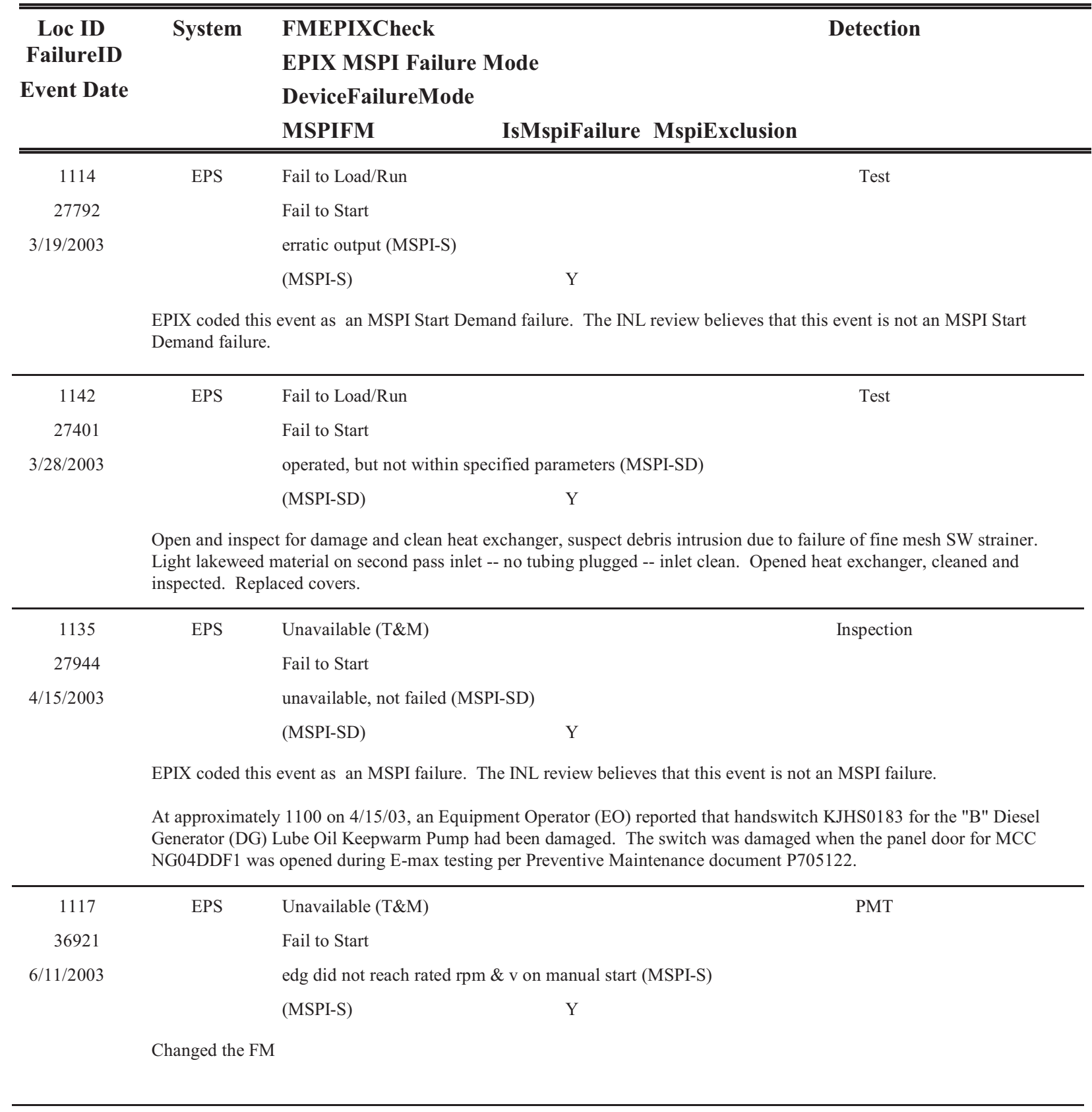




\section{Component Type GEN}

EPIX MSPI Failure Mode Fail to Start

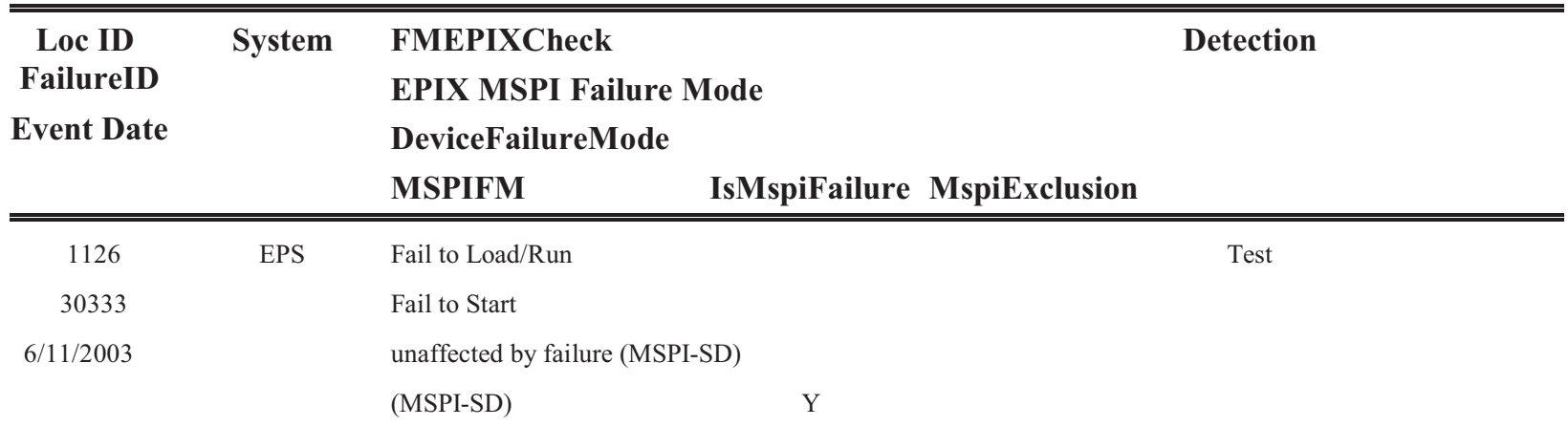

PROBLEM DESCRIPTION: OPT-214A, TRAIN B DIESEL GENERATOR 1-02 OPERABILITY TEST.

AS FOUND CONDITION: OPERABLE WITH KNOWN (IDENTIFIED) JACKET WATCH LEAK.

CORRECTIVE ACTION: DURING THE RUN PROMPT TEAM ATTEMPTED TO TIGHTEN FLANGE WITH JACKET WATER LEAK. LEAK RATE INCREASED IN EXCESS OF ALLOWABLE LEAKAGE OF 2.4.2 GPH OPT DATA ALL MEETS ACCEPTANCE CRITERIA AND THE OPT IS CONSIDERED SAT WITH THE DG LEFT INOPERABLE DUE TO THE JW LEAK.

PROBABLE CAUSE: NORMAL EQUIPMENT DEGRADATION.

EPS Fail to Load/Run
Fail to Start
operated, but not within specified parameters (MSPI-SD)
(MSPI-SD)
During performance of 0PT-12.2C on 7/24/03 following the DG3 outage the DG was loaded to 3500KW and 2000KVAR.
After 1 to 3 minutes at this load, the AO noted that KW had risen to 3800 and Kvar had decreased to 250 . The AO got the
SROs attention and attempted to raise KVAR and lower KW. KW responded as expected but KVAR did not increase. With
SRO and Tech. Reps. Concurrence, the AO attempted to raise KVAR again. At this time the KVAR indication pegged high
greater than 2500 and generator stator amps indicated greater than 800 amps. The decision was made to lower load, separate
from the bus and shutdown the DG. While the AO was lowering the load, generator stator amps and KVAR did not decrease
until the generator circuit breaker was opened. $\square 2$.Problem Description / Investigation Summary $\square$ The AC regulator board
had been replaced as part of the exciter tuning activities during the DG outage. The board had been replaced due to material
condition of the on-board components, not because the original board had failed. Prior to removal, a gain check was made
on the original board in order to establish a base line operating point. The new board was installed and calibration
performed utilizing the as-found gain in the set-up. A gain range test was made on the replacement board which supported
the as-found gain of the original board. Dynamic testing of the newly calibrated voltage regulator was performed during the
OP-39 unloaded maintenance run and excitation system operated as expected. The 0PT-12.2C operability test was then
performed with the results as described in Section 1. Event Description. After the EDG was shutdown following the
excitation system malfunction, the decision was made to replace the AC regulator board with another one from Stores.
During the voltage regulator recalibration following board replacement the new board was found to have a gain adjustment
range with a low and high value greater than the original and first replacement boards. The voltage regulator tuning was
completed using experience gained with the DG1 tuning effort and the excitation system performed satisfactorily and DG
declared operable.




\section{Component Type GEN}

EPIX MSPI Failure Mode Fail to Start

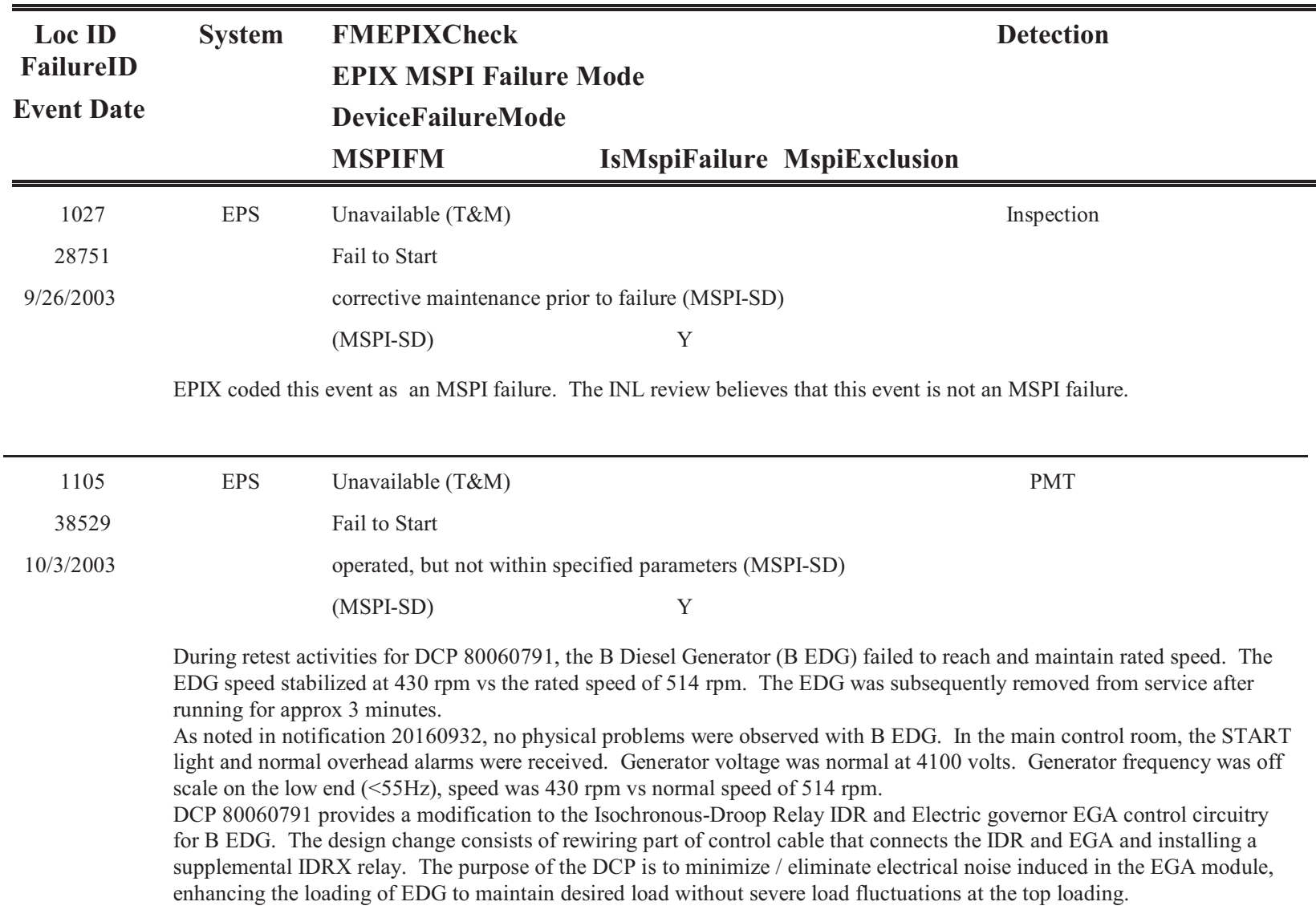

$\begin{array}{clll}1136 & \text { EPS } & \text { Unavailable (T\&M) } & \text { Inspection } \\ 29649 & & \text { Fail to Start } & \\ 12 / 29 / 2003 & & \text { unavailable, not failed (MSPI-SD) } & \\ & \text { (MSPI-SD) } & \text { Y }\end{array}$

EPIX coded this event as an MSPI failure. The INL review believes that this event is not an MSPI failure.

\begin{tabular}{rll}
\hline 1127 & EPS & Unavailable (T\&M) \\
30337 & Fail to Start & Inspection \\
$1 / 22 / 2004$ & unaffected by failure (MSPI-SD) \\
& (MSPI-SD) \\
& EPIX coded this event as an MSPI failure. The INL review believes that this event is not an MSPI failure. \\
\hline
\end{tabular}




\section{Component Type GEN}

EPIX MSPI Failure Mode Fail to Start

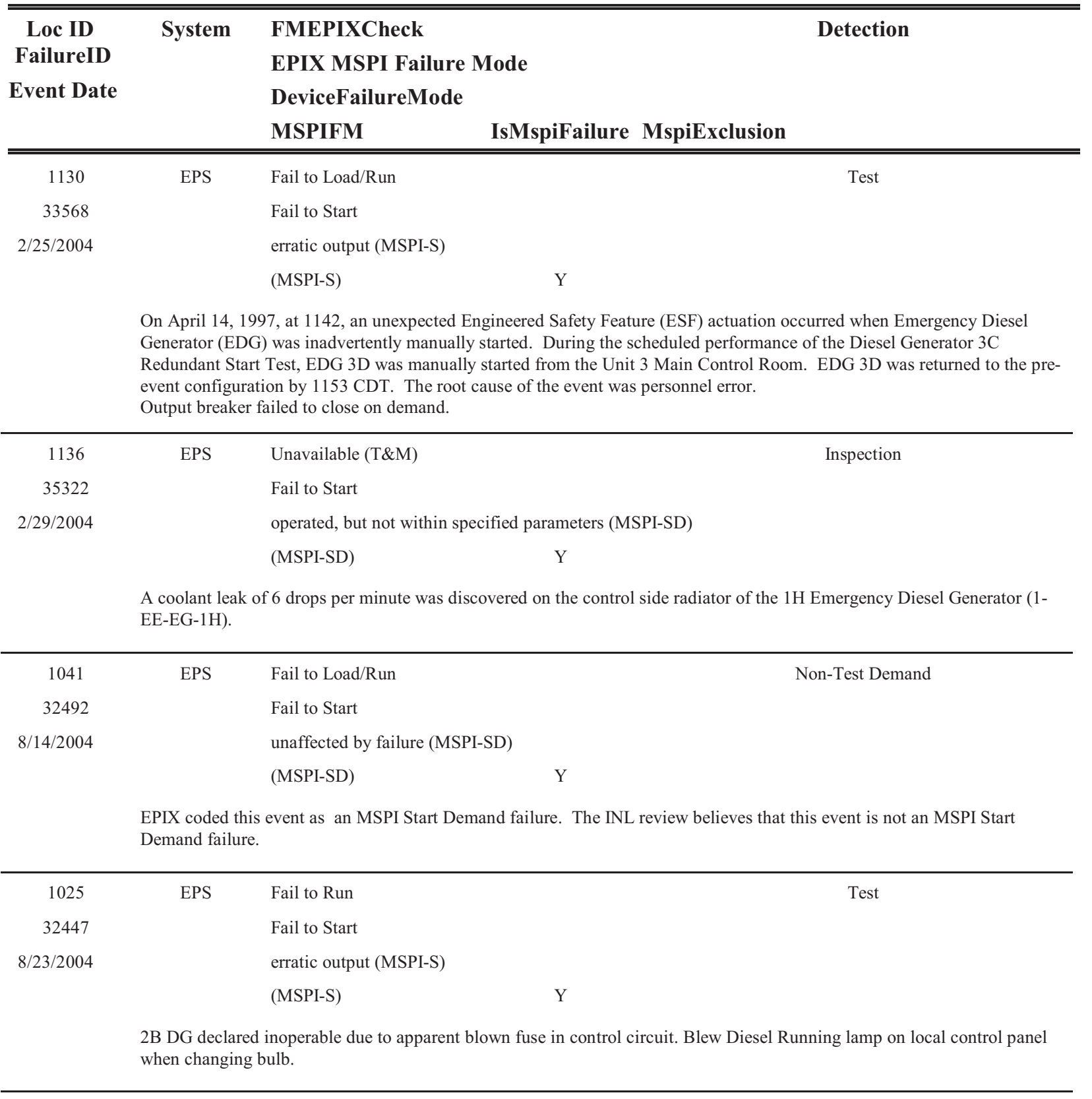




\section{Component Type GEN}

EPIX MSPI Failure Mode Fail to Start

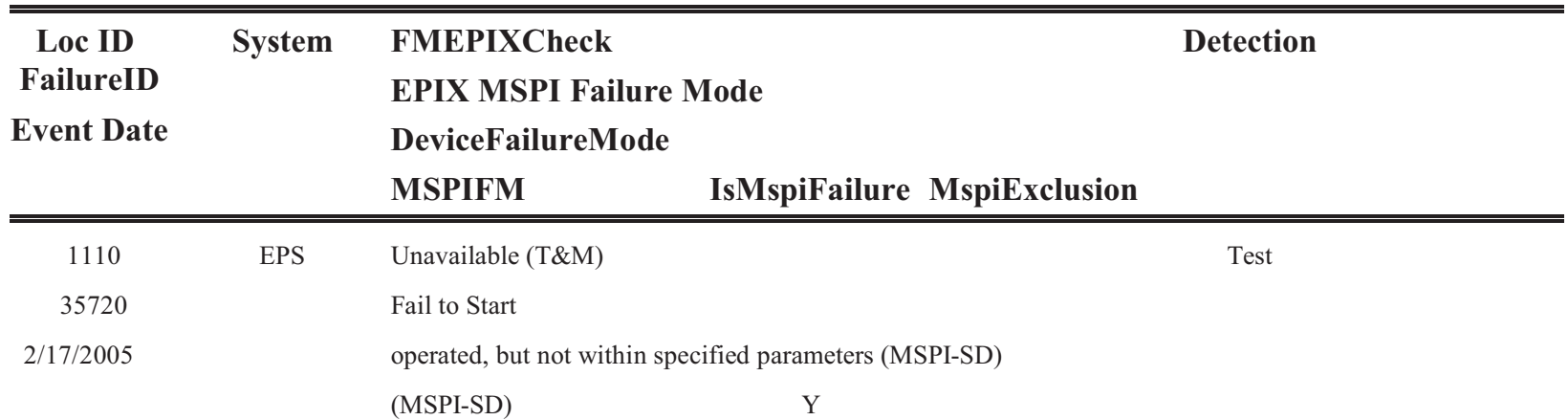

During Diesel Engine Generator (DEG) 2-1 Surveillance Test Procedure (STP) M-9A manual start the voltage stabilized at 119 volts at 13:31 seconds as measured by a stop watch. This is outside the less than or equal to 13 seconds. The speed and frequency were stable within their acceptance limits. Inspection revealed that the automatic voltage regulator (AVR) card that one of the stems on the thyristor CR 10 was found to be cracked and separated $\sim 3 / 4$ of the way around it.

The manufacturer, MPR, troubleshot the AVR card and could not repeat the same problem. MPR concluded that a possible cause of the abnormal DEG 2-1 startup voltage transient was malfunction of the SCR CR10due to lowered resistance from anode to gate or anode to cathode resulting in improper voltage regulator control current. Another possible cause would be improper control of SCR gating my MAGAMP L1 due to poor connections at cracked solder joints.

\begin{tabular}{|c|c|c|c|}
\hline 1118 & EPS & Fail to Load & Non-Test Demand \\
\hline 35974 & & \multicolumn{2}{|l|}{ Fail to Start } \\
\hline \multirow[t]{3}{*}{$6 / 10 / 2005$} & & \multicolumn{2}{|c|}{ operated, but not within specified parameters (MSPI-SD) } \\
\hline & & (MSPI-SD) & $\mathrm{Y}$ \\
\hline & \multicolumn{3}{|c|}{$\begin{array}{l}\text { Diesel generator breaker failed to close on undervoltage on bus } 17 \text {. Troubleshoot/repair "B" D/G breaker to bus } 17 \text {. } \\
\text { CAUSE: Investigation found the breaker alarm switch was actuated with no indication of a fault on the breaker's Amptector } \\
\text { overcurrent protection device. This indicated the breaker attempted to close but tripped free. Work order } 20502911 \\
\text { performed GME-50-02-DBTROUBLE. The investigation found the breaker required more force then typical to manually } \\
\text { close and an out of tolerance trip bar load weight. These indicated a need for lubrication. The breaker consistently closed } \\
\text { properly when tested on the bench. } \\
\text { Westinghouse was contacted and came to Ginna for an onsite failure investigation. The breaker had sat in the electric shop } \\
\text { for two days since its failure. Initial inspection and manual operation of the breaker found the operating mechanism lacked } \\
\text { sufficient lubrication. The breaker was hard to close by hand. When electrically operated the breaker failed to close } \\
\text { approximately } 50 \% \text { of the attempts. Further inspection of the operating mechanism found the control relay kicker operation } \\
\text { timing was not optimal, the close contact was released earlier then the Westinghouse technician would set it. Westinghouse } \\
\text { concluded the breaker failure was due to inadequate lubrication of the operating mechanism. The control relay release } \\
\text { timing was a contributing factor in that if set to release later in the close cycle the breaker may have been able to close, } \\
\text { however, the lack of lubrication would probably have resulted in a breaker failure prior to operating the } 200 \text { cycles a } \\
\text { properly lubricated breaker is designed to successfully perform between preventive maintenance periods. }\end{array}$} \\
\hline
\end{tabular}




\section{Component Type GEN}

EPIX MSPI Failure Mode Fail to Start

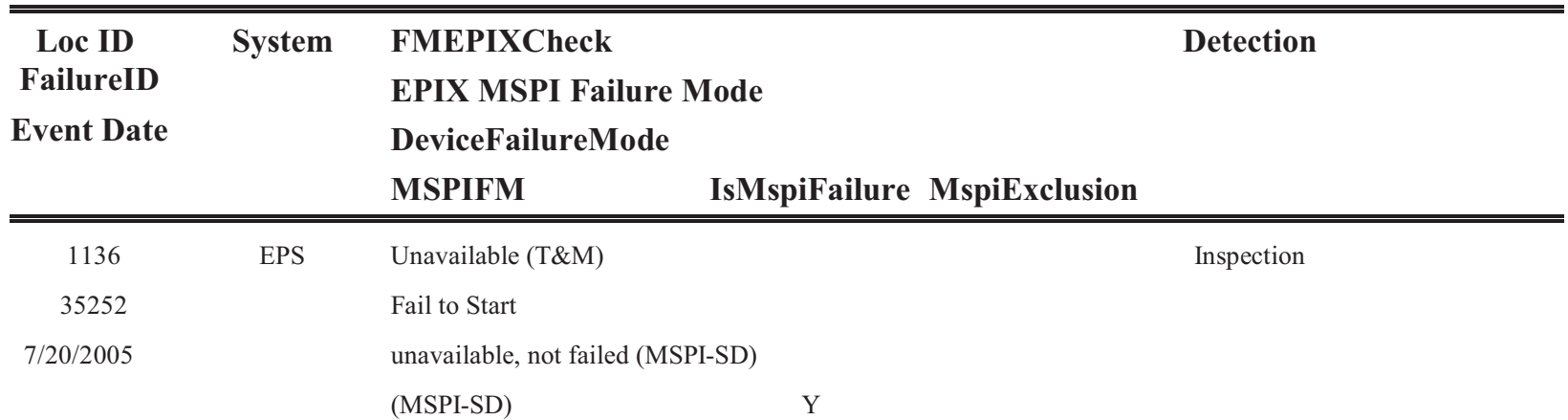

Removal from service of the 01-EE-EG-1J, Emergency Diesel Generator due to imminent failure of the 1-EG-P-4J, Standby Lube Oil Circulating Pump. Due to system configuration it is impractical to remove the 1-EG-P-4J pump from service to perform corrective actions required with out removing the 1J-EDG from service. Imminent failure of the 1-EG-P-4J pump would not of resulted in immediately declaring the $1 \mathrm{~J}-\mathrm{EDG}$ inoperable but would have allowed a decrease in oil temperature to occur resulting in eventually declaring the $1 \mathrm{~J}$-EDG inoperable based on low oil temperatures. Based on imminent failure of the 1-EG-P-4J, Standby Lube Oil Circulating Pump and unplanned entry into a LCO for the 1J-EDG the condition meets the requirements to be considered a MRFF.

Analysis:Motor was taken out service due to high vibrations and for the motor/pump making louder than usual noise. When motor outboard end bell was removed to inspect the motor for damage, the outboard bearing came apart and the roller balls fell out of the bearing. The bearing inner race remained on the motor shaft and the outer race remained in the end bell.

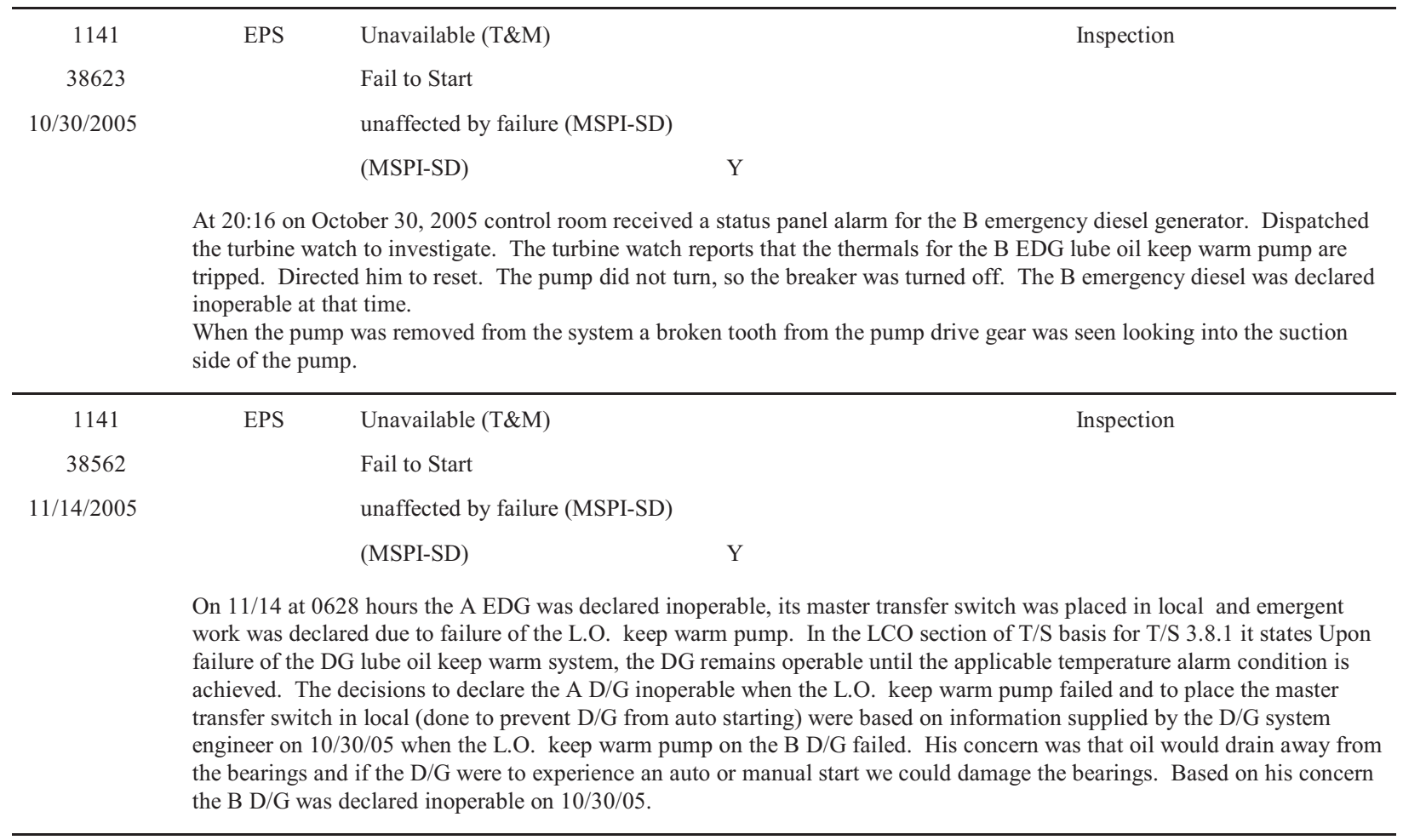




\section{Component Type GEN}

EPIX MSPI Failure Mode Fail to Start

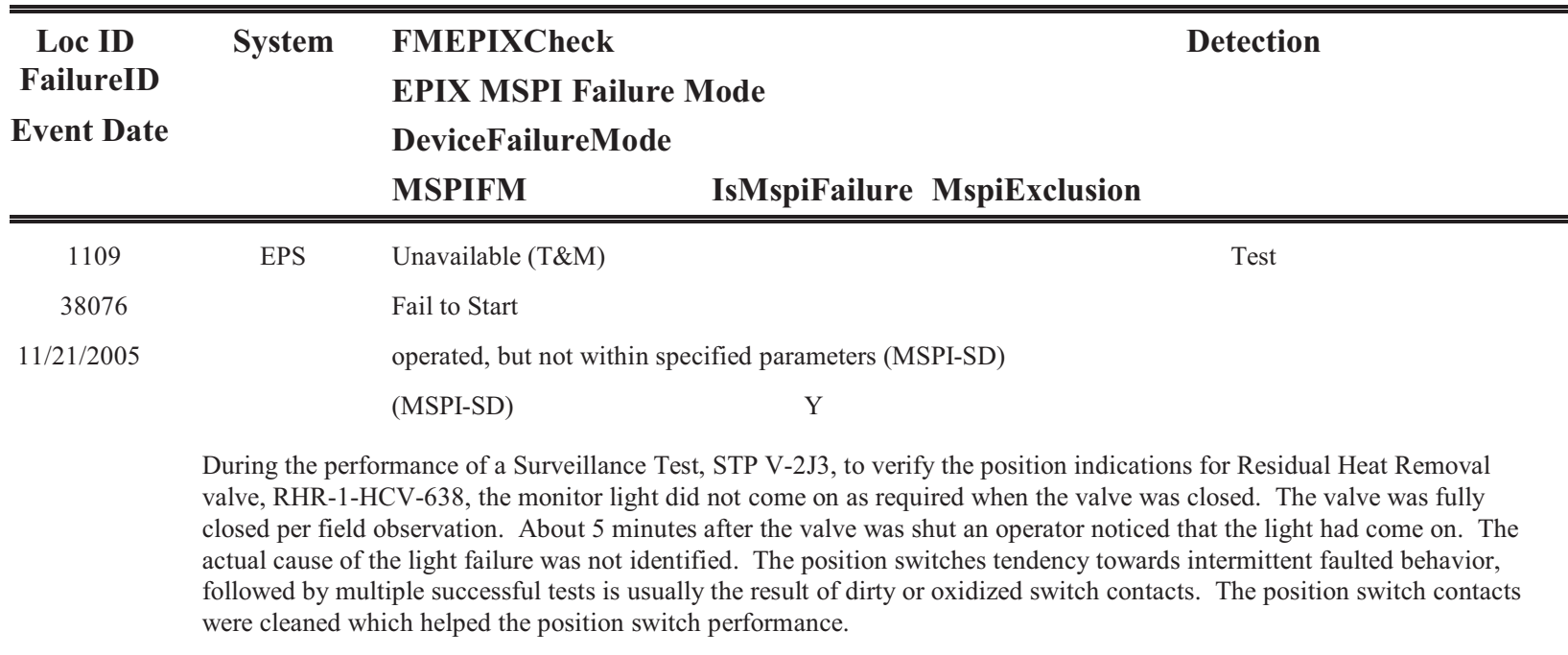

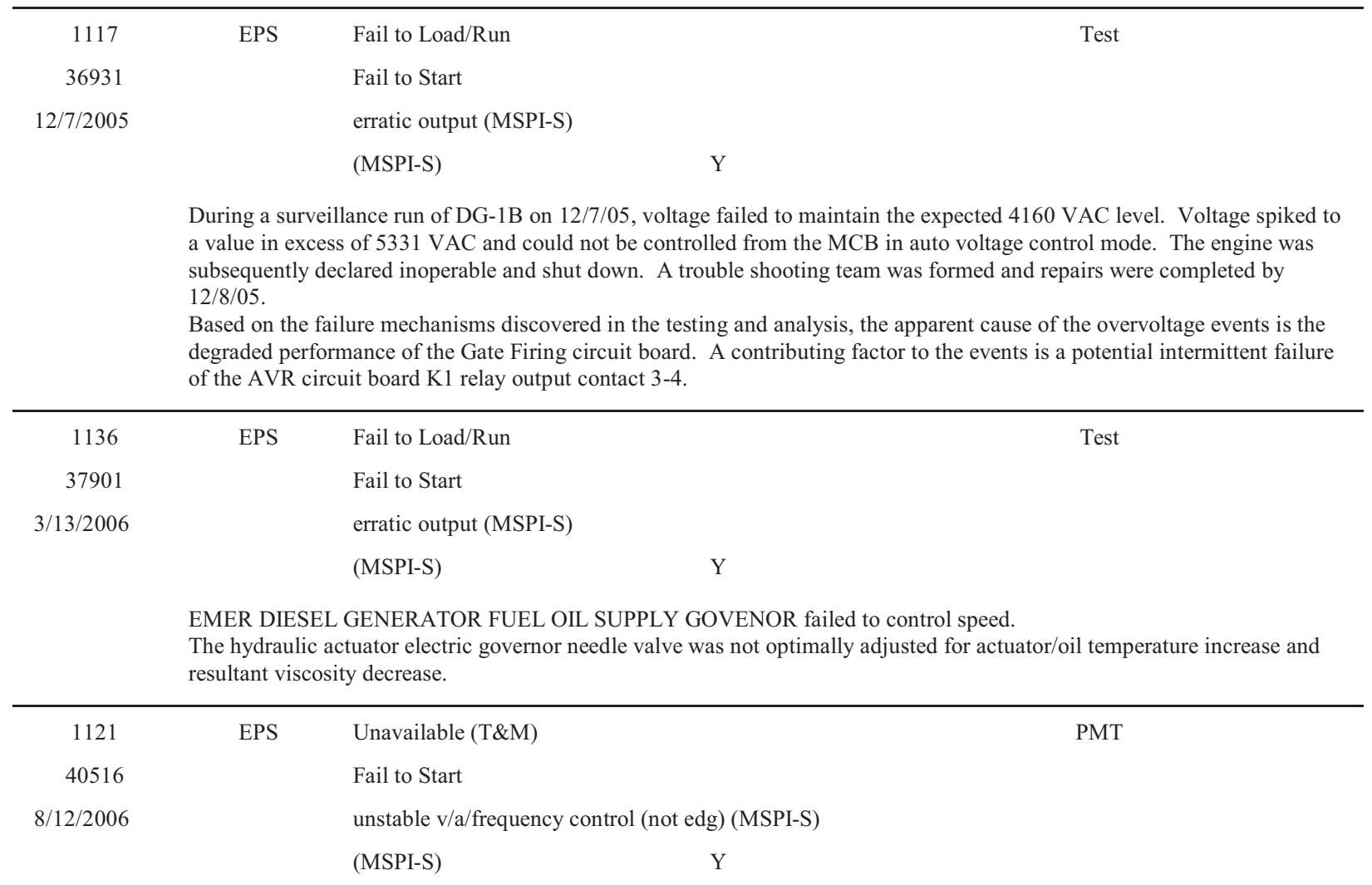

On August 12, 2006 at approximately 22:00, during a surveillance test of emergency diesel generator 2G003, MVAR output became erratic while in droop mode. The problem was determined to be associated with the Automatic Voltage Regulator (AVR).

PMT with failure directly related to maintenance. 


\section{Component Type GEN}

EPIX MSPI Failure Mode Fail to Start

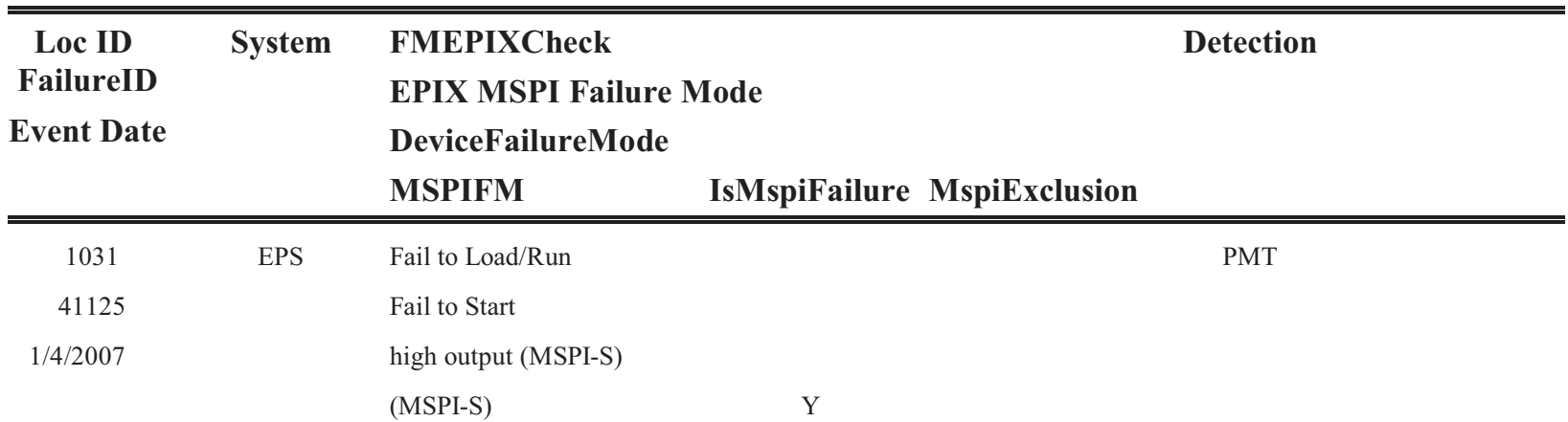

During a routine surveillance run on January 4, 2007 of the B EDG, Engineering was performing troubleshooting for the fuel rack hunting which was reported during the October and December surveillances. Engineering had an approved PNPS 3.M.1-34 plan which included instrumenting both the engine governor and voltage regulator controls with digital recorders. The engine was started per PNPS procedure 8.9.1 EDG \& Associated Emergency Bus Surveilance and an abnormal alarm PT blown fuse (C3 RC D5) was received and cleared immediately. With maintenance and engineering at the engine, no fuel rack oscillations were observed. The engine was run unloaded for 30 minutes.

The control room was then requested to proceed with paralleling the EDG to A6 bus. The operator exercised both the governor and the voltage regulator with no problems reported. The control room operator proceeded, by turning on the sync scope preparing to sync to the grid. While adjusting the voltage regulator to get the incoming voltage slightly above the running voltage per the 8.9.1 procedure the control room operator reported erratic upward swings in the incoming voltage meter. The operator again adjusted the voltage regulator to align the incoming voltage to be slightly higher than the running voltage. Once this was performed the control room operator closed the A609 breaker and immediately picked up $500 \mathrm{KW}$ per the 8.9.1 procedure. Before adjusting the KVAR to 250 per procedure the operator observed the KVAR meter ramping up to roughly $1600 \mathrm{KVAR}$. At this time the operator took action and proceeded to lower the KVAR down. The abort criteria of $1500 \mathrm{KVAR}$ was exceeded so the control room operator reduced the load and opened the A609 breaker. This evolution took approximately 30 seconds. The diesel remained running unloaded. A call to the field operator was made to notify him that they exceeded an abort criteria and that the A609 breaker was opened. Fuel rack troubleshooting continued until the steps in the 3.M.1-34 were completed and the engine was secured per the procedure. The engine was declared inoperable and a 72 hour LCO was declared on 1/4/07 after the run was aborted.

The most probable direct cause of the sudden KVAR increase was a poor quality connection on the potential transformer circuitry which supplies the necessary feedback voltage for the voltage regulator. The potential transformers convert the output voltage of the Emergency Diesel Generator $(4160 \mathrm{vac})$ to $120 \mathrm{vac}$ to be used in the engines control and metering circuits. The same potential transformer also supplies a signal proportional to the generator frequency to the Woodward governor to control the engines speed.

The investigation found one slightly loose fuse (F1) when compared to the other three fuses on the primary side of the transformer and oxidation and corrosion on the secondary side solid link. The primary fuses are accessed via a roll out drawer configuration. As the drawer is opened, the fixed and movable contacts on the primary side of the PT fuses opens. During a later inspection on January 22, the fixed and movable contacts on the primary side of the PT fuses were found to be slightly misaligned. This caused less than full contact on one set of contacts. The screw that holds the movable contact was found to be slightly loose and the contact seating force on this one phase was less than the other two phases. Both items were adjusted by Maintenance after the inspection of the as-found conditions. 


\section{Component Type GEN}

EPIX MSPI Failure Mode Fail to Start

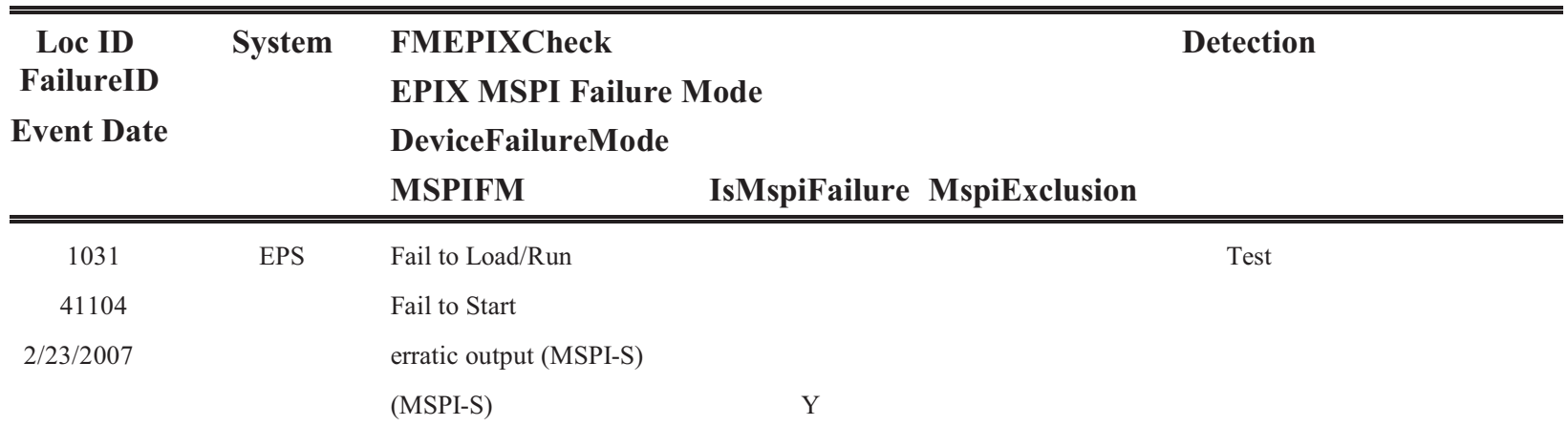

On February 23, 2007 while operating the "B" Emergency Diesel Generator (EDG)", oscillations in Kilowatt (KW) output were observed that reached administrative abort criteria of $>200 \mathrm{KW}$ total span. The "B" EDG was manually shutdown. Previously on January 25, 2007 during an operability test

following an overhaul of the "B" EDG, unexpected $\mathrm{KW}$ oscillations up to $150 \mathrm{KW}$ were observed but these oscillations did not reach the abort criteria.

The root cause of the oscillations was clogging of internal passages in the Woodward hydraulic governor due to the intrusion of foreign material. It was discovered that the oil in the governor was contaminated with particles of aluminum of varying size. The source of the particles was an aluminum label from the shutdown solenoid that separated from the solenoid and was free to move about inside the governor.

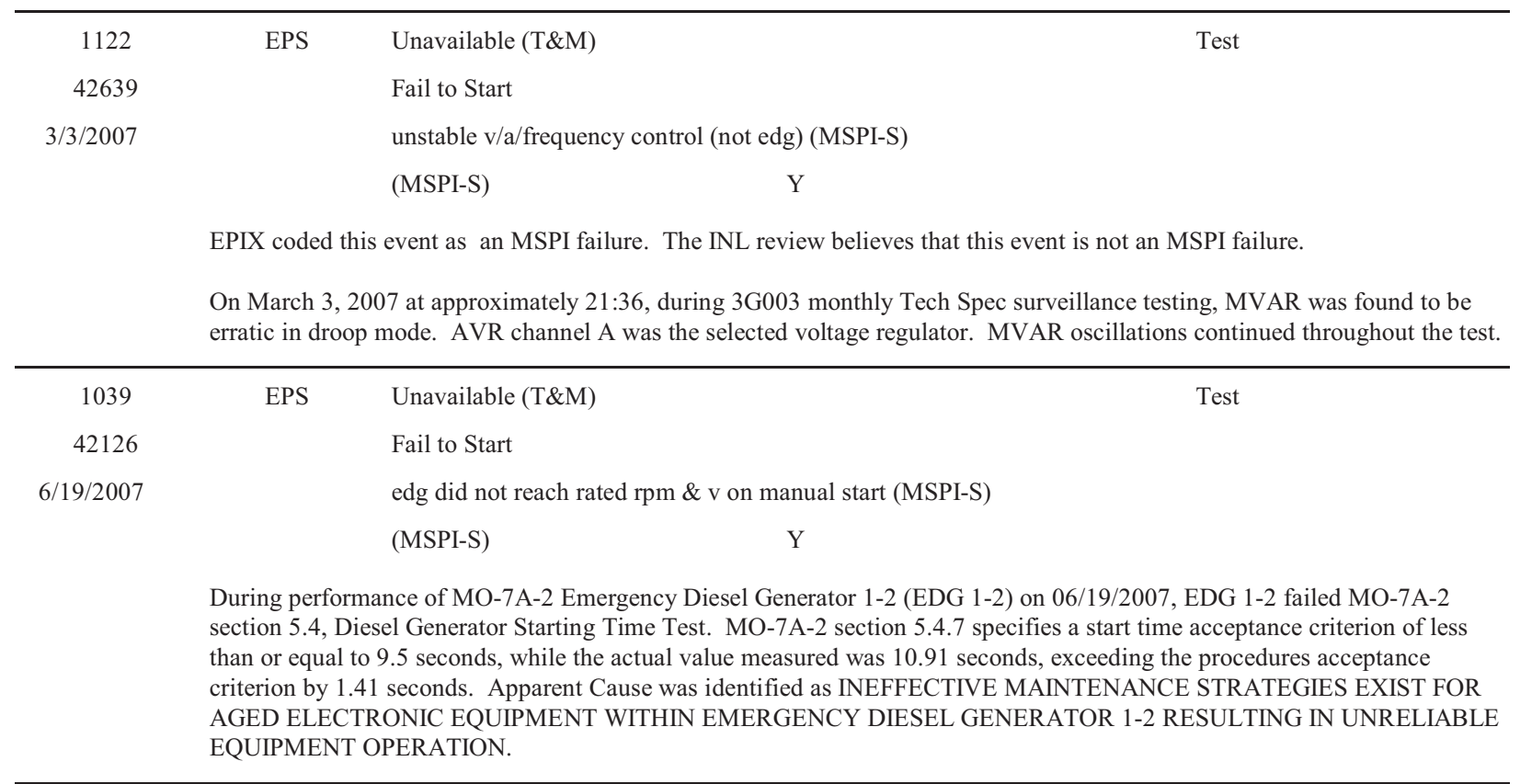




\section{Component Type GEN}

EPIX MSPI Failure Mode Fail to Start

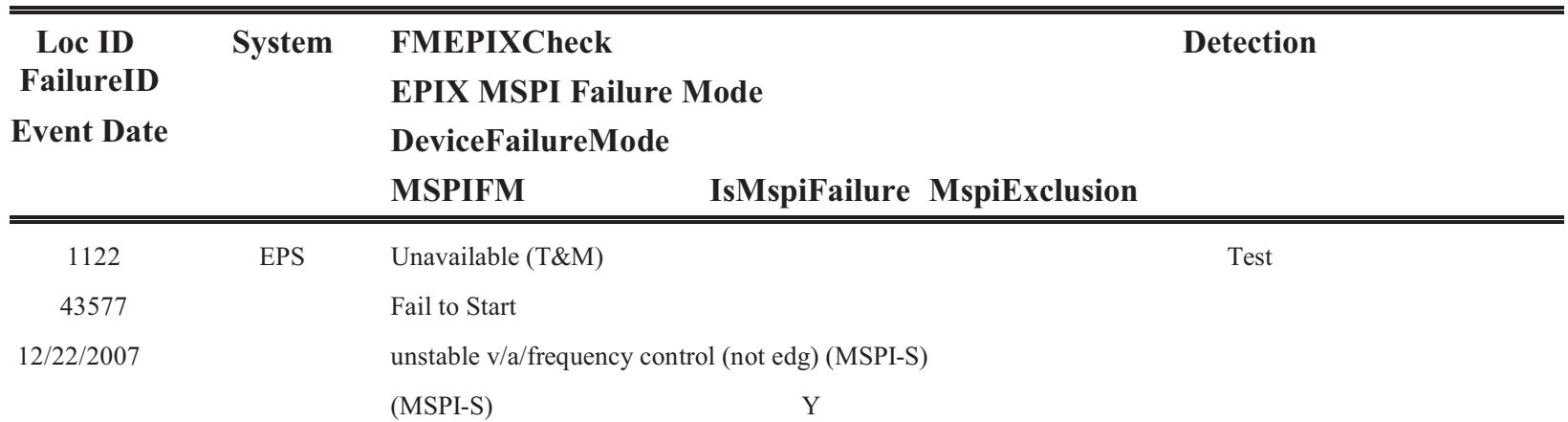

EPIX coded this event as an MSPI failure. The INL review believes that this event is not an MSPI failure.

On 12/22/07, Diesel Generator 3G002 was paralleled to the grid for a monthly load test. Toward the end of the test, while the DG was still paralleled to the grid and loaded, the control room operator noted a perturbation on the DG megawatt meter in the control room.

\begin{tabular}{|c|c|c|}
\hline 1102 & EPS & Fail to Load/Run \\
\hline 43681 & & Fail to Start \\
\hline \multirow[t]{3}{*}{$1 / 12 / 2008$} & & edg did not reach rated rpm \& v on manual start (MSPI-S) \\
\hline & & (MSPI-S) \\
\hline & \multicolumn{2}{|c|}{$\begin{array}{l}\text { During performance of RT-6-092-503-2 "D23 DIESEL GENERATOR GOVERNOR TUNING RESPONSE TEST", D23 } \\
\text { Bus voltage exceeded } 4900 \mathrm{~V} \text { ( }>5200 \mathrm{~V} \text { indicated) immediately followiing a '2C' RHR Pump start at step 4.7.6. D23 Bus } \\
\text { voltage and frequency were noted to lower following the RHR Pump start and then rise a few seconds later. D23 Bus voltage } \\
\text { did not stabilize, it continued to rise to a value upscale of the meter. The D23 D/G Output Breaker was opened and the D23 } \\
\text { Engine was secured per the RT. }\end{array}$} \\
\hline 1029 & EPS & Fail to Load/Run \\
\hline 44709 & & Fail to Start \\
\hline \multirow[t]{3}{*}{$3 / 30 / 2008$} & & operated, but not within specified parameters (MSPI-SD) \\
\hline & & (MSPI-SD) \\
\hline & \multicolumn{2}{|c|}{$\begin{array}{l}\text { EDG } 2 \mathrm{~A} \text { did not meet acceptance criteria for steady state frequency }(59.9-60.5 \mathrm{HZ} \text { ) following being placed into the } \\
\text { emergency run mode per step 8.9.30 of procedure } 73 \mathrm{ST}-9 \mathrm{DG} 01 \text { (ISG). }\end{array}$} \\
\hline 1064 & EPS & Unavailable (T\&M) \\
\hline 44722 & & Fail to Start \\
\hline \multirow[t]{3}{*}{$3 / 31 / 2008$} & & unaffected by failure (MSPI-SD) \\
\hline & & (MSPI-SD) \\
\hline & \multicolumn{2}{|c|}{$\begin{array}{l}\text { While securing Keowee Unit } 1 \text { from commercial generation, ACB-1 did not trip when expected. The failure of ACB-1 to } \\
\text { open caused KHU-1 to motor for a brief period ( } \sim 7 \text { minutes). Upon instruction from Keowee Supervision, KOPS activated } \\
\text { the KHU-1 GATE SAFETY (key inhibit) switch in order to secure KHU-1 (emergency lockout). KHU-1 shutdown but ACB- } \\
1 \text { still failed to open. With the emergency lockout activated and ACB-1 closed, the } 86 \mathrm{~T} \text { (Main Step-Up Transformer } \\
\text { lockout) actuated tripping PCB- } 8 \text { and PCB-9. ACB-1 still did not open on the actuation of the } 86 \mathrm{~T} \text {. Approximately } 25 \\
\text { minutes later, with no Operator action or work being performed, ACB-1 tripped. } \\
\text { Upon visual inspection of the ACB-1 auxiliary contacts, Maintenance observed one of the sliding links, Terminal Strip D } \\
\text { Link } 8 \text {, to be in a middle position, i.e. between the open and closed position. This link provides the path to the trip coil for } \\
\text { ACB-1. With the sliding link in the open position, ACB-1 would never trip from an external signal to the breaker. }\end{array}$} \\
\hline
\end{tabular}




\section{Component Type GEN}

EPIX MSPI Failure Mode Fail to Start

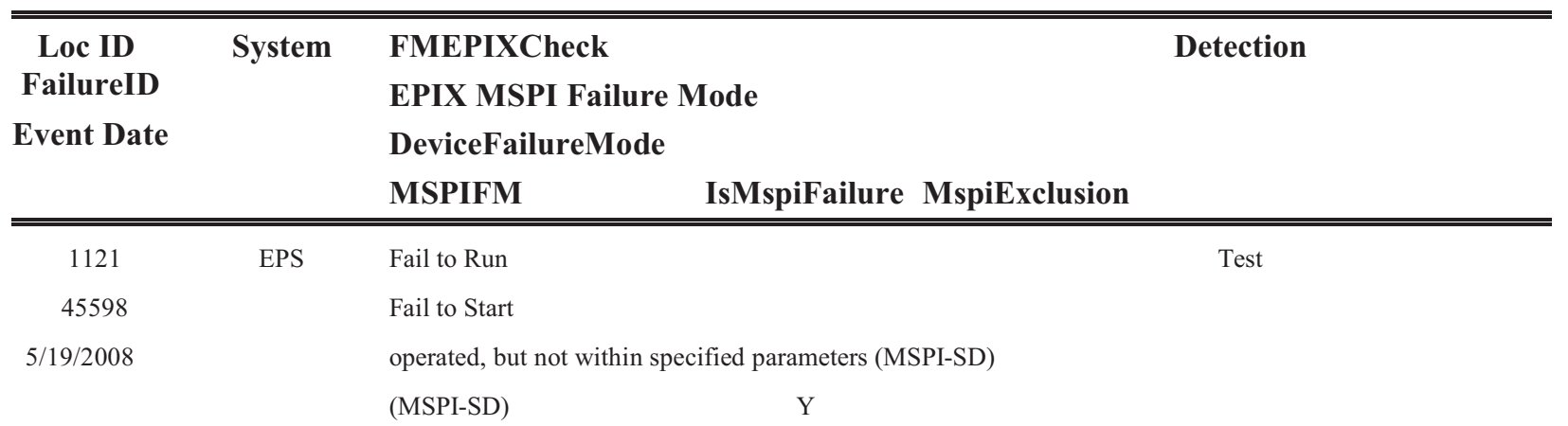

Following a monthly surveillance run of the Unit 2 Train B Emergency Diesel Generator (EDG) S22420MG003 on 5/19/08, two unexplained megawatt perturbations were noted during a post test data review. Data indicated that the MWs jumped from 4.6 to 4.8 , then down to 4.4 , then back to 4.6 over a five second period. Also, two minutes after the first perturbation, MWs jumped from 4.6 to 4.9 , then down to 4.4 , then back to 4.6 over a four second period. These two perturbations occurred about two minutes after the EDG achieved a full load condition.

On $5 / 25 / 08$, following replacement of the mechanical governors, the EDG was tested with no abnormalities in output were noted. The governor actuator levers between the mechanical governors and the fuel racks were removed. The eight bearings in the governor actuator levers showed significant wear and internal corrosion. Subsequently, it was determined that one governor bearing on the 20 cylinder engine was stuck and had affected the smooth operation of the governor of this engine, thus in turn causing the noted fluctuation in the power output of the generator. Consequently, all eight governor actuator lever bearings were replaced along with both mechanical governors to rectify the observed condition.

\begin{tabular}{|c|c|c|c|}
\hline 1114 & EPS & Fail to Run & Test \\
\hline 45773 & & Fail to Start & \\
\hline \multirow[t]{3}{*}{$6 / 30 / 2008$} & & erratic outpu & \\
\hline & & (MSPI-S) & $\mathrm{Y}$ \\
\hline & \multicolumn{3}{|c|}{$\begin{array}{l}\text { During Monthly SO-024-001 run of the C DG, load control became erratic with no control from the Control Room (CR). } \\
\text { Load increased to a maximum of approximately } 5560 \mathrm{~kW} \text {. The CR notifed the NPO to perform Emergency Stop of the C } \\
\text { DG. After the C DG was shutdown, the NPO observed that the EGB50P governer had no oil in the sight glass and that the } \\
\text { governor oil sprayed across the front of the C DG. Additionally, the NPO noted that the turbocharger sounded as if } \\
\text { turbocharger speed was very high when the engine was running at max load. }\end{array}$} \\
\hline 1043 & EPS & Fail to Run & Inspection \\
\hline 46955 & & Fail to Start & \\
\hline \multirow[t]{3}{*}{$11 / 21 / 2008$} & & \multicolumn{2}{|c|}{ found unavailable during nondemand observation (MSPI-SD) } \\
\hline & & (MSPI-SD) & Y \\
\hline & \multicolumn{3}{|c|}{$\begin{array}{l}\text { Jacket Water Low Pressure Trip Pressure Switch PS-01DG-2465B2V developed a jacket water leak quantified to be } 13.9 \\
\text { ounces per minute. This exceeds the informally calculated operability limit (ref. AR 301077) of } 4.8 \text { ounces per minute; } \\
\text { therefore, the B EDG was conservatively declared unavailable as of } 0630 \text { on } 11 / 21 / 08 \text {, which is the time when the security } \\
\text { guard discovered the significant leak at the pressure switch. The failure of the pressure switch is a MRFF since the B EDC } \\
\text { could no longer perform its MR function for a mission time of } 24 \text { hours due to the significant leak rate. }\end{array}$} \\
\hline
\end{tabular}




\section{Component Type GEN}

EPIX MSPI Failure Mode Unavailable (T\&M)

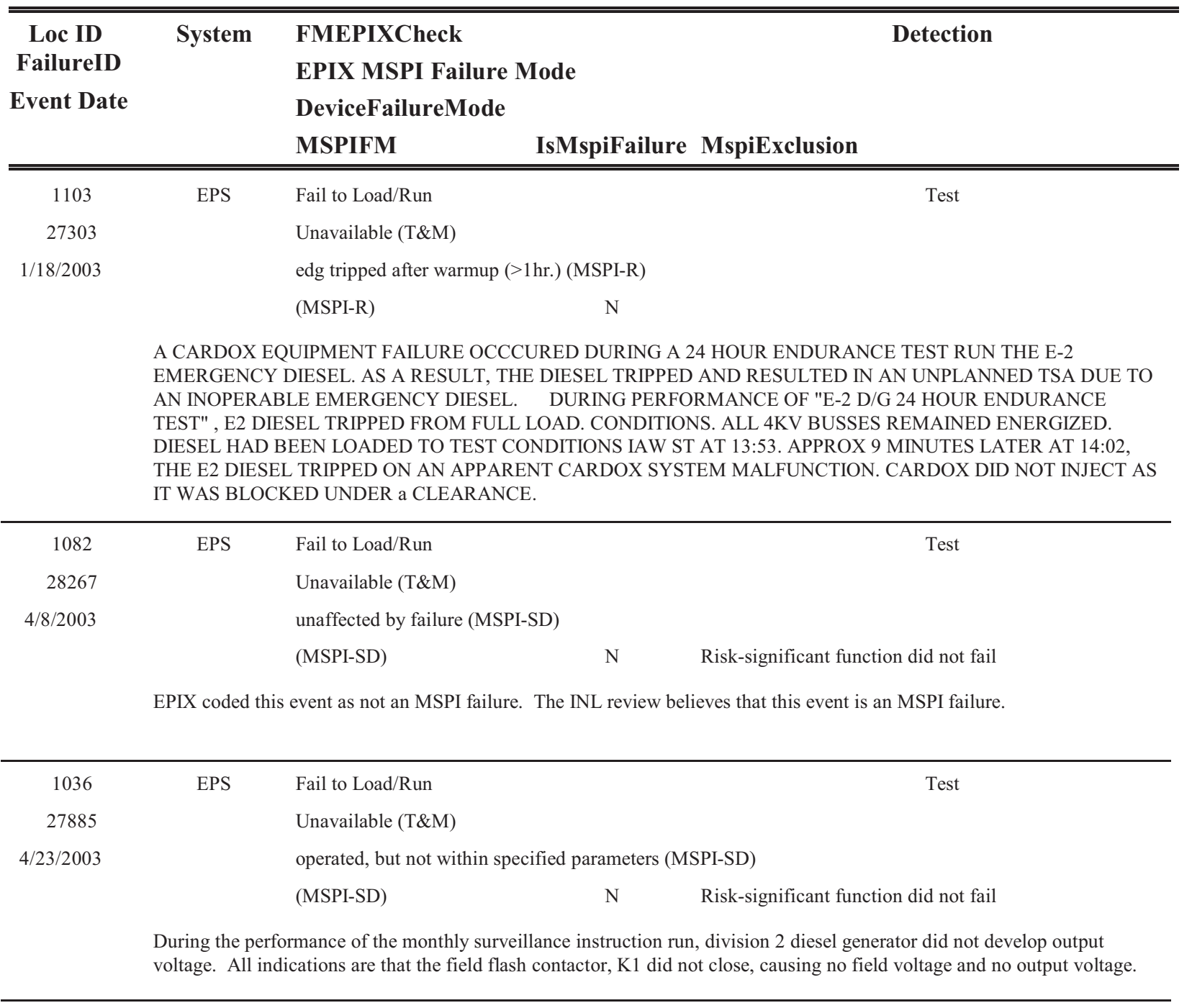




\section{Component Type GEN}

EPIX MSPI Failure Mode Unavailable (T\&M)

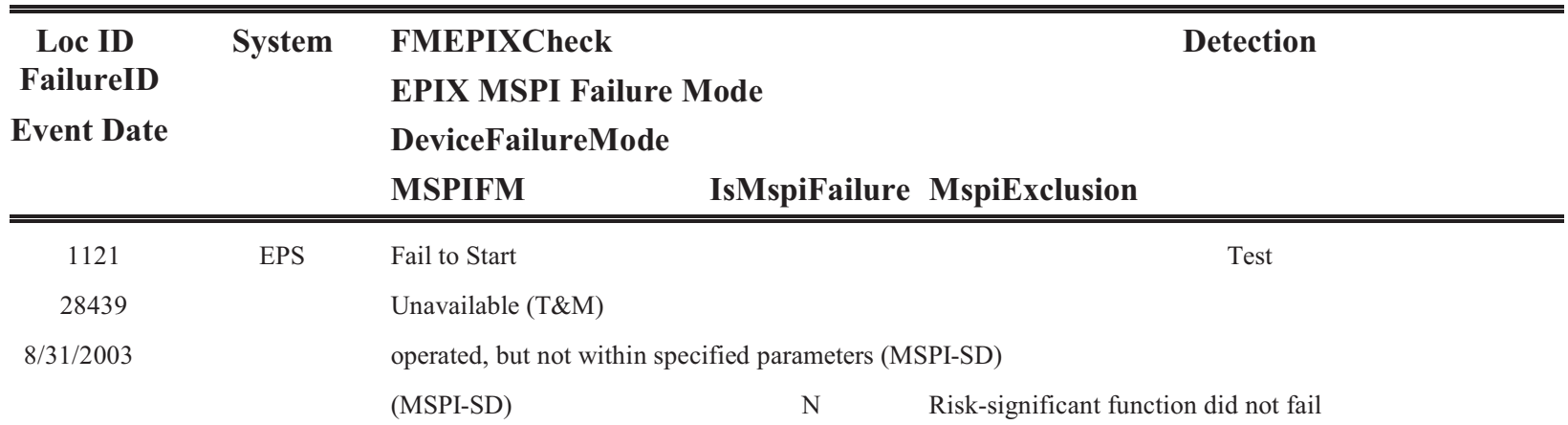

At approximately $0200,2 \mathrm{G} 002$ was started in idle mode to support a monthly surveillance test. The engine seemed to be running at rated speed based on the sound of the engine, an extinguished green stop light (extinguishes above $97 \%$ of rated speed), and the control room frequency meter which read 59.1 hertz. Due to these abnormal indications, the engine was secured after approximately 20 minutes of operation. AR 030801530 was initiated. $\square \square$ At approximately 1530, $2 \mathrm{G} 002$ was test started in Idle Mode in an attempt to recreate and troubleshoot the original problem. The engine cranked for ten seconds but failed to start. By design, if the engine does not reach $150 \mathrm{rpm}$ within 10 seconds, the start is aborted and a Failure to Start alarm is initiated. Data shows the engine reached only about $100 \mathrm{rpm}$. At the beginning of the start, the hydraulic actuators on both engines went full open for about one second, then went full closed within the following second. The acutators are reverse acting such that 17 volts input $=$ fuel rack fully closed, and 0 volts input $=$ fuel rack fully open. During the start attempt, the output from the electronic governor remained constant at 17 volts, so the governor never tried to open the fuel racks. The governor has an air-boost system which forces the fuel rack wide open on initial start, until hydraulic pressure can be developed. Based on this, it was concluded that the air boost system opened the fuel racks as designed, but the electronic governor did not hold the rack open as it should have.

\begin{tabular}{rlll}
\hline 1082 & EPS & Fail to Load/Run & Test \\
31008 & & Unavailable (T\&M) & \\
$4 / 11 / 2004$ & & & \\
& & unaffected by failure (MSPI-SD) & \\
& (MSPI-SD) & N & Risk-significant function did not fail
\end{tabular}

EPIX coded this event as not an MSPI failure. The INL review believes that this event is an MSPI failure.

\begin{tabular}{cll}
\hline 1096 & EPS & Fail to Start \\
32132 & & Pnavailable (T\&M) \\
discovered to be unable to run for mission time (MSPI-R) \\
(MSPI-R)
\end{tabular}




\section{Component Type GEN}

EPIX MSPI Failure Mode Unavailable (T\&M)

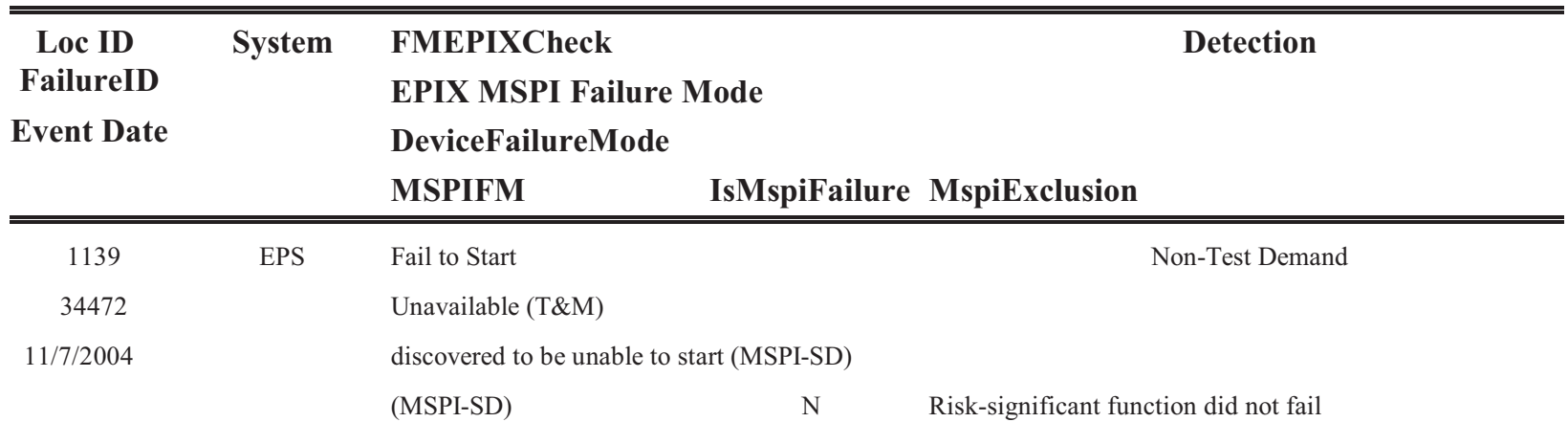

Start failure received when attempting to start \#2 Emergency Diesel Generator in accordance with 2-OPT-EG-001.

Moisture in the EDG starting air supply system caused corrosion to accumulate on the secondary seat (pilot valve) and pilot valve stem section of the air start valve (2-EG-44). The air start motor (2-EG-M-02) pinion experienced an abutment with the flywheel ring gear, which limited the flow rate of air to the control side of the air start valve. The increased pressure required to operate a corroded air start valve $(\mathrm{CC} 1)$ combined with the reduced flow rate of control air prevented the air start valve from opening within the required start failure time out (3 seconds).

\begin{tabular}{|c|c|c|c|}
\hline 1076 & EPS & Fail to Load/Run & Test \\
\hline 34300 & & Unavailable (T\&M) & \\
\hline \multirow[t]{4}{*}{$2 / 14 / 2005$} & & \multicolumn{2}{|l|}{ discovered to be unable to load (MSPI-L) } \\
\hline & & (MSPI-L) & PMT failure related to maintenance performed \\
\hline & \multirow{2}{*}{\multicolumn{3}{|c|}{$\begin{array}{l}\text { EPIX coded this event as not an MSPI failure. The INL review believes that this event is an MSPI failure. } \\
\text { 2C Diesel generator, 2R43S001C, output breaker failed to close while attempting to tie } 2 \mathrm{C} \text { D/G per } 34 \mathrm{SV}-\mathrm{R} 43-003-2 . . \\
\text { Alternate supply ACB135584 closed and S/U AUX XFMR 2D 2S11S005 was deenergized prior to performing this } \\
\text { surveillance. }\end{array}$}} \\
\hline & & & \\
\hline 1099 & EPS & Fail to Run & Test \\
\hline 35313 & & Unavailable (T\&M) & \\
\hline \multirow[t]{3}{*}{$4 / 11 / 2005$} & & unaffected by failure (MSPI-SD) & \\
\hline & & (MSPI-SD) & Risk-significant function did not fail \\
\hline & \multicolumn{3}{|c|}{$\begin{array}{l}\text { During the surveillance, two problems occurred. Engine } 1 \text { cylinder B4 exhaust temperature deviation alarmed ( } 727 \text { vs } 915 \\
\text { average). The engineer reported this was likely an injector problem. The second problem was that crankcase pressure in } \\
\text { Engine } \# 2 \text { experienced several stepwise increases during the } 1 \text { hour full load run, plateauing at } 22 ", 25-29 ", 32 " \text { then in less } \\
\text { than } 1 \text { minute increased to } 48 " \text { and rising. Operations unloaded the diesel per procedure to } 2000 \mathrm{KW} \text {, at which time } \\
\text { crankcase pressure reduced to } 10 " \text {. The diesel was run at the low load for cooldown then shut down. } \\
\text { The high crankcase pressure also caused oil to spray from the shaft seals. } \\
\text { The root cause of the elevated crank case pressure is piston ring sticking at high operating loads caused by particles inside } \\
\text { the piston ring groove. These particles reduce the tolerance between the piston ring and the piston ring groove. At higher } \\
\text { loads, differential expansion at the top of the piston can decrease the ring groove clearance. }\end{array}$} \\
\hline
\end{tabular}




\section{Component Type GEN}

EPIX MSPI Failure Mode Unavailable (T\&M)

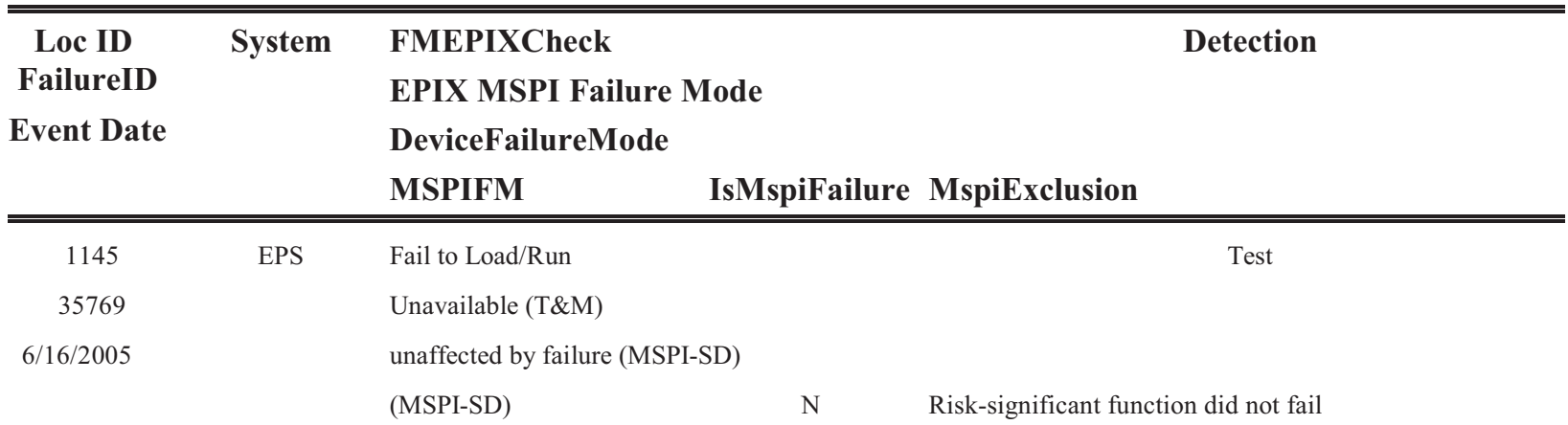

During the performance of SP-42-312A "Diesel Generator A Availability Test" step 6.24.9, Breaker 1-509 "DG A to Bus 5" failed to close. The synchroscope was rotating in the fast direction at approximately $5 \mathrm{rpm}$ and the breaker control switch was placed in close at the 9 o'clock position (per procedure). A second attempt to close the breaker was also unsuccessful. Electricians and OCC were contacted. Electricians were not immediately able to determine a cause and requested to rack the breaker out for troubleshooting.

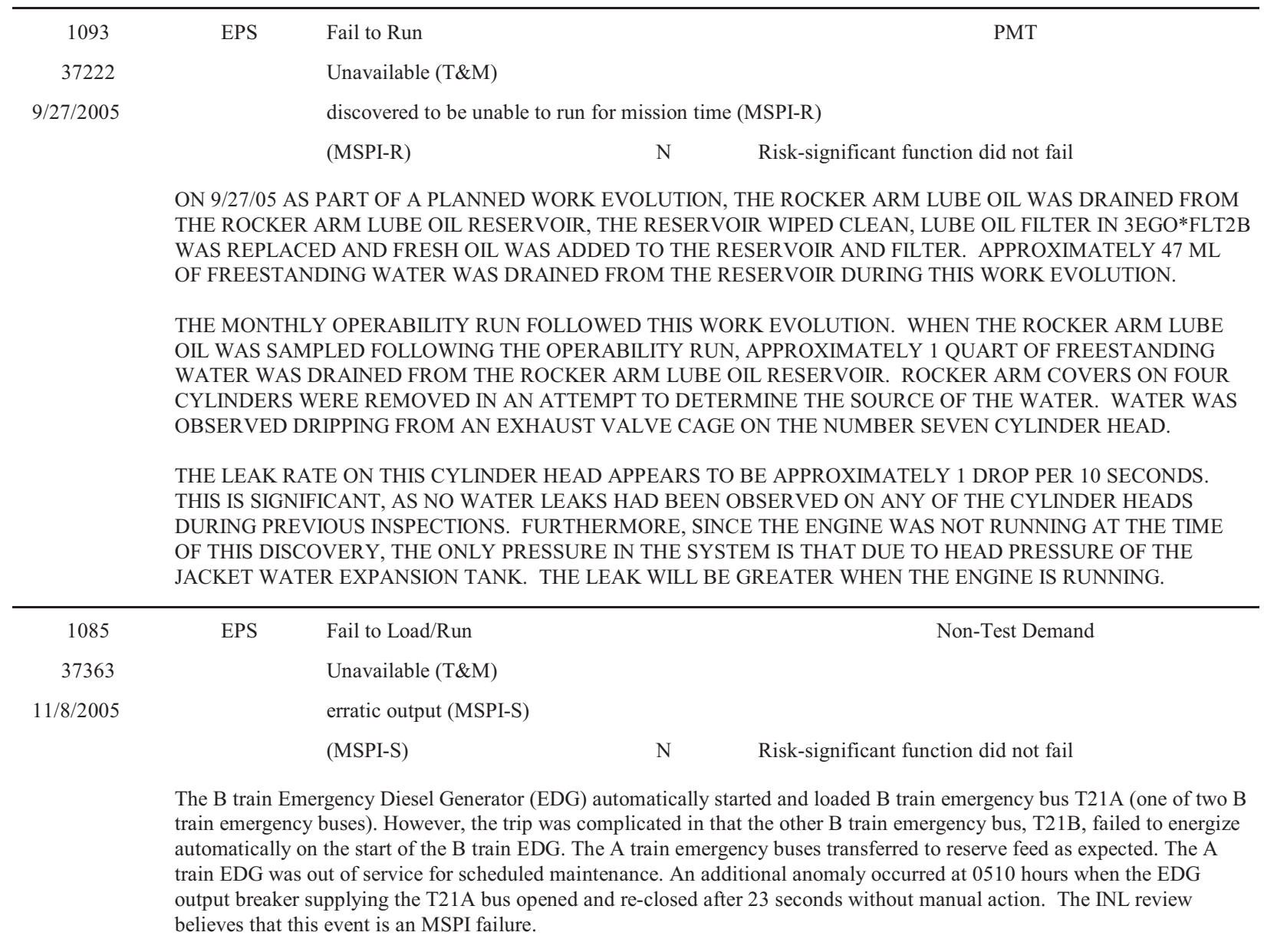




\section{Component Type GEN}

EPIX MSPI Failure Mode Unavailable (T\&M)

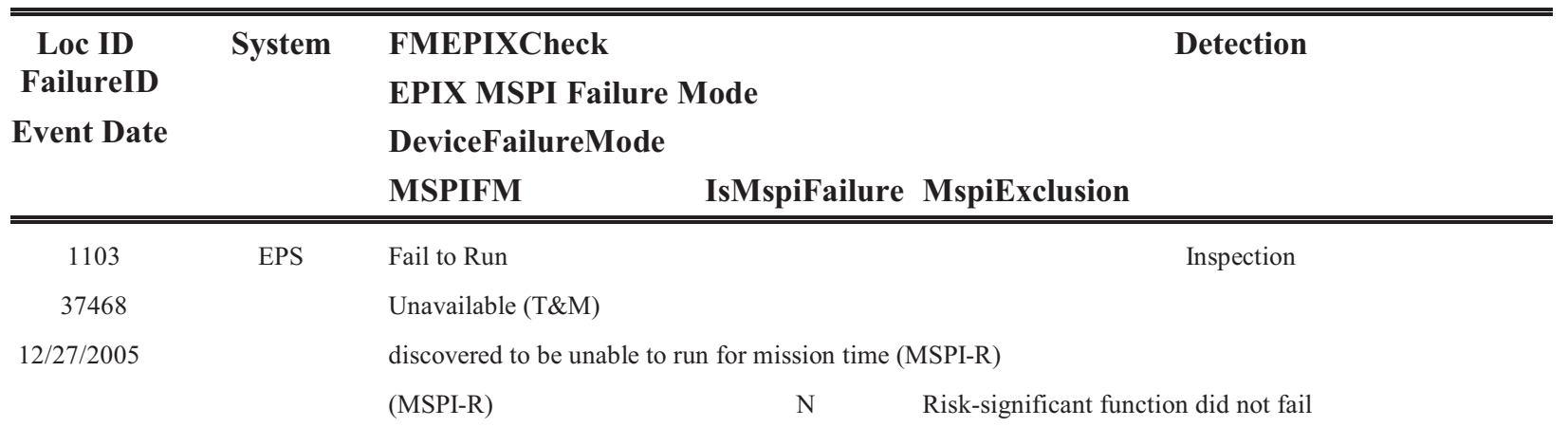

On 12/27/05, at approximately 2030 hours, while preparing for a test run of the E-2 EDG, an Equipment Operator identified approximately 10 gallons of water in the vicinity of the E-2 EDG cooling subsystem. The leakage was determined to be pump shaft packing leakage associated with the E-2 EDG Air Coolant Auxiliary Pump. The leak rate was later determined to be approximately 10 gallons per hour, but existed only when the E-2 EDG was operating. The leak rate resulted in the E-2 EDG being declared inoperable. It was later determined that the E-2 EDG had been inoperable dating back to 12/22/2005 when the PMT on the Air Coolant Auxiliary Pump was last performed and returned to service.

\begin{tabular}{|c|c|c|c|}
\hline 1024 & EPS & Fail to Run & Test \\
\hline 37635 & & \multicolumn{2}{|l|}{ Unavailable (T\&M) } \\
\hline \multirow[t]{4}{*}{$1 / 10 / 2006$} & & \multicolumn{2}{|c|}{ operated, but not within specified parameters (MSPI-SD) } \\
\hline & & (MSPI-SD) & Risk-significant function did not fail \\
\hline & \multicolumn{3}{|c|}{$\begin{array}{l}\text { While performing FNP-1-STP-80.1 (OTC\# } 07 / 08 / 0122: 46: 16 \text { ) on } 1 \mathrm{~B} \mathrm{D} / \mathrm{G} \text {, the diesel was shut down due to an exhaust } \\
\text { gasket failure. A maintenance mechanic was performing vibration measurements during this time.1B Diesel is being tagged } \\
\text { out to repair the gasket.Does not meet reportability criteria of } 10 \mathrm{CFR} 50.72 \text { or } 50.73\end{array}$} \\
\hline & \multicolumn{3}{|c|}{$\begin{array}{l}\text { Later investigations revealed that a section of the exhaust manifold itself blew out, rather than a gasket. The breach was } \\
\text { initially patched, but later a weld repair was performed, both under WO\# } 1000526 \text {. }\end{array}$} \\
\hline 1031 & EPS & Fail to Load/Run & Test \\
\hline 41921 & & Unavailable (T\&M) & \\
\hline \multirow[t]{4}{*}{$5 / 15 / 2007$} & & erratic output (MSPI-S) & \\
\hline & & (MSPI-S) & Risk-significant function did not fail \\
\hline & \multirow{2}{*}{\multicolumn{3}{|c|}{$\begin{array}{l}\text { On May } 15,2007 \text {, at approximately } 0651 \text { hours, and approximately } 45 \text { minutes into the } 60 \text { minute monthly operability } \\
\text { loaded run, the A EDG unexpectedly experienced sudden increasing/decreasing power oscillations of approximately }(+) /(-) \\
150 \mathrm{~kW}(300 \mathrm{~kW} \text { total) about the } 2600 \mathrm{~kW} \text { load setting. } \\
\text { Root Causes: } \\
\text { The stiff control linkage from the EGB through the output coil spring to the engine combined with a loose linkage allowed } \\
\text { the fuel rack position to get out of synch with the demand from the EGA to EGB. The Root Cause for this inconsistent } \\
\text { linkage performance was inadequate level of detail in the existing PM procedures }\end{array}$}} \\
\hline & & & \\
\hline 1085 & EPS & Fail to Start & Test \\
\hline \multirow{3}{*}{$\begin{array}{r}43666 \\
12 / 4 / 2007\end{array}$} & & \multicolumn{2}{|l|}{ Unavailable (T\&M) } \\
\hline & & \multicolumn{2}{|c|}{ edg did not reach rated rpm \& v on manual start (MSPI-S) } \\
\hline & & (MSPI-S) & Risk-significant function did not fail \\
\hline
\end{tabular}

EPIX coded this event as not an MSPI failure. The INL review believes that this event is an MSPI failure. 


\section{Component Type GEN}

EPIX MSPI Failure Mode Unavailable (T\&M)

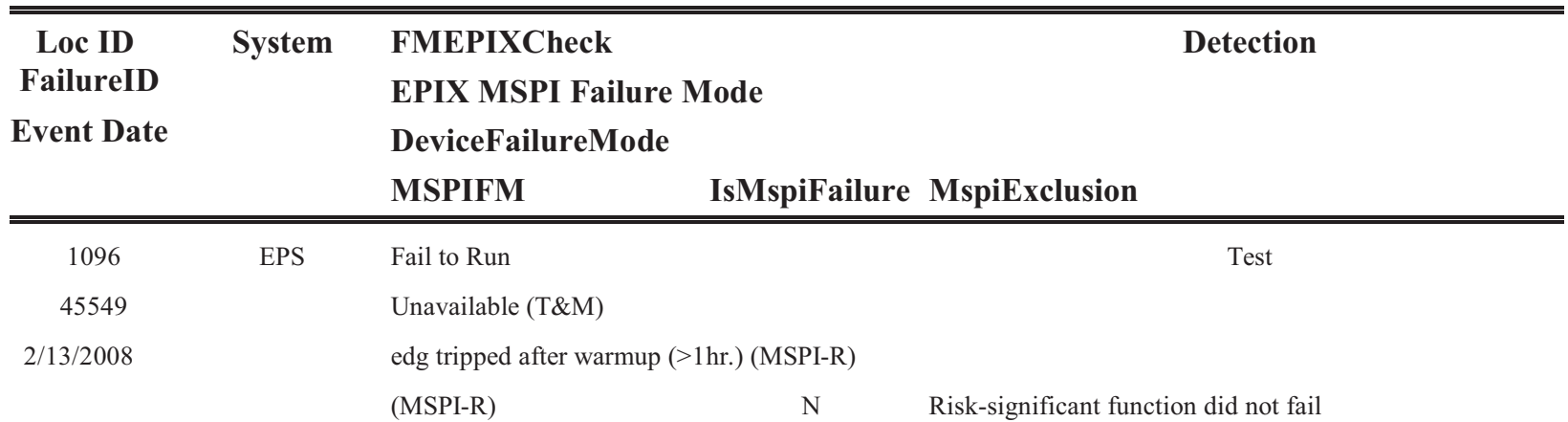

During performance of Surveillance Procedure 6.2DG.101, DIESEL GENERATOR 31 DAY OPERABILITY TEST (IST) (DIV 2), operator identified an oil leak from the welded joint at the discharge of the \#2 DG main lube oil pump. Leak rate estimated to be approximately 1 pint/minute.

Unloaded and secured \#2 DG per SP.

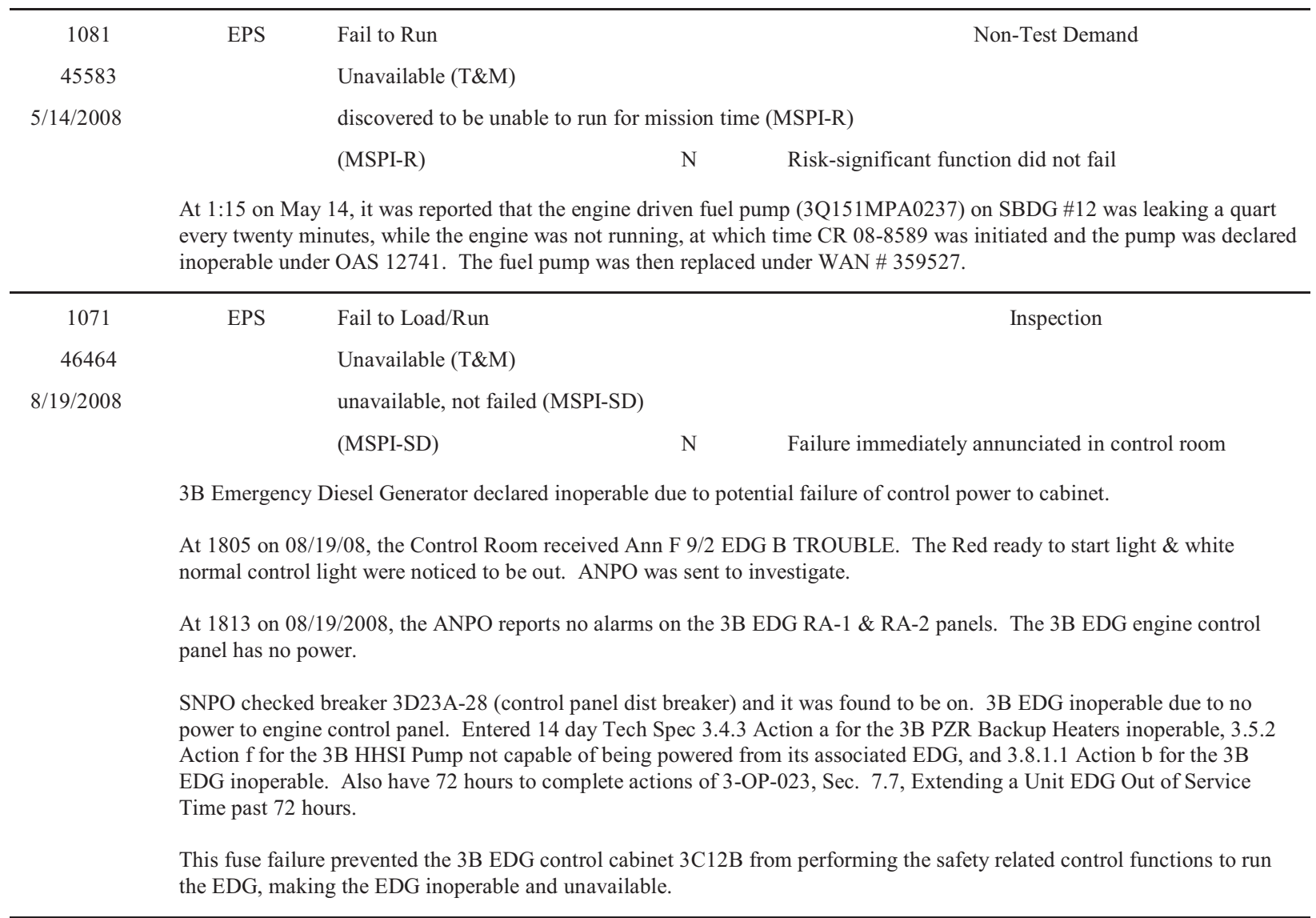




\section{Component Type GEN}

EPIX MSPI Failure Mode Unavailable (T\&M)

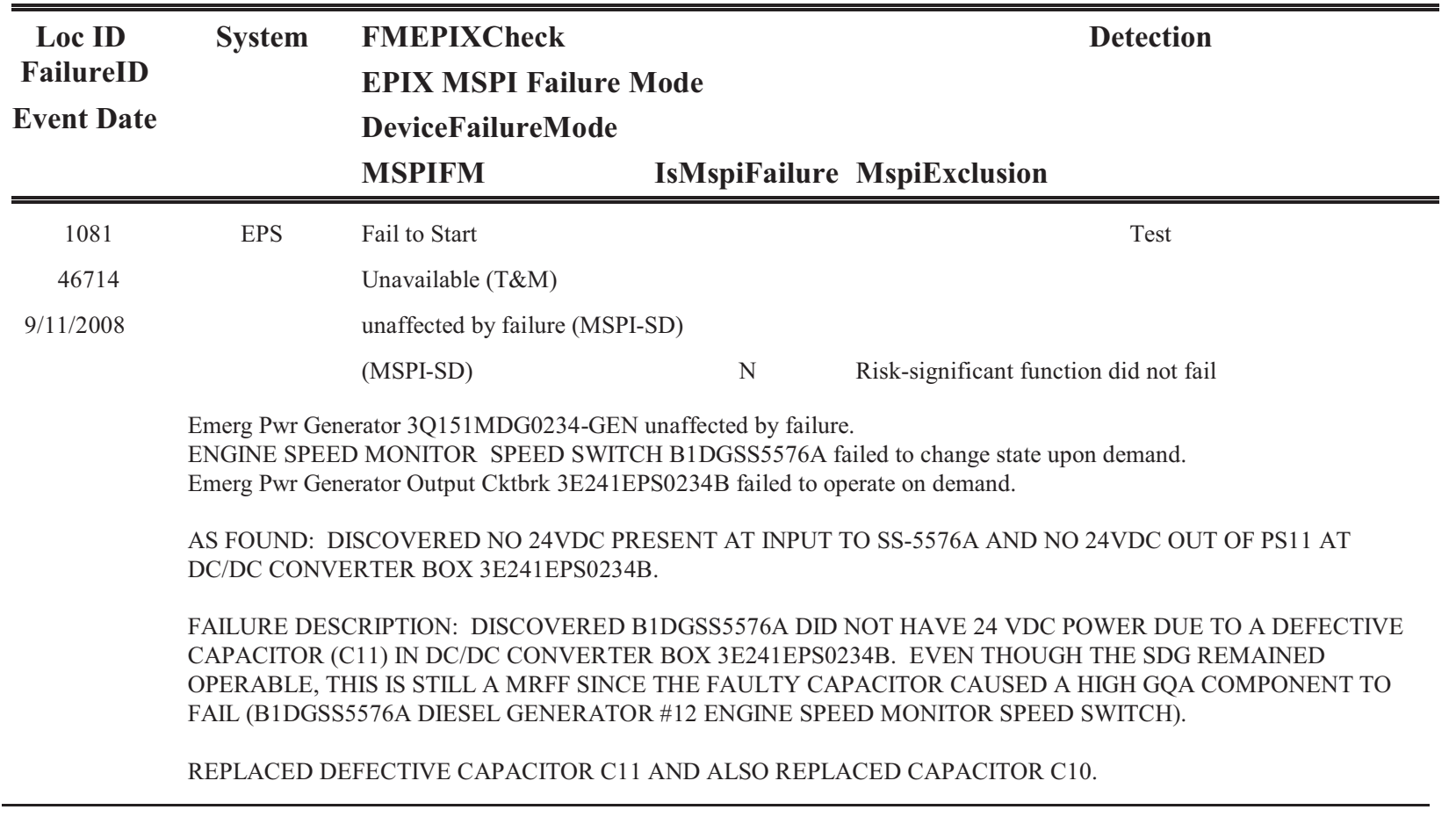


Component Type $\mathrm{HOV}$ 


\section{Component Type $\mathrm{HOV}$}

EPIX MSPI Failure Mode Unavailable (T\&M)

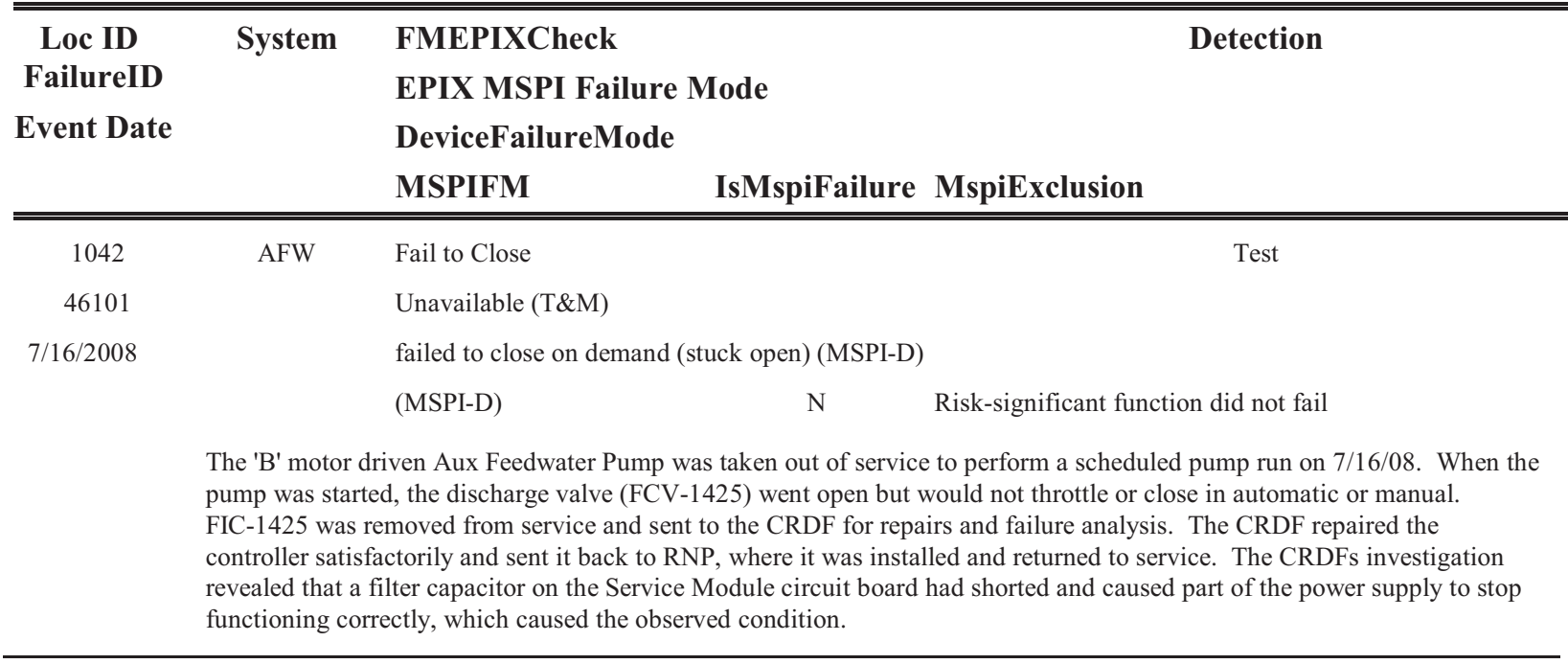




\section{Component Type $\quad$ MDP}

EPIX MSPI Failure Mode Fail to Run

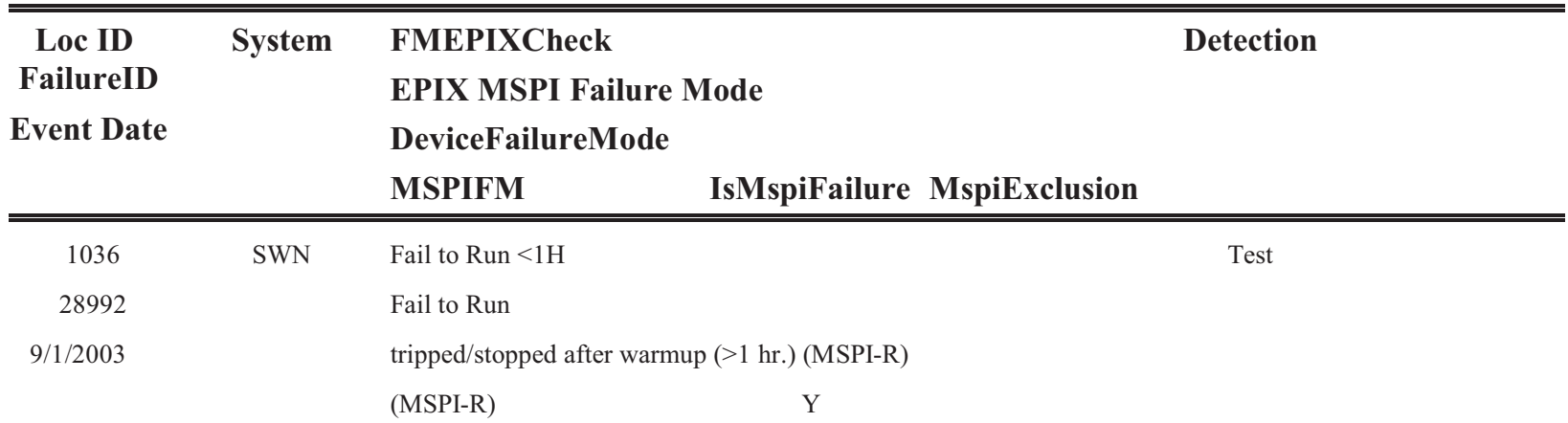

Emergency Service Water (ESW) A pump, 1P45C0001A, lost flow after 42 minutes of operation. Follow up investigation found no evidence of a pump or motor transient nor any sign of foreign material obstruction in the pump impellers.

Disassembly of the pimp found the first line shaft coupling sleeve had failed and was found in two pieces inside the pump assembly. Visual inspection of wear marks on the broken coupling sleeve halves indicated the coupling was not centered between the two shafts. This left approximately one inch of the key extending above the coupling during operation.

Event captured by LER 4402003004.

\begin{tabular}{rlll}
\hline 1106 & SWN & Fail to Run $<1 \mathrm{H}$ & Non-Test Demand \\
39480 & & Fail to Run \\
$10 / 5 / 2003$ & tripped/stopped after warmup $(>1 \mathrm{hr}).($ MSPI-R) \\
& $($ MSPI-R) & Y
\end{tabular}

After placing 16 Service Water Pump in service, it was noticed that the upper motor bearing temperature was 201 degrees. The pump was declared inoperable. Drain valve 16SW362 was opened and .other than liquid. material was flushed from the piping until all large particulates were removed. The motor bearing temperature stabilized at $\sim 143$ degrees and the pump was declared operable.

\begin{tabular}{rlll}
\hline 1036 & SWN & Fail to Run $<1 \mathrm{H}$ & Test \\
32268 & & Fail to Run \\
$5 / 21 / 2004$ & tripped/stopped after warmup $(>1 \mathrm{hr}).($ MSPI-R) \\
& $($ MSPI-R $)$ & Y
\end{tabular}

Flow total was normal, reading $11.93 \mathrm{~K}$ gpm. 2 minutes later (0150) received ESW A low flow and low discharge pressure alarms. Observed $0 \mathrm{gpm}$ and $20 \mathrm{amps}$ on the pump in the control room. Operator in the field reported that the pump was making an unusual vibration and there was an electrical burning smell. No smoke or fire observed. Pump was shutdown at 0159 .

Event captured by LER 4402004001.

\begin{tabular}{|c|c|c|c|}
\hline 1106 & SWS & Fail to $\mathrm{Run}<1 \mathrm{H}$ & PMT \\
\hline 35128 & & \multicolumn{2}{|l|}{ Fail to Run } \\
\hline \multirow[t]{3}{*}{$5 / 3 / 2005$} & & \multicolumn{2}{|l|}{ tripped/stopped after warmup (>1 hr.) (MSPI-R) } \\
\hline & & (MSPI-R) & \\
\hline & \multicolumn{3}{|c|}{$\begin{array}{l}\text { On 5/3/05, } 11 \text { Service Water Pump Motor Bearing temperature increased to } 190 \text { degrees following the pump being placed in } \\
\text { service. This caused the inoperability of the } 11 \text { SW Pump. Since } 13 \text { Service Water Pump was previously declared } \\
\text { inoperable, } 72 \text { hour Tech Spec Action Statement 3.7.4.1 was entered. } \\
\text { Cooler outlet drain valve } 11 \text { SW } 362 \text { was opened in order to flush debris out of the cooler and/or check valve } 11 \text { SW13. The } \\
\text { flush was successful as the motor upper bearing temperature stabilized at } 141 \text { degrees after being placed back in service. }\end{array}$} \\
\hline
\end{tabular}




\section{Component Type $\quad$ MDP}

EPIX MSPI Failure Mode Fail to Run

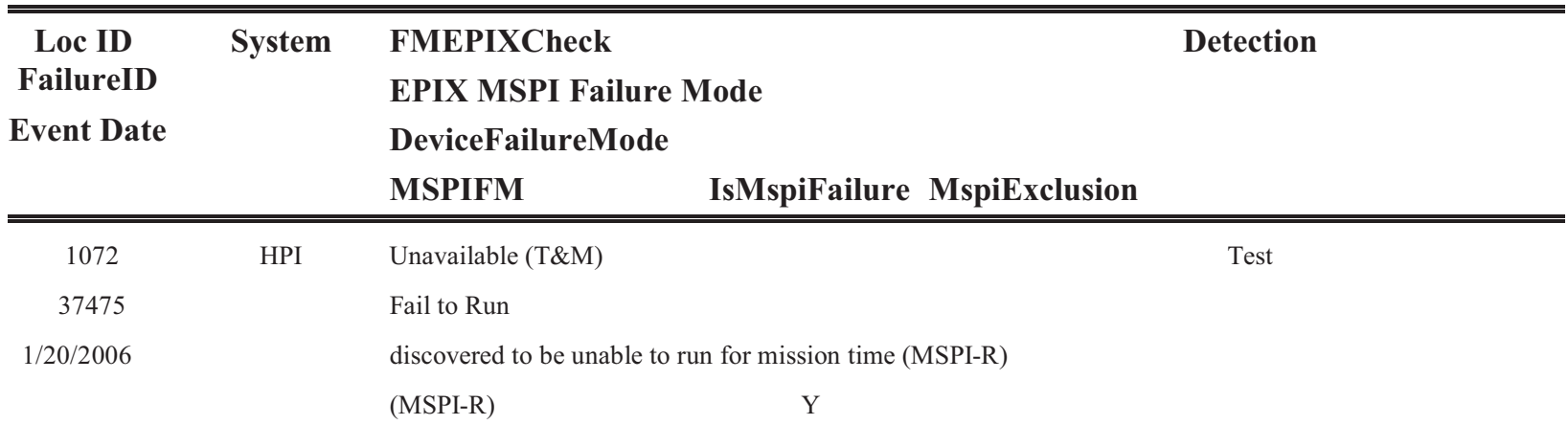

On 1/20/2006, during the performance of In-Service Testing per procedure 0-OSP-062.2 (Safety Injection System In-Service Test), it was observed that there was an oil leak of approximately 10 to 15 drops per minute on the outboard bearing oiler of the 4B HHSI pump (4P215B). It was noted, prior to pump start, that there was no leakage from the oiler.

The leakage only began with pump operation. After securing the 4B HHSI pump, the oil leak stopped and only residual oil was noted. It was also reported that the oiler rotated freely on its threaded connection with the bearing housing piping nipple. Immediate discussions with Operations resulted in the determination that the oil leak was sufficient to declare the pump inoperable. The 4B HHSI pump was then taken OOS and the Trico oiler was replaced and tested SAT

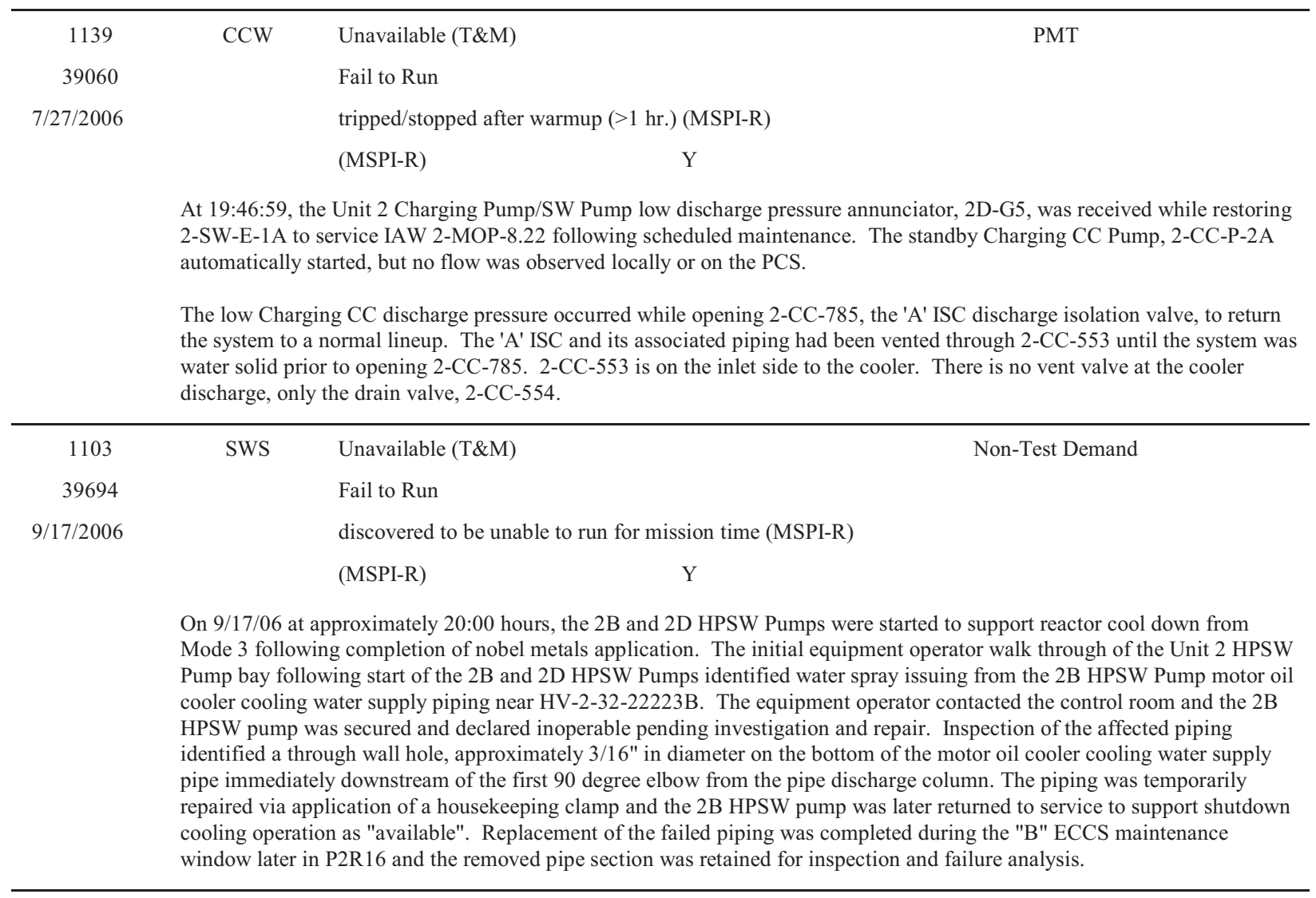




\section{Component Type MDP}

EPIX MSPI Failure Mode Fail to Run

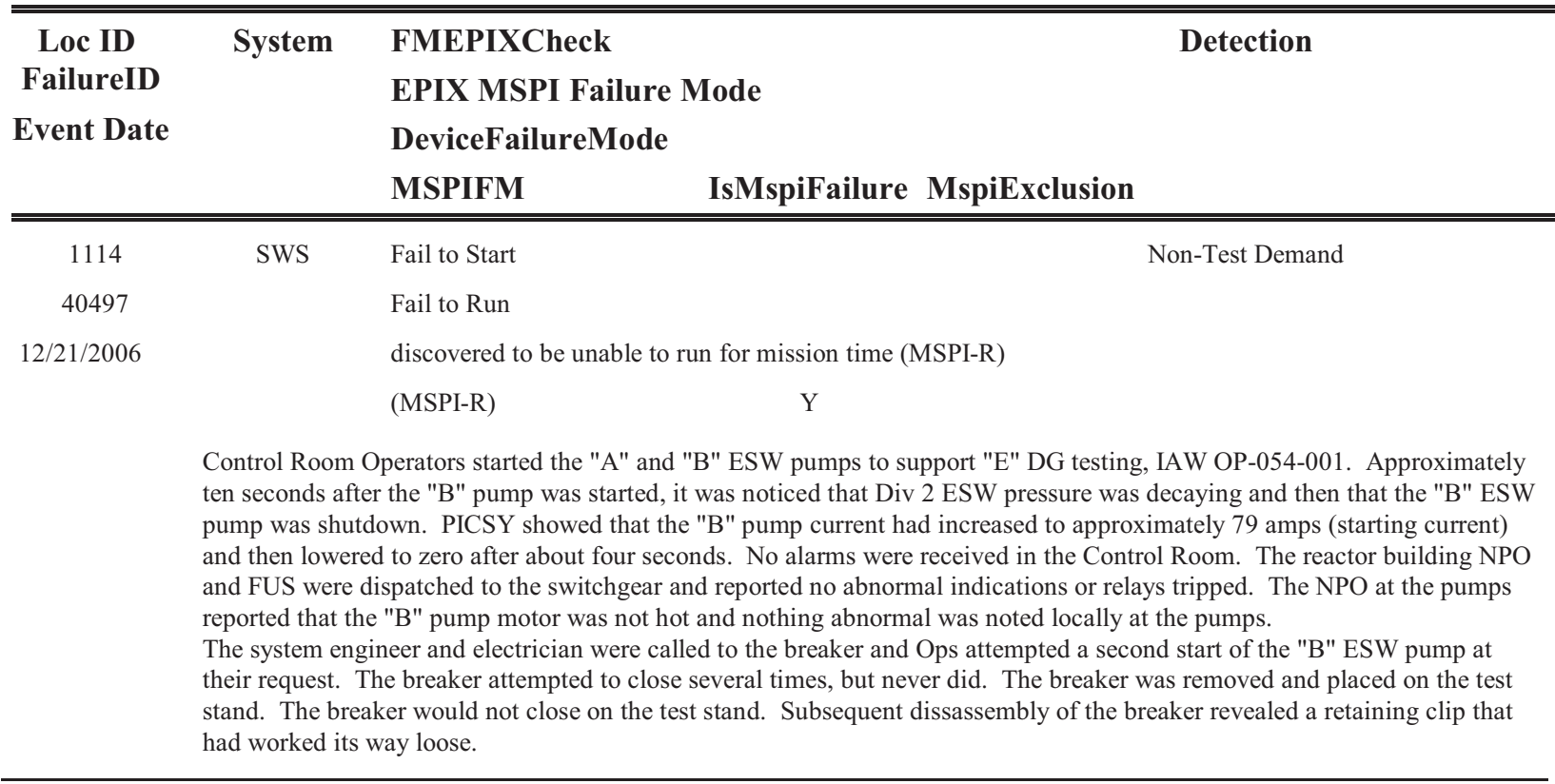

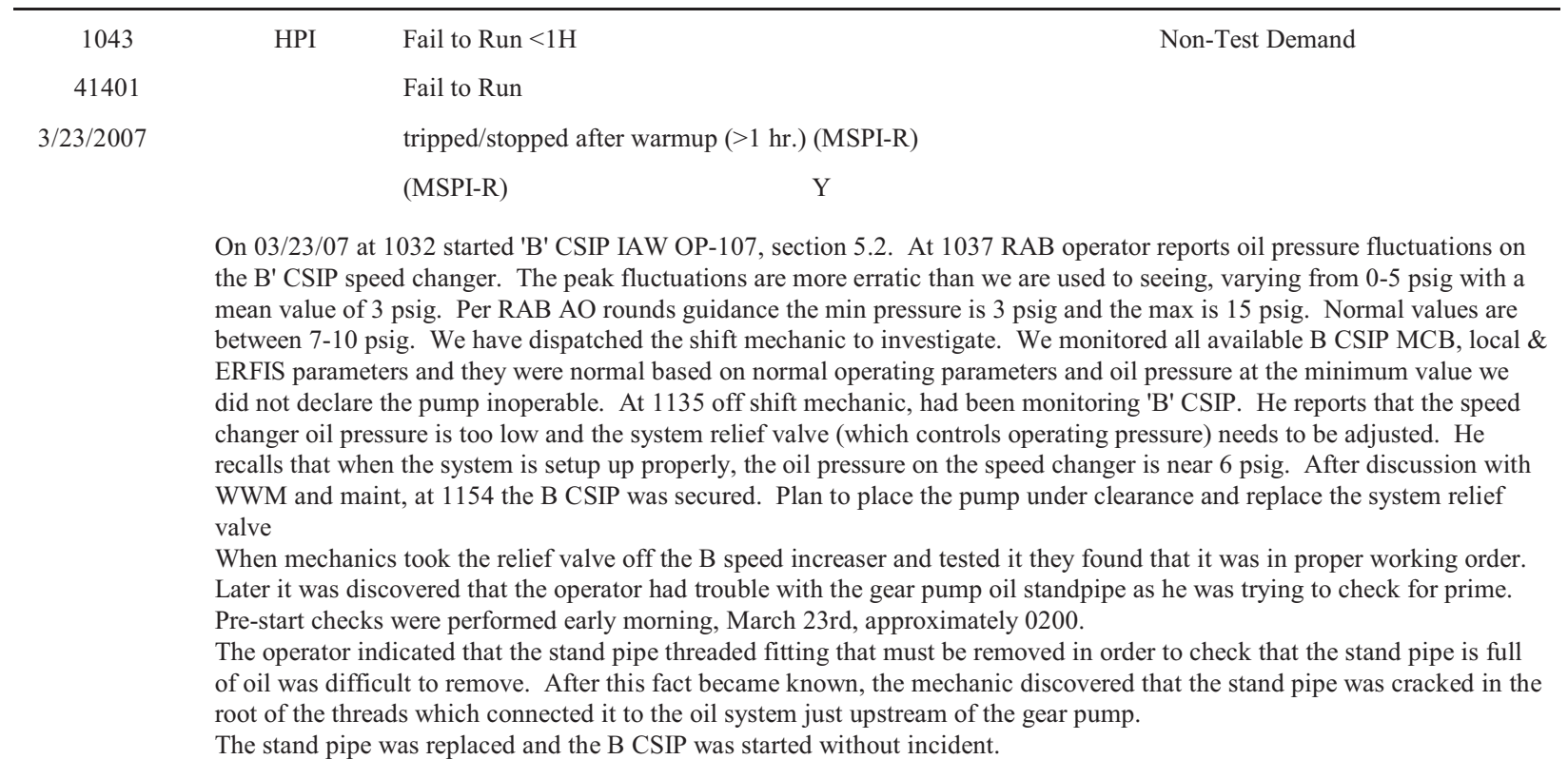




\section{Component Type $\quad M D P$}

EPIX MSPI Failure Mode Fail to Run

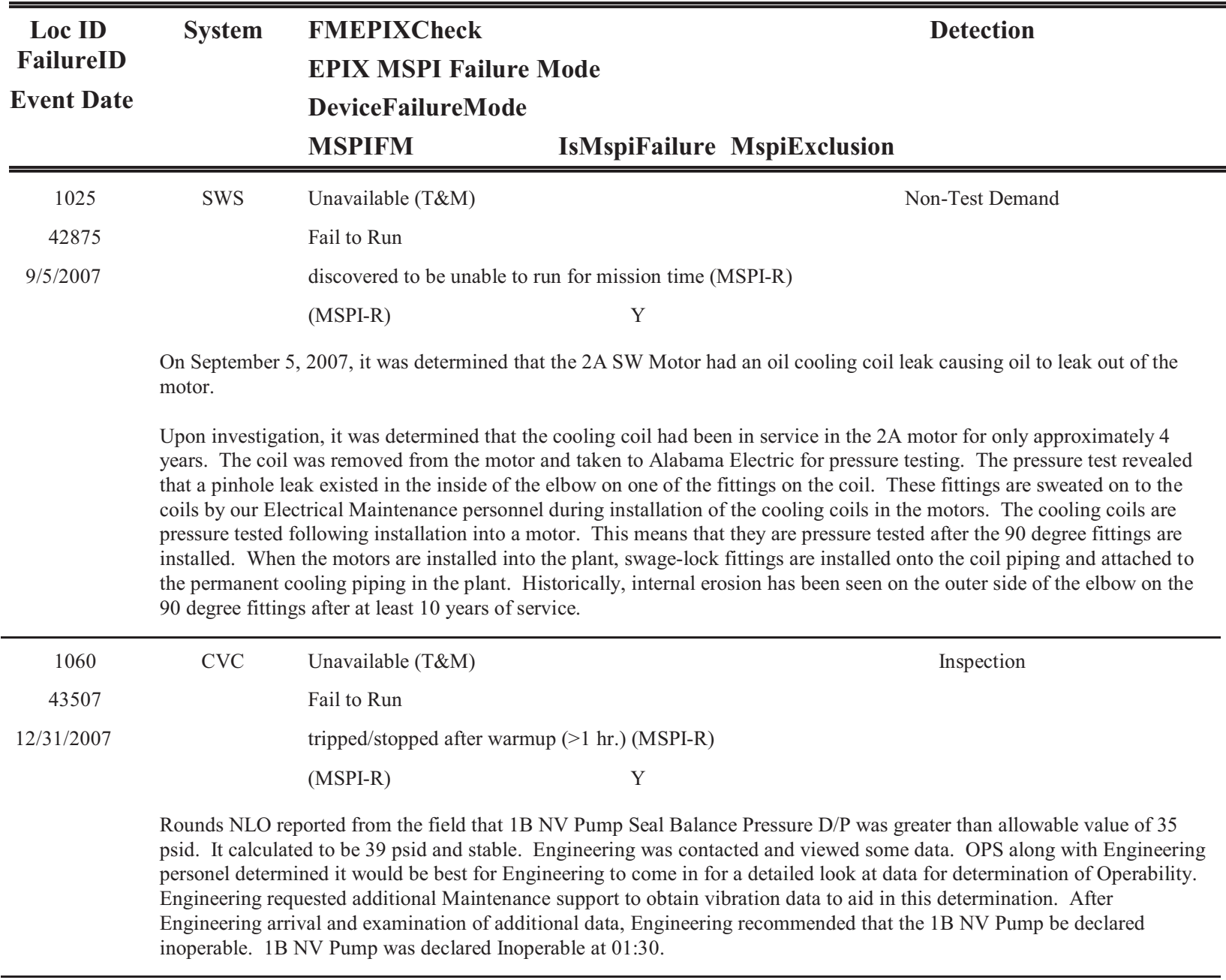




\section{Component Type $\quad$ MDP}

EPIX MSPI Failure Mode Fail to Start

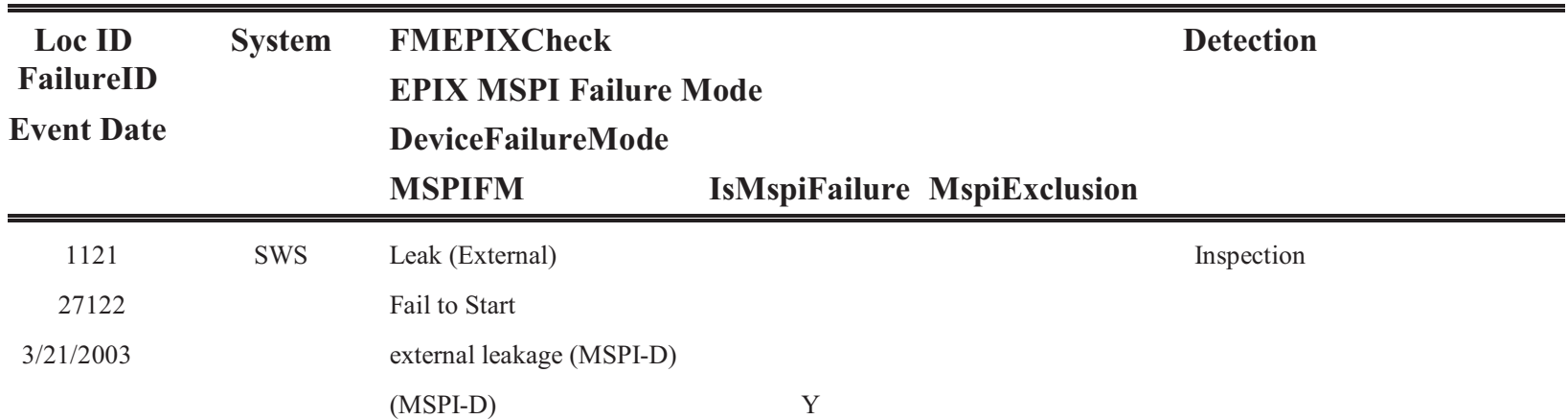

Salt water cooling pump S21413MP307 has developed a leak through a small hole, less than 1/8", at the 6 o'clock position on the inside of the elbow of the discharge head, between the pump flange and the bellows. The propose of this activity is to perform the necessary weld repairs to the through wall leak and to any other identified corroded areas on the inside of the discharge head of the pump.

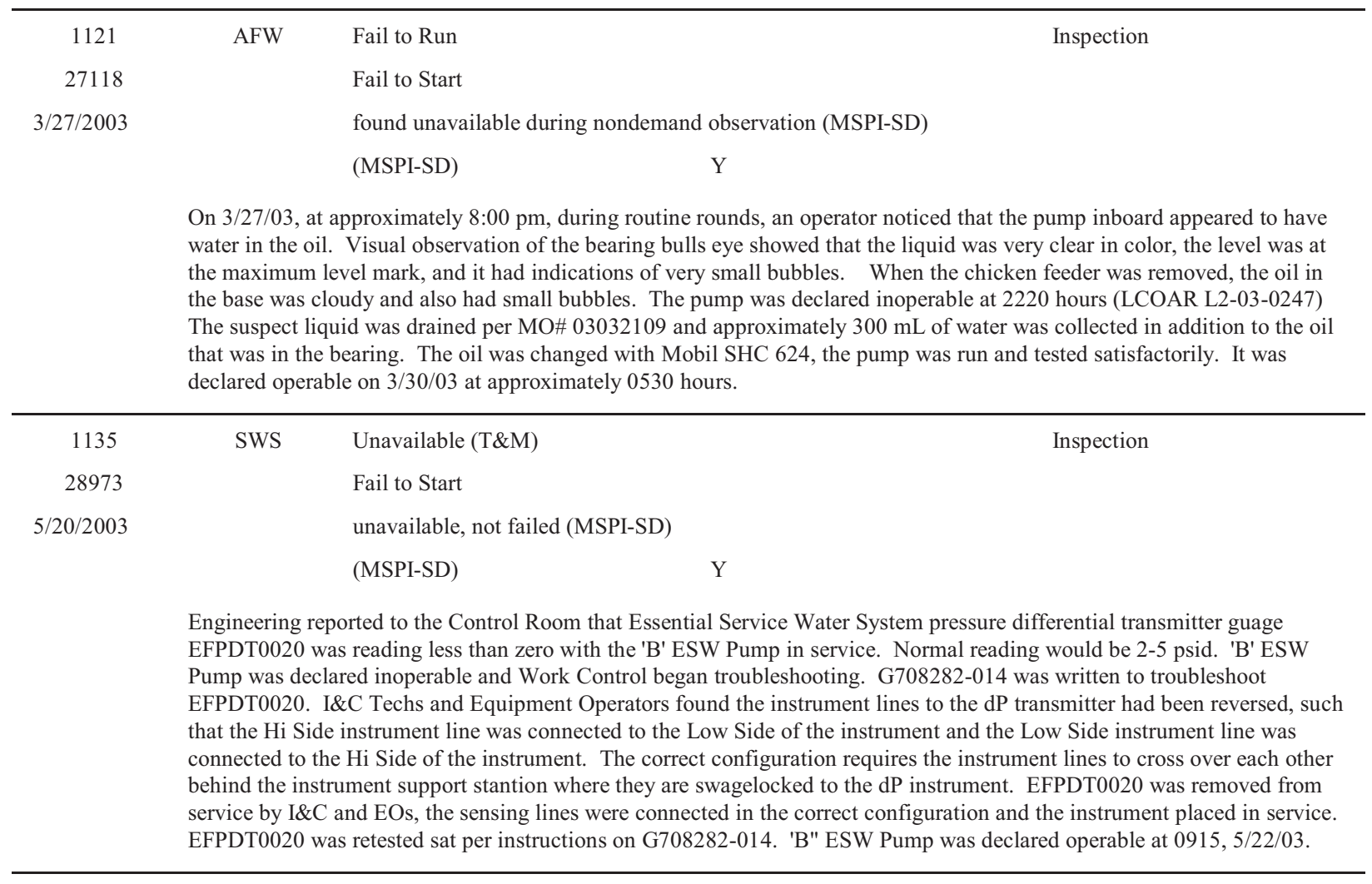




\section{Component Type $\quad$ MDP}

EPIX MSPI Failure Mode Fail to Start

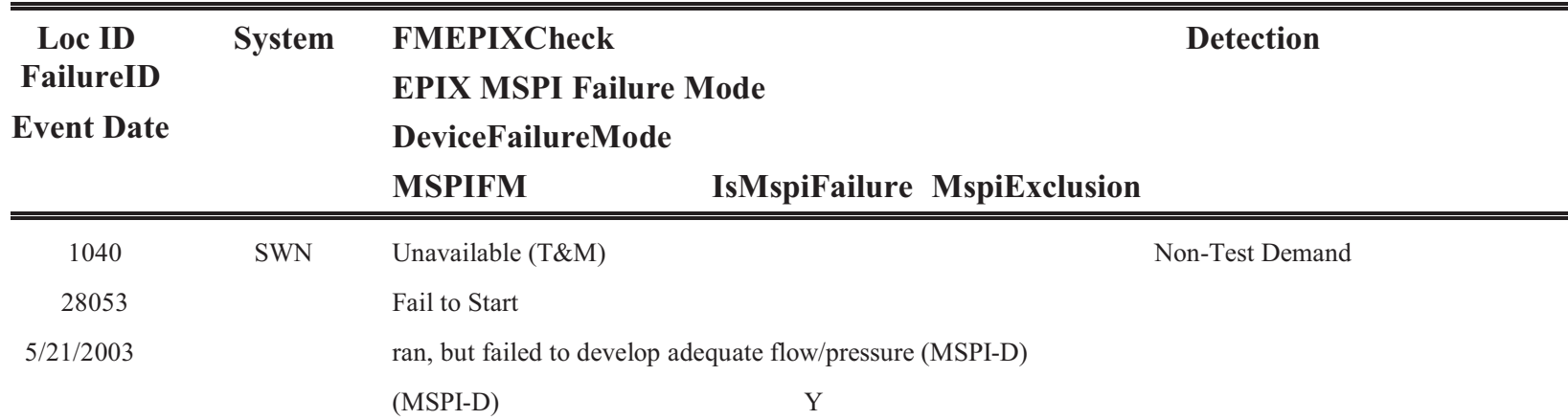

Three occurrences of Service Water Pump inoperability occurred between 9/20/02 and 10/3/02 due to excessive pressure differential across Service Water Pump discharge strainers. Corrective maintenance performed in each case found clogging of the strainers due to an accumulation of oyster shells.

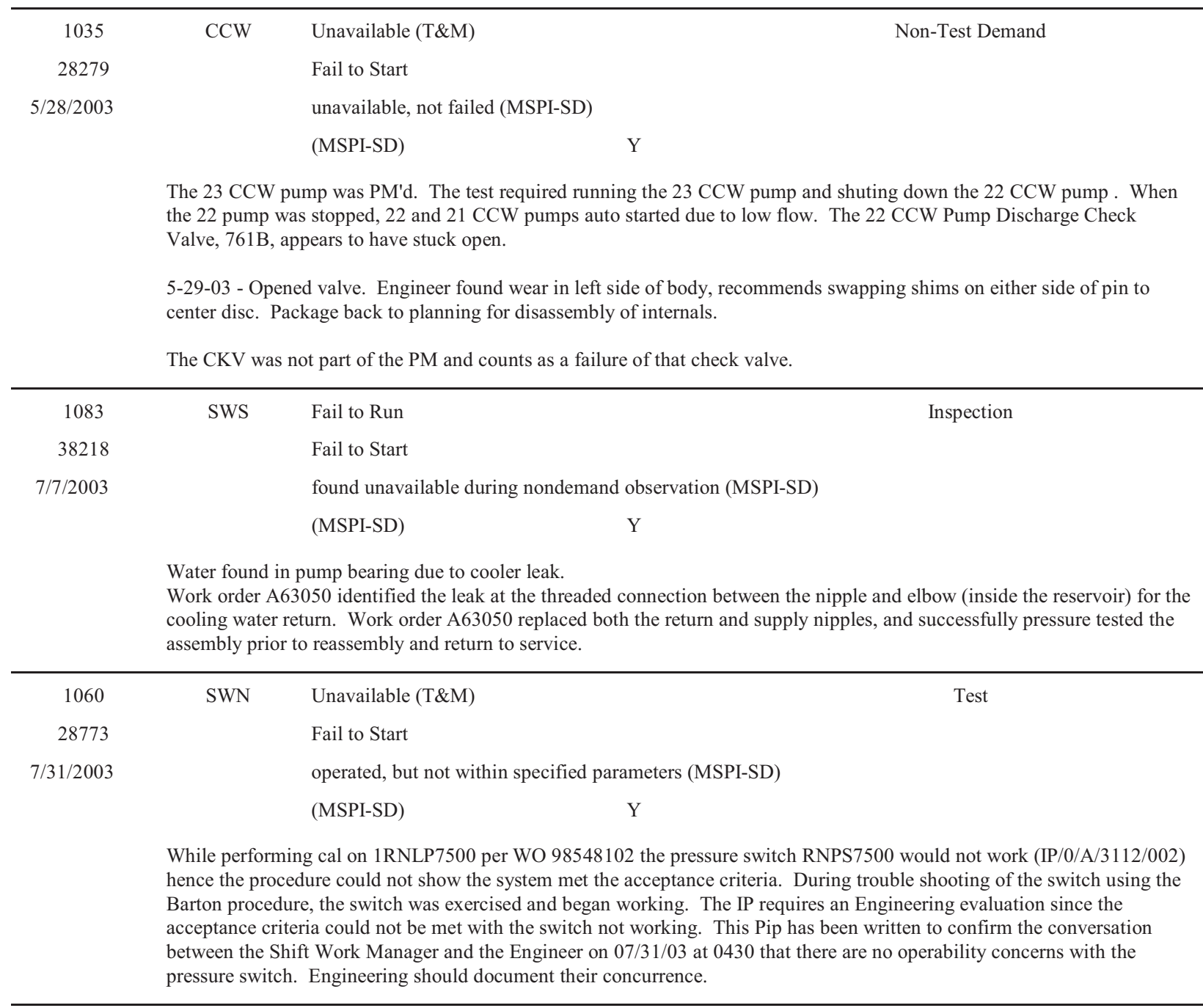




\section{Component Type $\quad M D P$}

EPIX MSPI Failure Mode Fail to Start

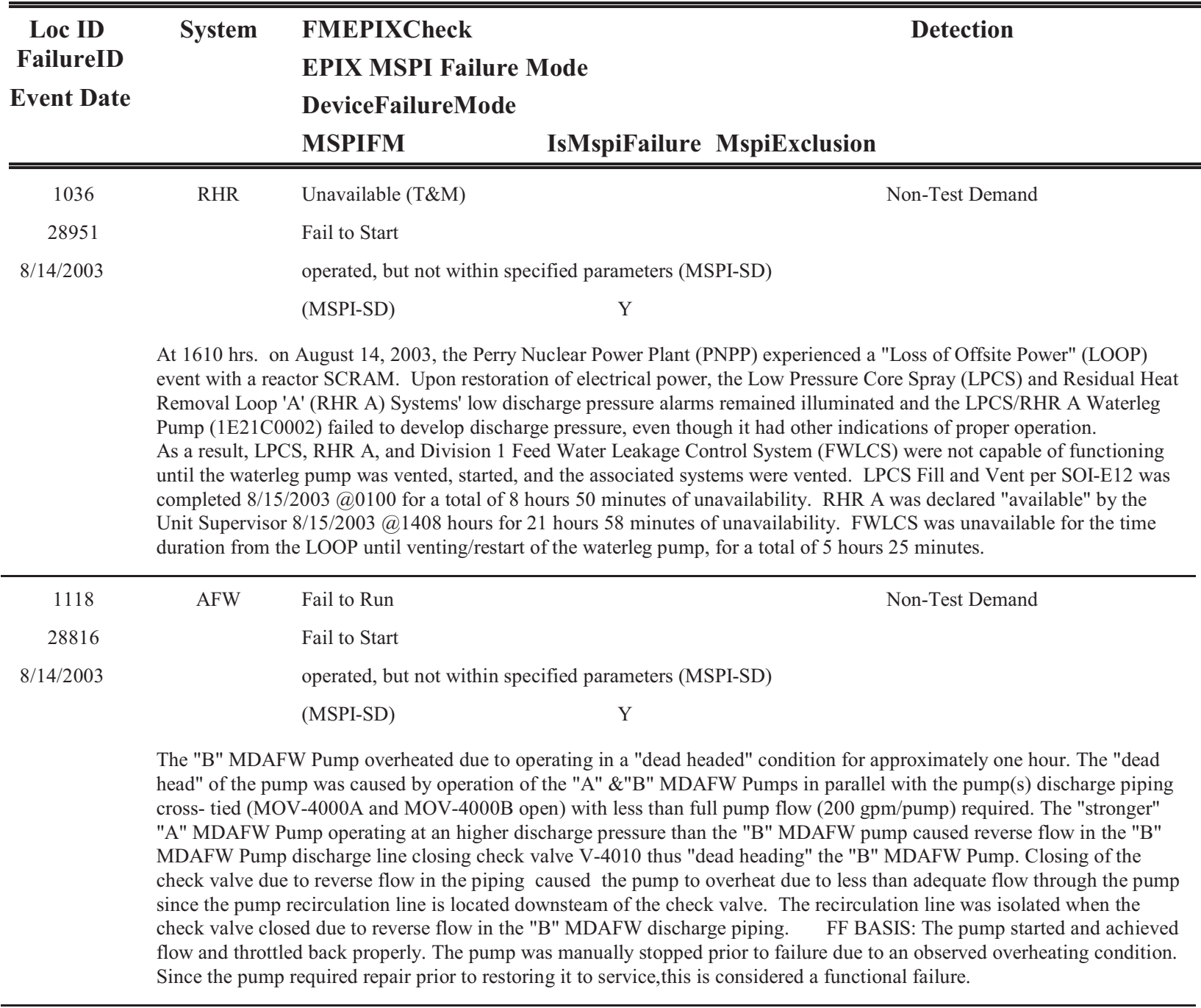




\section{Component Type $\quad$ MDP}

EPIX MSPI Failure Mode Fail to Start

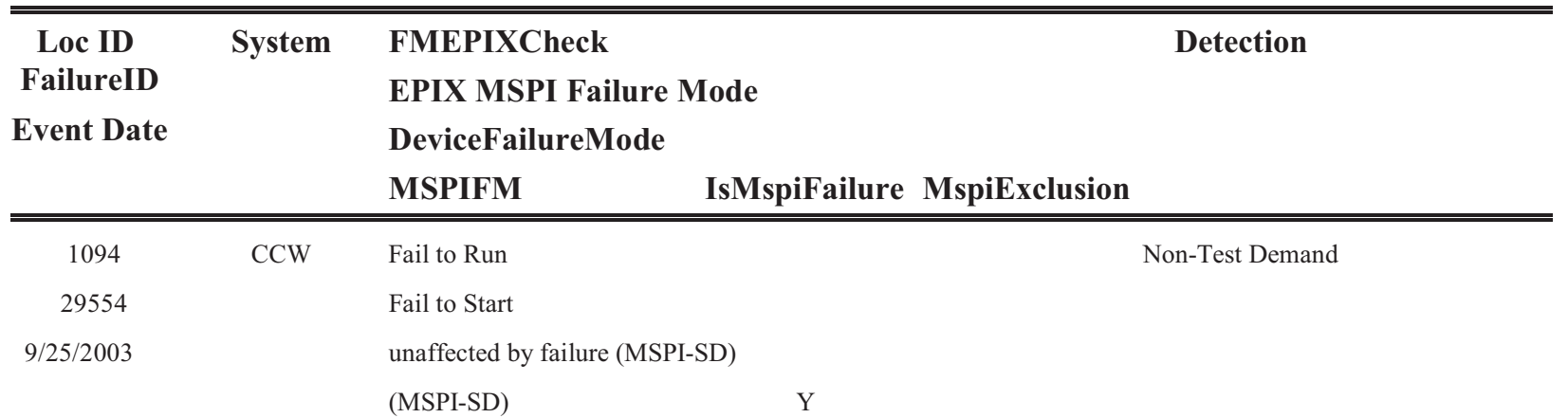

On 9/25/03 at 17:00 with NMP Unit 1 at 100 percent power, 12 RBCLC pump tripped unexpectedly. Computer points E166, A069, and B110 were received along with Control Room annunciators H1-2-1, H1-4-1, and F2-1-1 due to the reduction in flow. The ARP actions were taken to start 13 RBCLC pump and thus restore system parameters. After 13 RBCLC pump start, the computer points and annunciators cleared. The operator at the scene noted that the motor for 12 RBCLC pump was hot and there was an acrid odor present. The operator went to the breaker which has no flags and noted nothing abnormal.

The motor was troubleshot under GAP-PSH-10, Trouble shooting and testing. The resistance to ground was below one Meg $\mathrm{ohm}$ and the phase to phase resistance variance was approximately $17 \%$ [less than $10 \%$ required]. An as found inspection of the motor was performed with out disassembly. There was one section of windings that was darker in color. There was also indication of movement on the ties on the end turns of the windings. The motor was sent to Schulz for rewind, where a more extensive failure analysis was performed. The magnet wire was noted to be loose in the slot from the manufacturing process. When the motor was made it was Vacuum Pressure Impregnated [VPI] with epoxy, this should have filled the voids in the slot and kept the magnet wire rigid. With out a proper VPI, it appears the magnet wire was allowed to move in the slot, which abraded the insulation and caused the motor to fail prematurely turn to turn or turn to ground.






\section{Component Type $\quad$ MDP}

EPIX MSPI Failure Mode Fail to Start

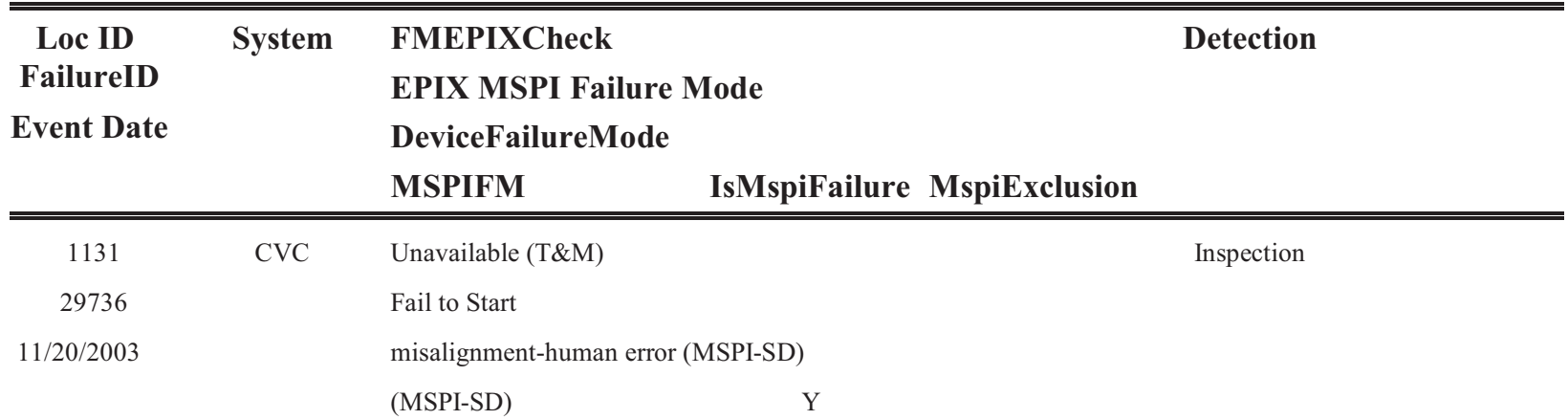

The 1B Centrifugal Charging Pump was tagged out of service when the 1B ERCW ESF Header was tagged. The Risk review of the schedule intended for the pump to remain available while the header was out of service. By tagging the CCP, U1 was placed in a white undefined condition for risk.

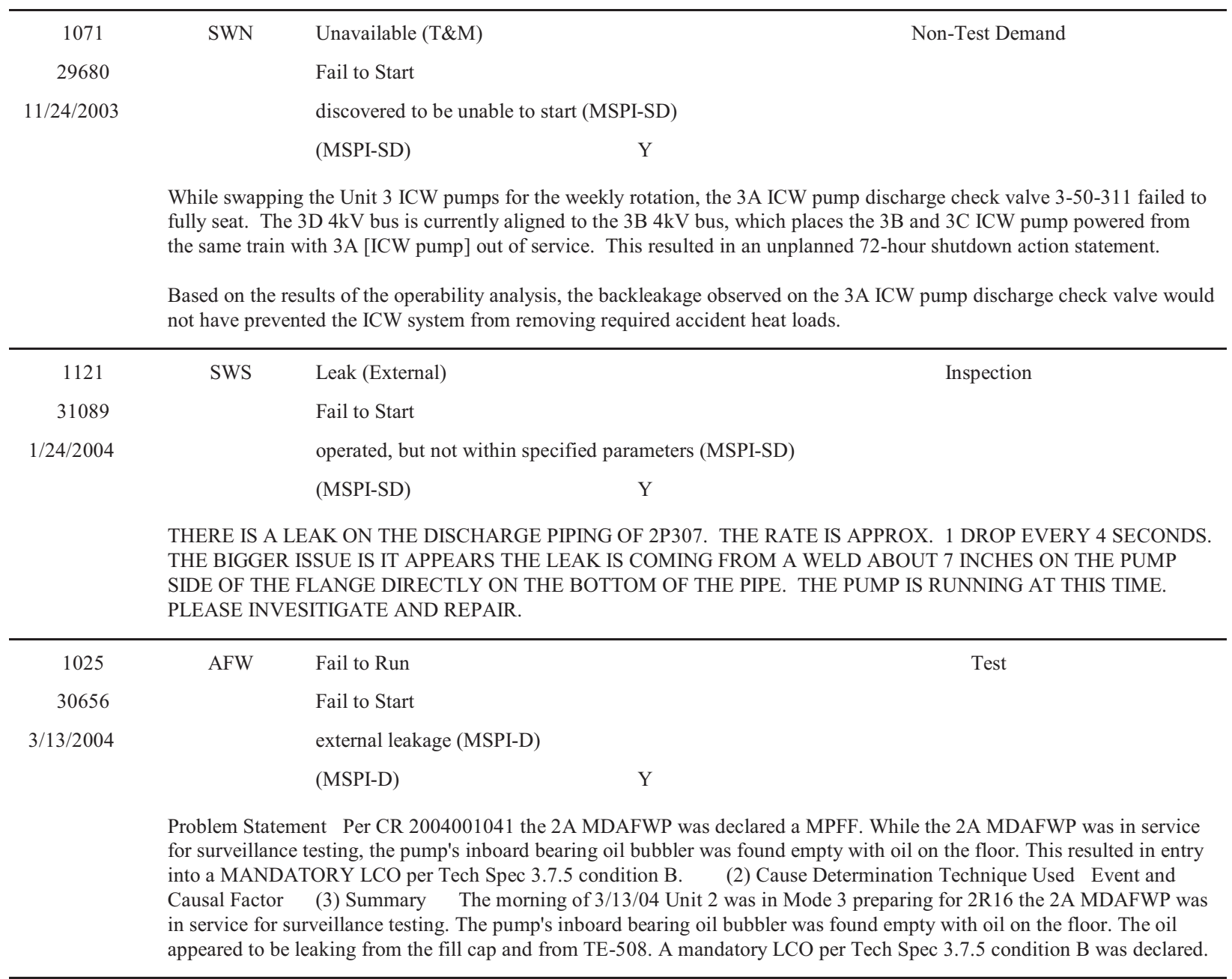




\section{Component Type $\quad$ MDP}

EPIX MSPI Failure Mode Fail to Start

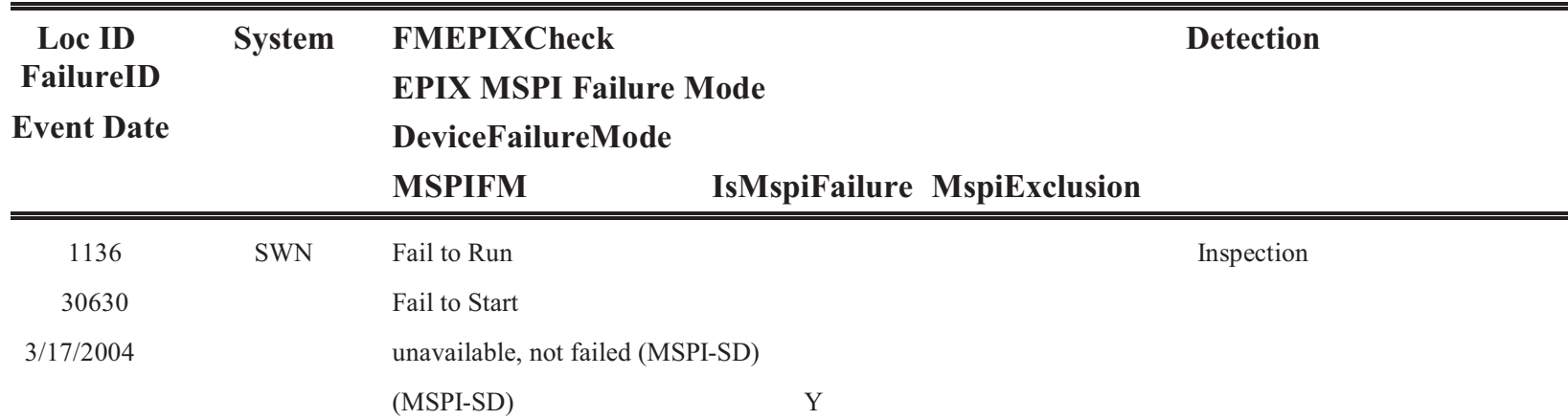

Oil leak found on the lower motor bearing on 1-SW-P-1A. The cause of the leak was determined to be from an o-ring that shrunk. The shrinkage was due to long term exposure to the bearing oil. The o-ring material is rated for use in oil environments but has a limited life. The o-ring should have been changed out before exceeding the end of life. $\square$ Analysis:In the morning of March 17, 2004, Electricians discovered an oil leak on 1-SW-P-1A-MOTOR that had not been in service for nearly three weeks. Disassembly of the motor later determined that an o-ring failed, leaving a 1/4" gap for the oil to leak by.

\begin{tabular}{|c|c|c|c|}
\hline 1075 & SWN & Fail to Run $<1 \mathrm{H}$ & Inspection \\
\hline 36060 & & \multicolumn{2}{|l|}{ Fail to Start } \\
\hline \multirow[t]{3}{*}{$5 / 5 / 2004$} & & \multicolumn{2}{|c|}{ tripped/stopped during warmup ( $<1 \mathrm{hr}$.) (MSPI-D) } \\
\hline & & (MSPI-D) & \\
\hline & \multicolumn{3}{|c|}{$\begin{array}{l}\text { When checking for leaks on 1P41F208D. Upon entering the intake noticed unusual smell, (like something was getting hot). } \\
\text { After checking for leaks on valve we investigated smell. Check motor and it was hot to the touch, checked other motors anc } \\
\text { they were about the same. Check oil levels found lower bearing oil level in normal range, also checked upper bearing oil } \\
\text { level and found it to be at bottom of site glass. Checked temperature gage on side of motor and it was } 80 \text { deg. Heard a high } \\
\text { pitch squealing noise and about the same time smoke started coming from the motor, had ops shut pump down. } \\
\text { This event is a functional failure. The event has been determined not to be maintenance preventable due to the oil levels } \\
\text { being marked incorrectly during the motor manufacturing process. }\end{array}$} \\
\hline 1074 & RHR & Unavailable (T\&M) & Test \\
\hline 31468 & & Fail to Start & \\
\hline \multirow[t]{3}{*}{$5 / 11 / 2004$} & & unaffected by failure & \\
\hline & & (MSPI-SD) & \\
\hline & \multicolumn{3}{|c|}{$\begin{array}{l}\text { Using this conservative methodology we find that sufficient quantity of transportable material was left in containment to } \\
\text { block the RHR sump screens beyond analyzed limits and may have prevented the RHA pumps from performing their safety- } \\
\text { related function post-LOCA. } \\
\text { The miscellaneous pieces of metal identified on were reviewed and considered to have negligible impact on containment } \\
\text { heat sink and hydrogen generation calculations and PCT calculations } \\
\text { CONSERVATISMS NOT INCLUDED IN EVALUATION } \\
\text { We did not factor into our evaluation the location of material in an attempt to determine if it would or wouldnt reach the } \\
\text { sump screens. Instead we considered that all transportable debris would reach the containment floor and ultimately reach } \\
\text { one of the four sumps. We assumed that this debris would rest flat and be distributed on the sump screen to obtain the } \\
\text { maximum blockage area. Finally, based on test results provided in support of GSI-191, it is likely that some of the debris } \\
\text { would have become lodged on obstructions on the way to the sum However, for this evaluation, all of the transportable } \\
\text { material was assumed to reach the sump. }\end{array}$} \\
\hline
\end{tabular}




\section{Component Type $\quad$ MDP}

EPIX MSPI Failure Mode Fail to Start

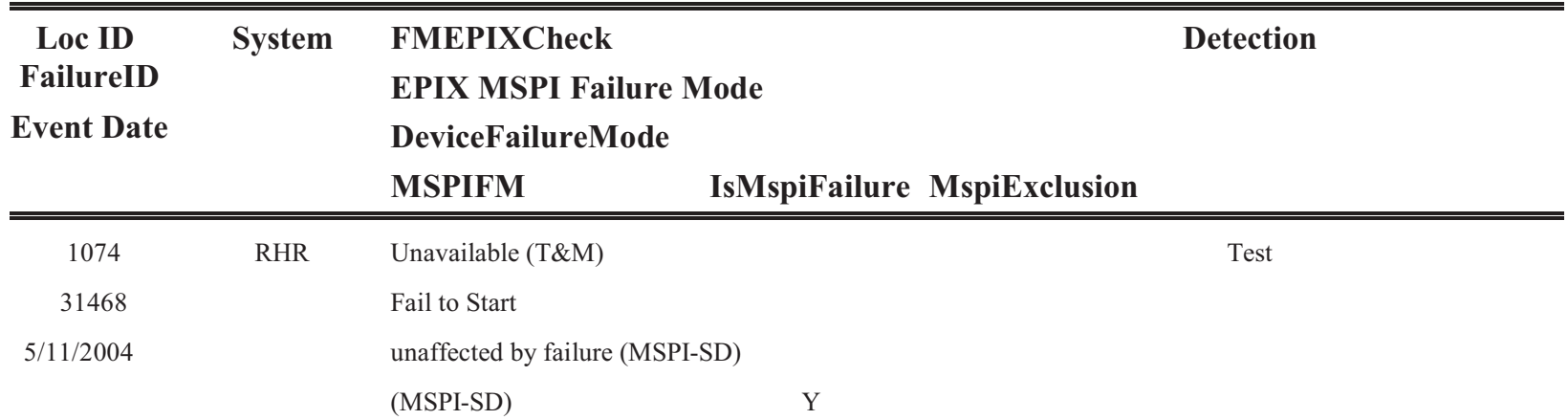

Using this conservative methodology we find that sufficient quantity of transportable material was left in containment to block the RHR sump screens beyond analyzed limits and may have prevented the RHA pumps from performing their safetyrelated function post-LOCA.

The miscellaneous pieces of metal identified on were reviewed and considered to have negligible impact on containment heat sink and hydrogen generation calculations and PCT calculations CONSERVATISMS NOT INCLUDED IN EVALUATION

We did not factor into our evaluation the location of material in an attempt to determine if it would or wouldnt reach the sump screens. Instead we considered that all transportable debris would reach the containment floor and ultimately reach one of the four sumps. We assumed that this debris would rest flat and be distributed on the sump screen to obtain the maximum blockage area. Finally, based on test results provided in support of GSI-191, it is likely that some of the debris would have become lodged on obstructions on the way to the sum However, for this evaluation, all of the transportable material was assumed to reach the sump.

SWN Unavailable (T\&M)
$\begin{aligned} & \text { Fail to Start } \\ & \text { ran, but failed to develop adequate flow/pressure (MSPI-D) } \\ & \text { (MSPI-D) }\end{aligned}$
During performance of 02-OHP-5030-019-002W, "West Essential Service Water System Flow Test" on 5/11/2004, 2-PP-7W
Unit 2 West Essential Service Water Pump was not able to produce adequate discharge pressure to pass the IST surveillance
test. The action value is 64.2 psid, with an alert range value of 65.6. The pump produced only 63.5 psid. The IST program
owner has verified these values. This failed surveillance led to pump being declared inoperable placing Unit 2 in the 72
hour action of TS 3.4.7.1.
After the pump was declared inoperable, a fault tree was started by a team consisting of members from System Engineering,
Production Engineering, Operations, and Maintenance. One identified fault was "impeller rubbing induced by low flow".
At this point the coupling gap adjustment was made and the pump then passed the operability test. Continuation of the fault
tree analysis was stopped at this point, since the apparent fault was discovered and corrected.
Per the maintenance rule evaluation of this CR, this did not result in a functional failure for the ESW Essential Service
Water system. This is based on the fact that the pump was still capable of performing its function (did not go below the
minimum operability limit) and it would have been able to meet is mission time of 30 days.




\section{Component Type $\quad$ MDP}

EPIX MSPI Failure Mode Fail to Start

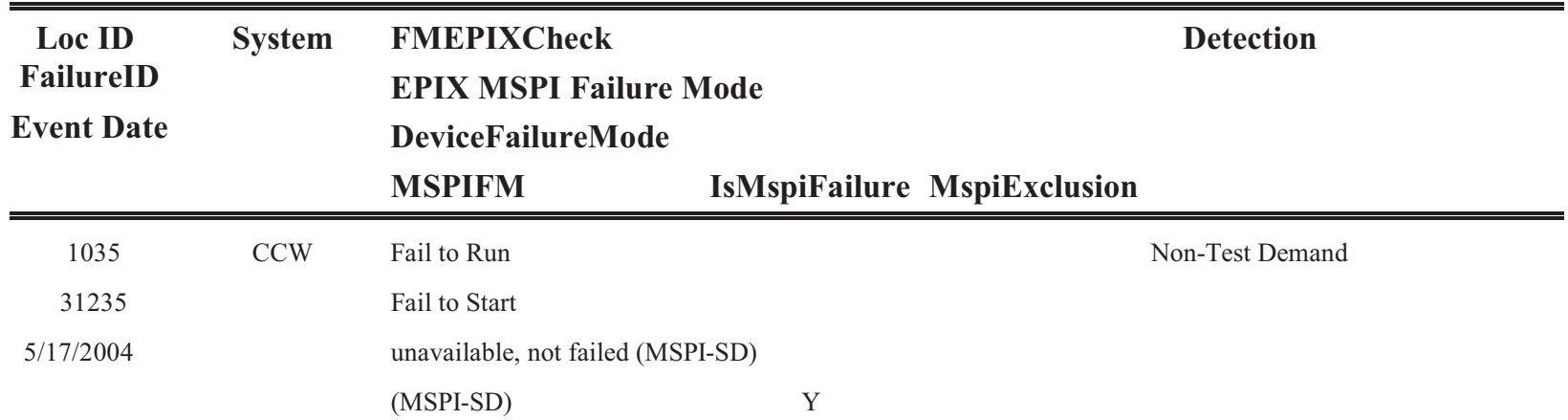

At 13:59 22 Component Cooling Water pump (22CCP) tripped on indication of over current (amber light). Multiple alarms on Control Room panel SG dealing with CCW flows and pressures momentarily annunciated and cleared. 21, and 22 CCWPs auto started. $480 \mathrm{~V}$ motor trip alarm remained up.

The direct cause of the motor failure was a phase-to-ground fault from coil insulation breakdown. According to Schulz Report N-9059-2, stator damage evidence of a turn-to-turn short existed, creating excessive currents that lead to heating and breakdown of motor insulation. The apparent cause for motor failure was a personnel error.

\begin{tabular}{|c|c|c|}
\hline 1129 & SWS & Unavailable (T\&M) \\
\hline 36541 & & Fail to Start \\
\hline \multirow[t]{3}{*}{$6 / 21 / 2004$} & & operated, but not within specified parameters (MSPI-SD) \\
\hline & & (MSPI-SD) \\
\hline & \multicolumn{2}{|c|}{$\begin{array}{l}\text { 06/21/04, the 2A RHR HEX outlet valve failed to open as required with the A2 pump in service during performance of step } \\
\text { 7.8.8 of 2-SI-4.5.C.1(3-COMP). } \\
\text { Cause Description: It was discovered that BKR } 52 \text { STA actuator arm set screw was loose. The set screw was tightened, } \\
\text { breaker installed and closed and the problem was alleviated. }\end{array}$} \\
\hline 1085 & SWN & Unavailable (T\&M) \\
\hline 31537 & & Fail to Start \\
\hline \multirow[t]{3}{*}{$6 / 27 / 2004$} & & ran, but failed to develop adequate flow/pressure (MSPI-D) \\
\hline & & (MSPI-D) \\
\hline & \multicolumn{2}{|c|}{$\begin{array}{l}\text { Based on the fault tree/support refute and the inspection performed, the most likely cause (apparent cause) of the pump } \\
\text { problem is that some foreign material was sucked up against the suction bell on the ESW pump causing the pump discharge } \\
\text { pressure and flow to decrease. When the ESW pump was turned off to prepare for replacement, the foreign material on the } \\
\text { suction of the pump was apparently pushed back into the forebay by the water draining back from the pump discharge } \\
\text { strained. Based on flow patterns in the screen house forebay the foreign material has probably moved over towards the Unit } \\
2 \text { Circulating Water pumps and is in some low flow area in the forebay or it has been sucked up by the Unit } 2 \text { Circulating } \\
\text { Water pumps and is not causing any problems. }\end{array}$} \\
\hline
\end{tabular}




\section{Component Type $\quad$ MDP}

EPIX MSPI Failure Mode Fail to Start

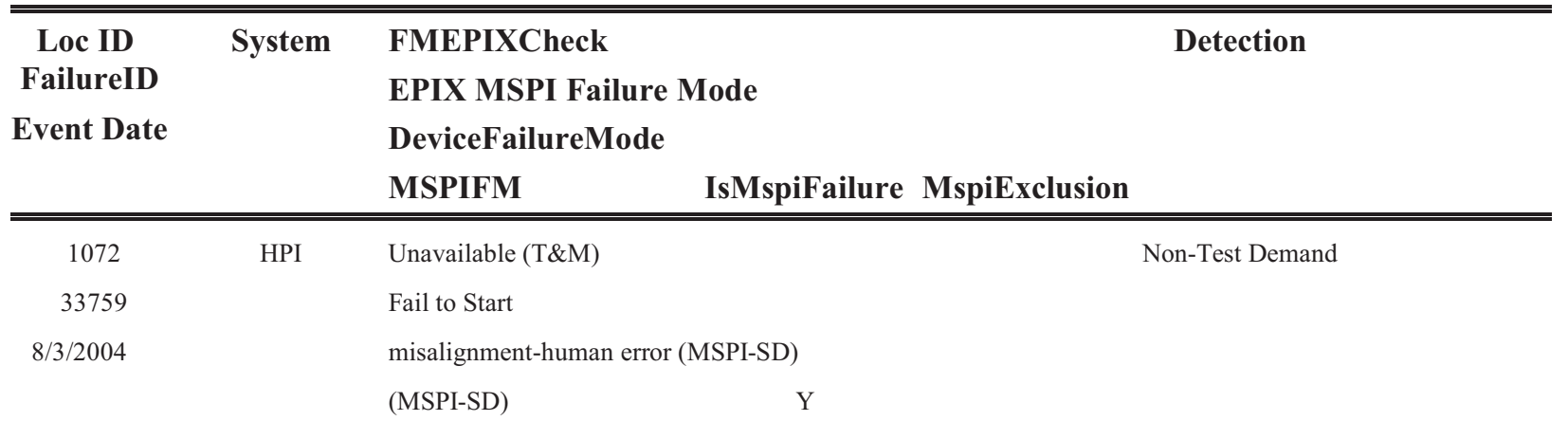

High-Press Inj Pump 4P215B/SISPUMP misalignment-human error. 4B HHSI Pump Outboard Bearing Oil Leak.

An oil leak in the outboard bearing housing would have caused the pump to lose sufficient amounts of oil during a 30 day mission time such that the pump would have eventually ceased to rotate.

The ongoing investigation identified during disassemble that evident damage to the thrust ring existed due to the antirotation pin not being properly aligned into the slot during the previous overhaul (workmanship, human performance error) In addition, the as-found gaskets from the inboard and outboard sides of the thrust bearing housing were sent to an outside lab for analysis. Also, new gaskets were sent for to the lab comparative analysis. The results indicate that the old gasket material was chemically different than the new gaskets. This seems to indicate that during the past overhaul incorrect gasket material was used. Although it is inconclusive as to when the material was added, what is known is that during the past overhaul in 1994 (ref. WO 94000737-01), there is no evidence that new gaskets were issued and used during the pump overhaul. This leads to two conclusions; one, that the old gaskets were reused and were incorrect, or two, that the gaskets were fabricated from incorrect material.

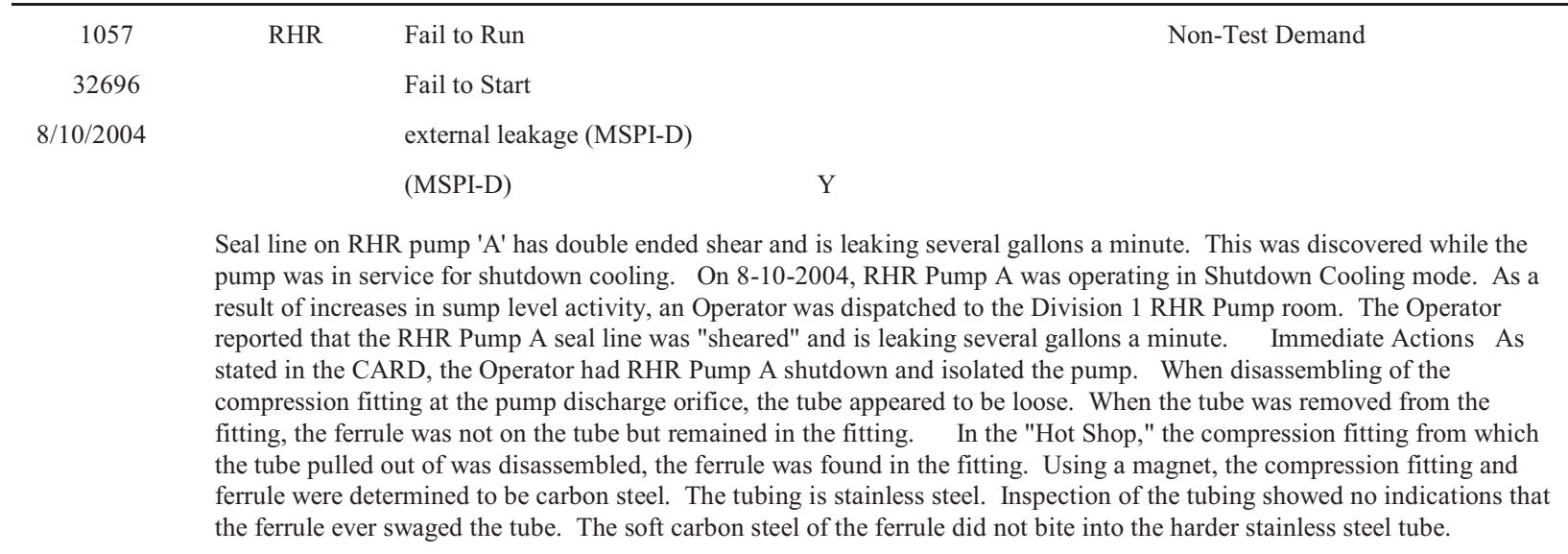

\begin{tabular}{|c|c|c|c|}
\hline 1071 & SWN & Unavailable (T\&M) & Non-Test Demand \\
\hline 33803 & & \multicolumn{2}{|l|}{ Fail to Start } \\
\hline \multirow[t]{3}{*}{$10 / 2 / 2004$} & & \multicolumn{2}{|l|}{ discovered to be unable to start (MSPI-SD) } \\
\hline & & (MSPI-SD) & \\
\hline & $\begin{array}{l}\text { le sway } \\
\text { Intake }\end{array}$ & $\begin{array}{l}\text { ICW Pp.s on Unit } 3 \text {, the } 3 \mathrm{~B} \text { ICW pump disch } \\
\text { tor reported the pump to be rotating backwar }\end{array}$ & $\begin{array}{l}\text { d not seat upon stopping the pump. } \\
\text { en stopped. }\end{array}$ \\
\hline
\end{tabular}




\section{Component Type $\quad$ MDP}

EPIX MSPI Failure Mode Fail to Start

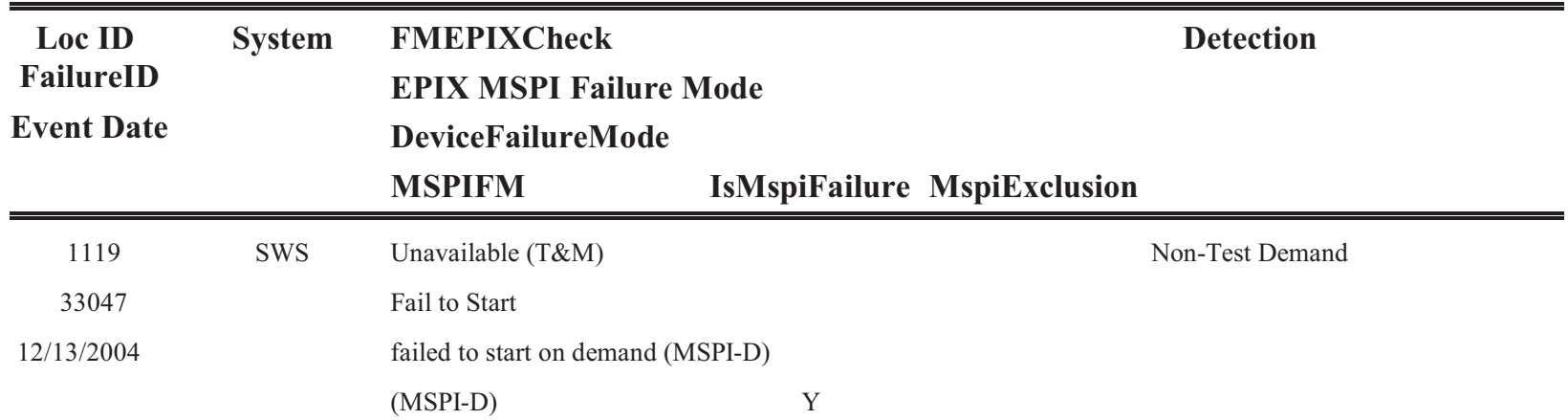

While attempting to rack up the "C" SW Pump breaker (XSW1EB 02) to support tagging out the "B" SW Pump for scheduled maintenance, Operations personnel noted that the charging springs failed to charge when the breaker was racked up.

\begin{tabular}{rlll}
\hline 1135 & CCW & Fail to Run & Inspection \\
34196 & Fail to Start & \\
$1 / 10 / 2005$ & misalignment-human error (MSPI-SD) \\
& (MSPI-SD) $\quad$ Y
\end{tabular}

At approximately 0050 on 1/10/05, the B CCW pump was secured. Grease was found coming from the coupling area of the pump. Per the SS turnonver, once the pump was secured, the grease was cleaned up.

An EFIN Engineer and the System Engineer walked down the pump at approximately 0715. Piles of greases were observed in the pump base and under the coupling guard (see atached photographs). Presumably, the piles slid off of the guard after the previous cleaning. However, not knowing the exact cause, the pump was placed in pull-to-lock and declared inoperable. While performing 05101114, Maintenance personnel could not determine if the gasket was between the coupling halves. They loosened the bolting enough to make the decision. They found the 3/8" coupling gap disk material had been installed such that it was smashed between the bolted coupling halves during performance of P718978 (see attached photographs). The gasket was torn with the excess material between the halves.

\begin{tabular}{|c|c|c|c|}
\hline 1084 & $\mathrm{CVC}$ & Fail to Run & Non-Test Demand \\
\hline 33818 & & \multicolumn{2}{|l|}{ Fail to Start } \\
\hline \multirow[t]{5}{*}{$1 / 13 / 2005$} & & \multicolumn{2}{|c|}{ operated, but not within specified parameters (MSPI-SD) } \\
\hline & & (MSPI-SD) & Y \\
\hline & \multicolumn{3}{|c|}{$\begin{array}{l}\text { Condition report CR } 05013003 \text { was written on } 1 / 13 / 2005 \text { for abnormal flow rates and high motor amps on the Unit } 1 \text { West } \\
\text { Centrifugal Charging pump, component number 1-PP-50W. }\end{array}$} \\
\hline & \multicolumn{3}{|c|}{$\begin{array}{l}\text { This condition was identified during normal operation of the pump. The pump was declared Inoperable because of the } \\
\text { abnormal flow rates and high motor amps. }\end{array}$} \\
\hline & \multicolumn{3}{|c|}{$\begin{array}{l}\text { System conditions observed included increase of motor amps from normal values ( } \sim 57 \text { amps) to } 75 \text { amps with amperage } \\
\text { swings of } 6 \text { to } 8 \text { amps. The level in the Pressurizer (component 1-OME-4) was noted to be lowering. Charging system flow } \\
\text { rate was also noted to be lowering. }\end{array}$} \\
\hline
\end{tabular}




\section{Component Type $\quad$ MDP}

EPIX MSPI Failure Mode Fail to Start

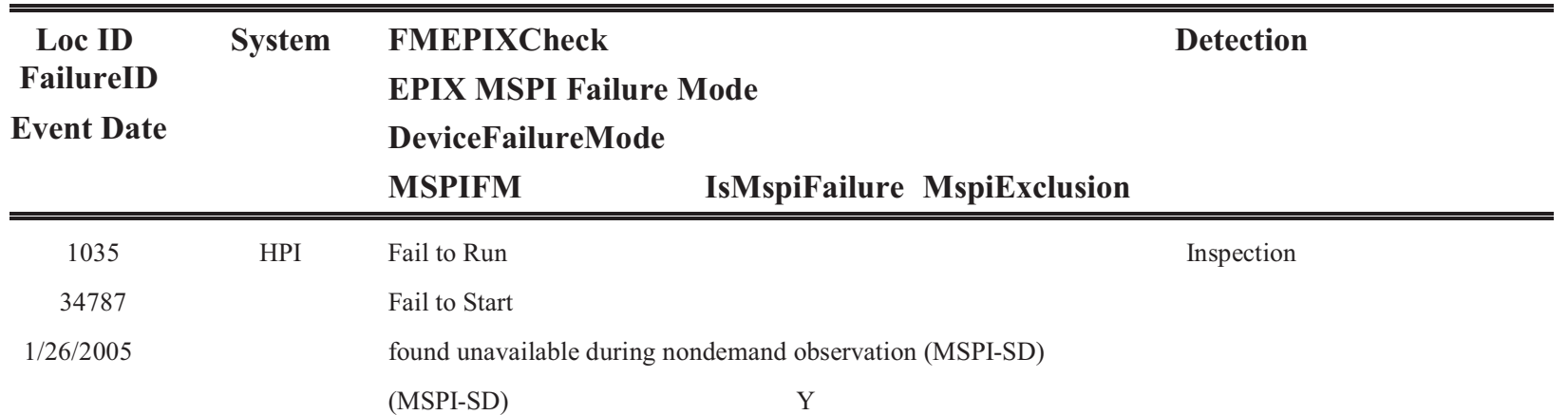

On February 18, 2005, while in mode 1 at $100 \%$ power, engineering analysis determined that the 23 Safety Injection Pump had been inoperable for an indeterminate period between the successful pump surveillance on 12/24/04 and 01/27/05 when gas was vented from the 23 SI pump casing due to gas build-up within the casing.

\begin{tabular}{rll}
\hline 1057 & RHR & Fail to Run $<1 \mathrm{H}$ \\
34254 & Fail to Start & Non-Test Demand \\
$2 / 4 / 2005$ & tripped/stopped during warmup (<1 hr.) (MSPI-D) \\
& (MSPI-D) & Y
\end{tabular}

The EIT performed a Causal and Effects analysis and determined the Root Cause of the event to be air in the RHR piping. The cause of the pump trip was a pressure spike generated due to air in the RHR piping.

The air was introduced into the system on 1-25-2005 due to the mis-alignment of the Division 2 RHR pump suction valves during the fill and vent evolution per SOP 23.205.

Follow-up discussion with the NRC resulted in a request to address the potential that a pump runout condition can result in an overcurrent trip of the motor. In addition, air could have accumulated in the 18"diameter elbow located between the RHR header and valves E1150-F028A and E1150-F028B and was not vented. The NRC requested the impact this potential air void would have on the RHR piping system.

As a result of these questions, an analysis was performed, TMSA-05-0025, that evaluated the impact this potential air void could have during LPCI and Suppression Pool Cooling operations. The overall analysis concluded that both LPCI and Suppression Pool Cooling would have remained fully operational assuming either modes were initiated when air voids were present in the system.

The operability assessment was revised to address the NRC's concern about the potential trip of the motor during pump runout conditions. The assessment also included the potential air void in the $18^{\prime \prime}$ diameter elbow that was not vented. Corrective actions, including both procedural and training enhancements, for the Human Performance issues that resulted in the air being admitted to the RHR system are being addressed in CARD 05-20760.

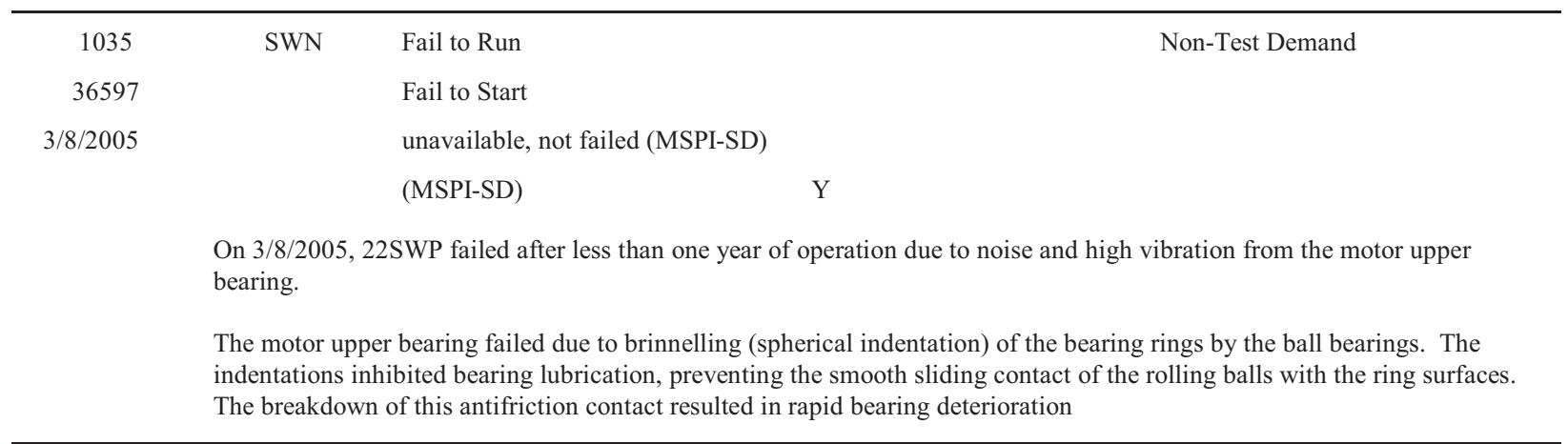




\section{Component Type MDP}

EPIX MSPI Failure Mode Fail to Start

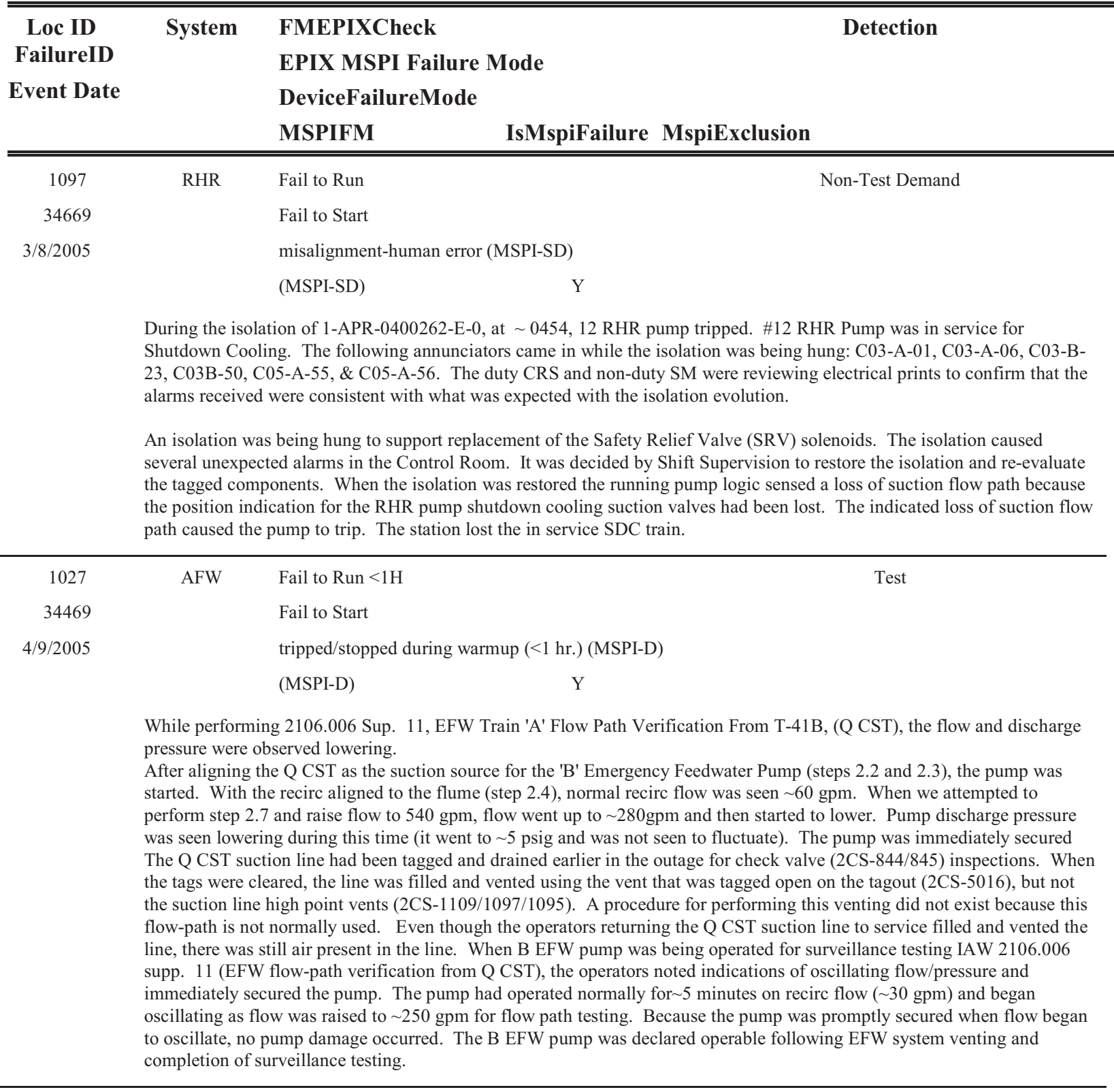




\section{Component Type $\quad$ MDP}

EPIX MSPI Failure Mode Fail to Start

\begin{tabular}{cclc}
\hline \hline Loc ID & System & FMEPIXCheck & Detection \\
FailureID & & EPIX MSPI Failure Mode & \\
Event Date & & DeviceFailureMode \\
& MSPIFM & IsMspiFailure & MspiExclusion \\
\hline \hline 1053 & SWS & Fail to Run $<1 \mathrm{H}$ & Non-Test Demand \\
35573 & & Fail to Start \\
$4 / 14 / 2005$ & & tripped/stopped during warmup $(<1 \mathrm{hr}).($ MSPI-D $)$ & \\
& & Y MSPI-D)
\end{tabular}

1D RHRSW Pump tripped after running 4 sec. Troubleshooting was performed under WO 793632. No equipment failure has been identified.

Statement of Cause:

The following is the write-up of the AT 324585-02 - Review conclusions of Troubleshooting pkg-WO 793632-01:

The purpose of this assignment is to document the engineering review of the troubleshooting performed under W0 793632-01 "Trip of the 1D RHR Service Water Pump on 04/14/05".

The Electrical Maintenance Department (EMs) performed troubleshooting at the 901-3 and 901-33 panels. Voltage measurements were taken at various points in the trip circuit, as defined in WO 793632-01. The test data did not indicate the suspected source of the trip. The 1D RHR Service Water Pump Motor was tested in accordance with MA-AA-723-330 "Electrical Testing of AC Motors Using Baker Instrument Advanced Winding Analyzer". Test results indicated no degradation to the motor. The protective relays were tested and had calibrations verified per WO 801430-01. No adverse conditions were identified while performing the calibration checks. While extensive tro

\begin{tabular}{|c|c|c|c|}
\hline 1113 & SWS & Fail to Run & Inspection \\
\hline 34757 & & Fail to Start & \\
\hline \multirow[t]{3}{*}{$5 / 6 / 2005$} & & \multicolumn{2}{|c|}{ operated, but not within specified parameters (MSPI-SD) } \\
\hline & & (MSPI-SD) & $\mathrm{Y}$ \\
\hline & \multicolumn{3}{|c|}{$\begin{array}{l}\text { During shutdown of the "A" ESW Pump following TST-104, the assigned NPO noticed that the packing gland sleeve was } \\
\text { intermittently rotating on the pump shaft. After discussions with PCE engineers it was determined that it was the packing } \\
\text { sleeve that was intermittently rotating and that the sleeve was displaced above the pump gland. This condition was } \\
\text { previously observed, documented, and evaluated in CR-JAF-2005-04625 in October, 2004. This previous CR documented } \\
\text { that the shaft sleeve had risen approx. } 2 \text { inches above the pump packing gland. Today's observation determined that the } \\
\text { sleeve had risen another } 3 \text { inches above the packing gland. }\end{array}$} \\
\hline 1029 & CSR & Fail to Run & Test \\
\hline 34880 & & Fail to Start & \\
\hline \multirow[t]{3}{*}{$5 / 10 / 2005$} & & tripped/stopr & hr.) (MSPI-D) \\
\hline & & (MSPI-D) & $\mathrm{Y}$ \\
\hline & \multicolumn{3}{|c|}{$\begin{array}{l}\text { On May 10, 2005, while operating on mini-flow recirculation for the performance of ECCS leakage surveillance testing per } \\
\text { 40ST-9SI09, the Unit } 2 \text { Containment Spray Pump A (2MSIAP03) tripped on an } 86 \text { ground fault. During troubleshooting } \\
\text { activities for the identified, faulted, pump motor cable under Work Order } 2798843 \text {, it was noticed that the ground could be } \\
\text { eliminated by wiggling the cable in the termination box. This indicated that the ground was near the end of the cable, } \\
\text { possibly inside the Armored Terminator. }\end{array}$} \\
\hline
\end{tabular}




\section{Component Type $\quad$ MDP}

EPIX MSPI Failure Mode Fail to Start

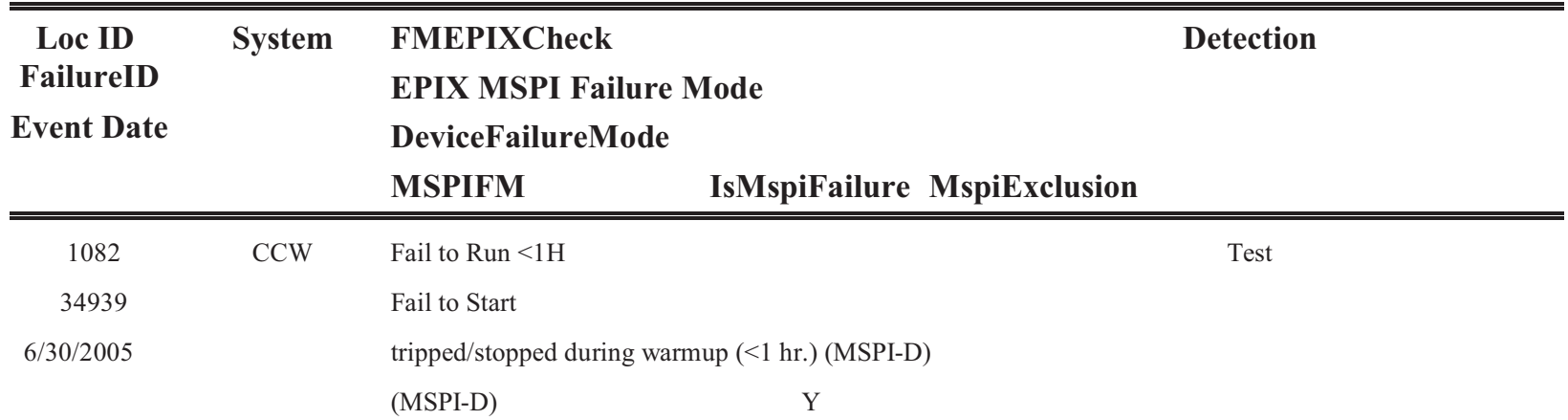

CCW PUMP 2C TRIPPED WHILE THROTTLING FLOW DOWN TO 9000 GPM. THE PUMP BREAKER OPENED UNEXPECTEDLY DUE TO A SPURIOUS ACTUATION OF THE COMPONENT COOLING WATER PUMP 2C OVERCURRENT 50/51 RELAY TIME DEVICE. THE RELAY WAS REMOVED AND SENT TO THE VENDOR FOR A FAILURE ANALYSIS SINCE A SPECIFIC REPEATABLE FAILURE IN THE RELAY SUB-COMPONENT(S) COULD NOT BE IDENTIFIED. THIS IS A MRFF SINCE THIS CONDITION CAUSED A LOSS OF A GQA AND PSA HIGH RISK RANKED FUNCTION OF CIRCULATING COOLING WATER. HISTORY REVEALS NO OTHER SIMILIAR FAILURE HAS OCCURRED WITHIN THE LAST 2 YEARS. CORRECTIVE ACTIONS: REPLACED RELAY AND CALIBRATED PER 0PMP05-ZE-0037.

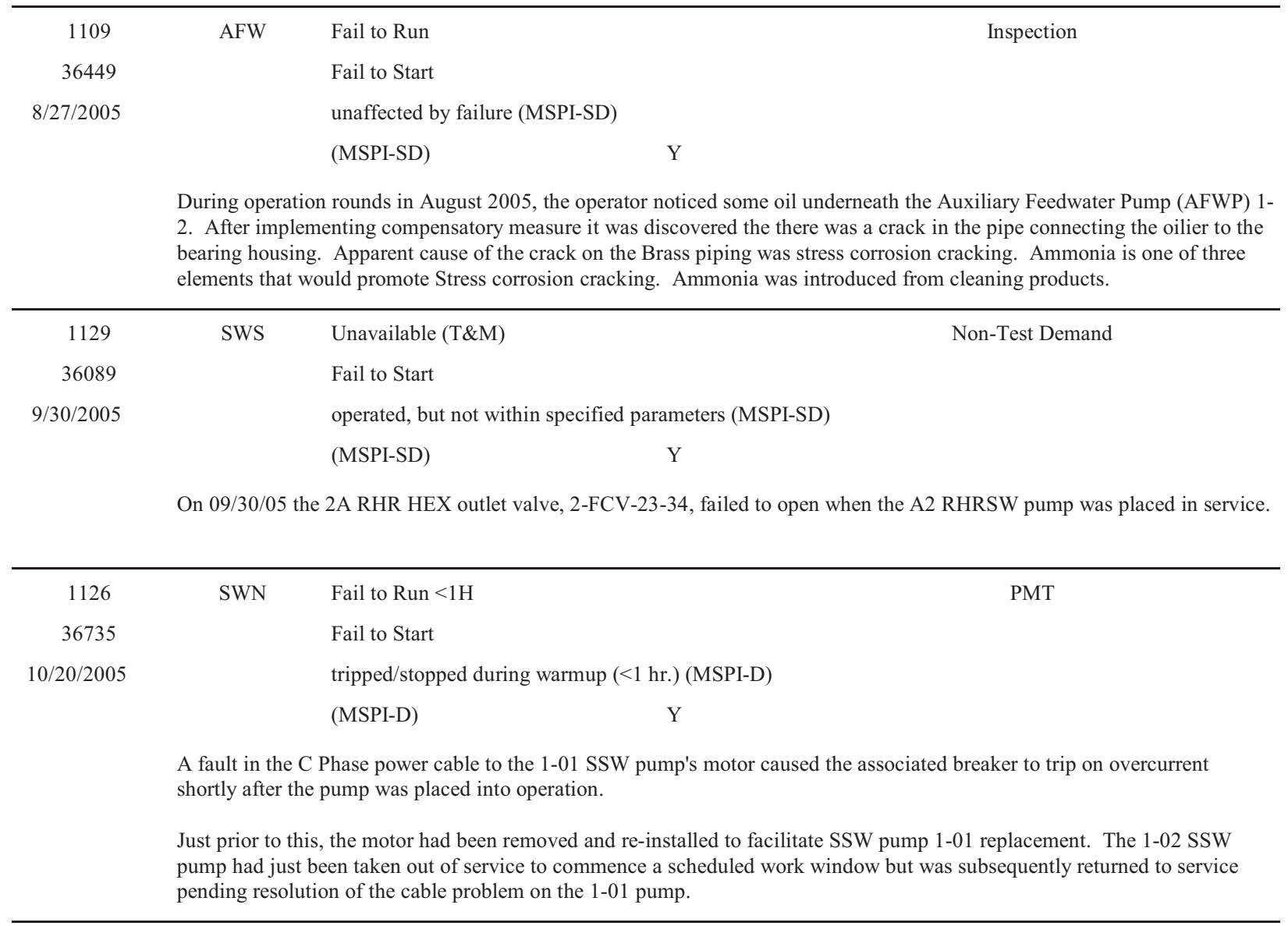




\section{Component Type MDP}

EPIX MSPI Failure Mode Fail to Start

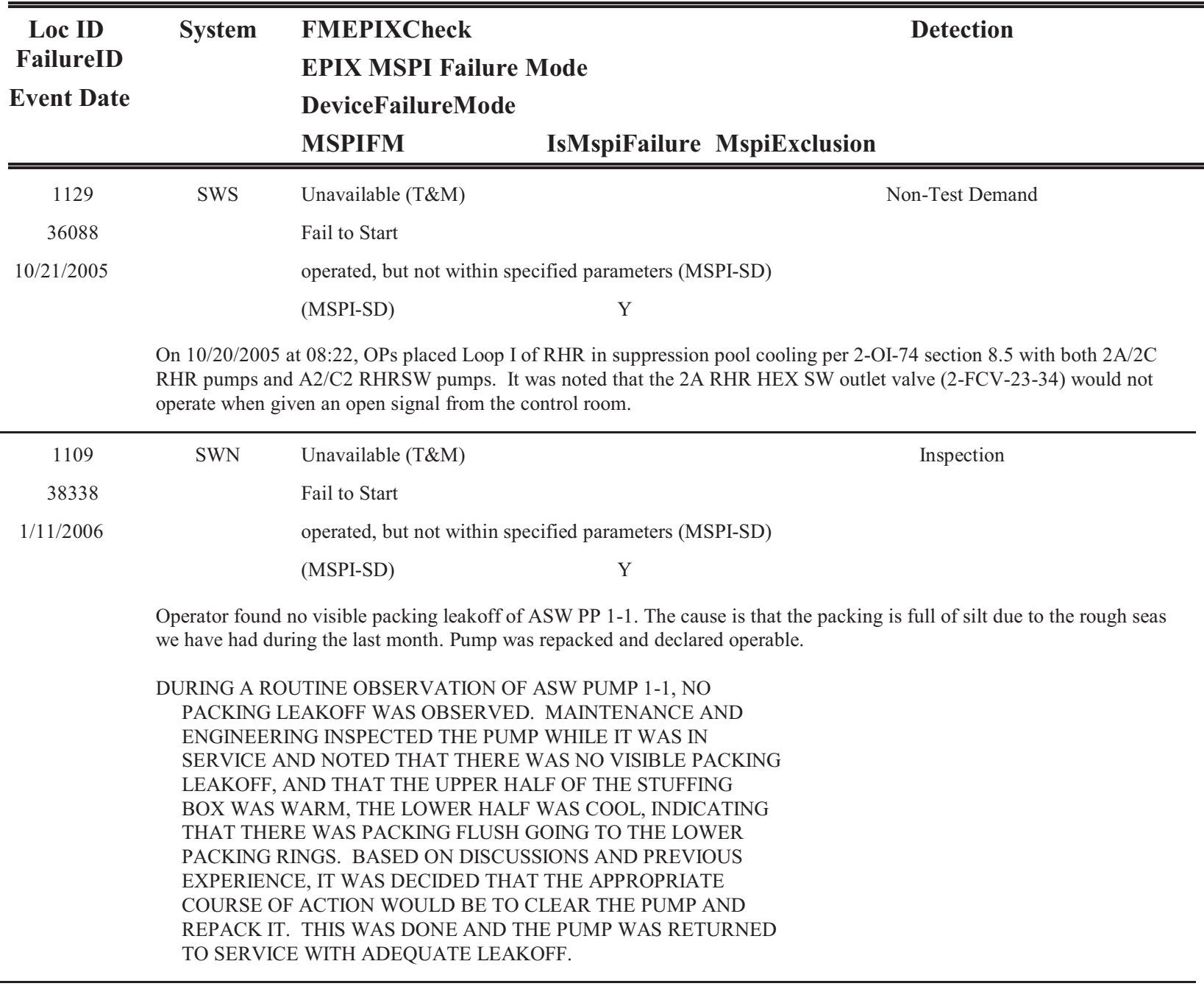




\section{Component Type $\quad$ MDP}

EPIX MSPI Failure Mode Fail to Start

\begin{tabular}{cclc}
\hline \hline Loc ID & System & FMEPIXCheck & Detection \\
FailureID & & EPIX MSPI Failure Mode & \\
Event Date & & DeviceFailureMode & \\
& & MSPIFM & Inspection \\
\hline \hline 1137 & HPI & Unavailable (T\&M) & \\
37904 & & Fail to Start & \\
$1 / 11 / 2006$ & & corrective maintenance prior to failure (MSPI-SD) & Y \\
& & (MSPI-SD)
\end{tabular}

The high vibrations that were detected at the pump were actually caused by the speed increaser. The speed increaser had been rebuilt and placed in-service four days prior to the high vibrations being detected. Disassembly and inspection of the speed increaser have determined that the high speed gear and bearings were wearing excessively in the journal areas. Maintenance changes the oil in the speed increaser every three years. Procedure 0-MPM-0103-01 does not instruct the craft to drain the oil from the oil cooler. With the oil cooler being mounted lower than the speed increaser on the pump skid, draining the oil in the speed increaser does not drain the oil from the oil cooler. This allowed dirty oil to stay in the system. The oil system of the speed increaser is a closed system that holds approximately fifteen gallons of oil. The debris that was found in the oil strainer as described in PI \#2006-0197 was most likely caused by wear materials from the bearings and shaft of the speed increaser. The relatively small quantity of oil in the closed loop system continuously cycled the debris through the system.

The new bearings installed in the speed increaser are typically field fitted (scraped) to ensure proper contact and clearances are obtained. The new bearings installed into the speed increaser were measured and blue checked and found to be in satisfactory condition for installation in accordance with the procedure as it was written. No scraping was done on the failed speed increaser bearings. Previous overhauls of other speed increasers have required several shifts needed to scrape the bearings to acceptable tolerance to pass a blue check. This may have led to tighter shaft clearances than is normal for the bearings. Debris in the old oil that was left in the oil cooler along with the tighter clearances associated with the new bearings appears to have caused the damage to the bearings and the shafts.

\begin{tabular}{clll}
\hline 1093 & CVC & Fail to Run $<1 \mathrm{H}$ & Test \\
37833 & & Fail to Start & \\
$1 / 24 / 2006$ & failed to start on demand (MSPI-D) & \\
& & (MSPI-D) & Y
\end{tabular}

The Unit 3 "B" charging pump was started on 1/24/06 for a surveillance run following maintenance activities. The pump ran for approximately 25 seconds before tripping on overcurrent. During the brief run, thrust bearing temperature spiked above $200 \mathrm{~F}$, and steam or mist was observed coming from the pump inboard seal.

The pump's lube oil filter assembly was opened and some non-ferrous metal particles were evident. Further disassembly of the pump revealed thrust bearing damage and a sheared pump shaft.

\begin{tabular}{|c|c|c|c|}
\hline 1110 & SWN & Unavailable (T\&M) & Non-Test Demand \\
\hline 38333 & & \multicolumn{2}{|l|}{ Fail to Start } \\
\hline \multirow[t]{3}{*}{$3 / 7 / 2006$} & & \multicolumn{2}{|c|}{ operated, but not within specified parameters (MSPI-SD) } \\
\hline & & (MSPI-SD) & \\
\hline & \multicolumn{3}{|c|}{$\begin{array}{l}\text { While performing the weekly ASW pump swap per operating procedure E-5:IV, it was discovered that the pump had no } \\
\text { leakoff flow. } \\
\text { The packing rings removed from this pump were found to be saturated with silt and other fine mtl. } \\
\text { The pump was repacked and returned to service with adequate leakoff. }\end{array}$} \\
\hline
\end{tabular}




\section{Component Type MDP}

EPIX MSPI Failure Mode Fail to Start

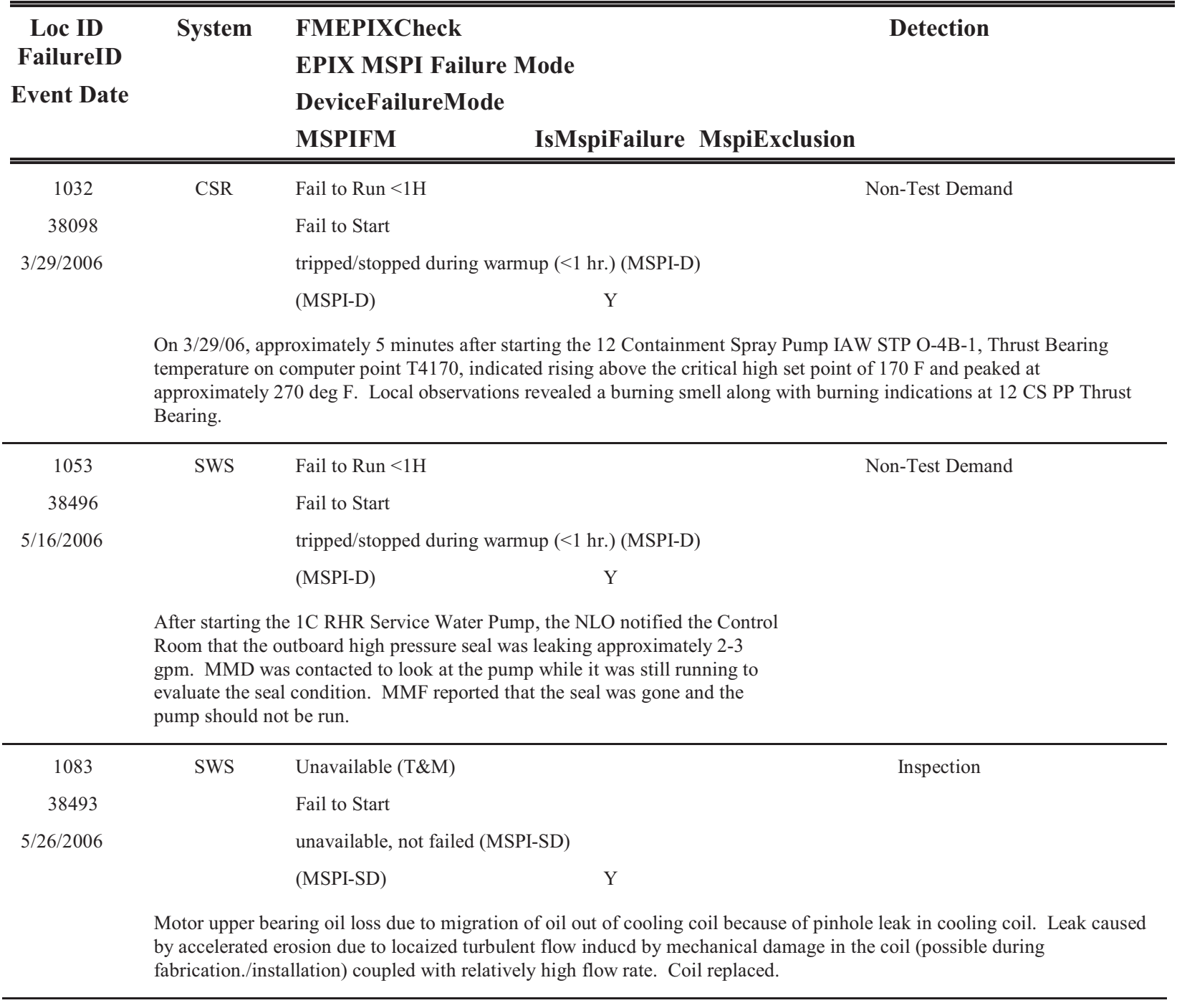




\section{Component Type $\quad$ MDP}

EPIX MSPI Failure Mode Fail to Start

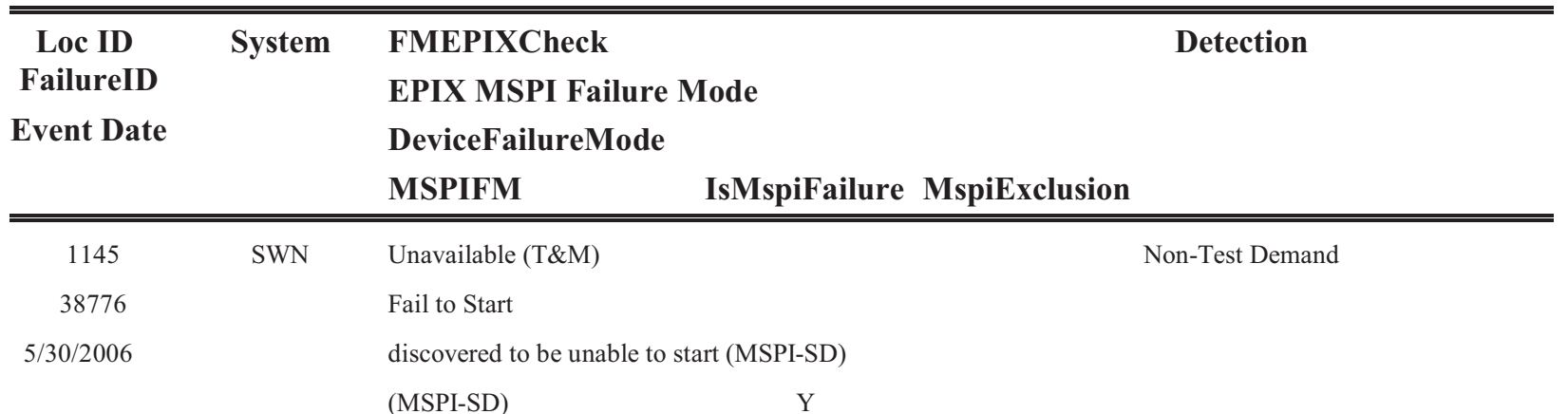

On 05/30/06@ 0934, while performing a Tagout of SW(T)-261Service Water Pumps Seal Water Regulator, SW-43B1 the Backup Seal Water Regulator for Service Water Pump B1 did not provide any Seal Water Flow or Pressure. Service Water Pump 1B1 and Service Water Train B was declared INOPERABLE. The cause of the failure was attributed to iron deposit buildup in the regulator and the regulator outlet piping, resulting in a failure of the regulator to supply flow as designed.

At 09:34 on 5/30/2006, with Kewaunee Power Station at 100 percent power, the backup safety-related bearing lube water supply to service water pump B1 was discovered to be inoperable, making both service water pump B1 and service water train B inoperable. Maintenance was performed, service water pump B1 was returned to service, and both the pump and train B were declared operable at $15: 31$ on 5/30/2006. The inoperability is assumed to have existed since the regulator was last demonstrated operable at 21:07 on 4/16/2006. During that 43.5 days of inoperability, the plant was at power twice (once for 10 days and once for 8 days). Also during that time, various Train A engineered safety features were concurrently inoperable. The direct cause of the safety-related bearing lube water flow disruption for service water pump B1 was the service water backup lube water supply pressure regulator stem sticking in the stem guide bushing as a result of contaminants from the plant equipment water lube supply adhering to the stem. Inspection of the plant equipment water system found the filter tanks and internal components severely corroded allowing water and contaminants to bypass the cartridge filters. This condition developed because the original plant equipment water cartridge filter retaining cup material was not suitable for the application and inadequate maintenance practices failed to identify and correct the issue.

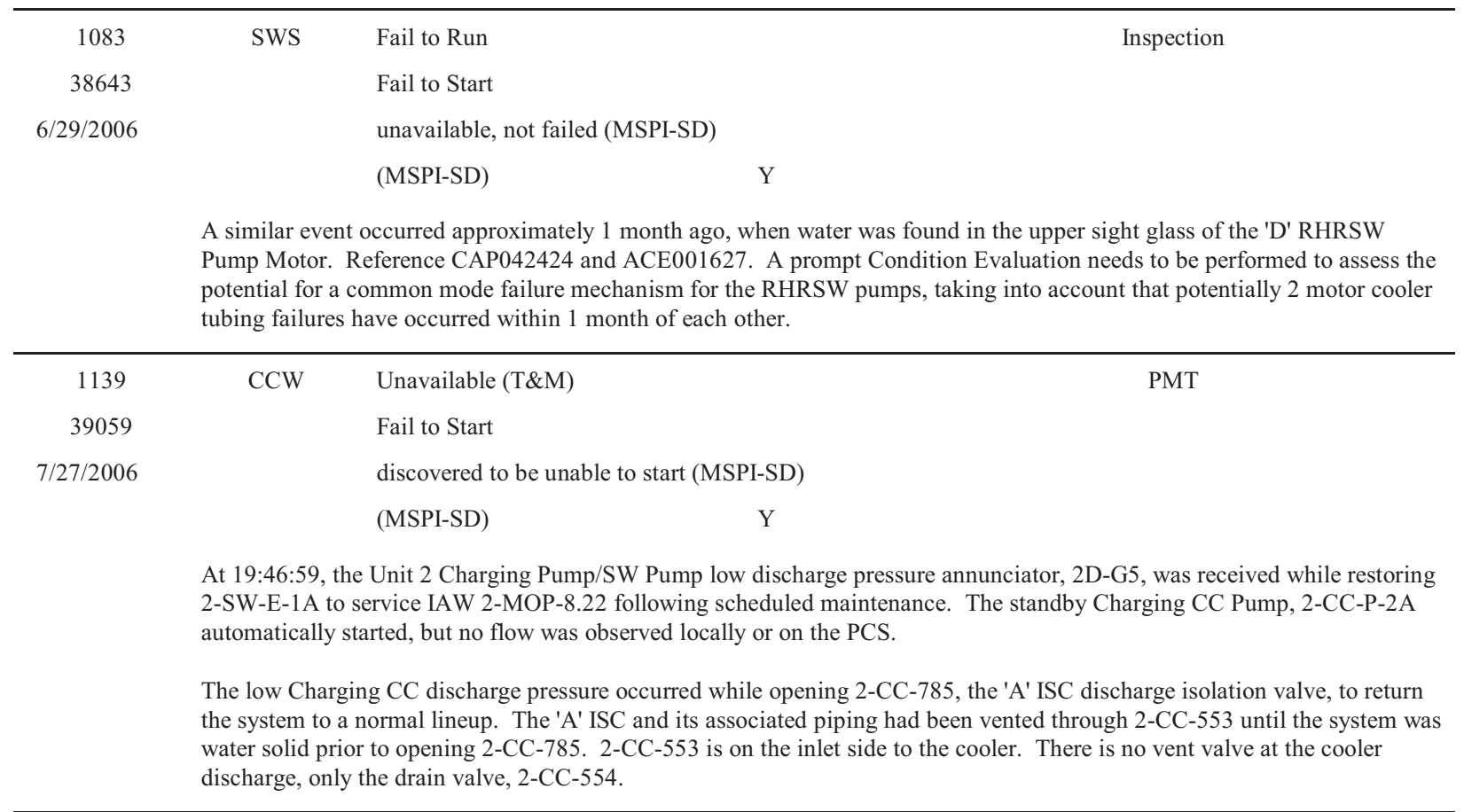




\section{Component Type $\quad$ MDP}

EPIX MSPI Failure Mode Fail to Start

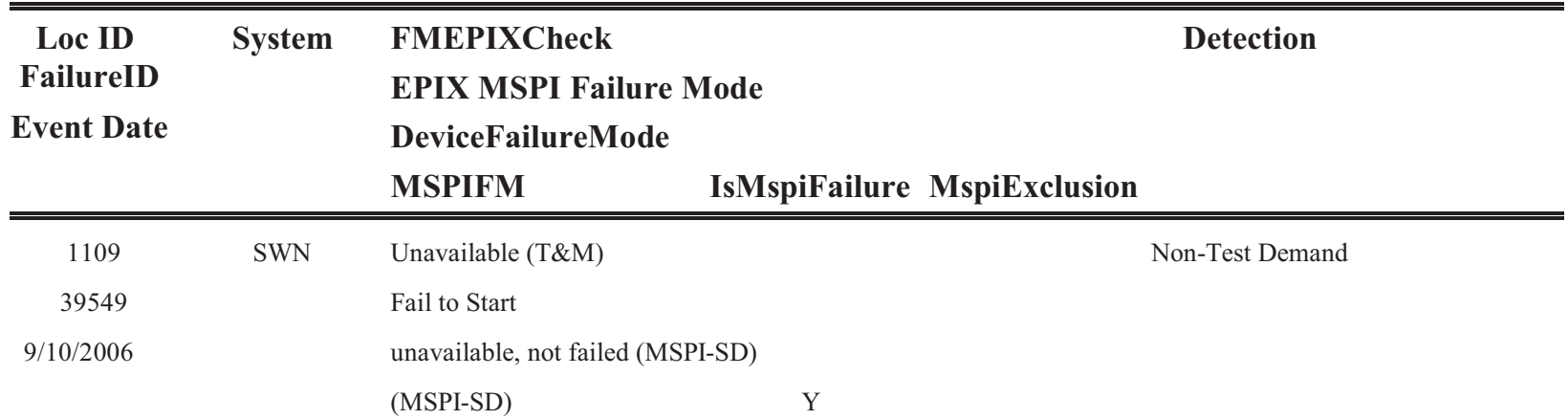

Auxiliary Saltwater Pump (ASP) 1-2 was started at 0150 on 9/10/06 to support a surveillance test for the Component Cooling Water Pump (CCWP) 1-1. 24 seconds later the ASP 1-2 room fan E-101 tripped on thermal overload (TOL). ASP 1-2 is inoperable as this fan is part of its acceptance criteria.

The cause of E-101 fan failing on TOL was that the fan motor was found seized.

The room fan is outside the MDP boundary.

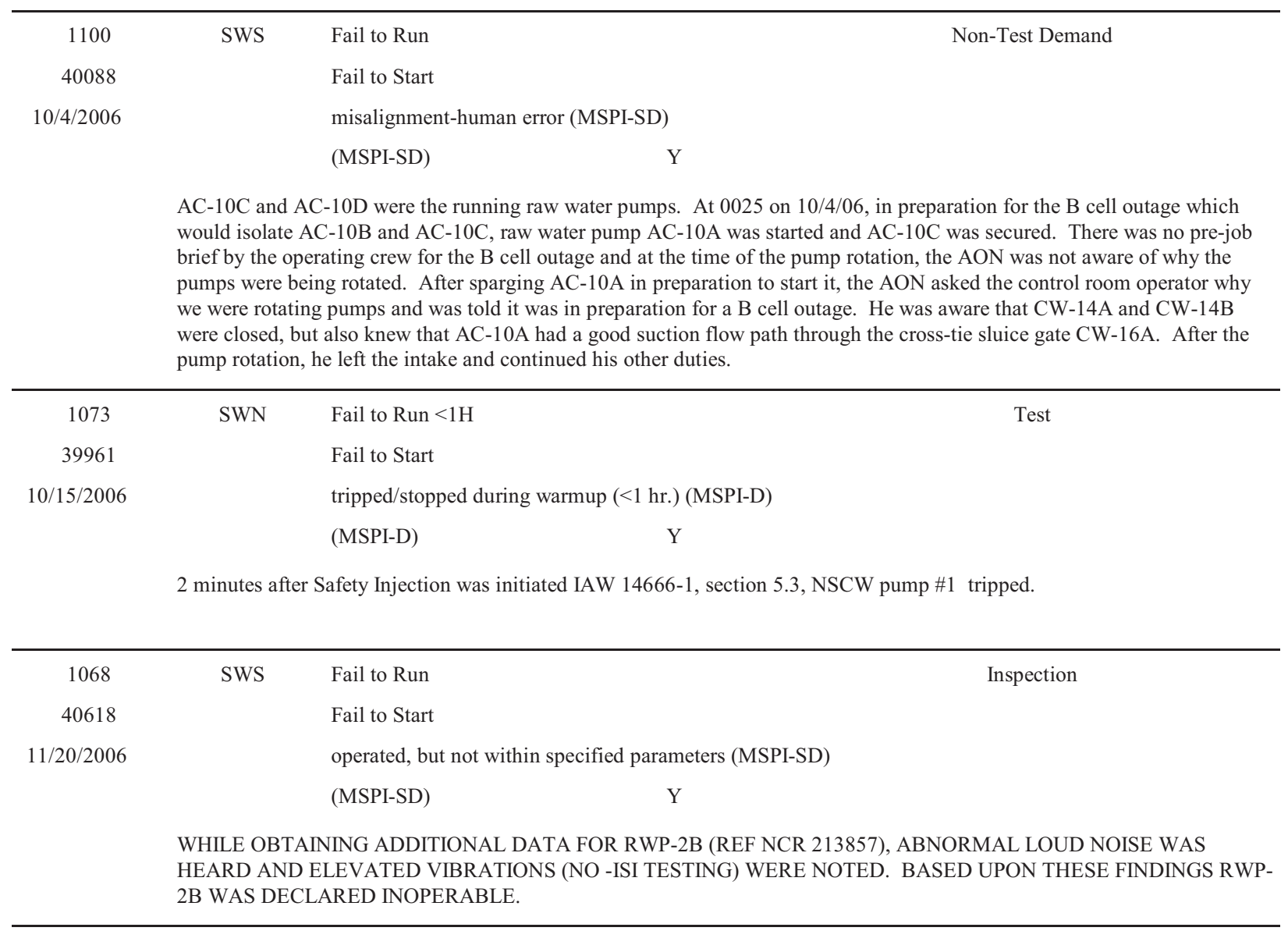




\section{Component Type MDP}

EPIX MSPI Failure Mode Fail to Start

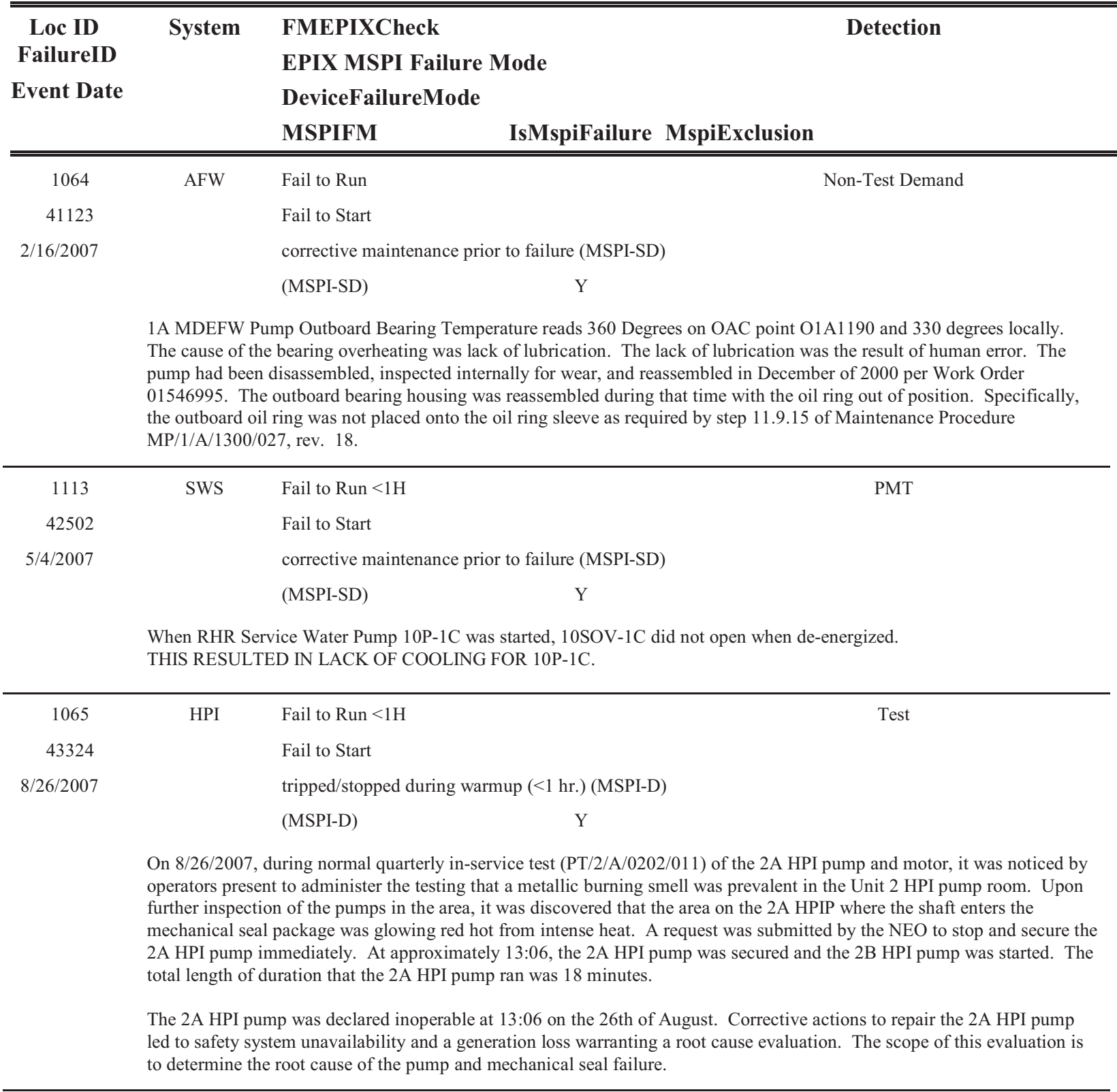




\section{Component Type $\quad$ MDP}

EPIX MSPI Failure Mode Fail to Start

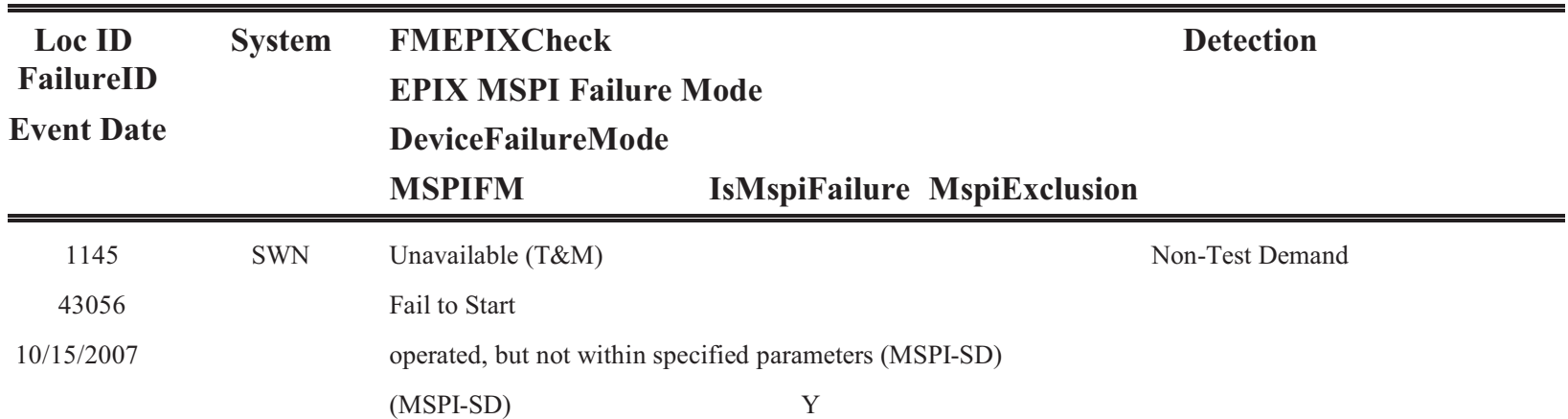

Problem Statement: Received annunciator 47052-P SER 241, Turbine Building Service Water Header B Air Accumulator Pressure Low. NAO reported that SV-33044 was rapidly venting air. Requested I\&C investigate, SV-33044 was mechanically agitated by I\&C technician and repositioned allowing SW-4B to close as designed. The SV-33044 is an ASCO model 8344 solenoid operated valve (SOV) which failed to properly close the service water valve, and was required to be mechanically agitated to perform its function. Closing the SW-4A/B valves is required to assure proper service water flow is maintained to critical equipment during emergency situations such Safety Injection coincident with low service water header pressure.

\begin{tabular}{cll}
\hline 1112 & SWS & Fail to Run \\
43984 & Fail to Start & Non-Test Demand \\
$10 / 17 / 2007$ & operated, but not within specified parameters (MSPI-SD) \\
& $($ MSPI-SD) & Y
\end{tabular}

On 10/17/2007, Operator heard banging noise from lower area of 36 SWP. After a vibration survey determined that vibration readings were above acceptable levels, the pump was secured.

CR 2007-3966: During 10/20/07 disassembly of 36 SWP, bolt heads holding the locking collar halves to the impeller were found severely eroded. Bolt locking tabs were completely missing but sufficient thread engagement remained to hold the locking collars fast to the impeller.

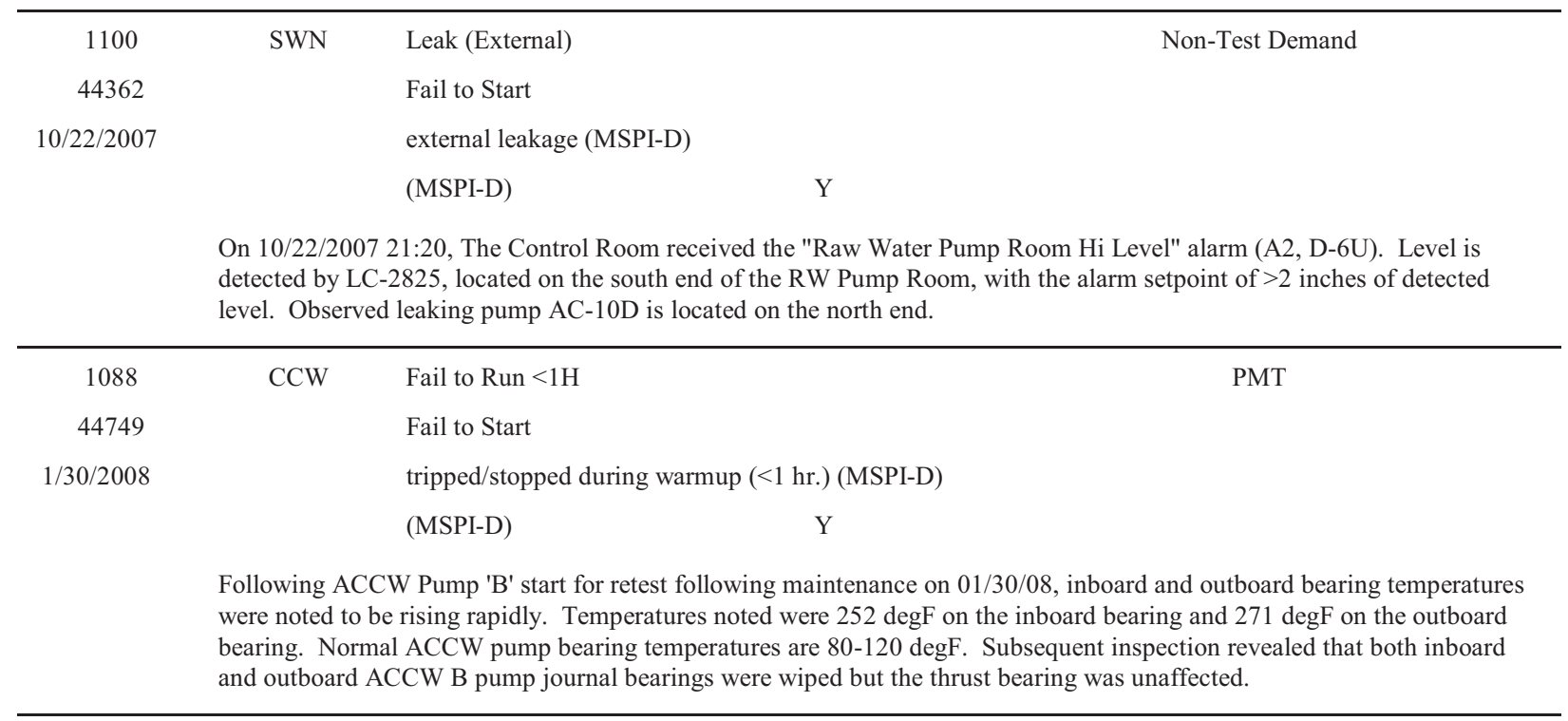




\section{Component Type $\quad$ MDP}

EPIX MSPI Failure Mode Fail to Start

\begin{tabular}{cclc}
\hline \hline Loc ID & System & FMEPIXCheck & Detection \\
FailureID & & EPIX MSPI Failure Mode & \\
Event Date & & DeviceFailureMode \\
& MSPIFM & IsMspiFailure MspiExclusion & Non-Test Demand \\
\hline \hline 1097 & SWS & Fail to Run & \\
44314 & & Fail to Start \\
$2 / 4 / 2008$ & & operated, but not within specified parameters (MSPI-SD) \\
& & Y Y
\end{tabular}

P-109A (11 RHRSW Pump) was placed in service per isolation instructions in C/O 27330 for work on "B" RHRSW loop motor cooler supply check valve PM. Operator stationed at pump noted low flow from the pump motor cooling line. Flow was quantified at 0.5 liters per minute (approx $0.1 \mathrm{gpm}$ ). Minimum required motor cooling flow is $2 \mathrm{gpm}$ (based on $90 \mathrm{~F}$ river temperature). Operator noted that motor cooling solenoid valve

SV-4937A indicated open; when the manual bypass around SV-4937A was opened, motor cooling flow was more than adequate. Based on this, it appeared that flow blockage was located at SV-4937A.

The flow blockage at SV-4937A reduced the motor cooling flow to the P-109A motor to less than the required 2 gpm, rendering the pump inoperable. The reduction of cooling water flow was sufficient enough to negate the beneficial effects of winter river temperatures and require that the pump be considered inoperable.

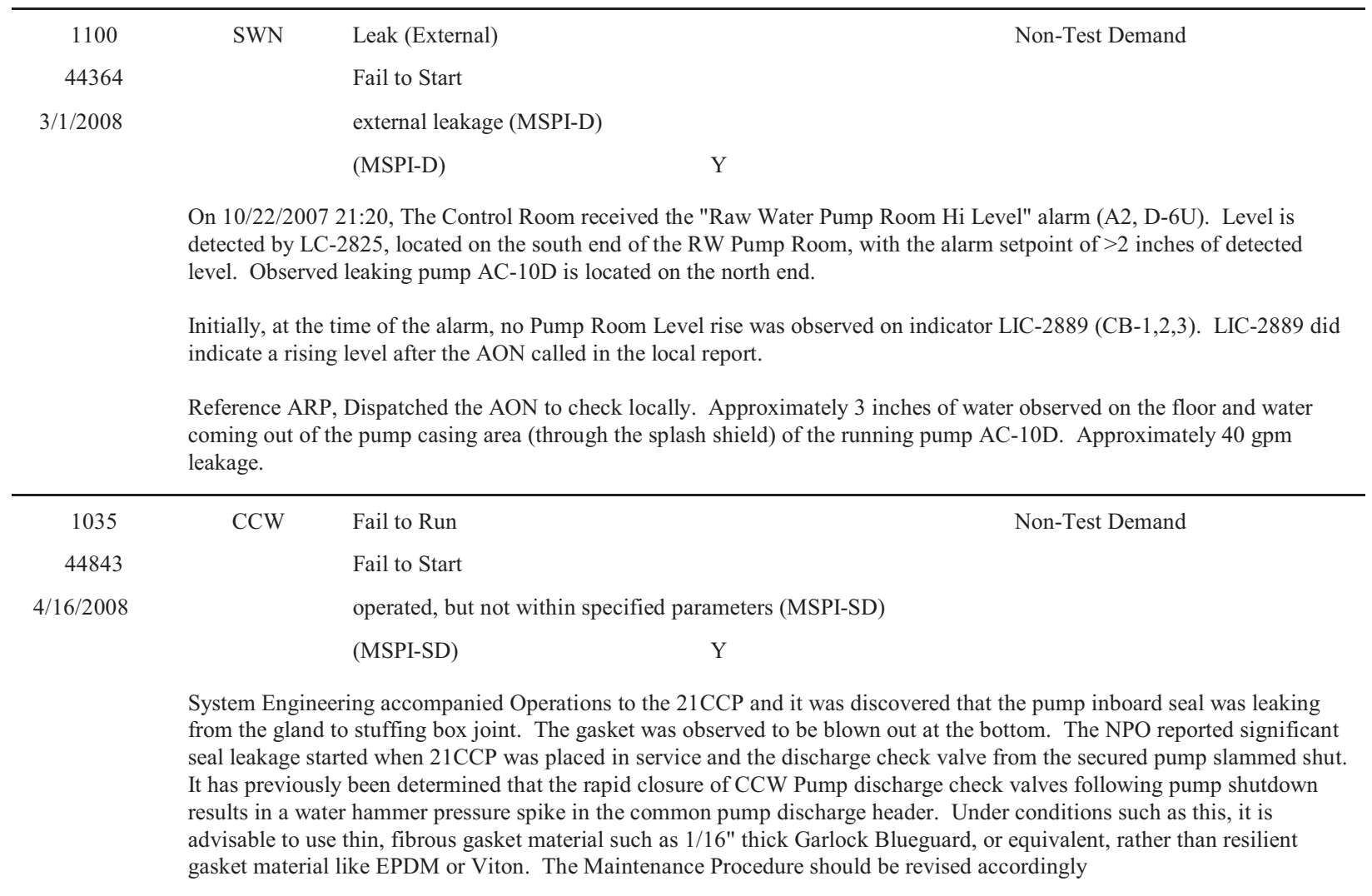




\section{Component Type $\quad M D P$}

EPIX MSPI Failure Mode Fail to Start

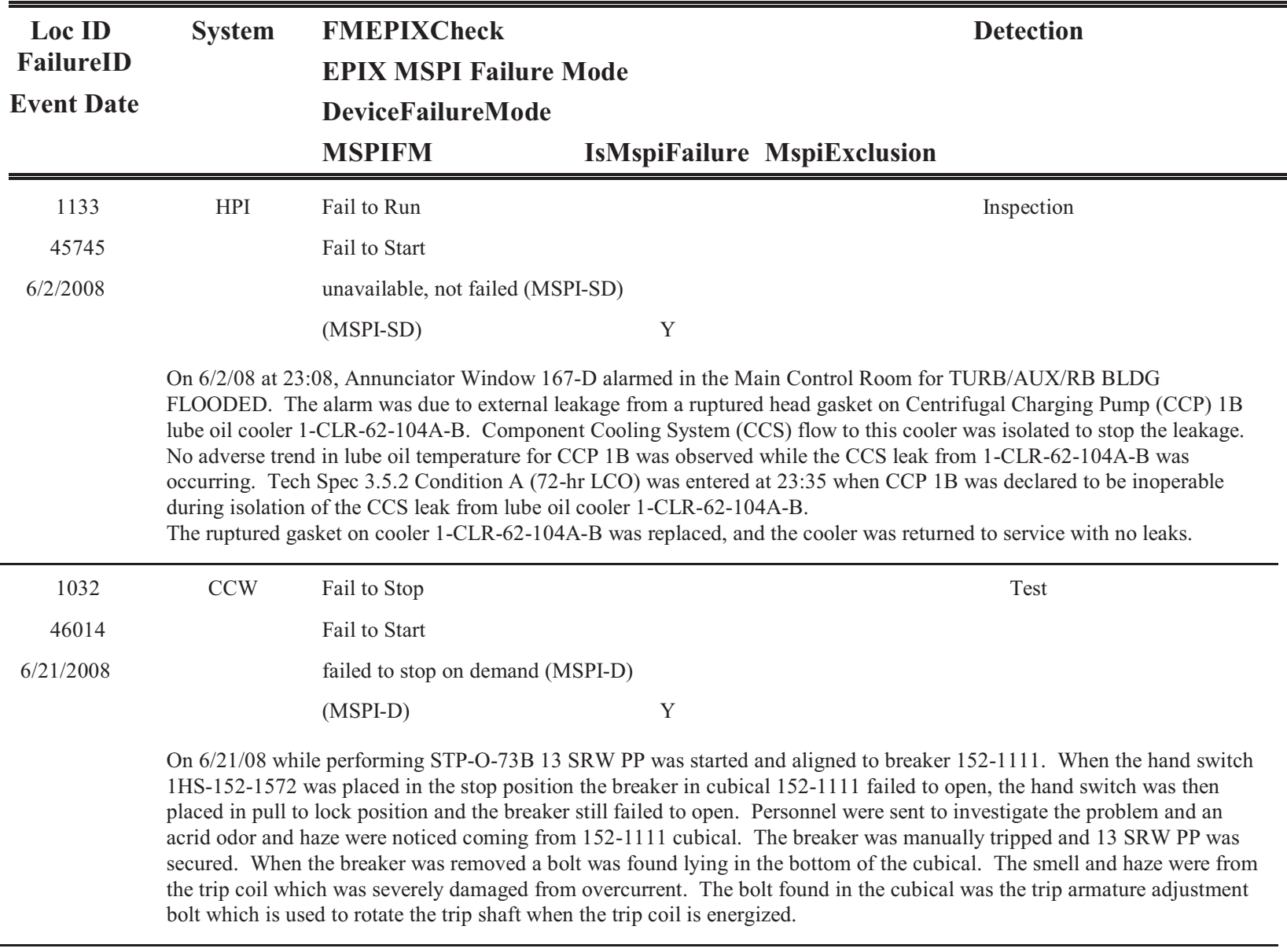




\section{Component Type MDP}

EPIX MSPI Failure Mode Unavailable (T\&M)

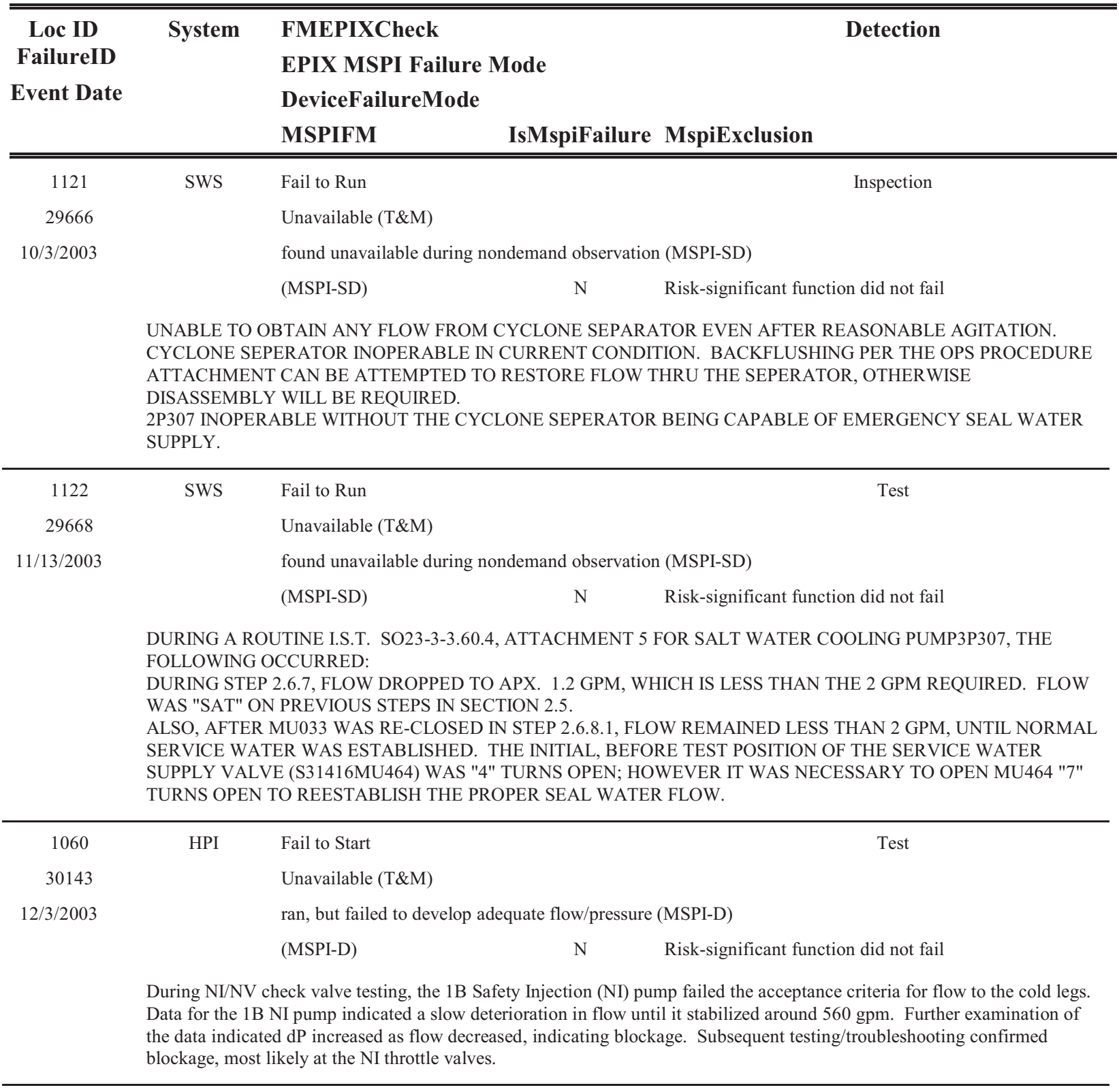




\section{Component Type $\quad$ MDP}

EPIX MSPI Failure Mode Unavailable (T\&M)

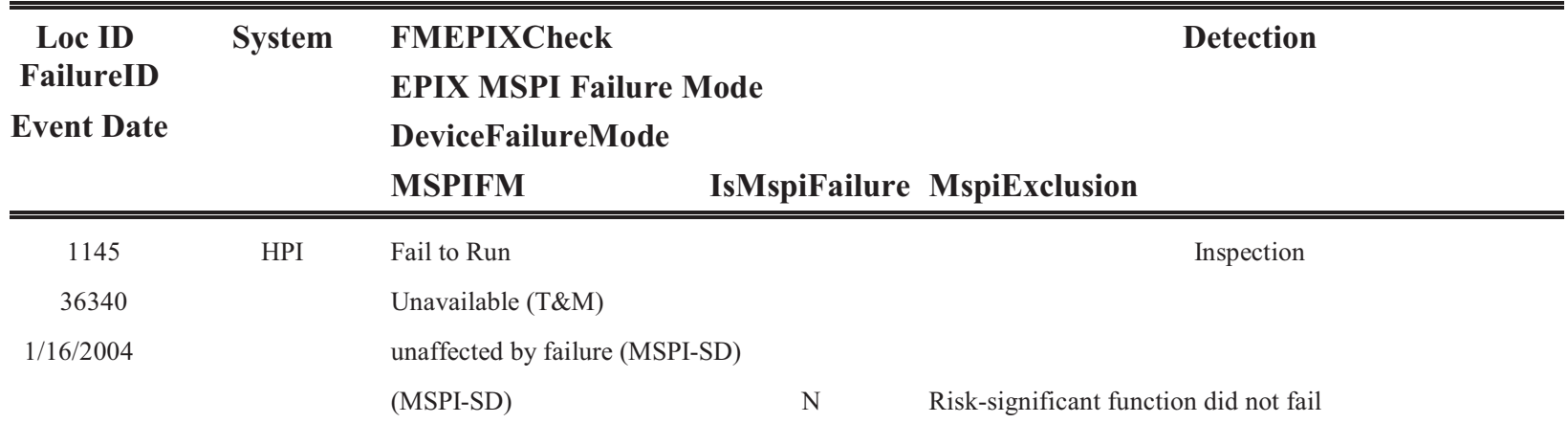

On $1 / 15 / 04$, with the plant operating at $100 \%$ power, the discovery of significant biofouling (blockage by biological matter) of both trains of Safety Injection (SI) Pump lube oil coolers resulted in initiating a Technical Specifications (TS) forced shutdown of the Kewaunee Nuclear Power Plant (KNPP). KNPP was taken offline at approximately 0600 on Friday, 1/16/04. During maintenance and inspection activities on SI pump A on 1/15/04, the lube oil cooler was found to be biofouled. After the cooler was cleaned similar conditions were found in SI pump B. Visible flow was occurring in only 3 of the 20 tubes in the B cooler inlet pass. Even though the coolers were cleaned and operational, the decision was made to shut down the plant.

\begin{tabular}{rlll}
\hline 1145 & HPI & Fail to Run & Inspection \\
36340 & & Unavailable (T\&M) & \\
$1 / 16 / 2004$ & & \\
& unaffected by failure (MSPI-SD) & & \\
& (MSPI-SD) & N & Risk-significant function did not fail
\end{tabular}

On $1 / 15 / 04$, with the plant operating at $100 \%$ power, the discovery of significant biofouling (blockage by biological matter) of both trains of Safety Injection (SI) Pump lube oil coolers resulted in initiating a Technical Specifications (TS) forced shutdown of the Kewaunee Nuclear Power Plant (KNPP). KNPP was taken offline at approximately 0600 on Friday, 1/16/04. During maintenance and inspection activities on SI pump A on 1/15/04, the lube oil cooler was found to be biofouled. After the cooler was cleaned similar conditions were found in SI pump B. Visible flow was occurring in only 3 of the 20 tubes in the B cooler inlet pass. Even though the coolers were cleaned and operational, the decision was made to shut down the plant.

\begin{tabular}{|c|c|c|c|}
\hline 1121 & SWS & Fail to Run & Inspection \\
\hline 31090 & & Unavailable (T\&M) & \\
\hline \multirow[t]{3}{*}{$1 / 30 / 2004$} & & external leakage (MSPI-D) & \\
\hline & & (MSPI-D) & Risk-significant function did not fail \\
\hline & \multicolumn{3}{|c|}{ SWC PUMP S21413MP113 IS INOP DUE TO CLOGGED CYCLONE SEPARATOR. } \\
\hline 1059 & HPI & Fail to Start & Inspection \\
\hline 31112 & & Unavailable (T\&M) & \\
\hline \multirow[t]{3}{*}{$2 / 2 / 2004$} & & \multicolumn{2}{|c|}{ found unavailable during nondemand observation (MSPI-SD) } \\
\hline & & (MSPI-SD) & Risk-significant function did not fail \\
\hline & \multicolumn{3}{|c|}{$\begin{array}{l}\text { During the monthly performance of 3BVT01.11.04 Void Monitoring a void was discovered at points } 22 \text { and 22a. These } \\
\text { points are located on the suction of the "C" charging pump. 2CHS-P21C was the spare charging pump at the time of } \\
\text { discovery. The stand by pump 2CHS-P21B suction piping was verified to be void free. }\end{array}$} \\
\hline
\end{tabular}




\section{Component Type $\quad$ MDP}

EPIX MSPI Failure Mode Unavailable (T\&M)

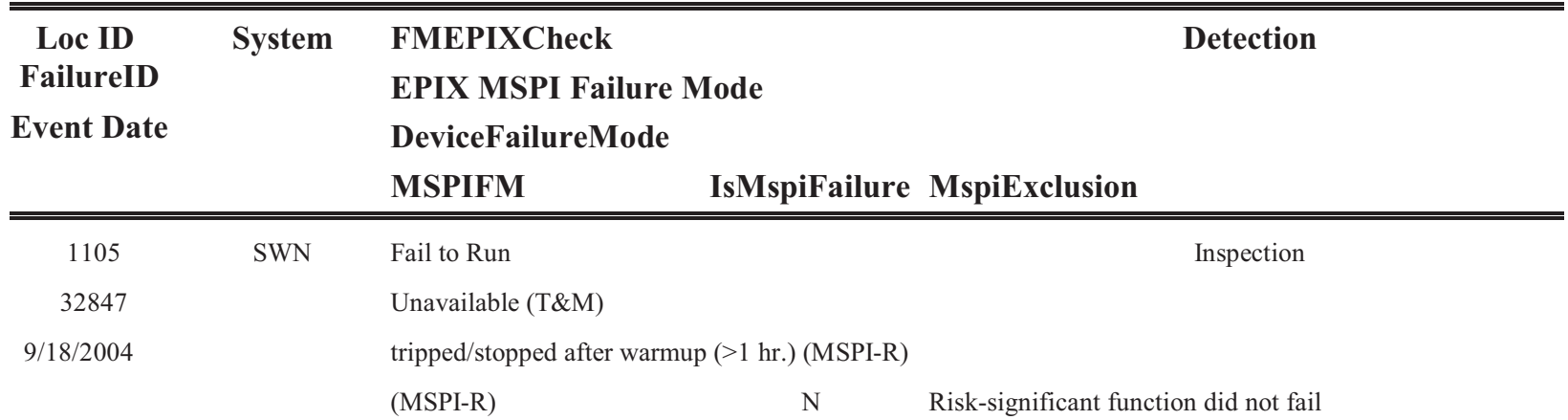

On 9/18/2004, notification 20204119 was initiated to document an excessive cyclic noise emanating from the 'B' Station Service Water Pump. Maintenance Technicians performed vibration collection on this pump two separate times and forwarded the results to the Main Control Room. The Vibration Program Manager was immediately contacted for data review and recommendations. Based on this data assessment, the recommendation was made to immediately remove the 'B' SSW pump from service for support of investigation and possible pump replacement. A 30-day action statement was entered IAW Hope Creek Station Technical Specification 4 / 3.7.1.2.

On 9/19/2004, the 'B' SSW bay received dewatering to facilitate a System Engineering inspection of the pump upper and lower seismic supports. This inspection identified two failed bolts on the lower seismic support, while the remaining two were in a loose condition. Seismic support repairs were complete and ultimately the 'B' pump and motor were replaced under work order 60038786 to return this subsystem back to a reliable and operable condition.

\begin{tabular}{|c|c|c|c|}
\hline 1024 & $\mathrm{CCW}$ & Fail to Start & Non-Test Demand \\
\hline 37953 & & Unavailable (T\&M) & \\
\hline \multirow[t]{3}{*}{$9 / 26 / 2004$} & & \multicolumn{2}{|l|}{ failed to start on demand (MSPI-D) } \\
\hline & & (MSPI-D) & Risk-significant function did not fail \\
\hline & \multicolumn{3}{|c|}{$\begin{array}{l}\text { When attempting to start the } 1 \mathrm{C} C \mathrm{CW} \text { Pump from the MCB for planned train swap, the supply breaker DF- } 04 \text { did not close. } \\
\text { Visual inspection found no obvious problems. EM contacted to investigate. EM racked the breaker out and cycled on test } \\
\text { stand satisfactorily and noted nothing abnormal. Breaker was racked back in and successfully closed from MCB. } \\
\text { Determined problem to be in handswitch and replaced it. }\end{array}$} \\
\hline 1024 & SWN & Fail to Start & Non-Test Demand \\
\hline 37641 & & Unavailable (T\&M) & \\
\hline \multirow[t]{3}{*}{$10 / 20 / 2004$} & & failed to start on demand (MSPI-D) & \\
\hline & & (MSPI-D) & Trip feature that is overridden in ESF actuation \\
\hline & \multicolumn{3}{|c|}{$\begin{array}{l}\text { Attempted to start 1D Service Water Pump. Immediately received the SW Pump tripped annunciator. No local signs of } \\
\text { damage seen at the pump. } \\
\text { No FF for breaker. Breaker was operated several times satisfactorily. Pump is operable and available. Problem was found } \\
\text { to be high resistance on the handswitch contacts. The signal did not reach the breaker to close. } \\
\text { Although the breaker did not close, if there were truly an SI signal received, the SW pump 1D would have started } \\
\text { automatically on demand. Which is supported by the satisfatory results of FNP-0-STP-40.2 }\end{array}$} \\
\hline
\end{tabular}




\section{Component Type $\quad$ MDP}

EPIX MSPI Failure Mode Unavailable (T\&M)

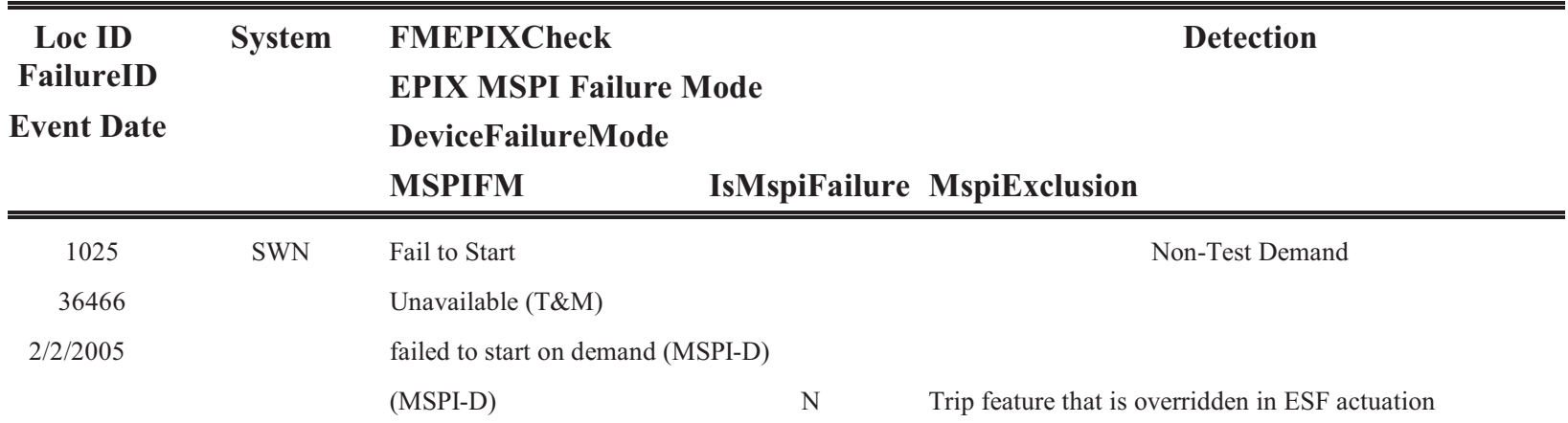

While attempting to start the 2D SW pump, the amber breaker tripped flag lit and annunciator AE4 "SW PUMP TRIPPED" alarmed. The breaker never closed. Breaker was checked and there was no indication of any tripped relays. Please investigate.

Work Completed: Found breaker handswitch contacts very dirty, replaced contact blocks.

\begin{tabular}{|c|c|c|c|}
\hline 1024 & AFW & Fail to Start & Test \\
\hline 37956 & & Unavailable (T\&M) & \\
\hline \multirow[t]{3}{*}{$2 / 12 / 2005$} & & failed to start on demand (MSPI-D) & \\
\hline & & (MSPI-D) & Risk-significant function did not fail \\
\hline & \multicolumn{3}{|c|}{$\begin{array}{l}\text { During performance of FNP-1-STP-73.1 Appendix K, at step 5.2.4.2, did NOT receive closed indication on HSDP breaker } \\
\text { position for the 1A MDAFW pump, as required. Took a time out and invoked P\&L 4.4, S.S. directed we "exercise" the } \\
\text { handswitch to clean supposedly dirty contacts. Cycled handswitch three additional times with no change at all in breaker } \\
\text { status. Subsequently checked out breaker DF10 for spring charged, control power on, and no loose parts or other problems-- } \\
\text { SAT. Decided to complete section of Appendix K for the 1A MDAFP, NOT perform section for 1B MDAFP, and restore } \\
\text { MCB switch positions to normal per steps5.3.6.6 and 5.3.6.7. }\end{array}$} \\
\hline 1144 & HCS & Fail to Run & Inspection \\
\hline 34335 & & Unavailable (T\&M) & \\
\hline \multirow[t]{3}{*}{$3 / 16 / 2005$} & & found unavailable during nondemand obs & n (MSPI-SD) \\
\hline & & (MSPI-SD) & Risk-significant function did not fail \\
\hline & \multicolumn{3}{|c|}{$\begin{array}{l}\text { HPCS was declared inoperable when severe cracking and degradation was found on the upper air deflector of the pump } \\
\text { motor during a maintenance activity. The cause was critical dimensions were not maintained during the motor reassembly } \\
\text { process in } 1992 \text {. }\end{array}$} \\
\hline 1097 & SWS & Fail to Run & Inspection \\
\hline 34848 & & Unavailable (T\&M) & \\
\hline \multirow[t]{3}{*}{$6 / 14 / 2005$} & & found unavailable during nondemand obs & n (MSPI-SD) \\
\hline & & (MSPI-SD) & Risk-significant function did not fail \\
\hline & \multicolumn{3}{|c|}{$\begin{array}{l}\text { During the performance of rounds, a Turbine Building Operator identified } 0 \text { psig on the B RHRSW Motor Cooler } \\
\text { Pressurizing Station. Shift Supervision was notified. Upon further investigation it was determined that sand had filled the } \\
\text { motor cooling piping. } \\
\text { The cause of the loss of motor cooling to the B RHRSW pump motors is due to the plugging of the motor cooler piping due } \\
\text { to sand build up from the keep fill system supplied by normal service water. } \\
\text { Repair was not required, flushing of the piping was performed to free the motor cooler lines of sand blockage. }\end{array}$} \\
\hline
\end{tabular}




\section{Component Type $\quad$ MDP}

EPIX MSPI Failure Mode Unavailable (T\&M)

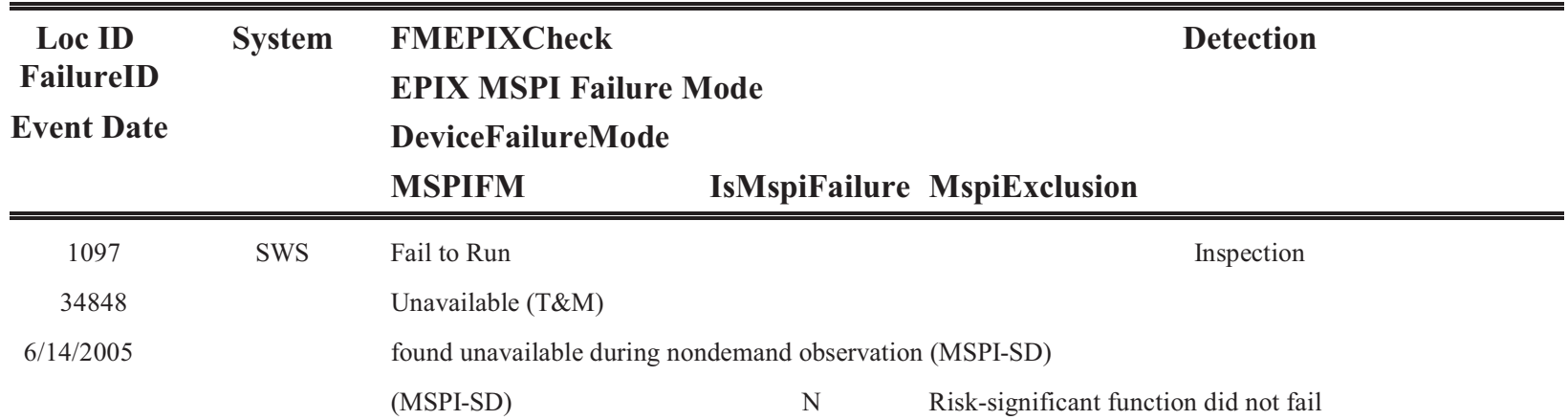

During the performance of rounds, a Turbine Building Operator identified 0 psig on the B RHRSW Motor Cooler Pressurizing Station. Shift Supervision was notified. Upon further investigation it was determined that sand had filled the motor cooling piping.

The cause of the loss of motor cooling to the B RHRSW pump motors is due to the plugging of the motor cooler piping due to sand build up from the keep fill system supplied by normal service water.

Repair was not required, flushing of the piping was performed to free the motor cooler lines of sand blockage.

\begin{tabular}{|c|c|c|c|}
\hline 1071 & $\mathrm{CCW}$ & Fail to Start & Test \\
\hline 38770 & & Unavailable (T\&M) & \\
\hline \multirow[t]{3}{*}{$4 / 3 / 2006$} & & \multicolumn{2}{|l|}{ failed to start on demand (MSPI-D) } \\
\hline & & (MSPI-D) & Risk-significant function did not fail \\
\hline & \multicolumn{3}{|c|}{$\begin{array}{l}\text { On April 3, 2006, 3C CCW pump (3P211C) breaker was removed and installed to support pump seal work. Operations } \\
\text { N/A'd the work order breaker PMT (3AD04) that would close the breaker after performing the associated pump } \\
\text { maintenance. Ref. CR 2006-10448. A pump demand was performed and the pump failed to start. This pump failure to } \\
\text { start is a MSPI monitored component failure, since the failure was outside PMT testing space. Had the breaker problem } \\
\text { been identified during a PMT, this failure would have been attributed directly to the work activity and post maintenance } \\
\text { testing. Post maintenance testing MSPI monitored component failures that are directly connected to the work being } \\
\text { performed are not counted as MSPI failures. }\end{array}$} \\
\hline 1145 & $\mathrm{AFW}$ & Fail to Run $<1 \mathrm{H}$ & Test \\
\hline 41185 & & Unavailable (T\&M) & \\
\hline \multirow[t]{3}{*}{$10 / 21 / 2006$} & & tripped/stopped during warmup ( $<1 \mathrm{hr}$.) & \\
\hline & & (MSPI-D) & Risk-significant function did not fail \\
\hline & \multicolumn{3}{|c|}{$\begin{array}{l}\text { While stabilizing S/G Levels during the RCS heatup to between } 380 \text { and } 400 \text { degrees F Balance of Plant Operator was } \\
\text { starting the AFW Pump B per N-FW-05B. AFW-2B was not closed as required by step 4.1.2.b. When the AFW Pump B } \\
\text { switch was taken to start, it tripped on low discharge pressure. S/G B pressure at the time was } 370 \text { psig. AFW Pump B } \\
\text { tripped at } 1629 \text { on } 10 / 21 / 06 \text {. }\end{array}$} \\
\hline 1092 & $\mathrm{CCW}$ & Fail to Run & Non-Test Demand \\
\hline 40934 & & Unavailable (T\&M) & \\
\hline \multirow[t]{3}{*}{$10 / 30 / 2006$} & & tripped/stopped after warmup ( $>1 \mathrm{hr}$.) ( $\mathrm{N}$ & \\
\hline & & (MSPI-R) & Risk-significant function did not fail \\
\hline & \multicolumn{3}{|c|}{$\begin{array}{l}\text { WHILE PERFORMING A SURVEILLANCE (2611E-2), TO MANUALLY STROKE THE C-RBCCW HX OUTLET } \\
\text { VALVES, A PROCEDURE STEP WAS MISSED, WHICH RESULTED IN ALIGNING THE A-RB PP DISCHARGE TC } \\
\text { BOTH THE A AND B RB HEADERS. THE MIS-ALIGNMENT CAUSED THE RB PP TO TRIP ON LOW SUCTION } \\
\text { PRESSURE. }\end{array}$} \\
\hline
\end{tabular}


Component Type $\quad$ MDP

EPIX MSPI Failure Mode Unavailable (T\&M)

\begin{tabular}{|c|c|c|c|}
\hline $\begin{array}{c}\text { Loc ID } \\
\text { FailureID } \\
\text { Event Date }\end{array}$ & System & $\begin{array}{l}\text { FMEPIXCheck } \\
\text { EPIX MSPI Failure Mode } \\
\text { DeviceFailureMode } \\
\text { MSPIFM IsMspiFailure }\end{array}$ & MspiExclusion \\
\hline 1071 & SWN & Fail to Run & Non-Test Demand \\
\hline 41863 & & Unavailable (T\&M) & \\
\hline \multirow[t]{2}{*}{$3 / 9 / 2007$} & & misalignment-human error (MSPI-SD) & \\
\hline & & (MSPI-SD) & Failure immediately annunciated in control room \\
\hline
\end{tabular}

During the performance of breaker inspection for 3AA13 on 3/9/07 at approximately 10:30 AM, a journeyman traveling through the switchgear room inadvertently bumped an isolation switch on cubicle door 3AA19, causing the breaker to trip, tripping the Safety Related 3A ICW Pump.

\begin{tabular}{|c|c|c|c|}
\hline 1042 & AFW & Fail to Start & Non-Test Demand \\
\hline 41947 & & Unavailable (T\&M) & \\
\hline \multirow[t]{3}{*}{$5 / 15 / 2007$} & & failed to start on demand (MSPI-D) & \\
\hline & & (MSPI-D) & Risk-significant function did not fail \\
\hline & \multicolumn{3}{|c|}{$\begin{array}{l}\text { The Train "A" motor-driven auxiliary feedwater (MDAFW) pump [P:BA] failed to start automatically, but it was started } \\
\text { manually within about one minute after the reactor trip by an operator. The cause of the Train "A" MDAFW pump failure } \\
\text { was subsequently determined to be a failure of the control switch [HS:BA], which prevented the automatic start signal. }\end{array}$} \\
\hline 1118 & SWN & Fail to Start & PMT \\
\hline 42121 & & Unavailable (T\&M) & \\
\hline \multirow[t]{3}{*}{$6 / 1 / 2007$} & & unaffected by failure (MSPI-SD) & \\
\hline & & (MSPI-SD) & Risk-significant function did not fail \\
\hline & \multicolumn{3}{|c|}{$\begin{array}{l}\text { ELECTRICIANS REQUESTED A BUMP FOR ROTATION CHECK OF THE B SERVICE WATER PUMP. WHEN THE } \\
\text { OPERATOR ROTATED THE START SWITCH, HE RECEIVED A GREEN LIGHT FOLLOWED BY A WHITE LIGHT } \\
\text { AND J-9 SAFEGUARD BREAKER TRIP. HE TOOK THE SWITCH TO THE STOP POSITION. THE PUMP DID } \\
\text { ROTATE IN THE CORRECT DIRECTION AND NOTED APPROXIMATELY } 50 \text { AMP JUMP ON BUS } 17 \\
\text { Although the B service water pump was out of service for maintenance, the failure of the breaker to close for the motor } \\
\text { rotation check is a functional failure. Racking of the breaker did not initiate the failure mechanism. If the breaker had not } \\
\text { failed to close during motor rotation check it would have eventually failed when the B SW pump was in service. }\end{array}$} \\
\hline 1118 & SWN & Fail to Start & Test \\
\hline 42122 & & Unavailable (T\&M) & \\
\hline \multirow[t]{2}{*}{$6 / 27 / 2007$} & & failed to start on demand (MSPI-D) & \\
\hline & & (MSPI-D) & Risk-significant function did not fail \\
\hline
\end{tabular}

During restoration from maintenance of the B service water pump the breaker tripped immediately after being closed. When the main control board switch was taken to the CLOSE position a green light followed by a white discrepancy light and J-9, safeguards breaker trip, was received. The pump was observed to rotate a few turns. 


\section{Component Type $\quad$ MDP}

EPIX MSPI Failure Mode Unavailable (T\&M)

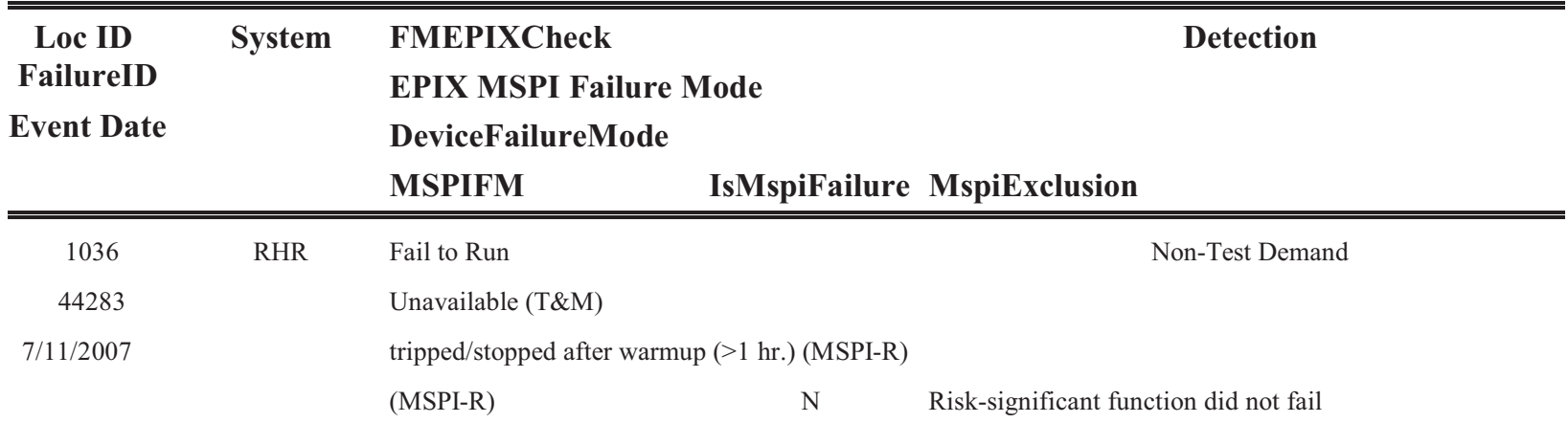

On July 11, 2007, at approximately 2313 hours, the Residual Heat Removal pump (RHR) B tripped off. At the time of the event, the plant was in Mode 4 (Cold Shutdown). With RHR B subsystem inoperable, an alternate method of decay heat removal for the RHR B subsystem could not be verified within one hour as required by Technical Specification Limiting Condition for Operation 3.4.10, Required Action A.1. Required Action A.1 was completed on July 12, 2007, at 0559 hours when the tripped RHR B pump was returned to standby.

The RHR B pump trip occurred when an Instrument and Control Technician performing Reactor Core Isolation Cooling (RCIC) surveillance testing unnecessarily loosened a wire connection from an electrical terminal, inducing a current from the RCIC circuitry into the electrically independent RHR B trip system. Modifications to separate the wiring and to install noise suppression diodes are being prepared for installation.

\begin{tabular}{clll}
\hline 1024 & HPI & Fail to Start & Test \\
43910 & & Unavailable (T\&M) & \\
$10 / 26 / 2007$ & failed to start on demand (MSPI-D) & \\
& (MSPI-D) & N & PMT failure related to maintenance performed
\end{tabular}

Attempted to start 1C Charging pump per FNP-1-STP-40.7. Breaker DG06 did not close.No light indications changed.The Rover reported that he heard a click from the breaker.No other noise was heard and no other indications of a failure. 1CB448 placed on 1C Chg pump handswitch.

The breakers required to auto cycle have been inspected. For the remaining breakers Maintenance is performing FNP-0EMP-1313.19, Multi-Point Inspection, on all breakers prior to installation in the plant. The Latch Check Switch inspection is performed by this procedure and also as part of the vacuum breaker installation procedure FNP-0-EMP-0-1313.11.

\begin{tabular}{rlll}
\hline 1053 & SWS & Fail to Run & Test \\
44700 & & Unavailable (T\&M) & \\
$1 / 11 / 2008$ & failed to start on demand (MSPI-D) & \\
& (MSPI-D) & $\mathrm{N}$ & Risk-significant function did not fail
\end{tabular}

During QCOS 6600-43 'Unit 1/2 Emergency Diesel Generator Load Test' step H.4.n.13 the 1/2 EDG tripped on High temp. The cooling water pump tripped causing the high temp condition. Control room indications show that the cooling water pump is running from Bus 18 on U1 and U2. Locally on the 2251-12 panel the pump indicates that the pump is running from Bus 28. At Bus 28 the breaker for the cooling water pump shows that the breaker is closed. The Breaker at Bus 18 is open. The EDG cooling water room cooler fans are running. The cooling water pp. was verified locally to be tripped. There was no report of any acrid or burnt smell. Received alarm 902-8 A2 '4kv Res Feed Breaker Trip', 901-8 C4 'Diesel Gen Fail to Start' and 901-8 A4 'Diesel Gen 1/2 Trouble. The Diesel was being loaded to 23-1 when the trip occurred. The EDG had just finished running fully loaded on 13-1 for 1.5 hours.

This record is of interest because the subcomponent (Cooling Water Pump) was coded as failed, but the supercomponent (EDG) was not. 


\section{Component Type $\quad$ MDP}

EPIX MSPI Failure Mode Unavailable (T\&M)

\begin{tabular}{|c|c|c|c|}
\hline \multirow{2}{*}{$\begin{array}{c}\text { Loc ID } \\
\text { FailureID }\end{array}$} & \multirow[t]{4}{*}{ System } & FMEPIXCheck & \multirow[t]{3}{*}{ Detection } \\
\hline & & EPIX MSPI Failure Mode & \\
\hline \multirow[t]{2}{*}{ Event Date } & & DeviceFailureMode & \\
\hline & & IsMspiFailure & MspiExclusion \\
\hline 1142 & SWN & Fail to Run & Non-Test Demand \\
\hline 44506 & & Unavailable (T\&M) & \\
\hline \multirow[t]{2}{*}{$2 / 2 / 2008$} & & operated, but not within specified parameters (M) & PI-SD) \\
\hline & & (MSPI-SD) & Risk-significant function did not fail \\
\hline
\end{tabular}

The direct cause of the high vibrations in P-032e was a bend in the $3 \mathrm{rd}$ intermediate shaft. The total indicated run out (TIR) was found to be well in excess of acceptance criteria. This created a radial force that accelerated shaft wear, as evident by the non-concentric wear pattern noted on disassembly. The wear became evident in vibrations transmitted from the shaft to the motor frame.

The apparent cause for the bent shaft was determined to most likely be due to pump shaft installation and rigging practices.

This event captured by LER 2662008002.

\begin{tabular}{|c|c|c|c|}
\hline 1110 & $\mathrm{CVC}$ & Fail to Run $<1 \mathrm{H}$ & Test \\
\hline 44413 & & \multicolumn{2}{|l|}{ Unavailable (T\&M) } \\
\hline $3 / 12 / 2008$ & & \multicolumn{2}{|c|}{ discovered to be unable to run for mission time (MSPI-R) } \\
\hline & & (MSPI-R) & PMT failure related to maintenance performed \\
\hline & \multicolumn{3}{|c|}{$\begin{array}{l}\text { During the initial start of the Centrifugal Charging Pump (CCP) } 2-2 \text {, the operators noted sparks being produced from the } \\
\text { outboard mechanical seal. The pump was immediately shut down. Initial investigation indicates a seal rub between the } \\
\text { disaster bushing and the shaft sleeve. Additional investigation by the system engineer, seal vendor, and pump vendor } \\
\text { determined that the seal tolerances were acceptable and the there must have been something between the seal and the shaft. } \\
\text { After further evaluation of the pump, seal, and affected parts by a Flowserve field service representative and evaluation by } \\
\text { Flowserve nuclear engineering we can conclude that the most likely cause of this event is the presence of foreign material } \\
\text { with the running clearance between the seals shaft sleeve and the disaster bushing. It is not possible to determine the source } \\
\text { of the foreign material because it was destroyed before the pump was stopped. }\end{array}$} \\
\hline
\end{tabular}

SWS $1096 \quad \begin{aligned} & \text { Fail to Start } \\ & \text { Unavailable (T\&M) } \\ & \text { operated, but not within specified parameters (MSPI-SD) } \\ & \text { (MSPI-SD) }\end{aligned}$
$\begin{aligned} & \text { The apparent cause of Service Water pump D high amps at start up was the design of the traveling water screens can not } \\ & \text { feasibly be made to prevent all river debris from entering the service water bay and possibly lodging between the impeller } \\ & \text { and bowl. }\end{aligned}$
$\begin{aligned} & \text { An attempt to turn the pump/motor shaft by hand was unsuccessful, therefore the pump was uncoupled from the motor. At } \\ & \text { this time, the motor shaft turned freely and did not indicate any roughness that would be indicative of a motor bearing } \\ & \text { problem. The pump shaft should have dropped down the amount of the pump lift setting, however it did not move when it } \\ & \text { was uncoupled. The pump shaft was then lifted and turned slightly and set back down. At this time, the pump shaft did } \\ & \text { drop down to the extent expected (pump lift setting). The most likely cause of this was debris wedged in between the } \\ & \text { impeller and the casing. By lifting the impeller up and rotating it, this debris was dislodged. }\end{aligned}$




\section{Component Type $\quad$ MDP}

EPIX MSPI Failure Mode Unavailable (T\&M)

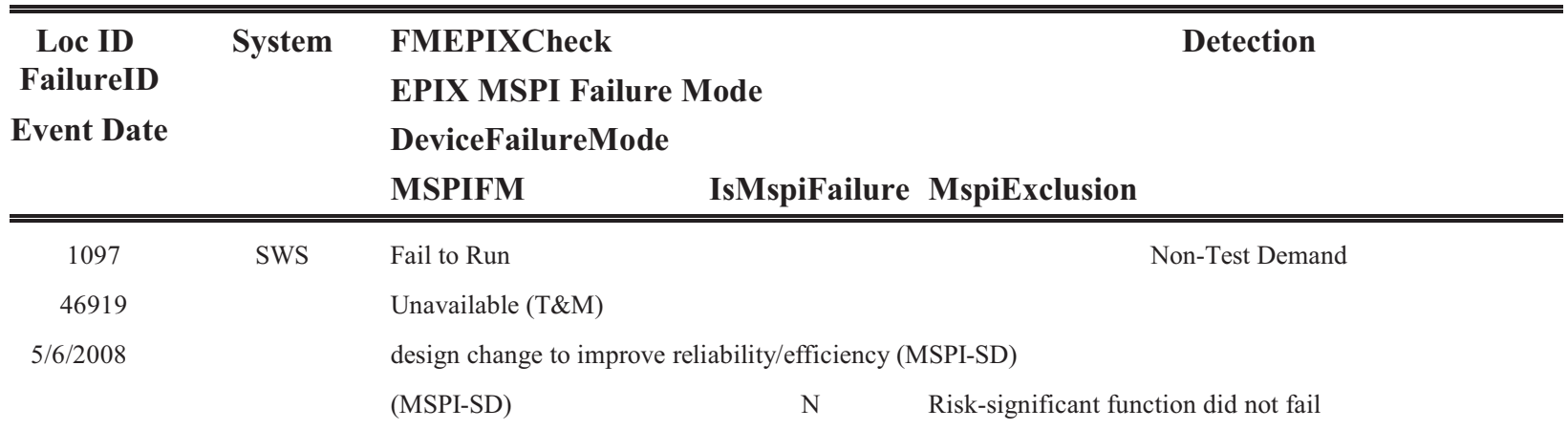

On May 6, 2008, during performance of procedure 0255-05-IA-1-2 (B RHRSW Quarterly Pump and Valve test) it was observed by out plant operators that there was little to no cooling flow available to 12 RHRSW pump motor. Upon further investigation, PI-7332 (motor cooling water pressure to 12 and 14 RHRSW pump motors) was observed to read 0 psig. Upon observing this, operations declared Loop B RHRSW inoperable and entered Tech Spec. 3.7.1. This was considered an unplanned LCO entry. The sand that was found to plug PCV-3005 was flushed from the keep-fill lines due to the specific valving steps in the procedure being perfromed.

The B Division of the RHRSW system was unable to perform its safety related maintenance rule function of removing the heat rejected by the RHR system. The A Division of RHRSW was able to perform its safety and non-safety related maintenance rule functions during this time. The quarterly surveillance procedure that flushed sand into the pressure control valve on the B side was not concurrently performed on the A side of the RHRSW system; thus the failure mode observed on May 6, 2008 on the B side was not introduced in the A side.

AR 1136919 was initiated and immediate action to correct the condition was planned. WO 361167 was performed to flush the motor cooling lines with PCV-3005 disassembled. The lines were flushed until clean, and the PMT was performed which verified adequate motor cooling flow rates with single and dual pump operation. An OPR approved by operations under AR01136919.

The B Loop of RHRSW pumps water from the Mississippi river to the B RHR heat exchanger, where it accepts the heat from the RHR system which is then cooling the suppression pool. The RHRSW then exits the heat exchanger and discharges back to the Mississippi river. The RHRSW loop B system was unable to perform this function of removing the heat rejected by the RHR system. 


\section{Component Type $\quad$ MDP}

EPIX MSPI Failure Mode Unavailable (T\&M)

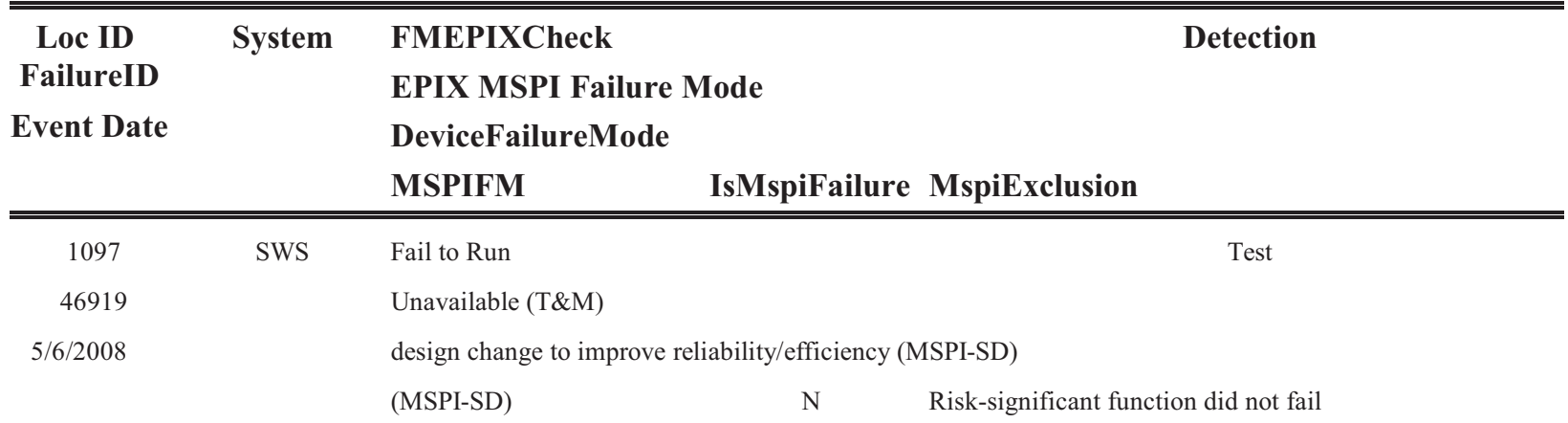

On May 6, 2008, during performance of procedure 0255-05-IA-1-2 (B RHRSW Quarterly Pump and Valve test) it was observed by out plant operators that there was little to no cooling flow available to 12 RHRSW pump motor. Upon further investigation, PI-7332 (motor cooling water pressure to 12 and 14 RHRSW pump motors) was observed to read 0 psig. Upon observing this, operations declared Loop B RHRSW inoperable and entered Tech Spec. 3.7.1. This was considered an unplanned LCO entry. The sand that was found to plug PCV-3005 was flushed from the keep-fill lines due to the specific valving steps in the procedure being perfromed.

The B Division of the RHRSW system was unable to perform its safety related maintenance rule function of removing the heat rejected by the RHR system. The A Division of RHRSW was able to perform its safety and non-safety related maintenance rule functions during this time. The quarterly surveillance procedure that flushed sand into the pressure control valve on the B side was not concurrently performed on the A side of the RHRSW system; thus the failure mode observed on May 6, 2008 on the B side was not introduced in the A side.

AR 1136919 was initiated and immediate action to correct the condition was planned. WO 361167 was performed to flush the motor cooling lines with PCV-3005 disassembled. The lines were flushed until clean, and the PMT was performed which verified adequate motor cooling flow rates with single and dual pump operation. An OPR approved by operations under AR01136919.

The B Loop of RHRSW pumps water from the Mississippi river to the B RHR heat exchanger, where it accepts the heat from the RHR system which is then cooling the suppression pool. The RHRSW then exits the heat exchanger and discharges back to the Mississippi river. The RHRSW loop B system was unable to perform this function of removing the heat rejected by the RHR system.

\begin{tabular}{|c|c|c|c|}
\hline 1060 & SWN & Fail to Run & Non-Test Demand \\
\hline 46159 & & Unavailable (T\&M) & \\
\hline \multirow[t]{3}{*}{$7 / 12 / 2008$} & & \multicolumn{2}{|c|}{ tripped/stopped after warmup (>1 hr.) (MSPI-R) } \\
\hline & & (MSPI-R) & Risk-significant function did not fail \\
\hline & \multicolumn{3}{|c|}{$\begin{array}{l}\text { At } 10: 41 \text { on } 7 / 12 / 2008 \text {, while in two pump flush alignment for B train RN, the flow and discharge pressure associated with } \\
\text { the } 1 \mathrm{~B} \text { RN pump dropped off completely. The } 2 \mathrm{~B} \text { RN pump aligned in parallel picked up the flow. } \\
\text { The Root Cause of this event was the use of the coupling sleeve manufactured from a deficiently formed alloy. Specifically, } \\
\text { the 1B RN Pump failed due to the heterogeneity of the upper Johnston coupling material [RC-1] Heterogeneity caused this } \\
\text { material to be highly susceptible to intergranular corrosion and cracking (IGSCC) as shown by an accumulation of fine } \\
\text { sulfide stringer inclusions along the boundaries of the failed coupling }\end{array}$} \\
\hline 1112 & $\mathrm{CCW}$ & Fail to Start & Test \\
\hline 46271 & & Unavailable (T\&M) & \\
\hline \multirow[t]{3}{*}{$8 / 10 / 2008$} & & failed to start on demand (MSPI-D) & \\
\hline & & (MSPI-D) & Risk-significant function did not fail \\
\hline & $\begin{array}{l}32 \text { Aux CC } \\
\text { tripped. Le }\end{array}$ & $\begin{array}{l}\text { Imp tripped on attempted start for schedule } \\
\text { st line fuse found bad }\end{array}$ & Saw red light illuminate for half a second before pump \\
\hline
\end{tabular}


Component Type MDP

EPIX MSPI Failure Mode Unavailable (T\&M)

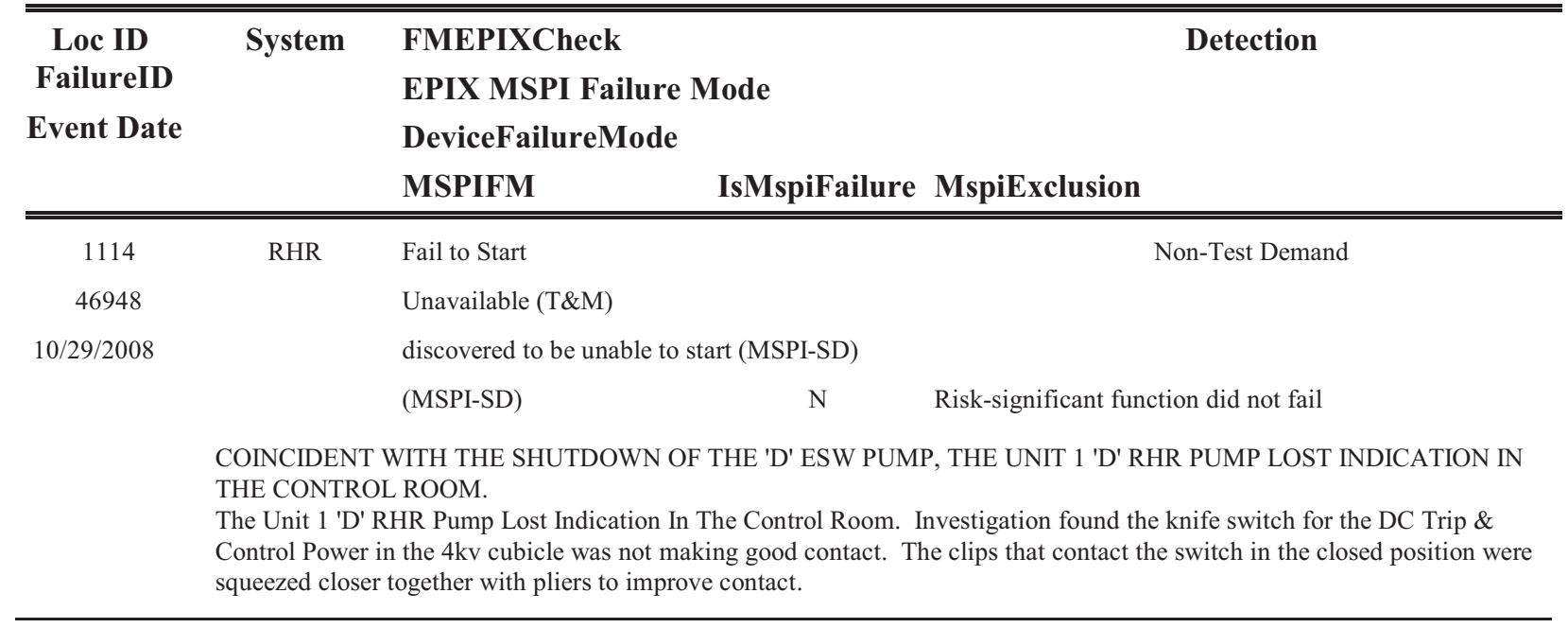




\section{Component Type $\quad \mathrm{MOV}$}

EPIX MSPI Failure Mode Fail on Demand

\begin{tabular}{|c|c|c|c|}
\hline \multirow{4}{*}{$\begin{array}{c}\text { Loc ID } \\
\text { FailureID } \\
\text { Event Date }\end{array}$} & \multirow[t]{4}{*}{ System } & FMEPIXCheck & \multirow[b]{4}{*}{ MspiExclusion } \\
\hline & & EPIX MSPI Failure Mode & \\
\hline & & DeviceFailureMode & \\
\hline & & IsMspiFailure & \\
\hline 1064 & \multirow[t]{4}{*}{ RHR } & Unavailable (T\&M) & \multirow[t]{4}{*}{ Non-Test Demand } \\
\hline 29585 & & Fail on Demand & \\
\hline $5 / 5 / 2003$ & & failed to close on demand (stuck open) (MSPI-D) & \\
\hline & & (MSPI-D) & \\
\hline
\end{tabular}

A review of Modification ONOE-16912 (Circuit Modifications to address spurious hot shorts affecting 3LP-19 \& 3LP-20) identified a vulnerability of the circuit during a postulated Control Room fire. Modification ONOE-16912 was initiated as a result of the problem documented in PIP O-02-1357. The proposed design has utilized a separate wire run for a critical conductor in the control circuit (the conductor that runs from the control switch in the Control Room to the MCC) from the MCC to a terminal strip inside the UB2 section of the Main Control Board. This separate wire run removed this critical conductor from the multi-conductor cable used to feed the other portions of the circuit. This successfully removed the potential of a hot short from occurring in the circuit from the MCC to the terminal strip. From the terminal strip to the control switch for one of the valves, the proposed design routed all of the circuit conductors for the valve (including the energized conductors for the indicating lights and the conductor running to the control switch) inside single flexible conduit. Since this design runs the conductor to the control switch inside the same conduit with energized conductors, this portion of the control circuit would still be susceptible to hot shorts causing a spurious actuation of the valve. The wiring from the terminal strip to the control switch for the other valve was to be left as originally installed, with no added protection for the wire from the control switch to the MCC. This also would still be susceptible to hot shorts causing a spurious actuation of the valve.

An Appendix R fire in the Main Control Room could cause LP-19 \& LP-20 to spuriously operate. This could result in a transfer of BWST inventory to the corresponding units RB basement. Water level in the Reactor Building could be high enough to cause the corresponding SSF RC makeup pump to fail.

\begin{tabular}{ll}
\hline 1064 & \multicolumn{1}{c}{ RHR $\begin{array}{l}\text { Unavailable (T\&M) } \\
\text { Fail on Demand } \\
\text { failed to close on demand (stuck open) (MSPI-D) } \\
\text { (MSPI-D) }\end{array}$} \\
A review of Modification ONOE-16912 (Circuit Modifications to address spurious hot shorts affecting 3LP-19 \& 3LP-20) \\
identified a vulnerability of the circuit during a postulated Control Room fire. Modification ONOE-16912 was initiated as a \\
result of the problem documented in PIP O-02-1357. The proposed design has utilized a separate wire run for a critical \\
conductor in the control circuit (the conductor that runs from the control switch in the Control Room to the MCC) from the \\
MCC to a terminal strip inside the UB2 section of the Main Control Board. This separate wire run removed this critical \\
conductor from the multi-conductor cable used to feed the other portions of the circuit. This successfully removed the \\
potential of a hot short from occurring in the circuit from the MCC to the terminal strip. From the terminal strip to the \\
control switch for one of the valves, the proposed design routed all of the circuit conductors for the valve (including the \\
energized conductors for the indicating lights and the conductor running to the control switch) inside single flexible conduit. \\
Since this design runs the conductor to the control switch inside the same conduit with energized conductors, this portion of \\
the control circuit would still be susceptible to hot shorts causing a spurious actuation of the valve. The wiring from the \\
terminal strip to the control switch for the other valve was to be left as originally installed, with no added protection for the \\
wire from the control switch to the MCC. This also would still be susceptible to hot shorts causing a spurious actuation of \\
the valve. \\
An Appendix R fire in the Main Control Room could cause LP-19 \& LP-20 to spuriously operate. This could result in a \\
transfer of BWST inventory to the corresponding units RB basement. Water level in the Reactor Building could be high \\
enough to cause the corresponding SSF RC makeup pump to fail.
\end{tabular}




\section{Component Type $\quad \mathrm{MOV}$}

EPIX MSPI Failure Mode Fail on Demand

\begin{tabular}{cclc}
\hline \hline Loc ID & System & FMEPIXCheck & Detection \\
FailureID & & EPIX MSPI Failure Mode & \\
Event Date & & DeviceFailureMode & \\
& & MSPIFM & Inspection \\
\hline \hline \multirow{2}{*}{1065} & RHR & Unavailable (T\&M) & \\
32318 & & Fail on Demand \\
$5 / 5 / 2003$ & & failed to close on demand (stuck open) (MSPI-D) & \\
& & Y MSPI-D)
\end{tabular}

A review of Modification ONOE-16912 (Circuit Modifications to address spurious hot shorts affecting 3LP-19 \& 3LP-20) identified a vulnerability of the circuit during a postulated Control Room fire. Modification ONOE-16912 was initiated as a result of the problem documented in PIP O-02-1357. The proposed design has utilized a separate wire run for a critical conductor in the control circuit (the conductor that runs from the control switch in the Control Room to the MCC) from the MCC to a terminal strip inside the UB2 section of the Main Control Board. This separate wire run removed this critical conductor from the multi-conductor cable used to feed the other portions of the circuit. This successfully removed the potential of a hot short from occurring in the circuit from the MCC to the terminal strip. From the terminal strip to the control switch for one of the valves, the proposed design routed all of the circuit conductors for the valve (including the energized conductors for the indicating lights and the conductor running to the control switch) inside single flexible conduit. Since this design runs the conductor to the control switch inside the same conduit with energized conductors, this portion of the control circuit would still be susceptible to hot shorts causing a spurious actuation of the valve. The wiring from the terminal strip to the control switch for the other valve was to be left as originally installed, with no added protection for the wire from the control switch to the MCC. This also would still be susceptible to hot shorts causing a spurious actuation of the valve.

An Appendix R fire in the Main Control Room could cause LP-19 \& LP-20 to spuriously operate. This could result in a transfer of BWST inventory to the corresponding units RB basement. Water level in the Reactor Building could be high enough to cause the corresponding SSF RC makeup pump to fail.

\begin{tabular}{ll}
\hline 1065 RHR & \multicolumn{1}{c}{ Unavailable (T\&M) } \\
Fail on Demand \\
failed to close on demand (stuck open) (MSPI-D) \\
(MSPI-D) \\
A review of Modification ONOE-16912 (Circuit Modifications to address spurious hot shorts affecting 3LP-19 \& 3LP-20) \\
identified a vulnerability of the circuit during a postulated Control Room fire. Modification ONOE-16912 was initiated as a \\
result of the problem documented in PIP O-02-1357. The proposed design has utilized a separate wire run for a critical \\
conductor in the control circuit (the conductor that runs from the control switch in the Control Room to the MCC) from the \\
MCC to a terminal strip inside the UB2 section of the Main Control Board. This separate wire run removed this critical \\
conductor from the multi-conductor cable used to feed the other portions of the circuit. This successfully removed the \\
potential of a hot short from occurring in the circuit from the MCC to the terminal strip. From the terminal strip to the \\
control switch for one of the valves, the proposed design routed all of the circuit conductors for the valve (including the \\
energized conductors for the indicating lights and the conductor running to the control switch) inside single flexible conduit. \\
Since this design runs the conductor to the control switch inside the same conduit with energized conductors, this portion of \\
the control circuit would still be susceptible to hot shorts causing a spurious actuation of the valve. The wiring from the \\
terminal strip to the control switch for the other valve was to be left as originally installed, with no added protection for the \\
wire from the control switch to the MCC. This also would still be susceptible to hot shorts causing a spurious actuation of \\
the valve. \\
An Appendix R fire in the Main Control Room could cause LP-19 \& LP-20 to spuriously operate. This could result in a \\
transfer of BWST inventory to the corresponding units RB basement. Water level in the Reactor Building could be high \\
enough to cause the corresponding SSF RC makeup pump to fail.
\end{tabular}




\section{Component Type $\quad \mathrm{MOV}$}

EPIX MSPI Failure Mode Fail on Demand

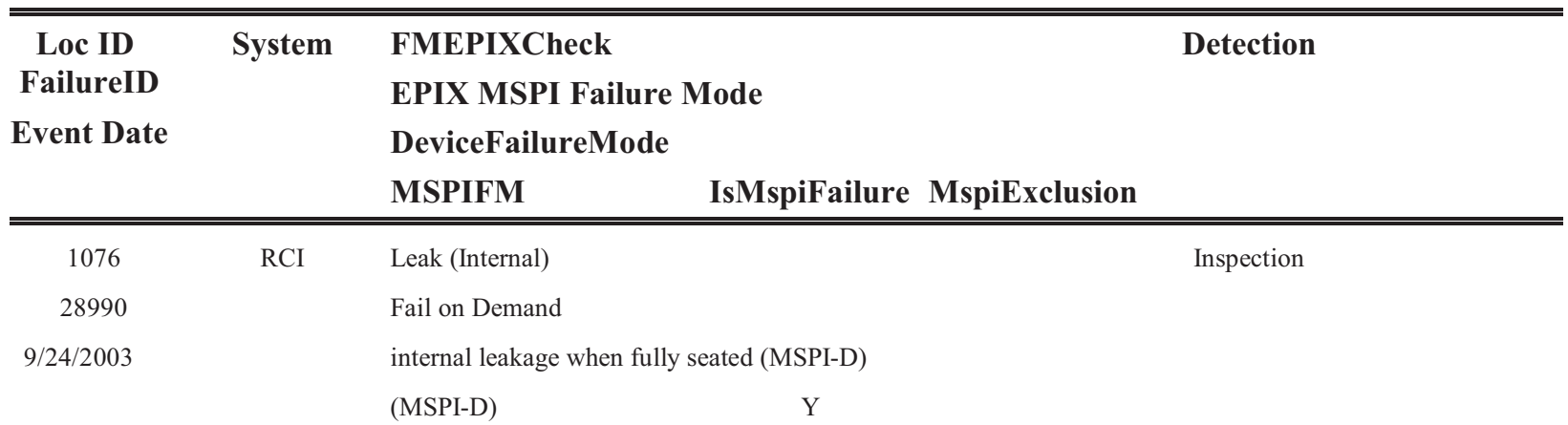

After disassembling 2E51-F045, it was found that steam cuts and draws had formed on the valve disk, allowing steam to leak past the seat through the turbine casing and into the exhaust line drain pot.

\begin{tabular}{rlll}
\hline 1040 & RHR & Unavailable (T\&M) & PMT \\
32443 & & Fail on Demand & \\
$8 / 2 / 2004$ & & unavailable, not failed (MSPI-SD) & \\
& & Y
\end{tabular}

While troubleshooting loss of open indication for 2-E11-F048A, the control power fuse was inadvertently blown resulting in loss of suppression pool cooling (SPC).

2.Problem Description / Investigation Summary

WO 597014 was initiated on 7/31/04 to troubleshoot the 2-E11-F048A red light (open) indicator which would not light. The valve was verified to be operable from the RTGB and full open per MCC indication. During trouble shooting on 8/3/04 the control power fuse was inadvertently blown which caused SPC to be inoperable.

\begin{tabular}{ccc}
\hline 1088 & CCW & Unavailable (T\&M) \\
& Fail on Demand \\
operated, but not within specified parameters (MSPI-SD) \\
(MSPI-SD)
\end{tabular}

On October 13, 2006 water started leaking from the packing of MO2405. Ops closed the valve leading to RCIC unplanned LCO and MPFF. This steam line should not have water present.

The Apparent Cause of this problem, is the leakage of condensate and steam past MO2404, which lead to trapped water and steam between MO2404 \& MO2405. This resulted in leakage of the water out through the packing of MO2405. 


\section{Component Type $\quad \mathrm{MOV}$}

EPIX MSPI Failure Mode Fail on Demand

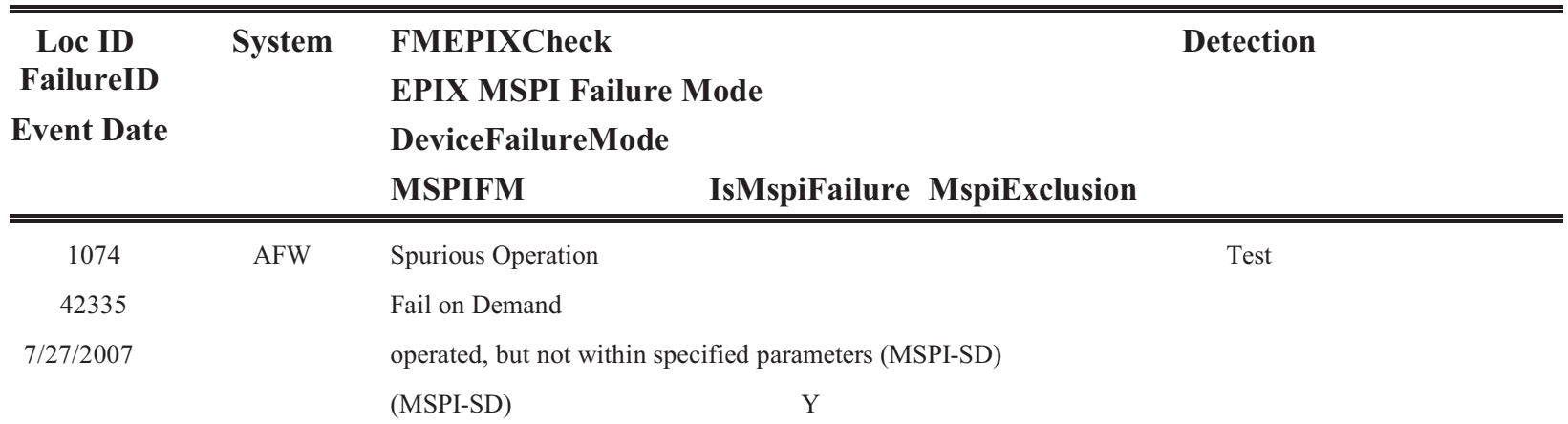

2HV5132 failed 14607-2 @ step 5.9: it failed to remain Closed in the Jog/Override position from 2HS5132A with an AFW actuation signal present. This condition report describes a condition where 2HV5132 failed remain Closed in the $\mathrm{Jog} /$ Override position from 2HS5132A with an AFW actuation signal present. This failure has been attributed to foreign material found inside the handswitch preventing one set of hand switch contacts to make up. The foreign material was likely from manufacturing based on the material, the color of the material, and the location of the material.

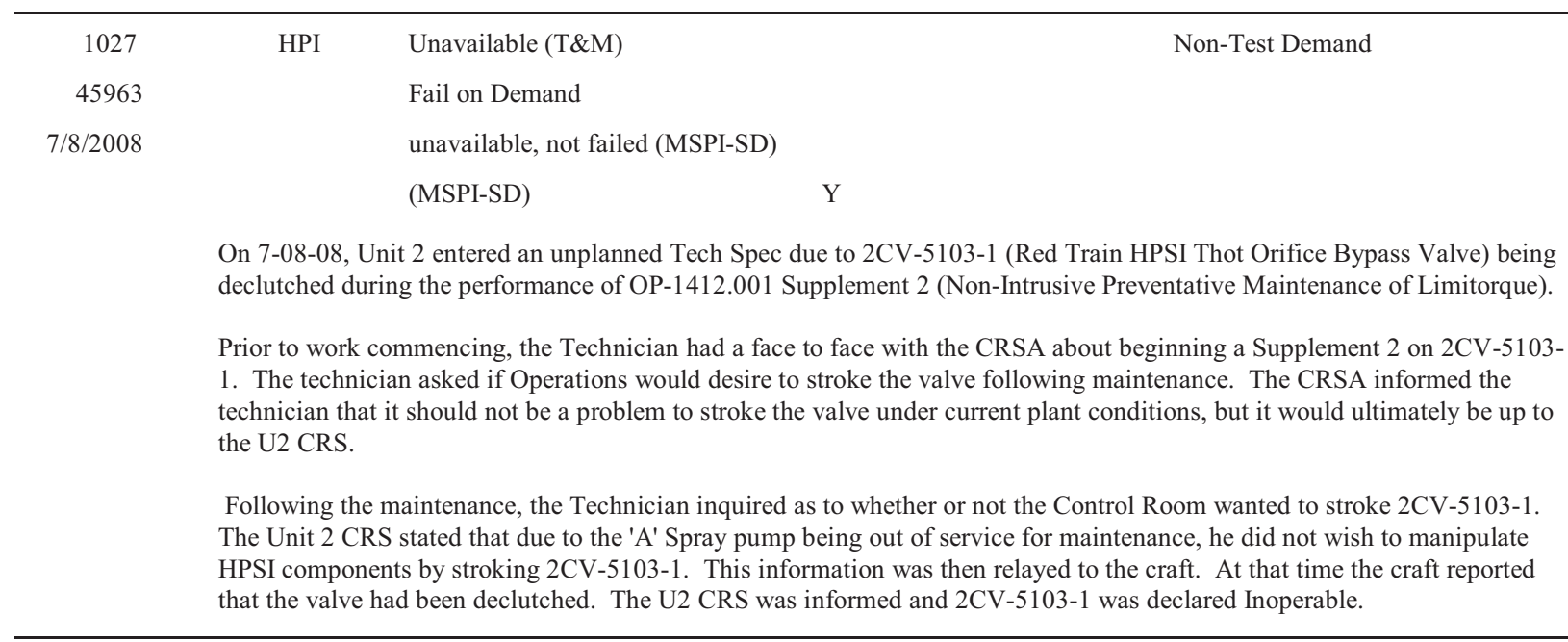




\section{Component Type $\quad \mathrm{MOV}$}

EPIX MSPI Failure Mode Unavailable (T\&M)

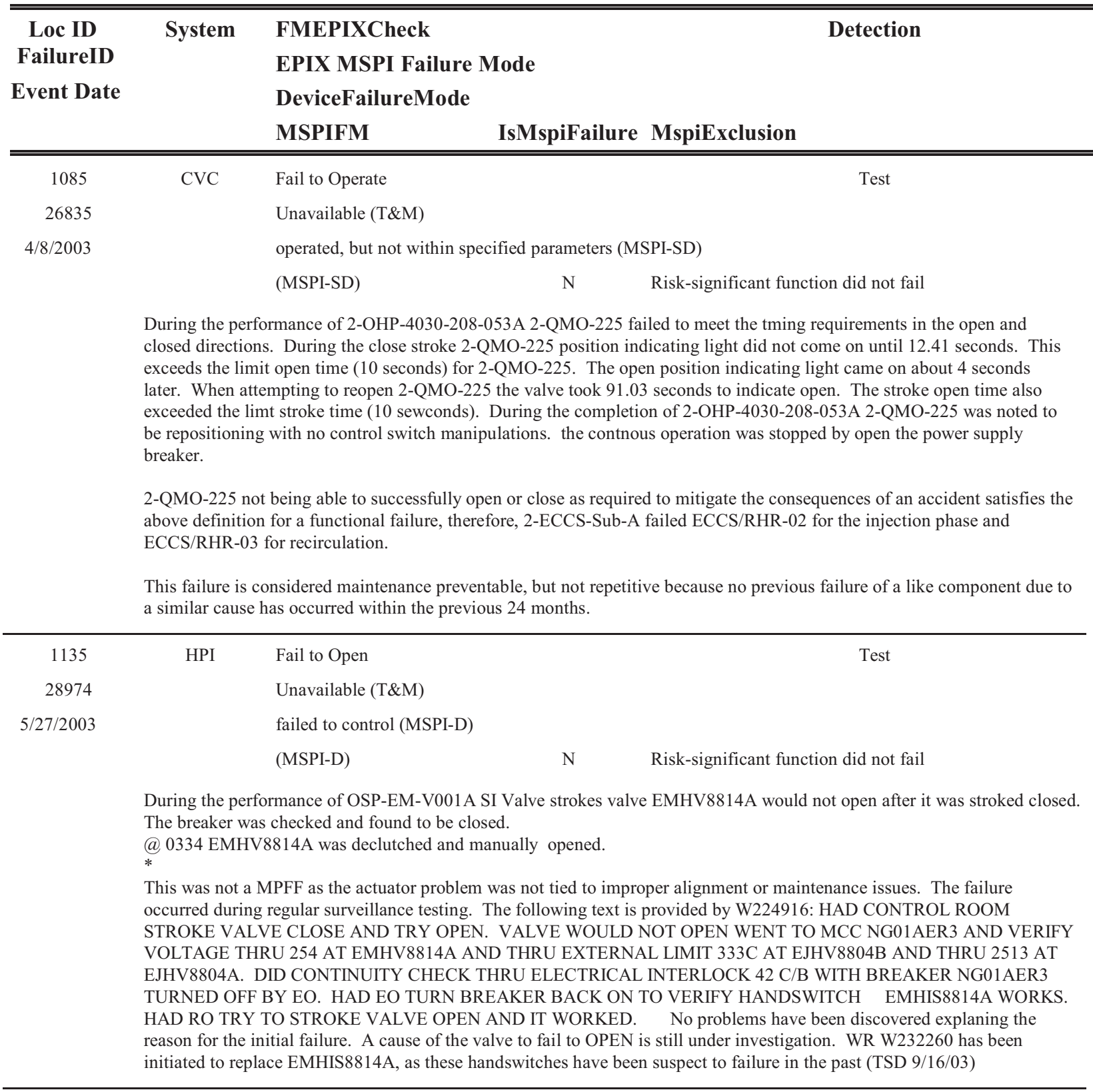




\section{Component Type $\quad \mathrm{MOV}$}

EPIX MSPI Failure Mode Unavailable (T\&M)

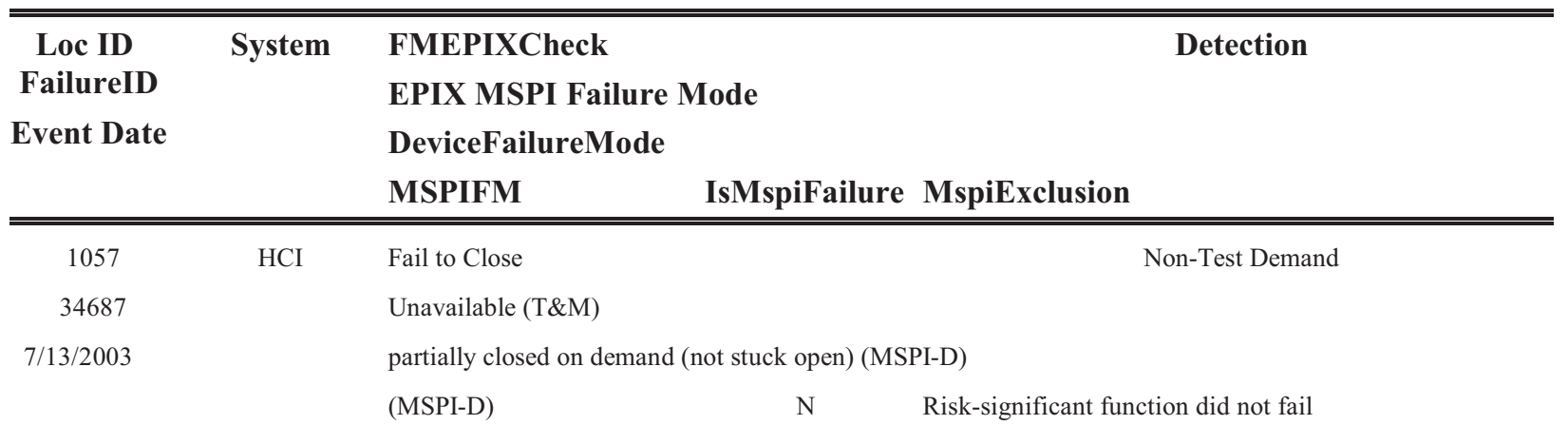

During performance of 24.202.01 (partial), HPCI Pump Time Response and Operability Test, after opening for stroke time (which was SAT), E4150F003 failed to fully close. Reopened E4150F003 to attempt to gather data and noted valve took about 2 seconds to indicate full open (normal stroke time is between $7.5 \mathrm{sec}$ and $12.4 \mathrm{sec}$ ). Troubleshooting was performed on E4150F003 by Electrical Maintenance personnel in accordance with Priority 1 Work Request 000Z032836 on

$7 / 14 / 2003$. The following activities were performed as part of troubleshooting:

* Electrical Maintenance (EM) verified that all connections were tight inside the motor control center (MCC),

* EM ensured that there was voltage at terminal 11 in the MCC which indicated that the normally closed (NC) portion of the open pushbutton was not the problem,

* Coordinated with the Control Room to cycle E4150F003 while monitoring with MPM by pressing and releasing the closed pushbutton (MOV moved closed momentarily),

* Coordinated with the Control Room to cycle E4150F003 while monitoring with MPM by pressing and holding in the closed pushbutton (MOV fully closed),

* Coordinated with the Control Room to cycle E4150F003 by pressing and holding in the closed pushbutton for approximately 5 seconds (MOV fully closed) [This indicated that there was a possible problem with the closed auxiliary seal in contact. The work request was revised to replace and test the auxiliary contact.]

RHR $1086 \quad \begin{aligned} & \text { Fail to Close } \\ & \text { Unavailable (T\&M) } \\ & \text { found unavailable during nondemand observation (MSPI-SD) } \\ & \text { (MSPI-SD) } \\ & \text { 3/26/2004 Risk-significant function did not fail }\end{aligned}$
IR 199068 was written because the breaker for 1E12F014A tripped. No valve manipulations were being performed. The
unit was in Mode 1 performing soft shut down for C1R09. The operator investigated the condition and found the control
power fuse blown. The fuse was replaced under the provisions of a one time fuse replacement.
The fuse was discarded and IR 199068 written for trending. The valve was declared Operable by Operations. Valve
1E12F014A is the RHR 'A' heat exchanger shutdown service water inlet. The impact of this condition caused an unexpected
LCO entry, Unplanned Unavailability for RHR 'A' and a Maintenance Rule Functional Failure. The significance is minimal,
the control power fuse was replaced and the component returned to operable status. This IR was written to document the
Maintenance Rule FF. By program requirements an EACE is required on the blown fuse.




\section{Component Type $\quad \mathrm{MOV}$}

EPIX MSPI Failure Mode Unavailable (T\&M)

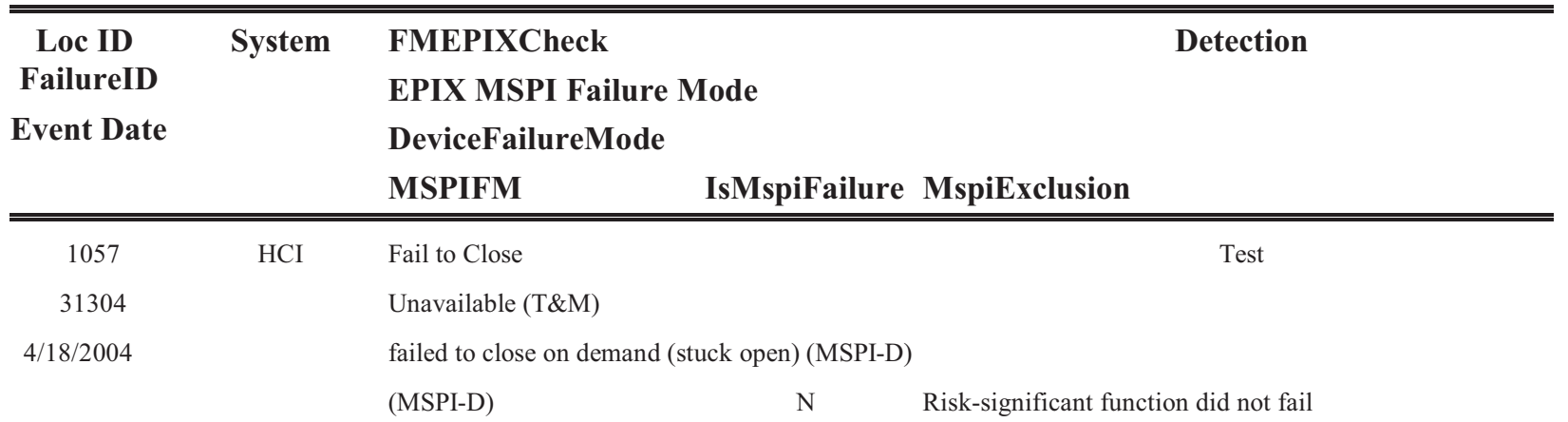

During 24.202.01, E4150-F003 was stroked open for stroke time (SAT). During the close stroke, the valve went dual and never closed. The valve was stroked open and closed earlier during the SOP run prior to the surveillance. The seal-in contact of this contactor was found not properly seated. This caused a distortion of the aux contact block. Review of history shows that this aux contact block was installed by Electrical Maint under WR\# 000Z032836 during 07/14/04. CARD 03-10957 addressed the failure of E4150-F003 to stroke and its root cause finding was determined to be the random failure of the closed seal-in aux contact due to poor contact surface material. WR\# 000Z032836 replaced the faulty seal-in aux contact and in doing so Electrical Maint seems to have induced a second random failure mode due to the aux contact block misalignment (see Attachment Photos).

After discussion with craft personnel who removed the aux contact block under 000Z032836 it was determined that the replacement was performed with the main contactor covers and movable contacts in place. Aux contact replacement can be performed this way, however it does make replacement more difficult. Due to the size of the starter and orientation of the leads it was necessary to land the leads on the aux contact prior to installation.This added tension to the aux contact block from the wires pulling away from contactor. After aux contact block replacement was completed, PMT was performed satisfactorily.

\begin{tabular}{rlll}
\hline 1086 & RCI & Fail to Close & Test \\
31608 & & Unavailable (T\&M) \\
$4 / 26 / 2004$ & failed to close on demand (stuck open) (MSPI-D) \\
& (MSPI-D) $\quad \mathrm{N} \quad$ Risk-significant function did not fail
\end{tabular}

While performing a maintenance run of RCIC following a system outage, as the RCIC turbine was being brought up to 1500$2000 \mathrm{rpm}, 1 \mathrm{E} 51-\mathrm{F} 019$ cycled at least 20 times and as many as 80 times, and eventually went full open. As flow was raised to $400 \mathrm{gpm}$ (above the min flow closure set-point), 1E51-F019 failed to close. Flow was lowered to $130 \mathrm{gpm}$ to raise RCIC discharge pressure to approximately $300 \mathrm{psig}$ (above $125 \mathrm{psig}$ valve opening criteria) and then raised flow to $340 \mathrm{gpm}$. RCIC Pump discharge pressure was approximately $180 \mathrm{psig}$ at $340 \mathrm{gpm}$. 1E51-F019 again failed to close. Per shift management discretion, the 20-minute maintenance run was completed with 1E51-F019 open, since the flowrate is minimal with respect to the amount of water being pumped from the RCIC Storage Tank to the Suppression Pool.

Secured RCIC IAW 3310.01 step 8.2.1.8.10. Minimum Flow valve 1E51F019 failed to close as required when the RCIC Turbine was secured. The RCIC Pump Minimum Flow Recirc To Suppression Pool valve should automatically close if the RCIC Pump discharge flow is $>240$ gpm or if either the RCIC Steam Supply Shutoff Valve (F045) or the RCIC Turbine Trip Throttle Valve (C002E) goes closed. Several attempts were made to close 1E51-F019 with the control switch in the $\mathrm{MCR}$, and were unsuccessful.

To comply with ITS LCO 3.6.1.3 Action A.1, 1E51-F019 was manually closed and deactivated. WR 116656 has been written to address this deficiency.

Investigation and troubleshooting revealed the auxiliary contacts for 1E51-F019 were found to be damaged. Further attempts to open and close 1E51-F019 from the MCR have been unsuccessful. The excessive Min flow valve cycling could result from starting the turbine manually with the existing logic, where the limit switch arm remains in contact with the round bar on the stem when the handwheel is only turned approximately one turn.

Due to the min flow valve logic (as shown below), in conjunction with the fact that the turbine-pump rotation will pump sufficient flow to satisfy the $120 \mathrm{gpm}$ and $125 \mathrm{psig}$ criteria; and without the Stop Valve being open far enough to actuate the full closed limit switch, the valve logic causes it to continuously cycle back and forth. 


\section{Component Type $\quad \mathrm{MOV}$}

EPIX MSPI Failure Mode Unavailable (T\&M)

\begin{tabular}{cclc}
\hline \hline Loc ID & System & FMEPIXCheck & Detection \\
FailureID & & EPIX MSPI Failure Mode & \\
Event Date & & DeviceFailureMode & \\
& & MSPIFM & Inspection \\
\hline \hline 1029 & HPI & Fail to Operate & \\
31387 & & Unavailable (T\&M) & \\
$6 / 2 / 2004$ & found unavailable during nondemand observation (MSPI-SD) & \\
& & $\mathrm{N}$ & Risk-significant function did not fail
\end{tabular}

Unit 2 Control Room received a SEIS alarm on "A" train valve HPSI Hdr "A" to RC LOOPs Isol Vlv HV698 (window 13L). Investigation showed no control room indication at SIAHV698 handswitch. Also, there is no indication of position locally at breaker PHAM3708. This alarm seemed to coincide with the start of the "A" ESP pump. No indications of any other abnormalities were found at this time. Locally SIAHV698 position matches that of SIBHV699. ERFDADS position indication for SIAHV698 was checked and there was no change in state, i.e. indicates open.

Entered LCO 3.5.3 Condition "B" and declared HPSI "A" INOPERABLE due to the loss of control power to SIAHV698. Background

CRDR 2713743 was written to document and address the receipt of a SEIS alarm on valve 2JSIAHV0698 (window 13L) which was also accompanied by a loss of control room indication at the valve handswitch. Local position indication was also lost. However, ERFDADS position

indication for 2JSIAHV0698 showed that the valve had not changed state (i.e. valve remained open). Troubleshooting was conducted under WO 2713742 and the only abnormality found was a defective 2.5 amp fuse in the associated Class $1 \mathrm{E} 480$ VAC MCC, 2EPHAM3708. The fuse

was replaced and the valve was confirmed to stroke satisfactorily.

\begin{tabular}{|c|c|c|c|}
\hline 1129 & SWN & Fail to Open & Non-Test Demand \\
\hline 36541 & & \multicolumn{2}{|l|}{ Unavailable (T\&M) } \\
\hline \multirow[t]{3}{*}{$6 / 21 / 2004$} & & \multicolumn{2}{|l|}{ unavailable, not failed (MSPI-SD) } \\
\hline & & (MSPI-SD) & Risk-significant function did not fail \\
\hline & \multicolumn{3}{|c|}{$\begin{array}{l}\text { 06/21/04, the 2A RHR HEX outlet valve failed to open as required with the A2 pump in service during performance of step } \\
\text { 7.8.8 of 2-SI-4.5.C.1(3-COMP). } \\
\text { Cause Description: It was discovered that BKR } 52 \text { STA actuator arm set screw was loose. The set screw was tightened, } \\
\text { breaker installed and closed and the problem was alleviated. }\end{array}$} \\
\hline 1086 & RHR & Fail to Open & Non-Test Demand \\
\hline 31559 & & \multicolumn{2}{|l|}{ Unavailable (T\&M) } \\
\hline $6 / 30 / 2004$ & & \multicolumn{2}{|c|}{ found unavailable during nondemand observation (MSPI-SD) } \\
\hline & & (MSPI-SD) & Risk-significant function did not fail \\
\hline & \multicolumn{3}{|c|}{$\begin{array}{l}\text { On 6/30/04 the control power fuse for 1AP76E-8A blew causing loss of power for 1E12F048B "RHR HX 1B SHELL SIDE } \\
\text { BYPASS VALVE" and resultant unplanned LCO and functional failure. Subsequent investigation and troubleshooting } \\
\text { revealed Agastat type GP relay 74X-E12FJB had sustained a coil circuit failure, which represents a typical end of life failure } \\
\text { mode for this device. This relay was discovered to be approximately } 15 \text { years old, as part of the modifications for Division } 2 \\
\text { remote shutdown capability installed in } 1989 \text { under WO } 144215 \text {. Review also revealed that this relay is normally energized } \\
\text { and does not have a periodic replacement PM, contrary to well established norms for this type device. Normally energized } \\
\text { relays of this type should be replaced on a periodic basis generally not more than } 10 \text { to } 12 \text { years. This is a demonstrated } \\
\text { effective technique to prevent or mitigate this failure mode, as these relays exhibit limited life in the normally energized state. }\end{array}$} \\
\hline
\end{tabular}




\section{Component Type $\quad \mathrm{MOV}$}

EPIX MSPI Failure Mode Unavailable (T\&M)

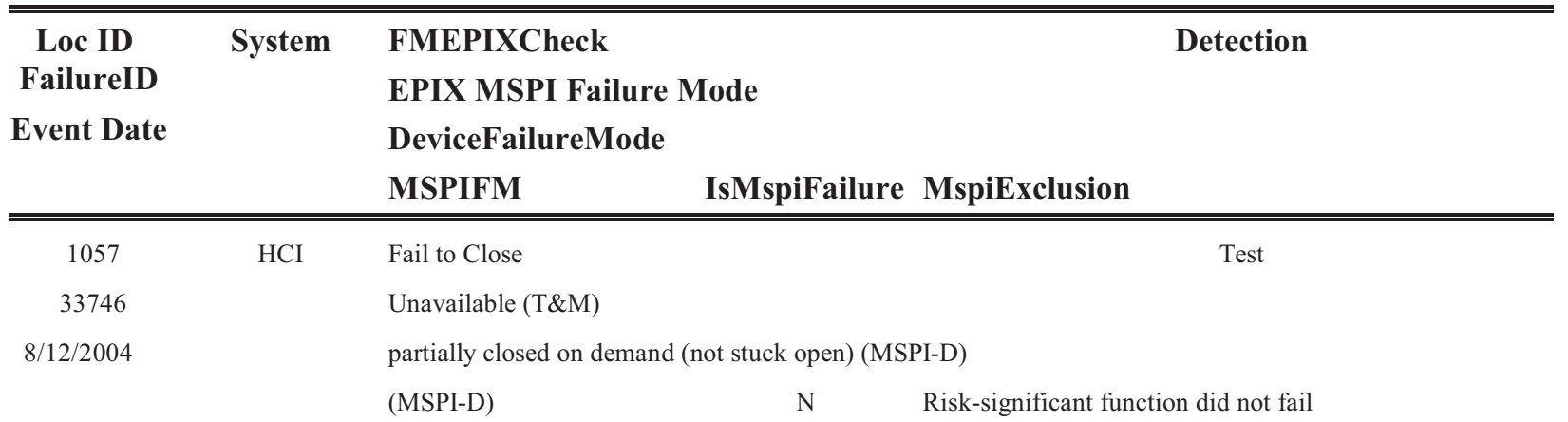

During surveillance 24.202.05 step 5.1.18 the E4150F003 failed to complete its closing stroke. Stopped the stopwatch after 2 minutes and re-opened the valve. The valve indicated full open approximately 2 seconds after depressing the open pushbutton. Stroked the valve closed again to determine repeatability and the valve stroked closed and indicated full closed in 11.2 sec (9.1-12.2 second specification). $\square$ This failure was identical in symptoms to two previous failures (CARD 0310957: 7/13/03; CARD 04-21564: 4/8/04). The first failure was attributed to an intermittent aux contact failure. The contact was replaced. The second failure was attributed to misaligned aux contacts (those installed as corrective action for the previous failure). The contacts were again replaced and correct alignment verified. $\square \square$ An EIT was formed immediately following the event. The team developed a fault tree, and from this developed a troubleshooting plan. The troubleshooting plan was implemented in accordance with Work Requests 000Z042333 (troubleshooting/inspection at the valve) and 000Z042337 (inspections and de-energized and energized checks from the MCC). Troubleshooting revealed no specific cause, but did indicate the problem was limited to the close seal-in portion of the control circuit. All active components in this portion of the circuit (close contactor, c/a relay, and open pushbutton) were replaced in accordance with Work Requests 000Z042337 (open pushbutton replacement) and 000Z973751 (bucket replacement), and the removed components quarantined for failure analysis. $\square$ The likely cause of this failure was the close seal-in contact on the open pushbutton not being electrically closed at the time of the first attempted closure. When the open PB was depressed it would have cycled that N.C. contact and restored it to its closed condition. That allowed the subsequent closing stroke attempt to be successful. $\square$ The entire contact block on the open pushbutton was replaced as corrective action.

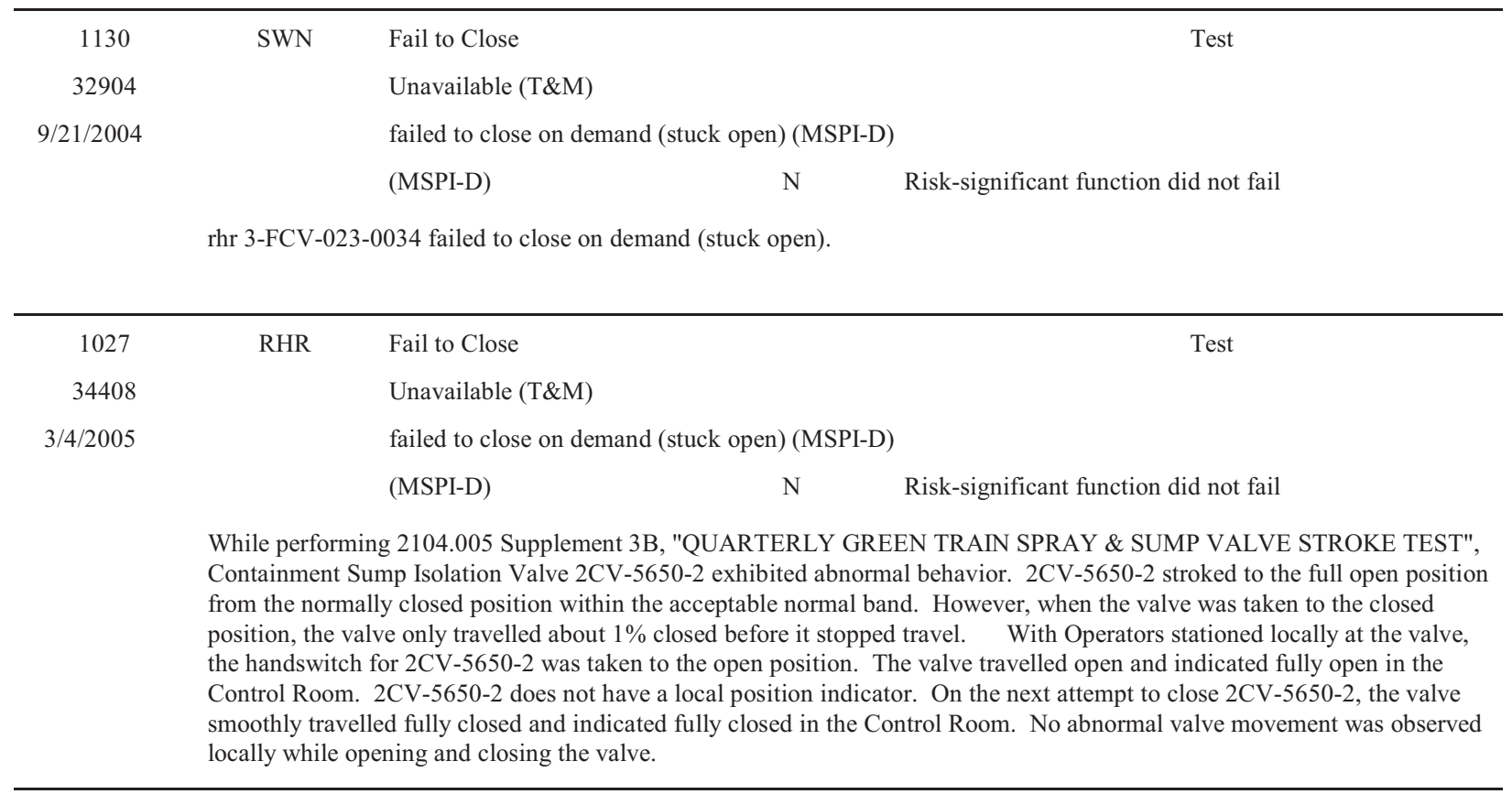




\section{Component Type $\quad \mathrm{MOV}$}

EPIX MSPI Failure Mode Unavailable (T\&M)

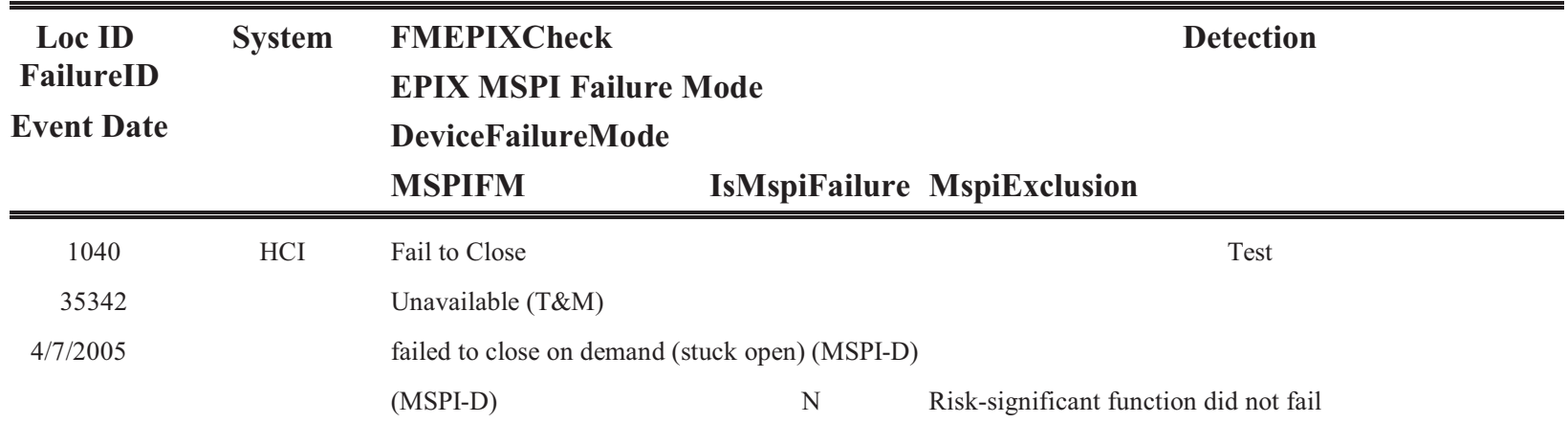

Operations attempted to stroke 1-E41-F001 in the closed direction during the performance of PT 9.2.4. The valve went to dual indication, i.e., mid-position, but did not fully close. The R.O. attempted to complete the close stroke multiple times by engaging the control switch, but was unsuccessful in completing the stroke. The valve was taken to the open direction, and it quickly indicated "full open." A subsequent attempt to electrically close the valve was successful.

Maintenance and Engineering personnel reviewed the Control Wiring Diagram (CWD) and determined the most likely cause of the problem to be a failure of the closed seal-in contactor to remain "closed" when Operations electrically cycled the valve. A troubleshooting plan was developed to monitor the contactor, along with actuation of the closed limit switch and the closed torque switch. I\&C technicians opened the MCC compartment door to attach run current and voltage monitoring equipment. When the door was opened, it was noted that a single wire, which was part of a bundle of wires in the compartment, was looped out of the bundle and was resting against the closed auxiliary seal-in contact. The wire was moved aside. Subsequently, Operations stroked the valve open and back closed. The valve operated properly and the stroke time was normal.

\begin{tabular}{|c|c|c|c|}
\hline 1129 & SWN & Fail to Open & Non-Test Demand \\
\hline 36089 & & \multicolumn{2}{|l|}{ Unavailable (T\&M) } \\
\hline \multirow[t]{3}{*}{ 9/30/2005 } & & \multicolumn{2}{|l|}{ discovered to be unable to open (MSPI-D) } \\
\hline & & (MSPI-D) & Risk-significant function did not fail \\
\hline & \multicolumn{3}{|c|}{ On 09/30/05 the 2A RHR HEX outlet valve, 2-FCV-23-34, failed to open when the A2 RHRSW pump was placed in service } \\
\hline 1135 & HPI & Fail to Open & Test \\
\hline 38985 & & Unavailable (T\&M) & \\
\hline \multirow[t]{2}{*}{$5 / 22 / 2006$} & & \multicolumn{2}{|c|}{ failed to open on demand (stuck closed) (MSPI-D) } \\
\hline & & (MSPI-D) & Risk-significant function did not fail \\
\hline & \multicolumn{3}{|c|}{ During performance of OSP-EM-V001A SI valve strokes, EMHV8814A would not open after it was stroked closed. } \\
\hline & Investigatec & b 06116807 and found the aux contact o & ose coil to be sticking. \\
\hline
\end{tabular}




\section{Component Type $\quad \mathrm{MOV}$}

EPIX MSPI Failure Mode Unavailable (T\&M)

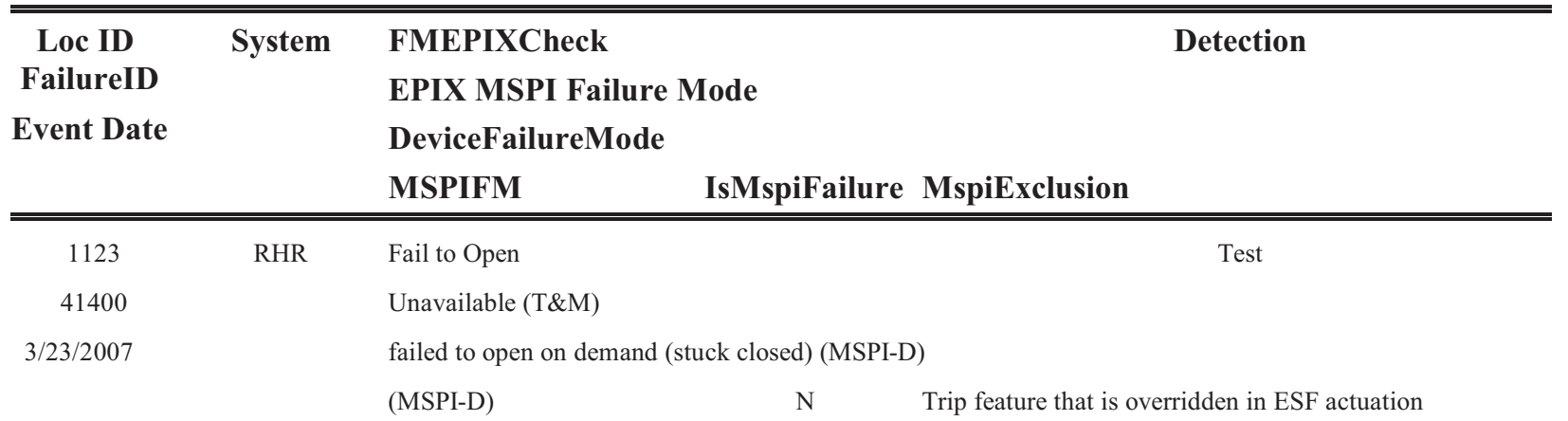

While performing 06-OP-1P75-R-0004, during step 5.8.27i. the following was observed:

1E12-F048B was fully closed by holding the handswitch.

When 1E12-F048B reached full closed and while still holding the handswitch, breaker 152-163103 tripped to the "trip free" position.

Breaker 152-163103 was reset and reclosed prior to the 10 minute limit and 1E12F048B stroked fully open when the handswitch was released.

The actual cause of the reported condition is not known at this time. The 1E12F048B valve appeared to operate properly before the power supply breaker tripped and after the power supply breaker had been reset. The condition reported by the referenced CR is to be resolved at a later date by completion of WO No. 106059. Until this WO is completed, the actual cause of the reported event may not be knowm. Thus, at this time, the reported event is consertatively considered to be a loss of Maintenance Rule Program Function M-E12-15, "OPEN RHR HEAT EXCHANGER BYPASS VALVE F048A/B". Since the F048B valve could not be immediately opened remotely, this function was apparently impacted by the reported event. After the referenced WO is completed, it would seem prudent to review the actual cause of the reported event to determine if the ability to CLOSE the F048B valve was impacted by the reported event

\begin{tabular}{|c|c|c|c|}
\hline 1130 & SWN & Fail to Close & Non-Test Demand \\
\hline 42397 & & \multicolumn{2}{|l|}{ Unavailable (T\&M) } \\
\hline \multirow[t]{4}{*}{$7 / 5 / 2007$} & & \multicolumn{2}{|c|}{ found unavailable during nondemand observation (MSPI-SD) } \\
\hline & & (MSPI-SD) & Risk-significant function did not fail \\
\hline & \multicolumn{3}{|c|}{$\begin{array}{l}\text { On 07/05/07, 3-FCV-023-0034 was found inoperable (Failed to close) during an attempt to isolate RHRSW flow to the } 3 \mathrm{~A} \\
\text { RHR HEX. }\end{array}$} \\
\hline & \multicolumn{3}{|c|}{$\begin{array}{l}\text { The valve was failed open and cooling water was provided. The } \\
\text { problem occurred on the closure of the valve. The valve was manually closed to provide isolation. }\end{array}$} \\
\hline 1074 & SWN & Fail to Open & PMT \\
\hline 43589 & & Unavailable (T\&M) & \\
\hline \multirow[t]{4}{*}{$8 / 23 / 2007$} & & discovered to be unable to open (MSPI-D) & \\
\hline & & (MSPI-D) & Risk-significant function did not fail \\
\hline & \multicolumn{3}{|c|}{ NSCW valve lost auto open function during instrument maintenance. } \\
\hline & \multicolumn{3}{|c|}{$\begin{array}{l}\text { During performance of MWO } 106189301 \text { (Correct MWO is } 1061895301-\mathrm{R} 1 \mathrm{X} \text { by AFS } 10 / 23 / 07) \text { for }(24229-1) \text {, removal } \\
\text { of NSCW 'A' Train Tower Control Valve, it was determined that the removal of the loop 1-T1668 for calibration resulted in } \\
\text { TS 3.7.9 Contion A. entry. This work was planned and scheduled in the POD. }\end{array}$} \\
\hline
\end{tabular}




\section{Component Type $\quad \mathrm{MOV}$}

EPIX MSPI Failure Mode Unavailable (T\&M)

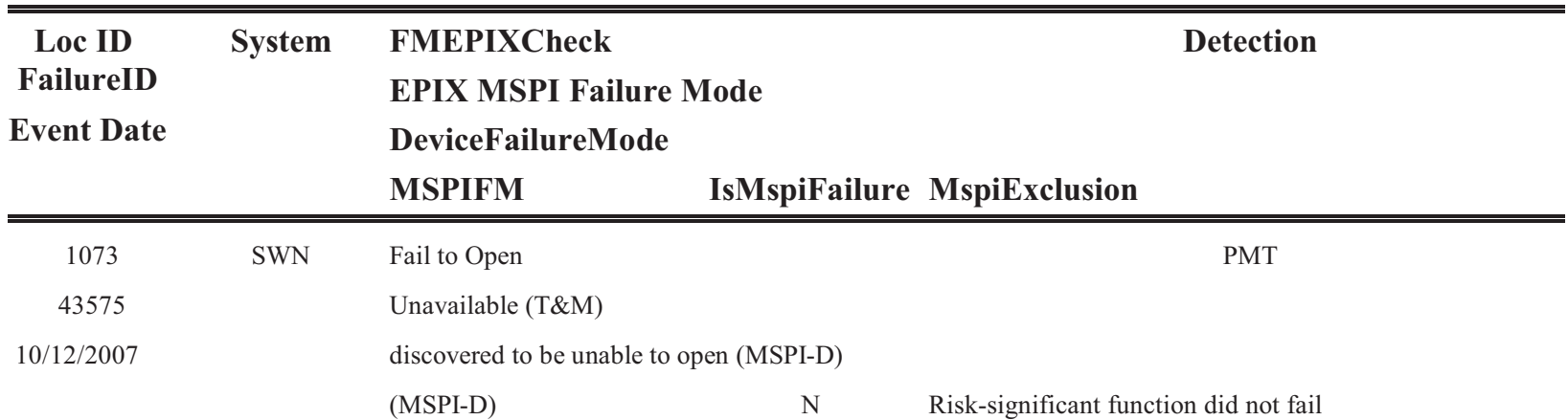

During performance of MWO 106189301 (Correct MWO is 1061895301 - R1X by AFS 10/23/07) for (24229-1), removal of NSCW 'A' Train Tower Control Valve, it was determined that the removal of the loop 1-T1668 for calibration resulted in TS 3.7.9 Contion A. entry. This work was planned and scheduled in the POD.

Not an actual failure,NSCW valve lost auto open function during maintenance on instrumentation

\begin{tabular}{|c|c|c|c|}
\hline 1057 & $\mathrm{RCI}$ & Fail to Open & PMT \\
\hline 43353 & & \multicolumn{2}{|l|}{ Unavailable (T\&M) } \\
\hline \multirow[t]{3}{*}{$11 / 10 / 2007$} & & \multicolumn{2}{|c|}{ failed to open on demand (stuck closed) (MSPI-D) } \\
\hline & & (MSPI-D) & Risk-significant function did not fail \\
\hline & \multicolumn{3}{|c|}{$\begin{array}{l}\text { RCIC PUMP SPLY TO FEEDWATER HEADER ISO VLV did not stroke from the control room during the performance of } \\
24.206 .02 \text {. The valve also made an abnormal noise during stroke attempts. } \\
\text { RCIC was already in an inoperable status. The testing was being performed for PMT following scheduled preventive } \\
\text { maintenance on the MOV. }\end{array}$} \\
\hline 1121 & AFW & Fail to Close & PMT \\
\hline 44790 & & Unavailable (T\&M) & \\
\hline \multirow[t]{2}{*}{$1 / 16 / 2008$} & & \multicolumn{2}{|l|}{ discovered to be unable to close (MSPI-D) } \\
\hline & & (MSPI-D) & Risk-significant function did not fail \\
\hline
\end{tabular}

On 16 Jan 08 after overspeed trip testing activities for 2P140, Steam Driven Auxiliary Feedwater Pump, the actuator for MOV 2HV4716, Aux Feedwater Turbine Steam Inlet Valve, failed to stroke to the closed position.

Troubleshooting found two sets components were identified as possible causes for the problem.

The limit switch (LS-5) was reported as failed, but subsequent bench testing induced recovery. The normally closed contacts from the Opening Coil (42 OC) were found open when they should have been closed, and this was a verifiable cause for the failure, singly or in combination of the suspect limit switch.

\begin{tabular}{|c|c|c|c|}
\hline 1041 & SWN & Fail to Open & Inspection \\
\hline 45766 & & \multicolumn{2}{|l|}{ Unavailable (T\&M) } \\
\hline \multirow[t]{3}{*}{$3 / 19 / 2008$} & & \multicolumn{2}{|c|}{ found unavailable during nondemand observation (MSPI-SD) } \\
\hline & & (MSPI-SD) & Risk-significant function did not fail \\
\hline & \multicolumn{3}{|c|}{$\begin{array}{l}\text { The 1-SW-V105 valve is a safety-related motor-operated butterfly valve that acts to provide a flow path for service water } \\
\text { from the U1 Nuclear Service Water (NSW) header to the 1B and 1D RHRSW Booster Pumps. Failure/loss of the disc pins } \\
\text { for the 1-SW-V105 introduces three concerns: (1) the loss of both pins would result in disc/stem separation that would allow } \\
\text { the butterfly to close when the operator is in the OPEN position, (2) a closed valve would not respond to an OPEN signal, } \\
\text { and (3) the loss of either disc pin introduces foreign material that has the potential to damage the downstream RHRSW } \\
\text { Booster Pumps. }\end{array}$} \\
\hline
\end{tabular}


Component Type TDP 


\section{Component Type TDP}

EPIX MSPI Failure Mode Fail to Run

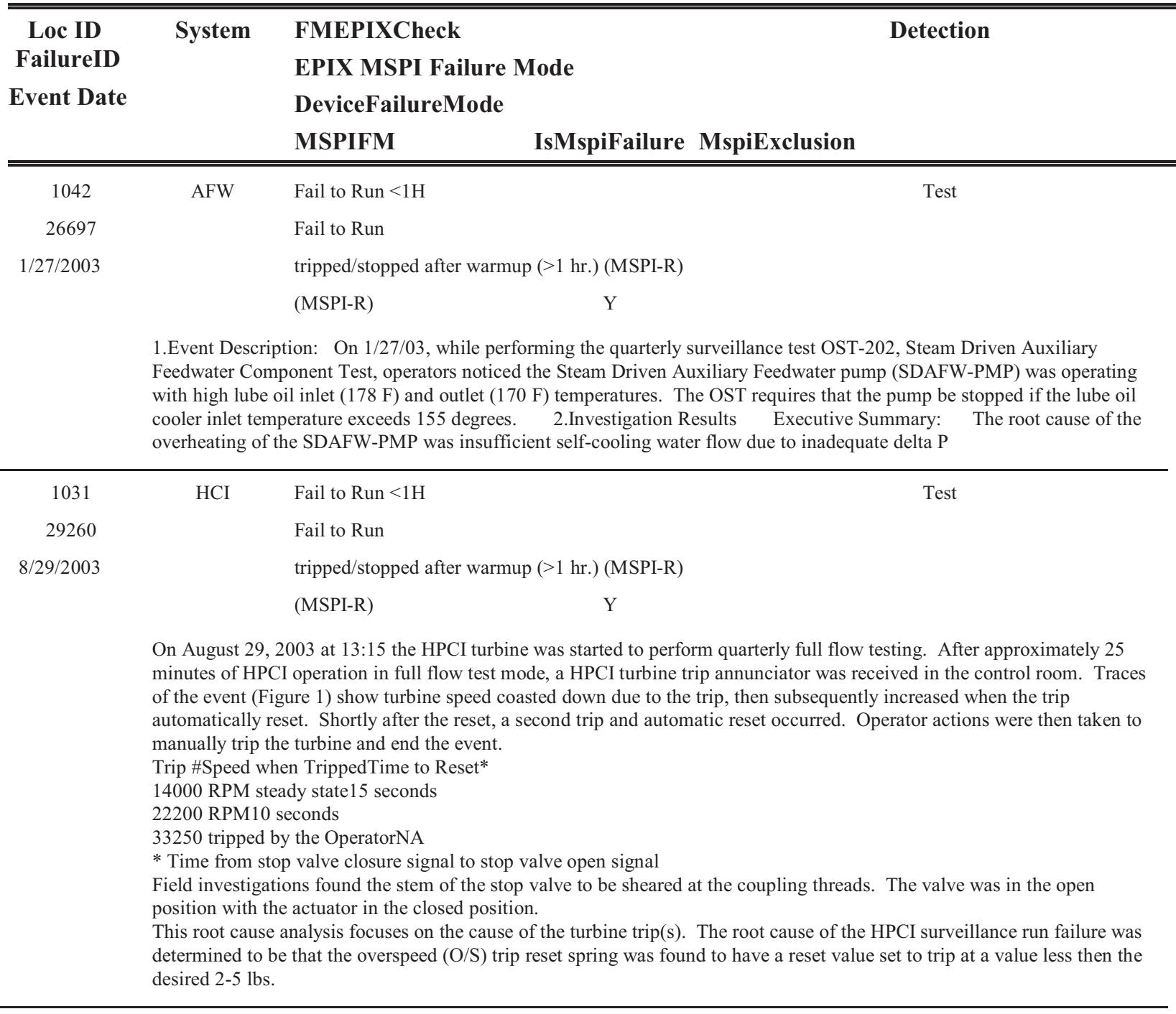




\section{Component Type TDP}

EPIX MSPI Failure Mode Fail to Run

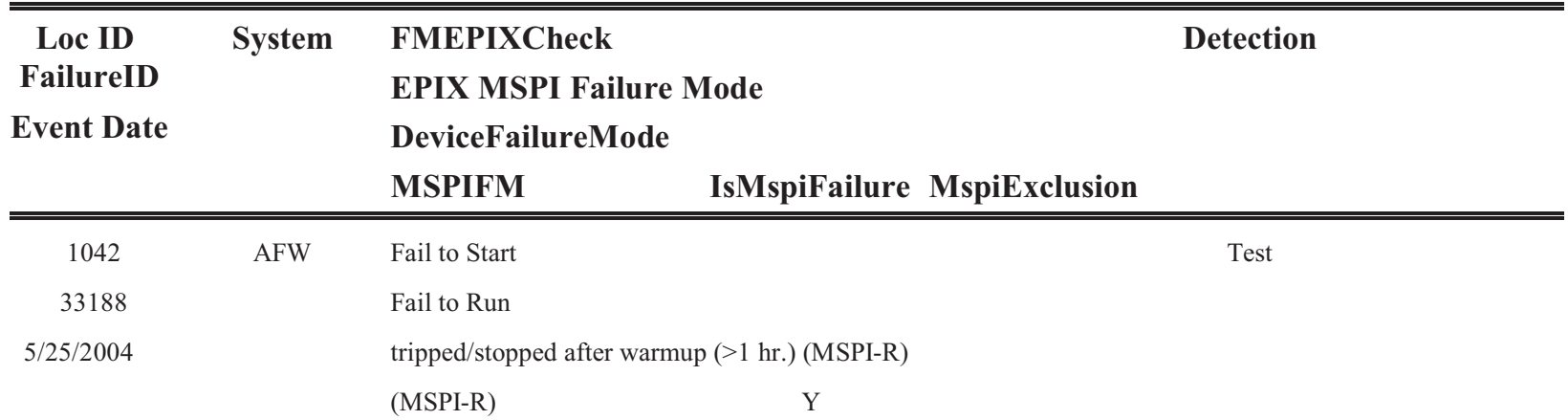

During performance of OST-202 on 5/25/04, the SDAFW pump began to emit sparks from the pump deflector inspection port. The pump was secured after $10-15$ seconds, and an inspection was performed to determine if foreign material had entered the gap between the deflector and diaphragm. No obvious foreign material was revealed. Subsequent pump starts on the same day (2258 hrs. and 2324 hrs.) produced similar results. During the 2258 start, sparks were emitted immediately, died out, and then re-appeared. The pump was tripped after $30-40$ seconds. During the 2324 start, sparks were emitted immediately and more severe than previous starts. The pump was tripped after 2030 seconds.

2. Problem Description

A normal SDAFW-PMP start would be smooth with no interferences such as visible sparks and metal-to-metal rubbing noise. Sufficient disassembly of the pump to reveal the face of the deflector revealed rolled or deposited metal on the deflector face and adjoining diaphragm face. The gap between the two parts had closed causing interference between the deflector and the diaphragm.

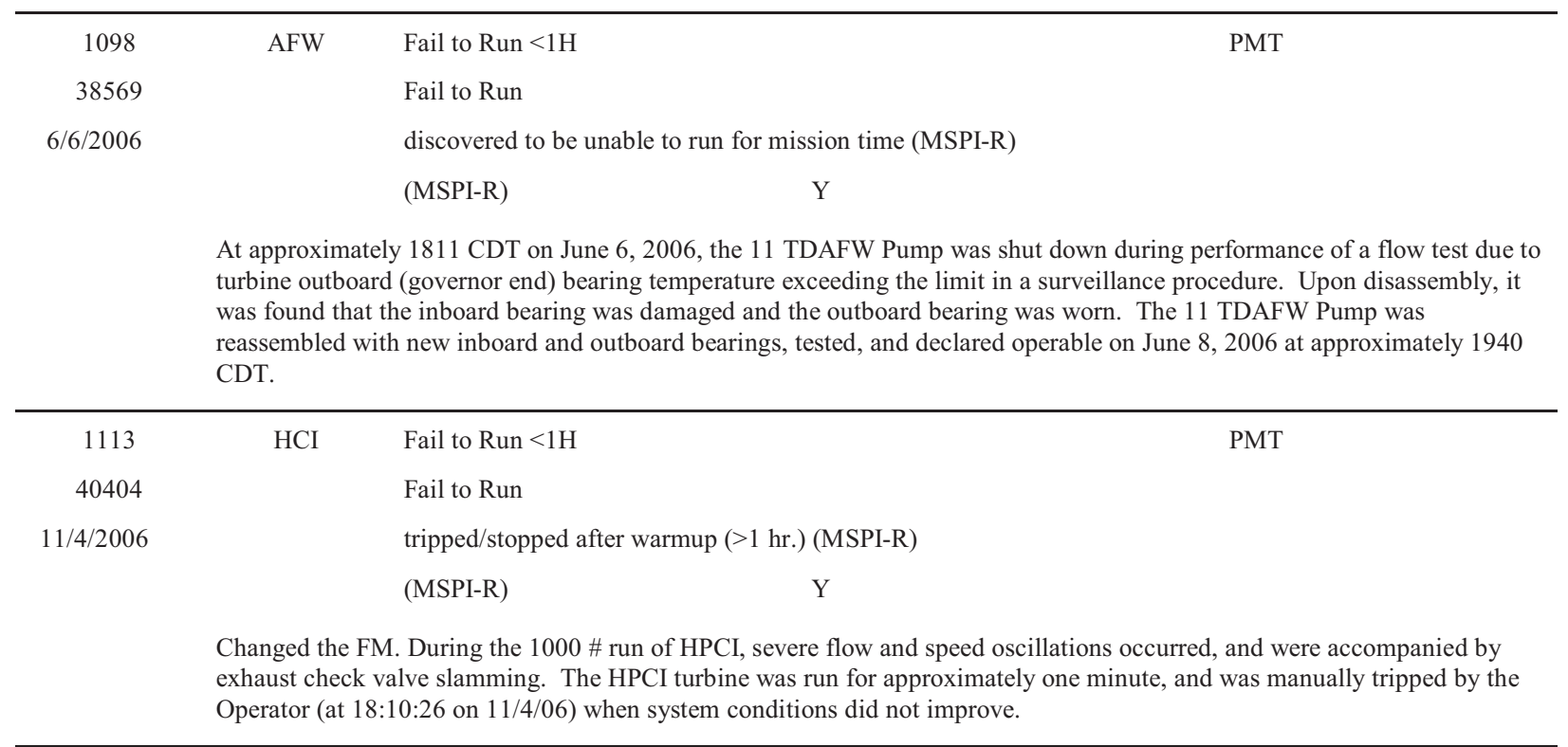




\section{Component Type TDP}

EPIX MSPI Failure Mode Fail to Start

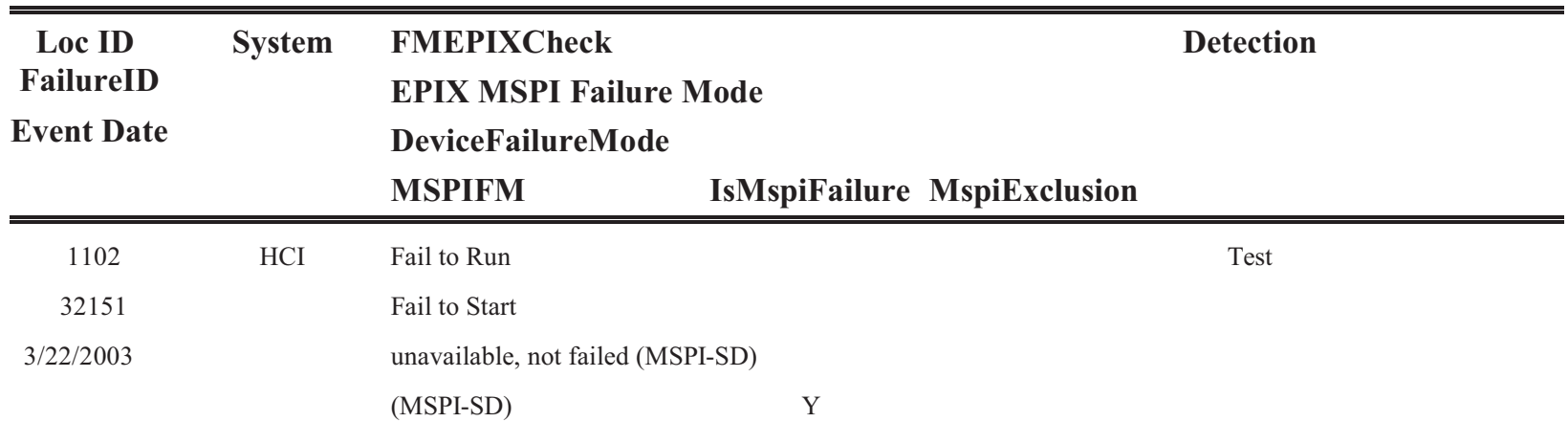

Unplanned RCIC inoperability during the performance of ST-2-055-601-1 (ECCS - CONDENSATE STORAGE TANK LEVEL - LOW, DIV 2 (HPCI)FUNCTIONAL TEST (LIS-55-1N661B)). The inoperability occurred when the HPCI suction swapped which caused a pressure change on the CST supply line to both HPCI and RCIC. This change in pressure caused the "RCIC pump suction low pressure" (116 RCIC window B1) and the "RCIC pump suction high pressure" (116 RCIC window B2)alarms to annunciate. The pump suction low pressure caused a RCIC turbine trip. The ST states that the following in the "shift permission to test section":

- Due to the change in head pressure when HPCI valve line-up changes from CST to Suppression Pool, performance of this test may affect the following RCIC alarms/indications, which may be reset as necessary. 1. Annunciator 116 RCIC-A1 (10C848-1), RCIC OUT OF SERVICE. 2. GROSS FAIL Indication on FIS-49-1N651, (RCIC PUMP DISCHARGE). 3. GROSS FAIL Indication on FS-49-1N659, (RCIC PUMP DISCHARGE). 4. Status Light DS18 at RCIC Panel 10C648, (DIVISION 1); "RCIC T/U IN CAL OR GROSS FAIL" RCIC turbine trip was reset using S49.1.C and operability restored to RCIC at 02:51.

HCI Unavailable (T\&M)
Fail to Start
operated, but not within specified parameters (MSPI-SD)
(MSPI-SD)
On 3/29/2003/03 at 245 EST, Unit 2 was in the Startup mode with the reactor critical at a power level of approximately $1 \%$
CMWT and reactor pressure of approximately 165 psig. Major maintenance was performed on the High Pressure Coolant
Injection (HPCI) system during the refueling outage. Surveillance procedure 34SV-E41-005-2, "HPCI Pump Operability
165 PSIG Test" was being performed when it was determined that the control valve, 2E41-F3052, went to the fully open
position and the flow controller, 2E41-R612, showed a system flow in excess of 5200 GPM.
Investigation uncovered the fact that the gap between the toothed sensing gear and the magnetic speed pickup sensor was
greater than the .008" required by procedure. This caused the governor system to incorrectly sense a zero speed condition
and attempt to increase the turbine speed to correspond to the speed demand signal from the flow controller. Once the flow
controller sensed that flow was increasing past the flow controller setpoint of 4250 GPM, the speed demand from the flow
controller was automatically decreased to try to bring the flow back to the controller's setpoint. This demand was decreased
until the low speed signal of 4 ma was reached (which corresponds to approximately 850 RPM). Since the governor system
was still seeing zero speed, the governor system still tried to reach 850 RPM by continually opening the control valve until it
was fully open. Since reactor pressure was low, there was not sufficient motive force to drive the turbine to an overspeed
condition(reference CR 2003004227). Briefly, the magnetic speed pick-up that supplies the speed feedback signal to the
governor system was incorrectly set-up. Subsequently, the magnetic speed pick up was adjusted and the HPCI surveillance
test was successfully completed and the HPCI system was declared operable at 1215 EST.




\section{Component Type TDP}

EPIX MSPI Failure Mode Fail to Start

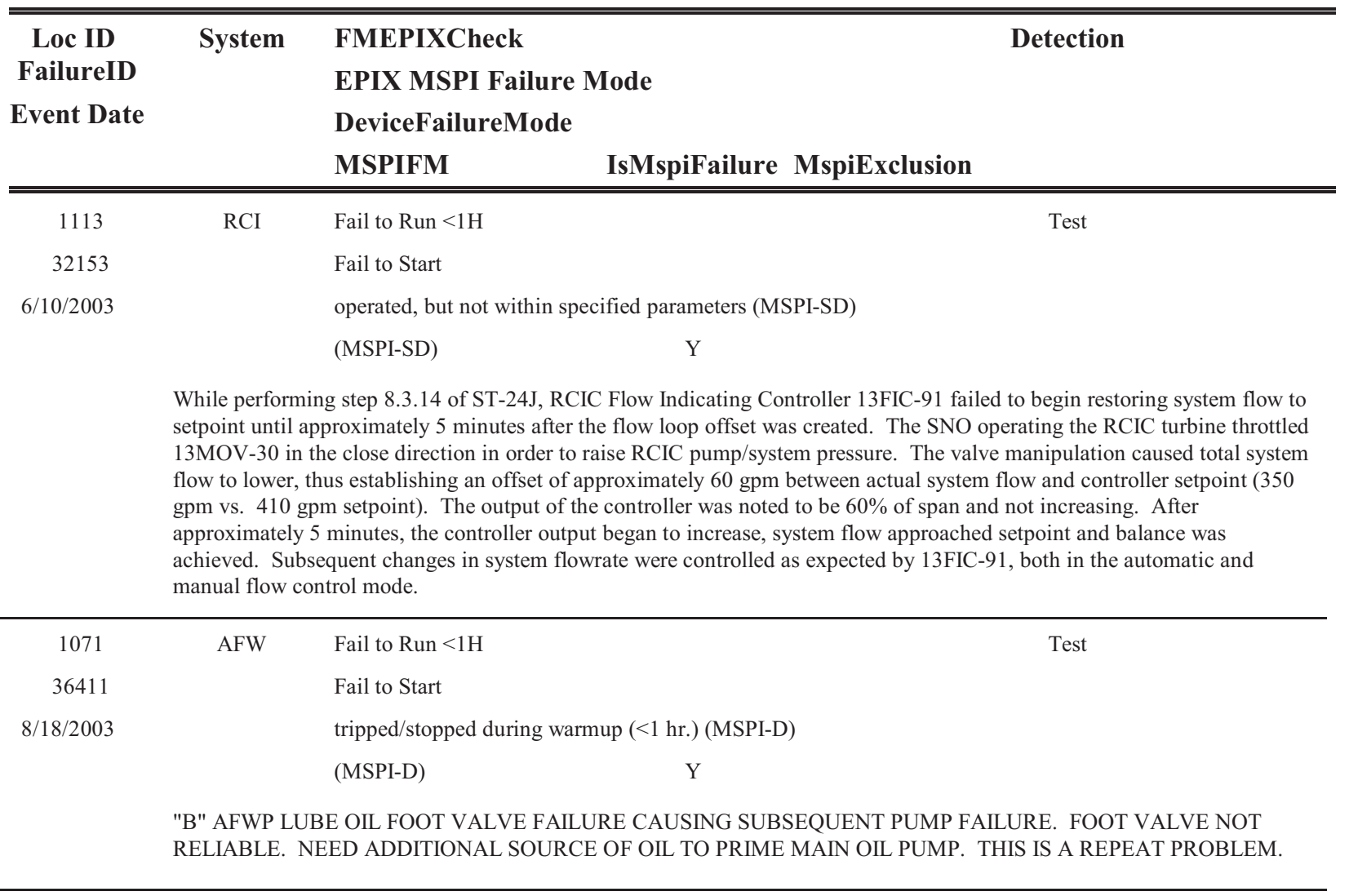




\section{Component Type TDP}

EPIX MSPI Failure Mode Fail to Start

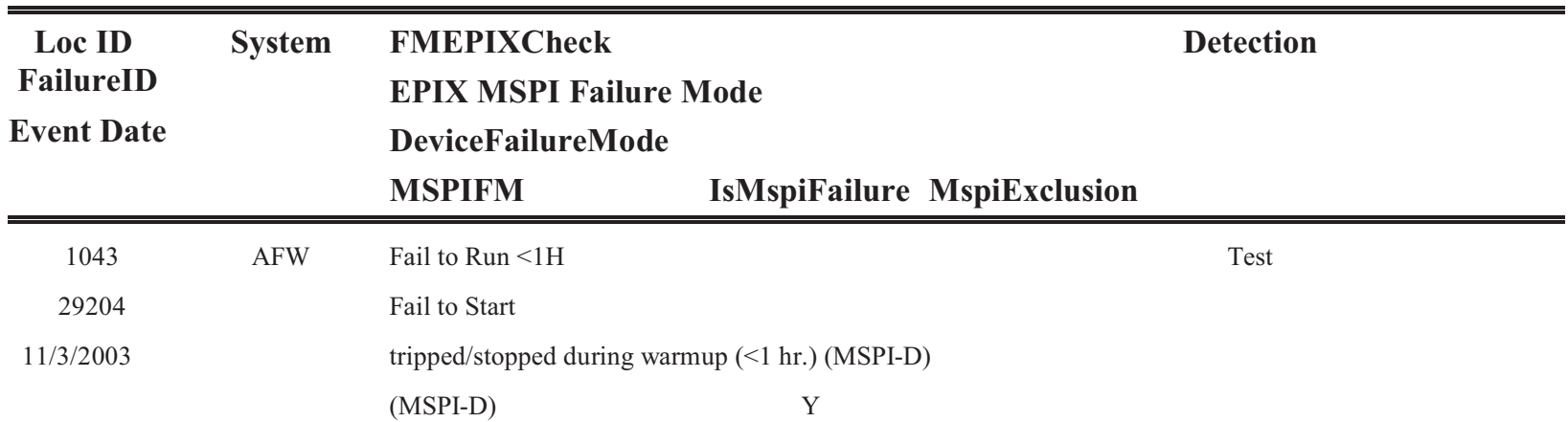

With the TDAFW discharge FCV shut and recirculation flow path aligned, the TDAFW pump was started by opening 1MS72. Within approximately 15 seconds the trip and throttle valve tripped closed due to mechanical overspeed. The turbine casing relief was observed to lift. It was noted locally that the governor did not appear to respond to control speed, as expected, during the start. ERFIS and OSI-PI captured a peak speed of $4863 \mathrm{rpm}$ which is in excess of the normal maximum control band speed of $4100 \mathrm{rpm}$. EIR 20030783 and WR\# 120370 initiated. $\square \square$ Request: $\square \square$ Perform Maintenance Rule Review $\square \square$ Response: $\square \square$ The TDAFW pump trip on mechanical overspeed that occurred on 11/03/03 at 14:28 was a Maintenance Rule functional failure, for further information see maintenance rule entry. $\square \square$ Maintenance Rule Entry: $\square \square$ The TDAFW pump tripped on mechanical overspeed shortly after start in support of OST-1411. Investigation determined that electronic problem existed with the dropping resistor that supplied power to electronic governor and the ramp generator. The dropping resistor is replaced periodically (PMID\# 23341-01 $=728$ days). The ramp generator is replaced when the component can not be successfully calibrated. $\square \square$ The last functional failure for the TDAFW pump was recorded on 8/26/97 due to excessive vibration on the inboard bearing of the TDAFW pump. $\square \square$ This TDAFW pump performance monitoring group consists of the turbine driven AFW pump, turbine, turbine controls, and all of the turbine train piping and valves (open position) between the pump suction and the steam generator nozzles. This group also includes the ability of components in the turbine steam supply lines to open or remain open and to adequately remove condensate. Components in the flow paths to the individual steam generators are included with this performance group since the turbine speed control system is sensitive to changes in the flow configuration. A value of 144 unavailability hours per 18 month period $(1.1 \%)$ was chosen to accommodate planned train outages with a provision for unplanned down time. A reliability performance criteria of one FF per two operating cycles was also selected based upon historical system performance. This criteria was evaluated as part of the integrated PSA review of all system unavailability (NF-96A-0190) and determined to be acceptable. $\square \square$ Event Description $\square \square$ WITH THE TDAFW DISCHARGE FCV SHUT AND RECIRC. FLOWPATH TDAFW PUMP WAS STARTED BY OPENING 1 MS-72. WITHIN 15 SECS. THE T\&T TRIPPED CLOSED DUE TO MECHANICAL OVERSPEED. THE TURBINE CASING RELIEF WAS OBSERVED TO LIFT. IT WAS NOTED LOCALLY THAT THE GOVERNOR DID NOT APPEAR TO RESPOND TO CONTROL SPEED, AS EXPECTED, DURING THE START. ERFIS AND OSI PI CAPTURED A PEAK SPEED OF 4863 RPM WHICH IS IN EXCESS OF THE NORMAL MAXIMUM CONTROL BAND SPEED OF 4100 RPM. EIR 20030783 AND WR 120370 INITIATED. $\square$ 2.Problem Description / Investigation Summary $\square$ TDAFW pump tripped on over speed during OST-1411 and caused the plant to enter a 72 hour unplanned LCO. WO 480783-01 was initiated to repair this condition. Investigation revealed that R5, a $200 \mathrm{ohm}$ voltage dropping resistor, had failed. The RGSC, ramp generator signal converter, was also found defective and was replaced.

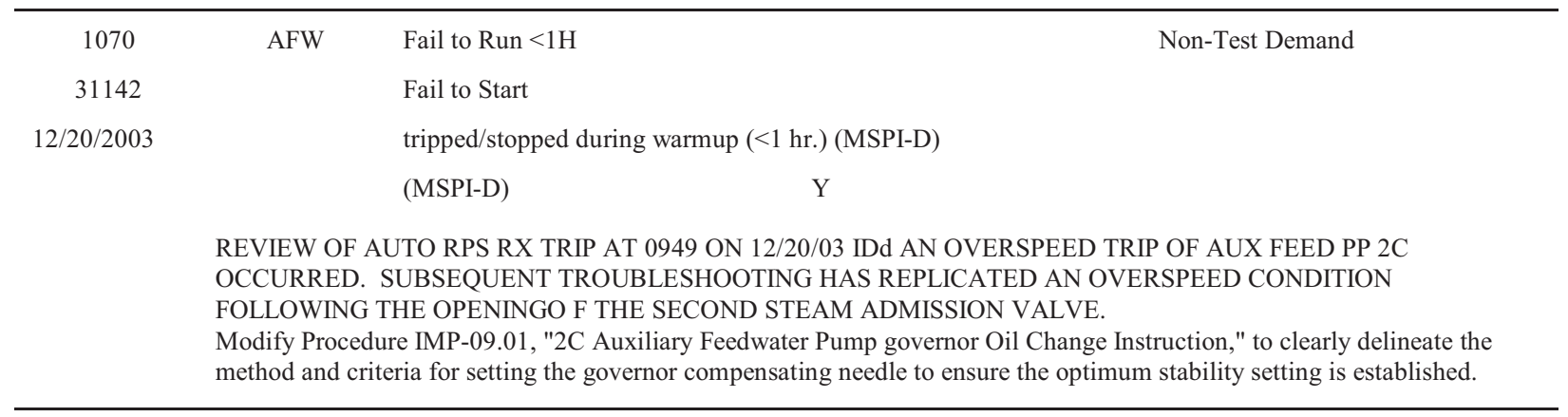




\section{Component Type TDP}

EPIX MSPI Failure Mode Fail to Start

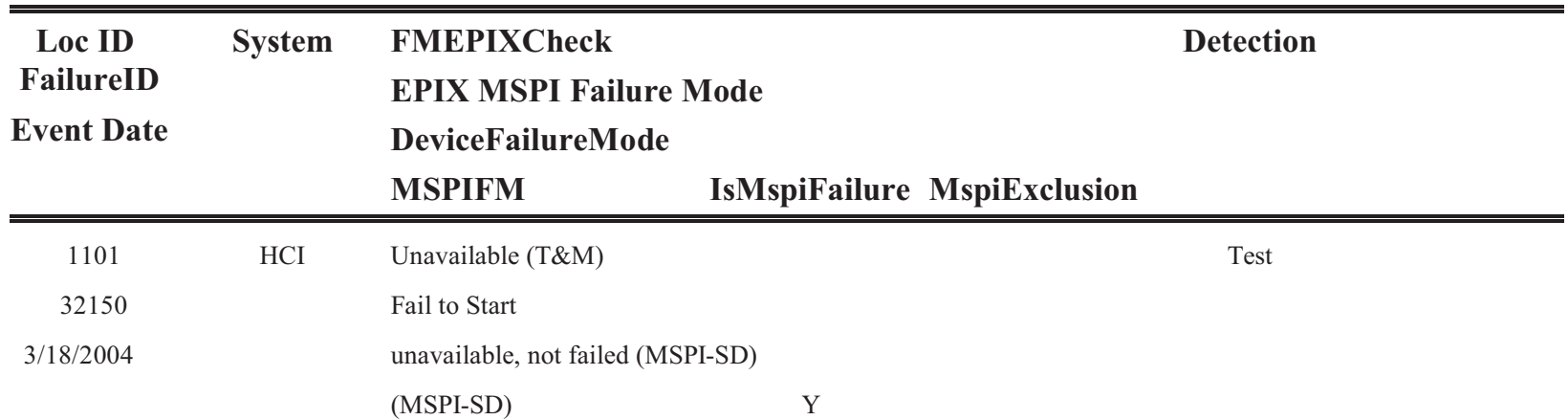

Unplanned RCIC inoperability during the performance of ST-2-055-601-1 (ECCS - CONDENSATE STORAGE TANK LEVEL - LOW, DIV 2 (HPCI)FUNCTIONAL TEST (LIS-55-1N661B)). The inoperability occurred when the HPCI suction swapped which caused a pressure change on the CST supply line to both HPCI and RCIC. This change in pressure caused the "RCIC pump suction low pressure" (116 RCIC window B1) and the "RCIC pump suction high pressure" (116 RCIC window B2)alarms to annunciate. The pump suction low pressure caused a RCIC turbine trip. The ST states that the following in the "shift permission to test section":

\begin{tabular}{|c|c|c|c|}
\hline 1103 & \multirow[t]{2}{*}{$\mathrm{HCI}$} & Fail to Run & \multirow[t]{2}{*}{ Non-Test Demand } \\
\hline 32024 & & Fail to Start & \\
\hline $5 / 15 / 2004$ & & \multicolumn{2}{|c|}{ unaffected by failure (MSPI-SD) } \\
\hline & & (MSPI-SD) & Y \\
\hline & \multicolumn{3}{|c|}{$\begin{array}{l}\text { During a Unit } 2 \text { HPCI run, the MCR received a low oil pressure alarm. Anequipment operator stationed in the Unit } 2 \mathrm{HPC} \\
\text { room notified the ShiftManager that the local pressure indicator for the HPCI governor oilpressure indicated } 0 \text { psig. The } \\
\text { Shift Manager directed the U/2 HPCIturbine to be tripped. With the aux oil pump still in service, the otherHPCI oil } \\
\text { pressures were checked and confirmed to be in spec.Additionally, a hand valve that supplies oil to the journal bearing } \\
\text { wasfound to be out-of-adjustment..The consequence of this hand valve failing to supply sufficient oil to thejournal bearing } \\
\text { led to the wiping of the journal bearing and the scoringof the main HPCI turbine shaft..Statement of Cause:.The cause is } \\
\text { determined to be insufficient oil to the journal bearing dueto a bumped or jarred hand valve in the oil supply line. It is } \\
\text { believedthat this hand valve was bumped or jarred sometime after the successfulcompletion of the pump valve and flow. } \\
\text { Interviews of the individuals who performed work during this timeframe could not identify any actions takenwhich resulted } \\
\text { in the valve being bumped or jarred. }\end{array}$} \\
\hline
\end{tabular}

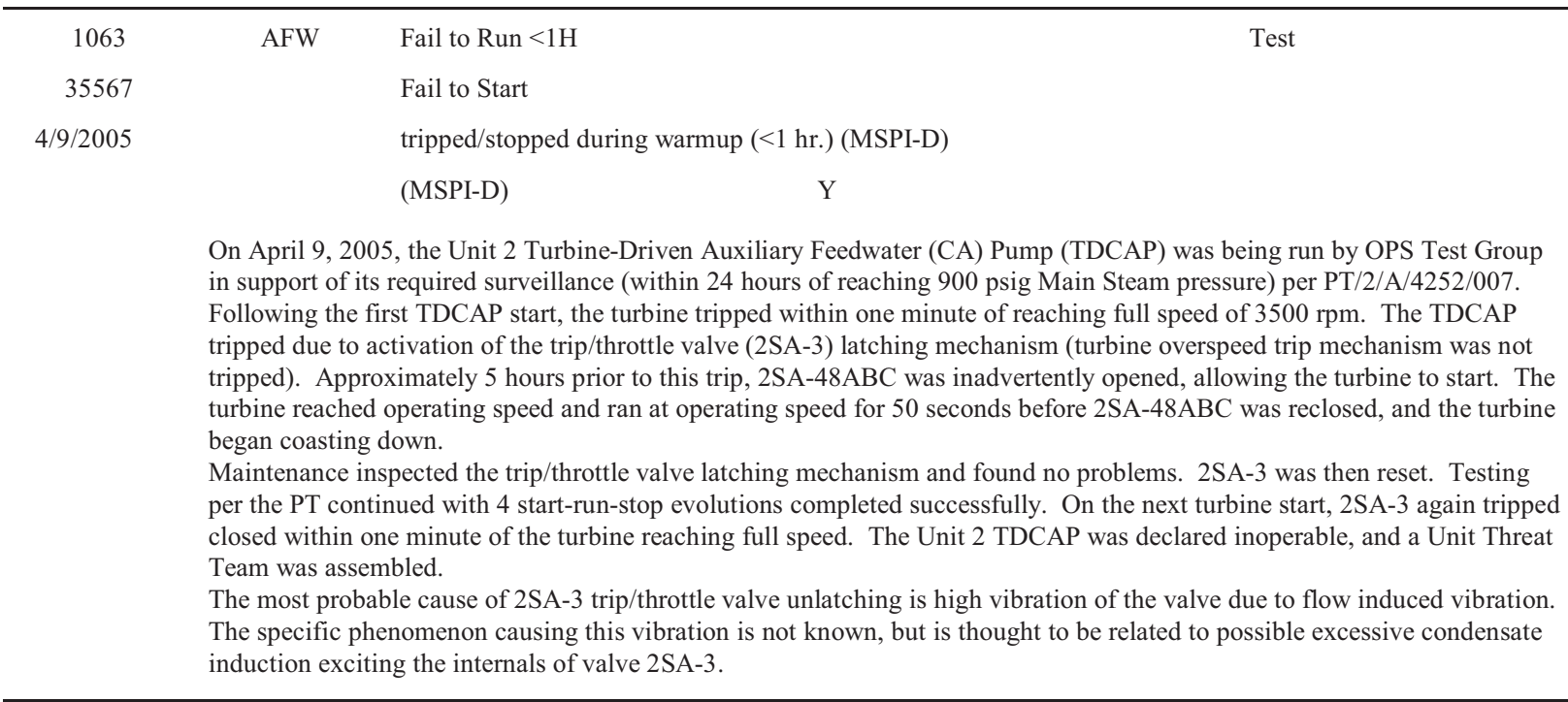




\section{Component Type TDP}

EPIX MSPI Failure Mode Fail to Start

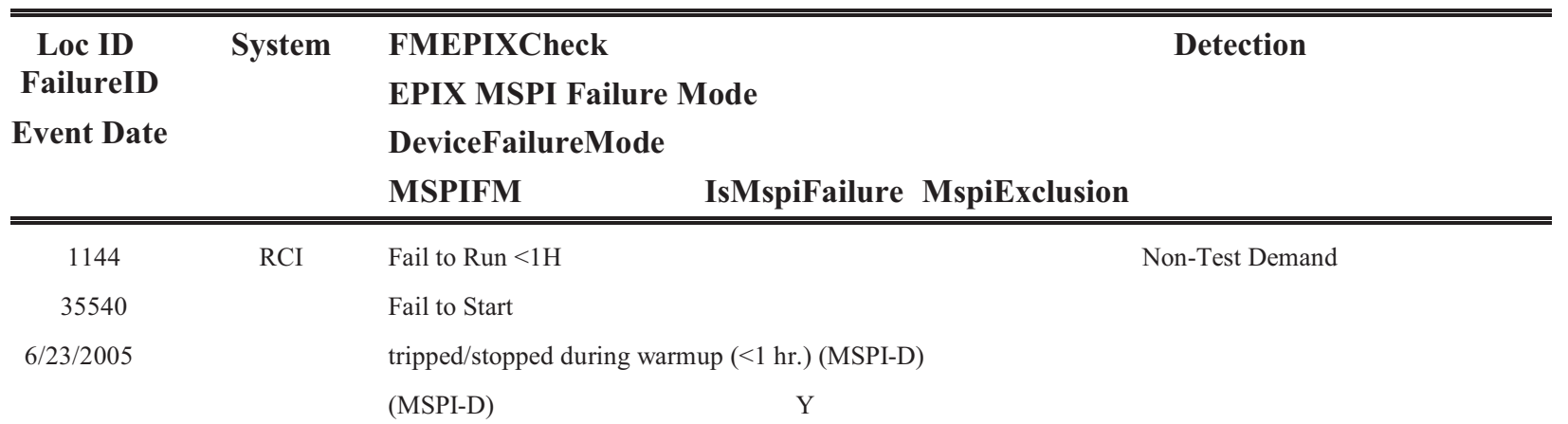

The RCIC turbine (RCIC-DT-1) has tripped during its initial ramp on several electronic initiations using the control room pushbutton. The Reactor Operator has stated that RCIC was successfully started and run by manually ramping up the flow demand signal in the control room. On the initial start of RCIC from the control room pushbutton, the RCIC system ramped up to rated flow properly and controlled level as designed. After RX water had been restored to an acceptable level, the RCIC turbine was tripped by closing the switch for RCIC-V-1 in the control room. After restoring RCIC-V-45 to its standby position, the Reactor Operator was unable to reset the trip on RCIC-V-1 in the control room. The trip was reset locally at the turbine. A short time later, the Reactor Operator depressed the initiation pushbutton to start RCIC. The RCIC turbine ramped up properly, then at maximum flow a trip occurred. The total time from initiation to trip was approximately 18 seconds. The RCIC valve lineup was again restored, and a subsequent initiation produced another similar trip. On a final attempt, the Reactor Operator placed the RCIC flow controller in manual mode and brought the RCIC system up to rated flow in a controlled manner. The RCIC system was run successfully for an extended period with no subsequent trip. A review of startup/run data and the RCIC initiation logic diagrams indicates the most likely cause as a problem with either the Low Pump Suction Pressure Switch or the High Turbine Exhaust Pressure Switch.

RCIC was not able to perform its design function due to a latent flaw in the original design of the system.

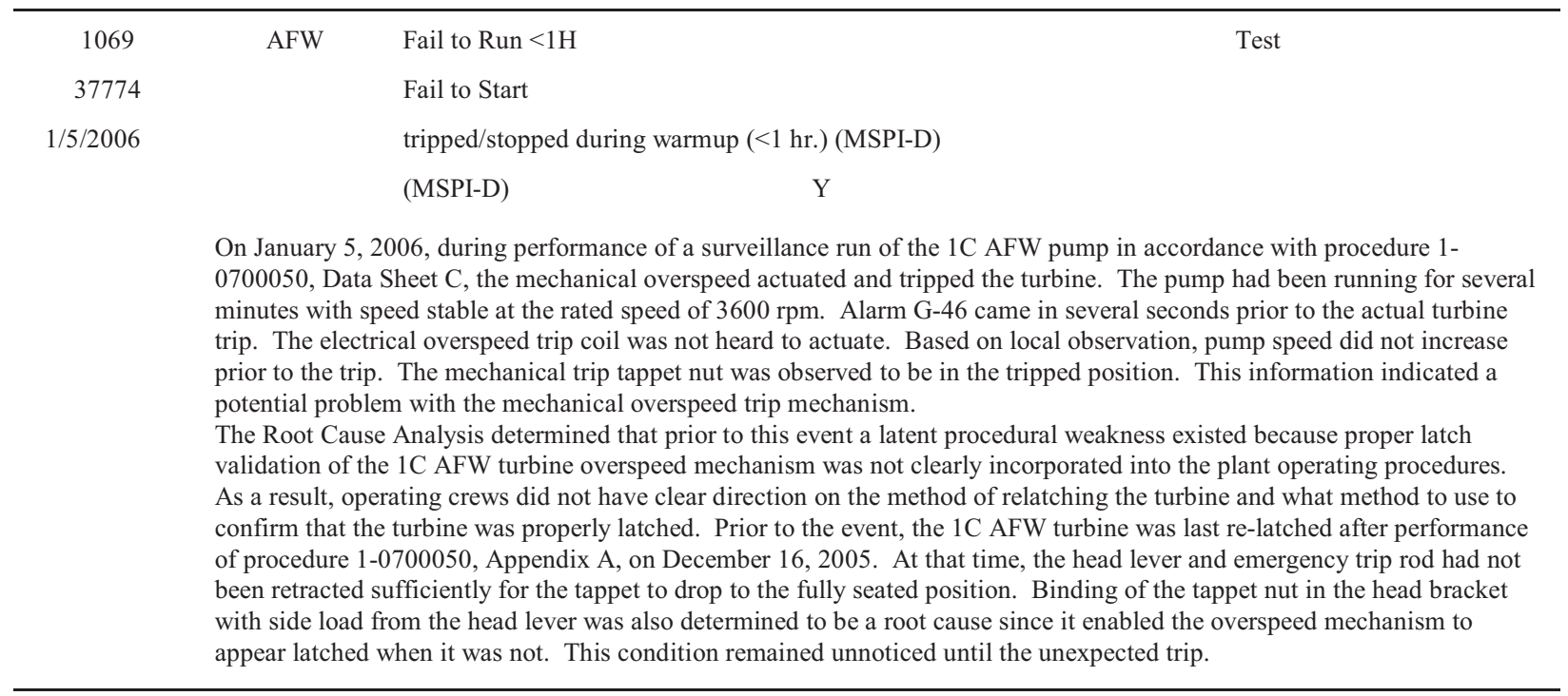




\section{Component Type TDP}

EPIX MSPI Failure Mode Fail to Start

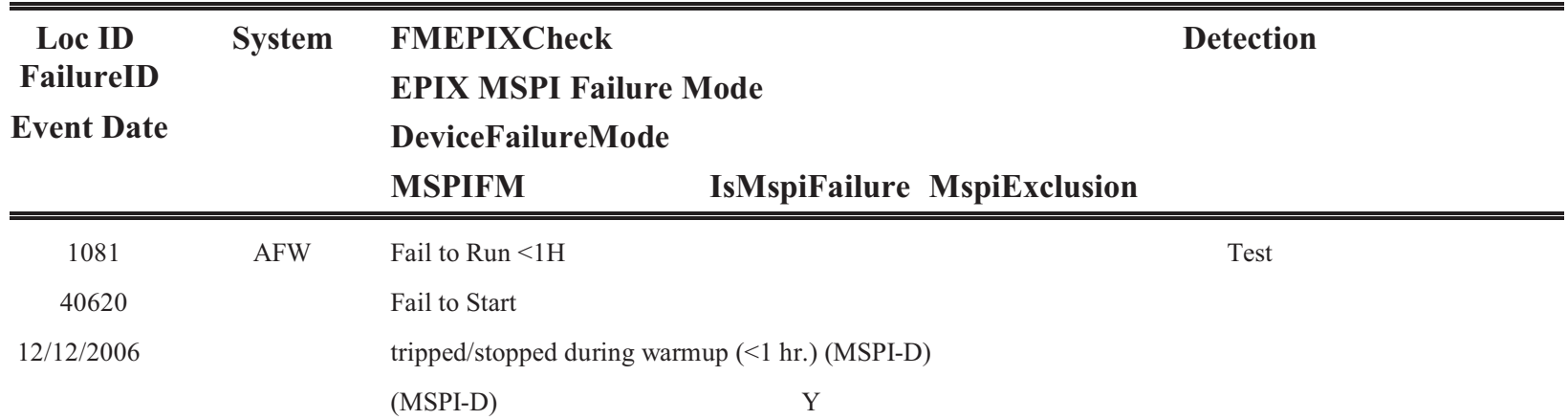

THE FAILURE OF AFWP \#14 TO START IS LESS THAN ADEQUATE LEVEL OF DETAIL IN THE ASSOCIATED WORK INSTRUCTIONS, RESULTING IN THE IMPROPER ADJUSTMENT OF THE TRIP LATCH LINKAGE AND THE REQUIRED IMPACT SPACE. IN ADDITION TO THE IMPROPER IMPACT SPACE, DISCOVERED EXCESSIVE GREASE APPLIED TO THE TRIP HOOK / LATCH-UP MATING SURFACES. ADJUSTMENT TO THE IMPACT SPACE AND REPLACEMENT OF THE OVERSPEED TRIP LINKAGE ROD END ASSSEMBLY WAS PERFORMED. SUBSEQUENT TESTING DEMONSTRATED REPEATABLE SATISFACTORY PERFORMANCE.

\begin{tabular}{|c|c|c|c|}
\hline 1033 & AFW & Fail to Run & PMT \\
\hline 41346 & & \multicolumn{2}{|l|}{ Fail to Start } \\
\hline \multirow[t]{4}{*}{$3 / 31 / 2007$} & & \multicolumn{2}{|c|}{ unaffected by failure (MSPI-SD) } \\
\hline & & (MSPI-SD) & Y \\
\hline & \multicolumn{3}{|c|}{$\begin{array}{l}\text { The AFW pump was tripped two hours into a test run due to foaming of the bearing lube oil and increasing bearing } \\
\text { temperature. }\end{array}$} \\
\hline & \multicolumn{3}{|c|}{$\begin{array}{l}\text { The forced oil modification (ES200100565) was installed on the } 22 \text { Auxiliary Feedwater (AFW) Pump Turbine during the } \\
2007 \text { Refueling Outage (RFO). Foaming/ air entrainment occurred during Post Modification testing on March } 17 .\end{array}$} \\
\hline 1102 & $\mathrm{HCI}$ & Fail to Run & Non-Test Demand \\
\hline 41641 & & Fail to Start & \\
\hline \multirow[t]{3}{*}{$4 / 24 / 2007$} & & \multicolumn{2}{|c|}{ operated, but not within specified parameters (MSPI-SD) } \\
\hline & & (MSPI-SD) & $\mathrm{Y}$ \\
\hline & \multicolumn{3}{|c|}{$\begin{array}{l}\text { Following an automatic unplanned Unit } 2 \text { reactor SCRAM on April 24, 2007, the High Pressure Coolant Injection (HPCI) } \\
\text { and Reactor Core Isolation Cooling (RCIC) systems automatically started, as expected, but experienced full-scale flow } \\
\text { oscillations, which is the subject of this root cause analysis. The subsequent investigation determined that the Unit } 2 \text { Main } \\
\text { Control Room (MCR) HPCI and RCIC flow controllers had the tunable parameters of gain and reset set considerably } \\
\text { different than the same controllers on Unit } 1 \text { and considerably different than the as-left Unit } 2 \text { startup testing settings. While } \\
\text { the Unit } 2 \text { HPCI and RCIC control systems were sufficiently tuned to ensure stable operation in full flow test mode, the as- } \\
\text { found flow controller tunable parameters resulted in unstable operation during vessel injection mode, which is not routinely } \\
\text { tested. The unacceptable setting adjustments were performed in May of } 1999 \text { and rendered both systems inoperable. The } \\
\text { root cause of this problem is a less than adequate maintenance procedure, and contributing causes stem from a less than } \\
\text { adequate training lesson plan. In addition to correcting the associated procedure and training, improvements are planned for } \\
\text { the operating experience assessment program. flow controller configuration controls, and maintenance record keeping. }\end{array}$} \\
\hline
\end{tabular}




\section{Component Type TDP}

EPIX MSPI Failure Mode Fail to Start

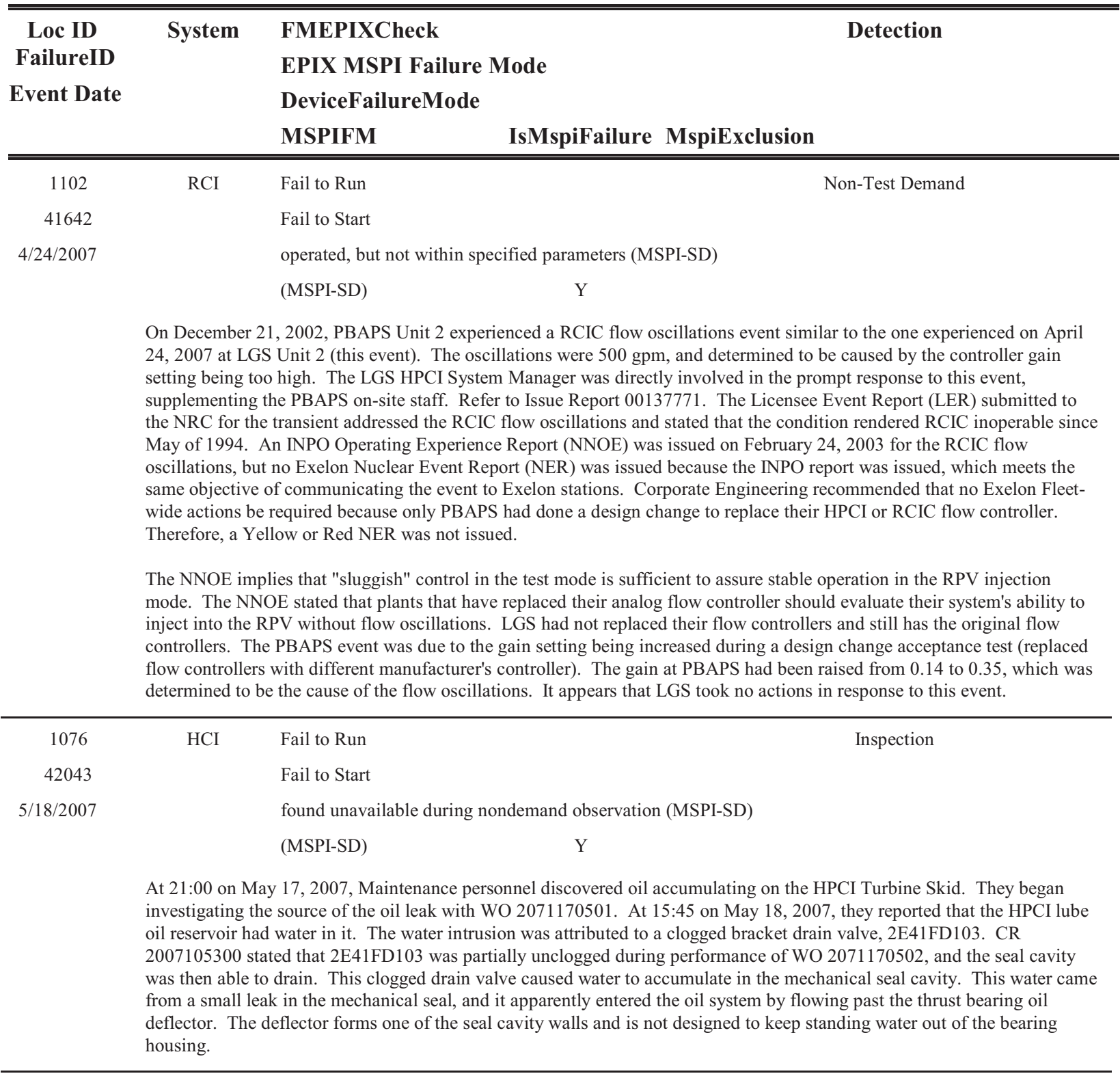




\section{Component Type TDP}

EPIX MSPI Failure Mode Fail to Start

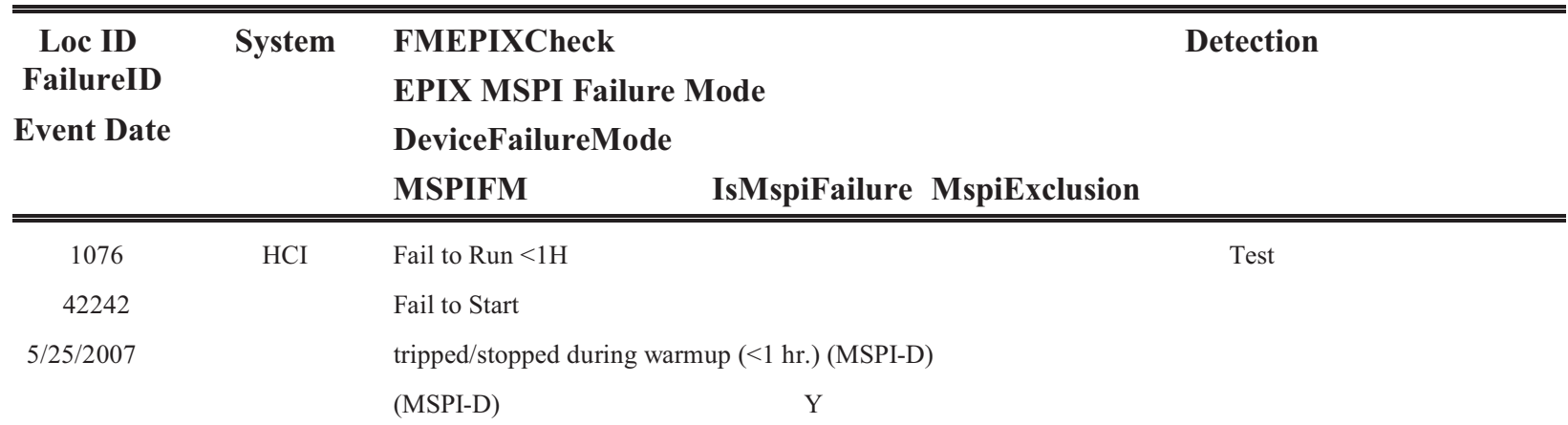

During the performance of 34SV-E41-002-2, High Pressure Coolant Injection (HPCI) Time Response Testing, following the Unit 2 HPCI System Outage, the system tripped after reaching rated speed, flow, and pressure. The system subsequently reset and restarted, returning to rated speed, flow, and pressure for completion of 34SV-E41-002-2.

The reset spring setting was discovered to be low. The as-found trip reset spring setting was $1.0 \mathrm{lbf}$. This is below the procedure criteria of $2.0-5.0 \mathrm{lbf}$. The spring was adjusted to $4.0 \mathrm{lbf}$, and the system was retested. Since the trip reset spring setting was not optimal, the spring did not perform its function of holding the trip tappet in place. Therefore, the tappet was released causing the spurious turbine overspeed trip.

\begin{tabular}{cllc}
\hline 1042 & AFW & Fail to Run $<1 \mathrm{H}$ & Test \\
42847 & Fail to Start \\
$8 / 12 / 2007$ & tripped/stopped during warmup $(<1 \mathrm{hr}$. $)($ MSPI-D) \\
& (MSPI-D) $\quad \mathrm{Y}$
\end{tabular}

The SDAFW Pump was started IAW OST-206 for a PMT of MS-V1-8A following a breaker PM. Approximately 15 seconds after opening V1-8A and starting the SDAFW Pump, APP-007-F5 (SD AFW PMP LO DISCH PRESS TRIP) was received. V1-8A closed and the SDAFW Pump tripped.

The troubleshooting data obtained concluded the Woodward Governor air supply solenoid valve was most likely not repositioning in a timely manner (sticking). This would not allow the SDAFW Pump to come up to speed prior to the discharge pressure timer relay activation.

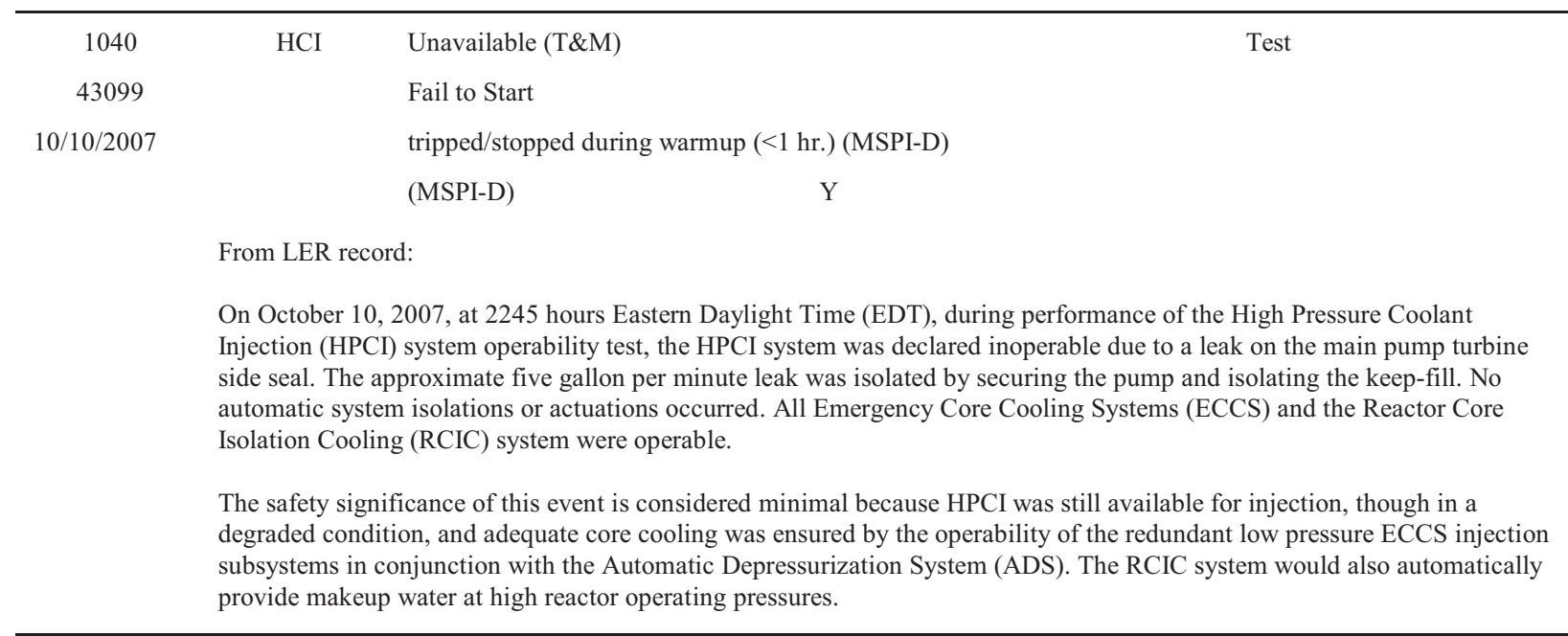




\section{Component Type TDP}

EPIX MSPI Failure Mode Fail to Start

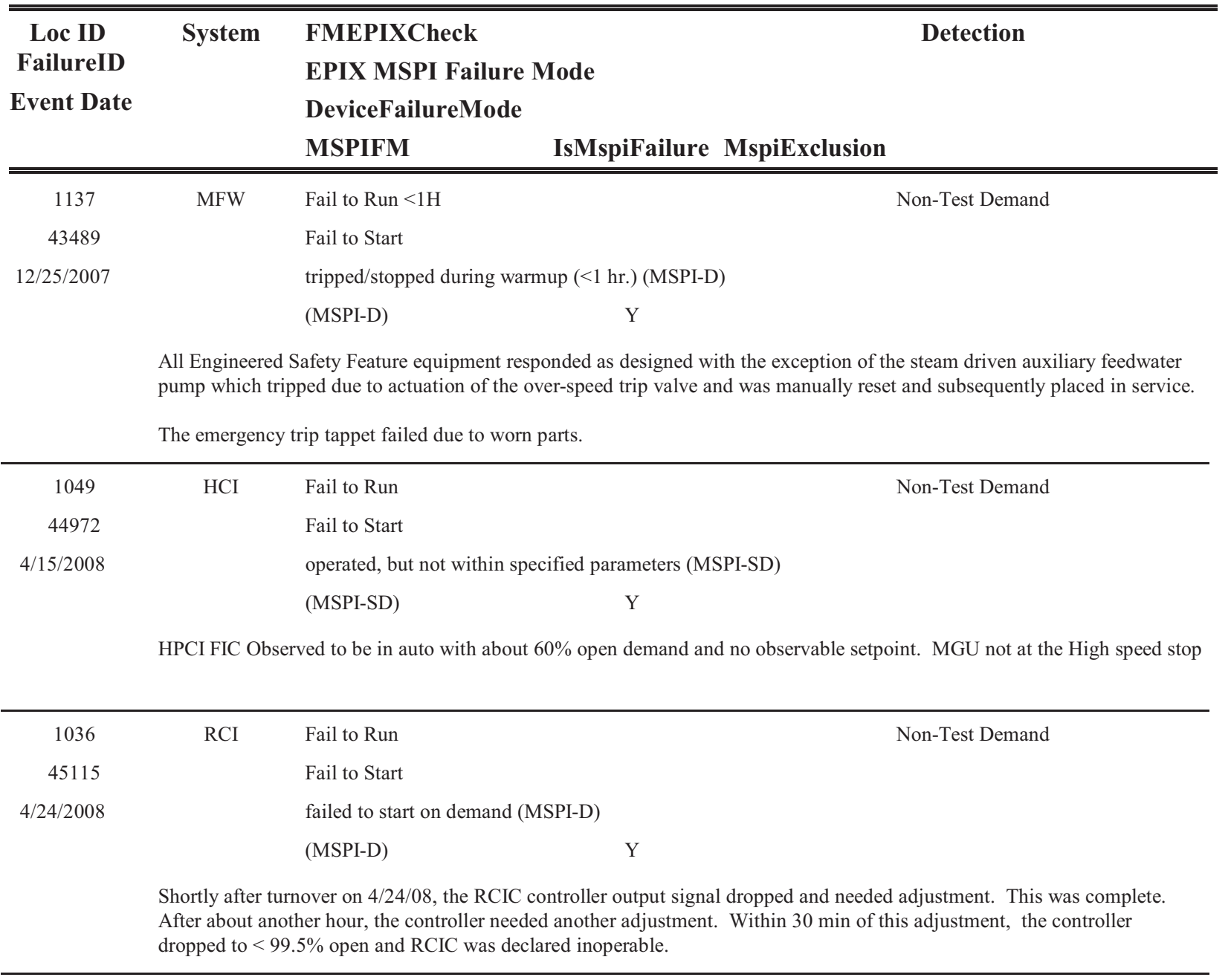




\section{Component Type TDP}

EPIX MSPI Failure Mode Unavailable (T\&M)

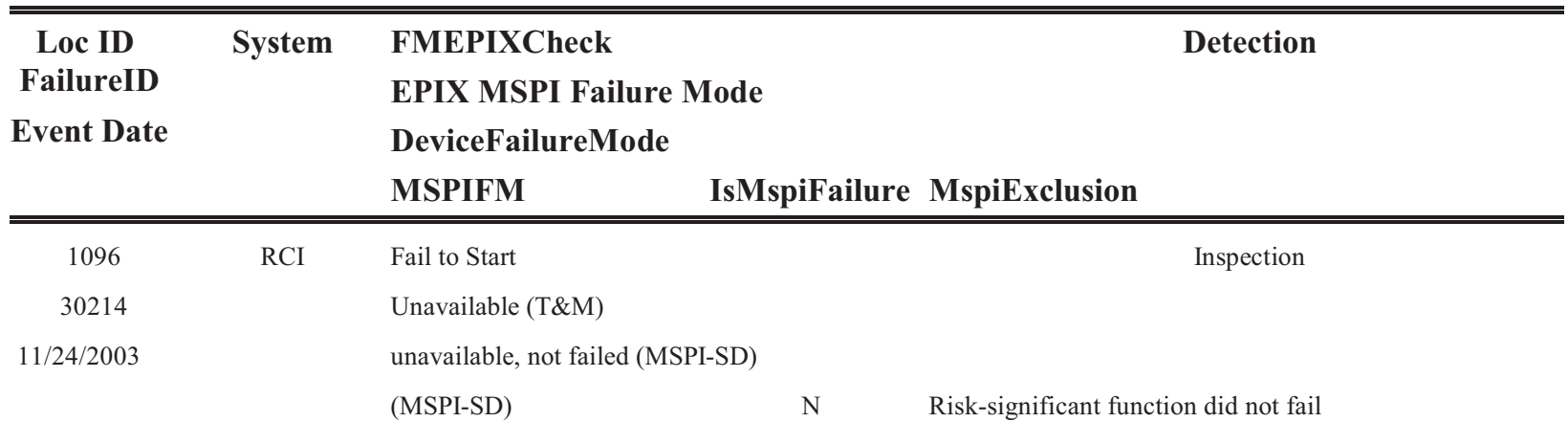

On November 24, 2003, RCIC-IVTR-1A shut down causing RCIC-FIC-91 to lose power and demand no flow. RCIC was declared inoperable and the inverter was replaced. The inverter failure is considered a maintenance rule functional failure since RCIC was incapable of supplying required flow. This evaluation will determine the apparent cause of the RCIC inverter failure and review the current PMs and industry operating experience for applicability as required per CNS Procedure 0.27 .

Evaluation:

The RCIC inverter (CNS-1-RCIC-IVTR-1A) converts $125 \mathrm{Vdc}$ power to a $60 \mathrm{~Hz}, 120 \mathrm{Vac}$ power for the RCIC flow controller (CNS-1-RCIC-FIC-91), the RCIC square rooter (RCIC-SQRT-99) and the RCIC test mode power supply (CNS-1RCIC-ES-100).

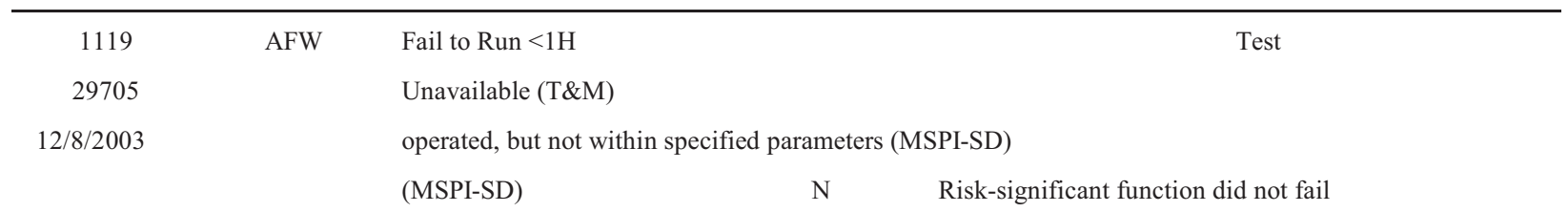

On 12/8/04 during performance of STP0220.002, the TDEF on initial start increased in speed to 4170 RPM, which was within the required speed range. However, the speed began to increase and when it was attempted to adjust speed for IST data collection, speed could not be reduced. The turbine speed continued to increase slowly and when speed exceeded 4400 RPM, it was decided to trip the TDEFP. It was initially believed that the speed knob had loosened, but it was found to be secure. Upon further investigation, it was determined that the governor valve linkage was binding and the governor valve was not traveling to the full closed position. Because of a potential concern with over adjusting the valve in the closed position to the point where it would not go full open, it was decided to maintain valve travel at it's existing setting without adjusting it to travel more in the closed position. The procedures for linkage adjustment were not clear and a vendor rep was en route to the plant for assistance, if needed. The governor valve linkage was lubricated and readjusted and the surveillance test was completed satifactorily prior to vendor arrival. However, using the governor speed knob the turbine could only be reduced to about 3700 RPM, but normal speed and the IST data collection speed were achieved.

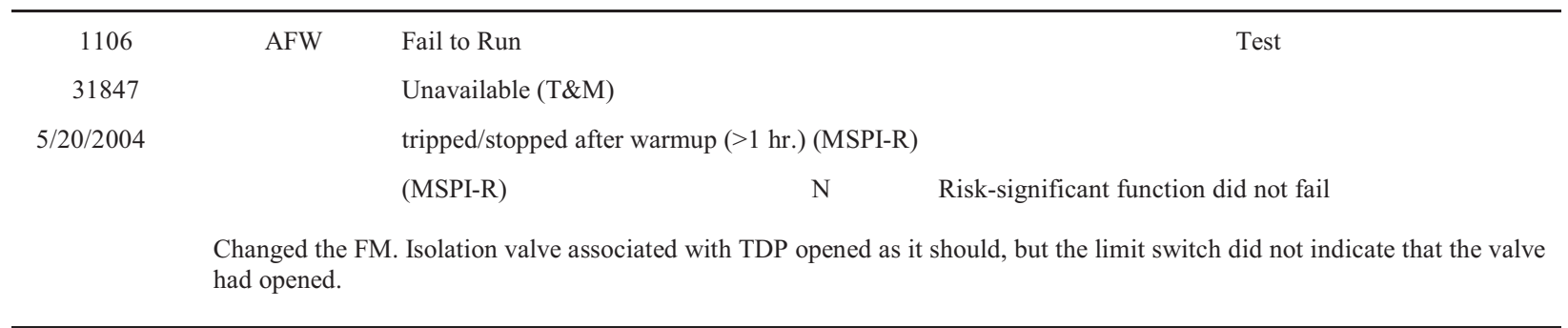




\section{Component Type TDP}

EPIX MSPI Failure Mode Unavailable (T\&M)

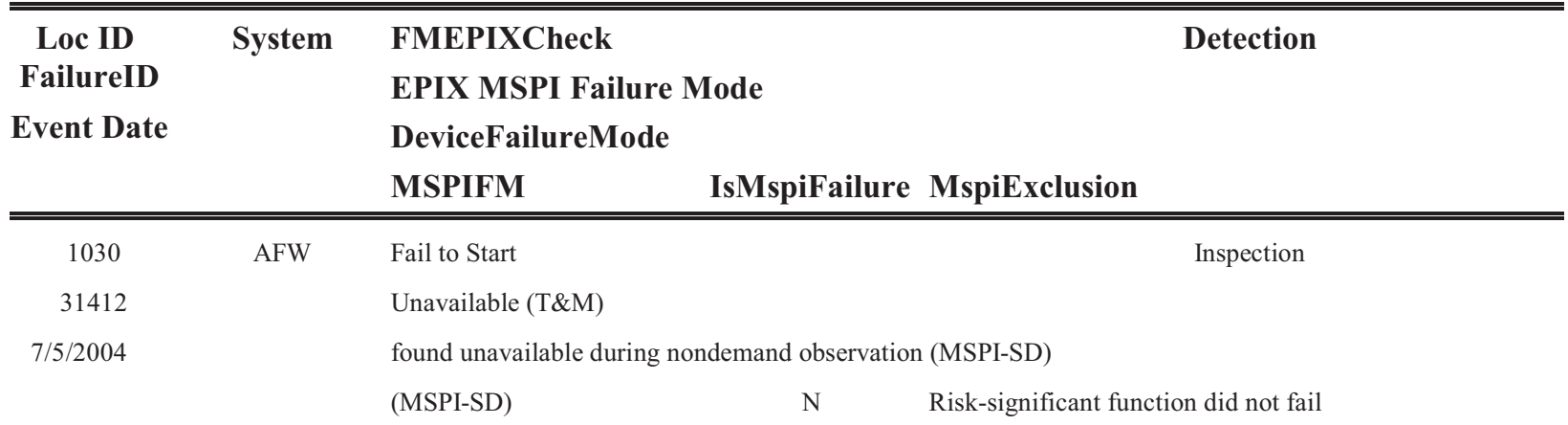

On July 5, 2004 at 10:15 'A' Train AF SEIS alarms were received; AUX FW SG1 and AUX FW SG2. The Alarm Response Procedure indicates that AUX FW PMP TURB SYSTEM TRBL may be caused by loss of power to the governor control circuit. This condition was confirmed by verifying that the 'EGM POWER ON' light was not illuminated. The 'A' AF pump was declared INOPERABLE and has been quarantined. There were no maintenance activities on-going at the time of the SEIS Alarms. This is similiar to the event that occurred in Unit 2 in May 2004; ref CRDR 2709451. MRFF Review

The Unit 3 Turbine Driven Auxiliary Feedwater Pump spontaneously lost governor control power.

\begin{tabular}{|c|c|c|c|}
\hline 1096 & $\mathrm{RCI}$ & Fail to Start & Inspection \\
\hline 32130 & & \multicolumn{2}{|l|}{ Unavailable (T\&M) } \\
\hline \multirow[t]{7}{*}{$9 / 30 / 2004$} & & \multicolumn{2}{|l|}{ unavailable, not failed (MSPI-SD) } \\
\hline & & (MSPI-SD) & Risk-significant function did not fail \\
\hline & \multicolumn{3}{|c|}{ RCIC-FIC-91 CONTROLLER OUTPUT HAS FAILED DOWNSCALE TO 0. NORMAL THE OUTPUT IS 100.} \\
\hline & \multicolumn{3}{|c|}{ REQUIREMENT NOT MET: NO CONTROL OF RCIC FLOW } \\
\hline & \multirow{3}{*}{\multicolumn{3}{|c|}{$\begin{array}{l}\text { METHOD OF DISCOVERY: PANEL WALKDOWN } \\
\text { IMMEDIATE ACTIONS TAKEN: CHECKED RCIC INVERTER (RCIC-IVTR-1) AND IT APPEARS TO BE NOT } \\
\text { WORKING SO THERE IS NO POWER TO THE CONTROLLER }\end{array}$}} \\
\hline & & & \\
\hline & & & \\
\hline 1076 & \multirow[t]{4}{*}{$\mathrm{RCI}$} & Fail to Run $<1 \mathrm{H}$ & PMT \\
\hline 34287 & & \multicolumn{2}{|l|}{ Unavailable (T\&M) } \\
\hline \multirow[t]{3}{*}{$3 / 13 / 2005$} & & \multicolumn{2}{|c|}{ tripped/stopped during warmup $(<1 \mathrm{hr}$.) (MSPI-D) } \\
\hline & & (MSPI-D) & Risk-significant function did not fail \\
\hline & \multicolumn{3}{|c|}{$\begin{array}{l}\text { After RCIC tripped on " RCIC Pump Exhaust Pressure High " SOs were sent to verify the normal position ( open ) of the } \\
\text { 2E51-F001 valve ( Exhaust Line Stop Check Valve ) as a possible cause of high exhaust pressure. The SOs reported back to } \\
\text { me that the valve was open. As a result of this report, RCIC was started up a second time and subsequently tripped again on } \\
\text { " RCIC Pump Exhaust Pressure High ". The 2E51-F001 was checked again as a possible cause of high exhaust pressure } \\
\text { and this time the valve was unlocked and found to be CLOSED. RCIC Operability } \\
\text { CAP } \\
\text { This CR identifies a valve found out of its required position. The valve has been restored to its required position. }\end{array}$} \\
\hline
\end{tabular}




\section{Component Type TDP}

EPIX MSPI Failure Mode Unavailable (T\&M)

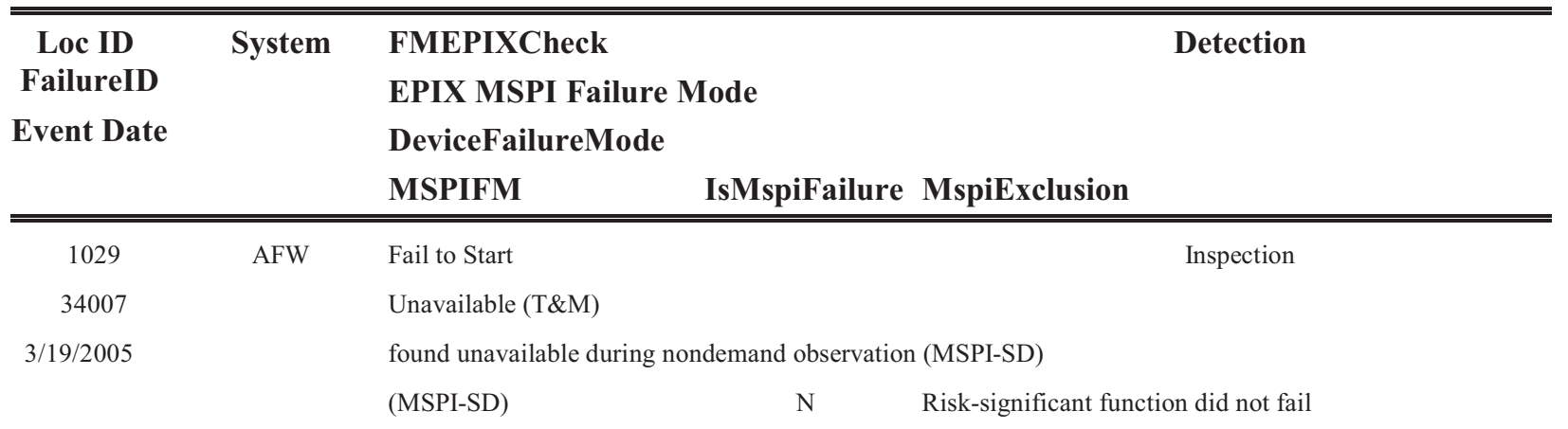

(U-3) FAILURE OF THE AFA-P01 GOVERNOR CONTROL CIRCUIT HAS RESULTED IN THE AF PUMP BEING DECLARED INOPERABLE.

On July 5, 2004 at 10:15 'A' Train AF SEIS alarms were received; AUX FW SG1 and AUX FW SG2. The Alarm Response Procedure indicates that AUX FW PMP TURB SYSTEM TRBL may be caused by loss of power to the governor control circuit. This condition was confirmed by verifying that the 'EGM POWER ON' light was not illuminated. The 'A' AF pump was declared INOPERABLE and has been quarantined. There were no maintenance activities on-going at the time of the SEIS Alarms. This is similiar to the event that occurred in Unit 2 in May 2004; ref CRDR 2709451.

WE HAVE LOST DC CONTROL POWER TO THE "A" AUX. FEED WATER PUMP GOVERNOR CONTROL CIRCUIT, BASED ON THE EGM POWER ON LIGHT BEING OFF.THE PUMP IS INOPERABLE. TROUBLESHOOT THE LOSS OF EMERGENCY GOVERNOR CONTORL POWER TO AFA-P01 IN ACCORDANCE WITH THE ENGINEERING GAME PLAN. REPLACE WOODWARD GOVERNOR DROPPING RESISTOR PER WSL 281406 AND CALIBRATE SPEED LOOP PER WSL 259028.

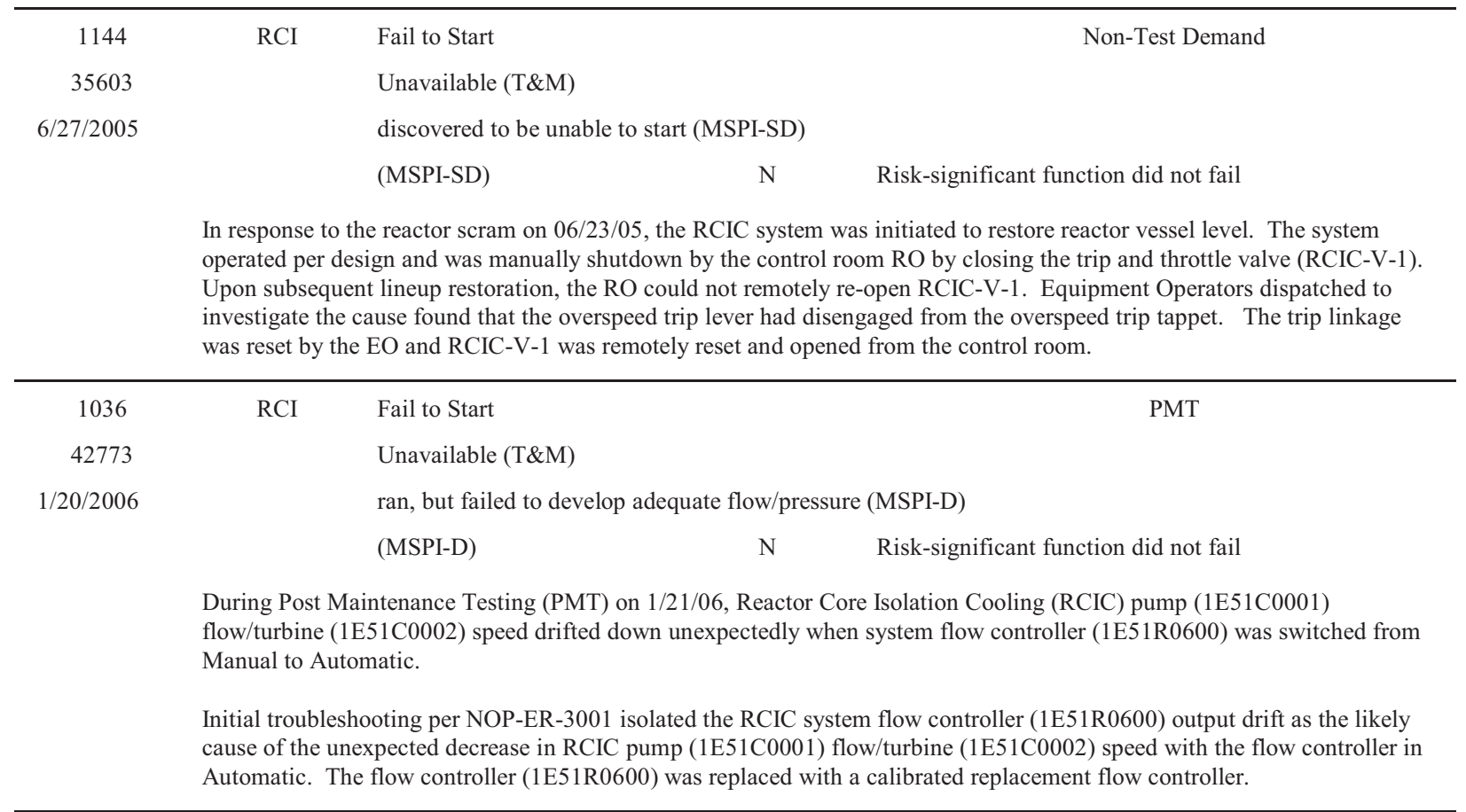




\section{Component Type TDP}

EPIX MSPI Failure Mode Unavailable (T\&M)

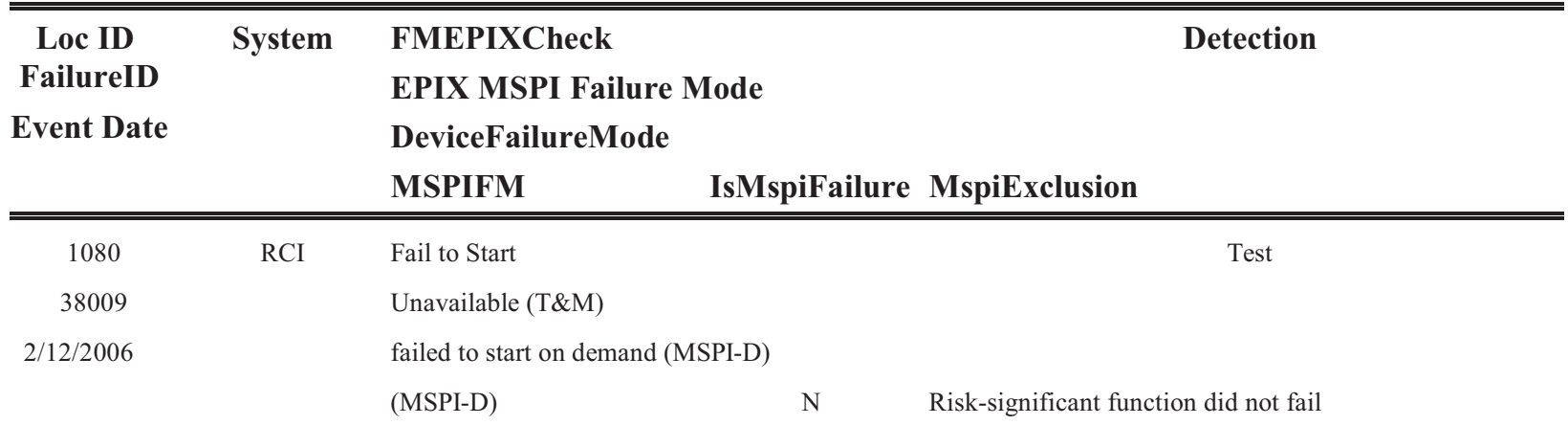

During STP-051-4224, the relay E51A-K60 has high contact resistance between M1-T1, this relay feeds RCIC initiation signal from Vessel Low water - reference 828E539AA sht-4, Work request \# 70273 written for electrical to clean/replace relay as needed

Relay E51-K60 replaced per WO\#81860. Retest all SAT. No additional actions required and this CR may be closed.

\begin{tabular}{|c|c|c|c|}
\hline 1073 & $\mathrm{AFW}$ & Fail to Start & Inspection \\
\hline 44020 & & Unavailable (T\&M) & \\
\hline \multirow[t]{3}{*}{$5 / 13 / 2007$} & & \multicolumn{2}{|l|}{ discovered to be unable to start (MSPI-SD) } \\
\hline & & (MSPI-SD) & Risk-significant function did not fail \\
\hline & \multicolumn{3}{|c|}{$\begin{array}{l}\text { This condition report documents the power supply for the driver failed, disallowing operation of the driver. With the driver } \\
\text { unable to operate, there was no speed control available for the terry turbine. If the terry turbine had started, the turbine } \\
\text { would have tripped on overspeed. }\end{array}$} \\
\hline 1143 & AFW & Fail to Run & Test \\
\hline 45091 & & Unavailable (T\&M) & \\
\hline \multirow[t]{3}{*}{$11 / 13 / 2007$} & & discovered to be unable to run for mission & MSPI-R) \\
\hline & & (MSPI-R) & Risk-significant function did not fail \\
\hline & \multicolumn{3}{|c|}{$\begin{array}{l}\text { Oil samples collected from the 2P-029-T Aux Feed Turbine OB bearing contained visible water. The sample had a significant } \\
\text { level of cloud with free water sitting in the bottom of the sample container. Actual measured water levels in the oil are not } \\
\text { available until external lab sample analysis is complete These results should be available on Friday } 11 / 2 / 2007 \text {. The sample } \\
\text { was collected under WO } 347138-04 \text { after the OI } 62 \mathrm{~B} \text { Cold start of the turbine/pump Sample collected from the IB bearing of } \\
\text { the turbine had no indication of water Samples collected prior to the operation of the turbine under OI } 62 \text { had no visible } \\
\text { indication of water in either the IB or OB bearings Today's run indicated visible steam vapor in the area of the OB bearing } \\
\text { steam gland during the first } 20 \text { minutes of operation After the visible steam had disappeared at approximately } 25 \text { minutes } \\
\text { after start up a hand placed near the gland area would feel wet. After } 30 \text { minutes of operation no external indication of a } \\
\text { steam leak was present All areas around the OB gland were dry. }\end{array}$} \\
\hline 1024 & AFW & Fail to Start & Inspection \\
\hline 46150 & & Unavailable (T\&M) & \\
\hline \multirow[t]{3}{*}{$6 / 10 / 2008$} & & unavailable, not failed (MSPI-SD) & \\
\hline & & (MSPI-SD) & Risk-significant function did not fail \\
\hline & \multicolumn{3}{|c|}{$\begin{array}{l}\text { The Unit } 1 \text { Turbine Driven Auxiliary Feed Water Uninterruptible Power Supply (TDAFWP UPS) failed, resulting in a } 72- \\
\text { hour Mandatory LCO. }\end{array}$} \\
\hline
\end{tabular}




\section{Component Type TDP}

EPIX MSPI Failure Mode Unavailable (T\&M)

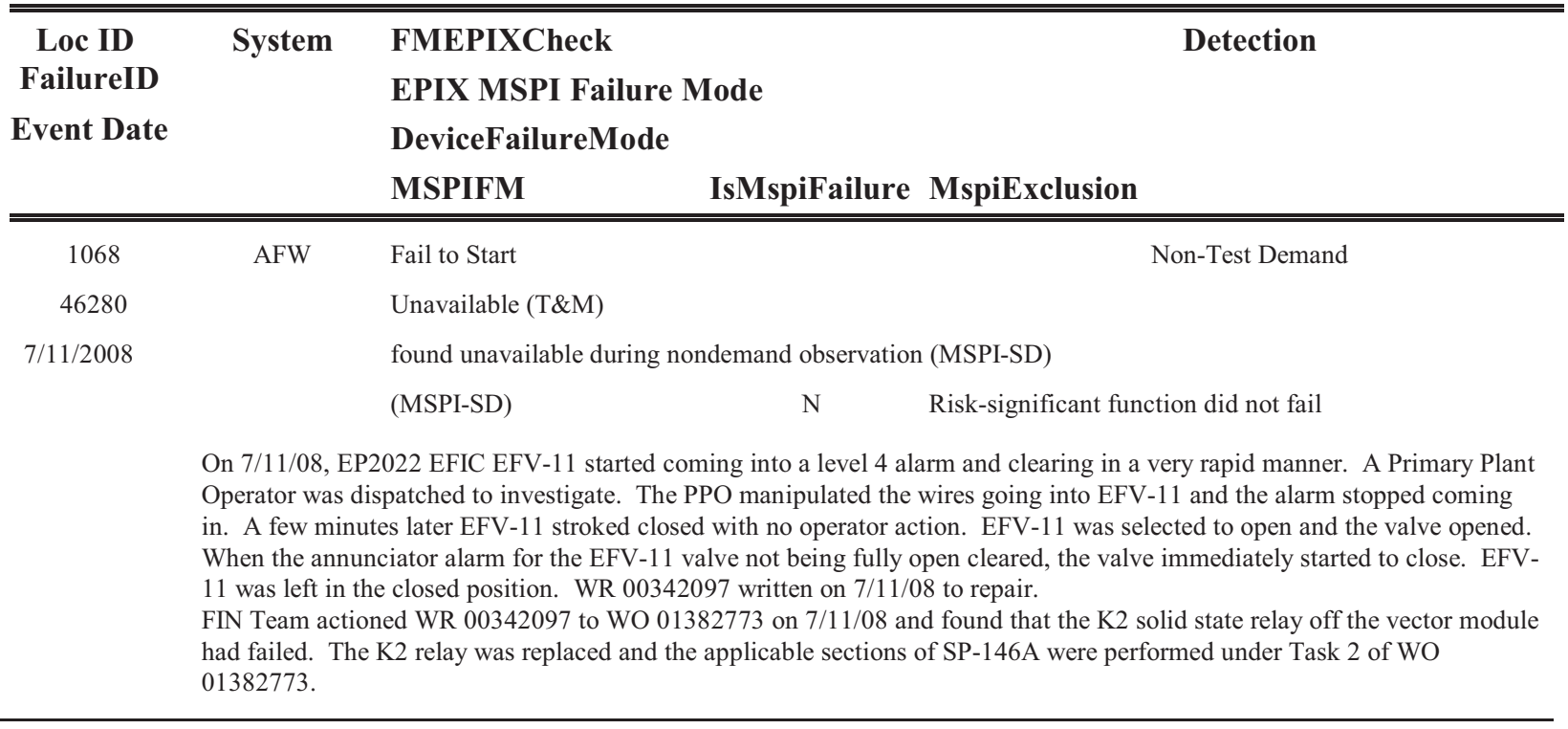

